Final Report

FHWA/IN/JTRP-2006/25

\title{
EXPERT SYSTEM TO SUPPORT SITE INVESTIGATION FOR SAFETY IMPROVEMENT
}

\author{
By \\ Andrew Kwasniak \\ Graduate Research Assistant \\ Bogdan Chivoiu \\ Graduate Research Assistant \\ and \\ Andrew P. Tarko \\ Associate Professor \\ School of Civil Engineering \\ Purdue University \\ Joint Transportation Research Program \\ Project No. C-36-59LL \\ File No. 8-5-38 \\ SPR-2951 \\ Conducted in Cooperation with the \\ Indiana Department of Transportation and the \\ U.S. Department of Transportation \\ Federal Highway Administration
}

The contents of this report reflect the views of the authors, who are responsible for the facts and the accuracy of the data presented herein. The contents do not necessarily reflect the official views or policies of the Indiana Department of Transportation or the Federal Highway Administration at the time of publication. The report does not constitute a standard, specification, or regulation.

Purdue University

West Lafayette, Indiana

December 2006 


\begin{tabular}{|c|c|c|c|c|}
\hline $\begin{array}{l}\text { 1. Report No. } \\
\text { FHWA/IN/JTRP-2006/25 }\end{array}$ & \multicolumn{2}{|c|}{ 2. Government Accession No. } & \multicolumn{2}{|l|}{ 3. Recipient's Catalog No. } \\
\hline \multicolumn{3}{|l|}{ 4. Title and Subtitle } & \multicolumn{2}{|l|}{$\begin{array}{l}\text { 5. Report Date } \\
\text { December } 2006\end{array}$} \\
\hline \multicolumn{3}{|c|}{$\begin{array}{l}\text { Expert System to Support Site Investigation for Safety } \\
\text { Improvement }\end{array}$} & \multicolumn{2}{|c|}{ 6. Performing Organization Code } \\
\hline \multicolumn{3}{|c|}{$\begin{array}{l}\text { 7. Author(s) } \\
\text { Andrew M. Kwasniak, Bogdan Chivoiu, Andrew P. Tarko }\end{array}$} & \multicolumn{2}{|c|}{$\begin{array}{l}\text { 8. Performing Organization Report No. } \\
\text { FHWA/IN/JTRP-2006/25 }\end{array}$} \\
\hline \multirow{2}{*}{\multicolumn{3}{|c|}{$\begin{array}{l}\text { 9. Performing Organization Name and Address } \\
\text { Joint Transportation Research Program } \\
550 \text { Stadium Mall Drive } \\
\text { Purdue University } \\
\text { West Lafayette, IN 47907-2051 }\end{array}$}} & \multicolumn{2}{|c|}{ 10. Work Unit No. (TRAIS) } \\
\hline & & & \multicolumn{2}{|l|}{$\begin{array}{l}\text { 11. Contract or Grant No. } \\
\text { SPR-2951 }\end{array}$} \\
\hline \multirow{2}{*}{\multicolumn{3}{|c|}{$\begin{array}{l}\text { 12. Sponsoring Agency Name and Address } \\
\text { Indiana Department of Transportation } \\
\text { State Office Building } \\
100 \text { North Senate Avenue } \\
\text { Indianapolis. IN } 46204\end{array}$}} & \multicolumn{2}{|c|}{$\begin{array}{l}\text { 13. Type of Report and Period Covered } \\
\text { Final Report }\end{array}$} \\
\hline & & & \multicolumn{2}{|c|}{ 14. Sponsoring Agency Code } \\
\hline \multicolumn{5}{|c|}{$\begin{array}{l}\text { 15. Supplementary Notes } \\
\text { Prepared in cooperation with the Department of Transportation and Federal Highway Administration. }\end{array}$} \\
\hline \multirow{2}{*}{\multicolumn{5}{|c|}{$\begin{array}{l}\text { 16. Abstract } \\
\text { One of the goals of traffic safety specialists is to improve road geometry and traffic control at high-crash locations to reduce } \\
\text { the risk of crash. The most difficult part of site investigation is determining the causes of crashes. This task may be } \\
\text { overwhelming, particularly for inexperienced investigators. Experienced investigators often may have difficulties in } \\
\text { connecting various pieces of information and knowledge due to the high level of uncertainty, the high complexity of safety } \\
\text { impacts, and the gaps in what is known about driver performance during the crash occurrence. An AI method is proposed to } \\
\text { help investigators identify the crash causes. A developed knowledge-based system utilizes information from two sources: (1) } \\
\text { extracted from the crash database and (2) collected during a site investigation. It connects these pieces of information with } \\
\text { relevant safety countermeasures. } \\
\text { We propose to deploy a tree-like structure of a knowledge base allowing for fast search of the solution. The knowledge } \\
\text { needed for the tool has been sufficiently documented in published work. The knowledge base structure is transparent and } \\
\text { understandable and a user can easily edit it. The safety improvements suggested by RSIT are well justified. The report } \\
\text { generated by RSIT can be added to the final investigation report. The developed prototype software called Road Safety } \\
\text { Investigation Tool (RSIT) is user-friendly. Its preliminary evaluation has brought promising results. The developed tool can } \\
\text { reduce the required size of the investigation team and/or decrease the time spent at the investigated site. }\end{array}$}} \\
\hline & & & & \\
\hline $\begin{array}{l}\text { 17. Key Words } \\
\text { high-crash locations, safety co } \\
\text { improvements, knowledge-bas } \\
\text { audits }\end{array}$ & $\begin{array}{l}\text { armeasures, safety } \\
\text { ystem, road safety }\end{array}$ & $\begin{array}{l}\text { 18. Distribut } \\
\text { No rest } \\
\text { public } \\
\text { Spring }\end{array}$ & $\begin{array}{l}\text { tatement } \\
\text { on. This document is } \\
\text { the National Informa } \\
\text { VA } 22161\end{array}$ & $\begin{array}{l}\text { ailable to the } \\
\text { Service, }\end{array}$ \\
\hline $\begin{array}{l}\text { 19. Security Classif. (of this report) } \\
\text { Unclassified }\end{array}$ & 20. Security Clas & $\begin{array}{l}\text { (of this page) } \\
\text { lassified }\end{array}$ & $\begin{array}{l}\text { 21. No. of Pages } \\
192\end{array}$ & 22. Price \\
\hline
\end{tabular}




\section{TABLE OF CONTENTS}

TABLE OF CONTENTS ................................................................................................ 3

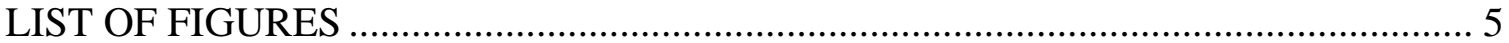

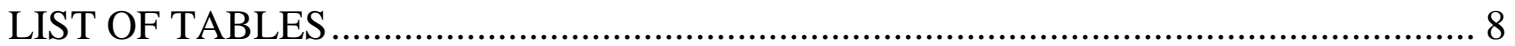



CHAPTER 2 REVIEW OF SITE INVESTIGATION METHODS .................................. 13

$2.1 \quad$ Overview of existing methods .................................................................................. 18

2.1.1 Road Safety Audits vs. Road Safety Reviews ............................................................................ 18

2.1.2 IHSDM Intersection Diagnostic Review Model....................................................................... 25

$2.2 \quad$ Proposed procedure of safety investigation............................................................. 27

2.3 Summary of site investigation methods .................................................................. 29

CHAPTER 3 METHODOLOGY ………………………......................................... 32

3.1 Method with unstructured knowledge base ............................................................. 33

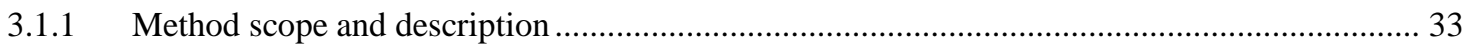

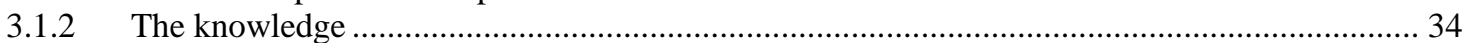

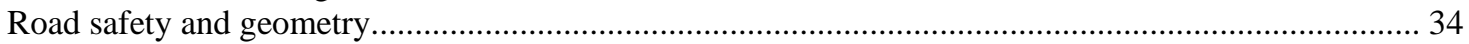

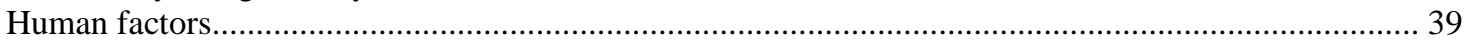

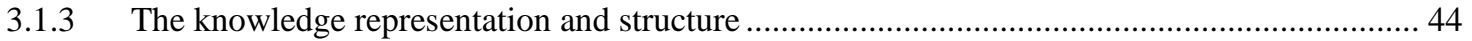



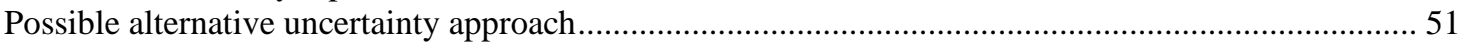



3.2 Evaluation of the proposed method........................................................................... 64

3.3 Method with structured knowledge base................................................................. 66

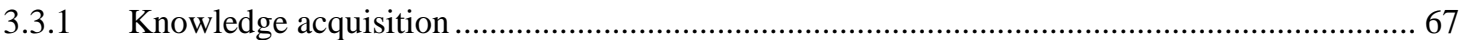



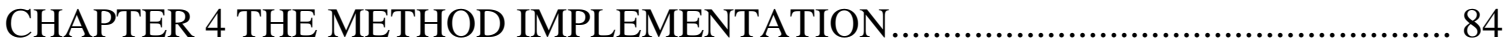

4.1 Description of buttons and commands................................................................. 84

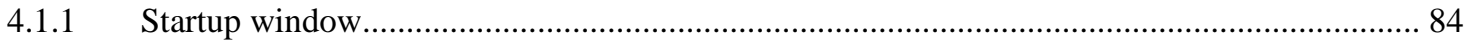

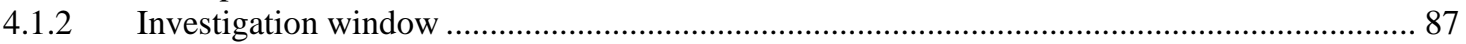

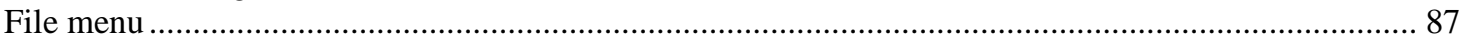

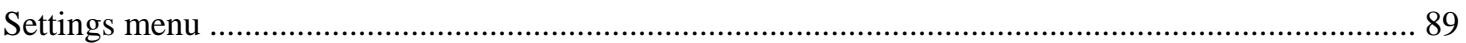



4.2 Description of investigation steps ............................................................................... 93

CHAPTER 5 METHOD EVALUATION ..................................................................... 106

5.1 The Evaluation Phases............................................................................................ 106

$5.2 \quad$ The RSIT evaluation................................................................................................. 107 
5.2.2 Locust Rd. and Ireland Rd, St. Joseph County, Indiana ..................................................... 113

5.3 Summary of the evaluation stage.......................................................................... 123

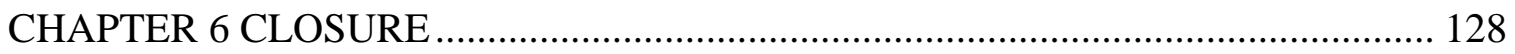

6.1 Research Summary ...................................................................................... 128

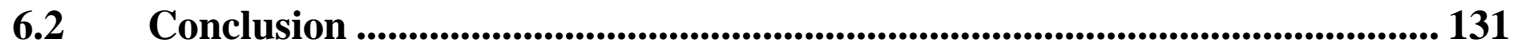

6.3 Future Research ................................................................................................... 132

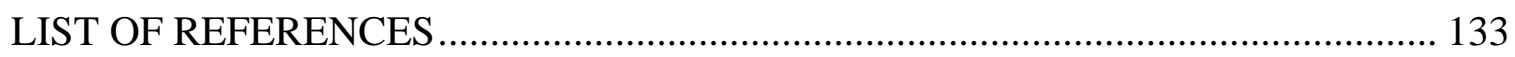

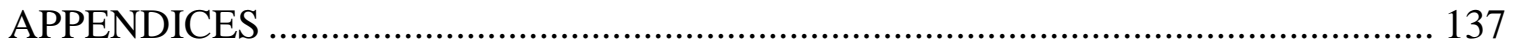

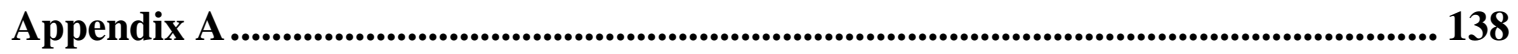

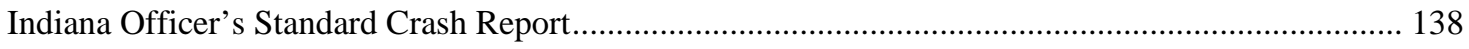

Appendix B ......................................................................................................................... 142



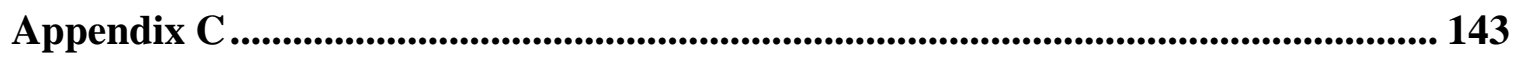



Appendix D .......................................................................................................................... 148

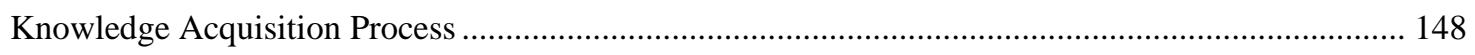

Appendix E ......................................................................................................................... 162

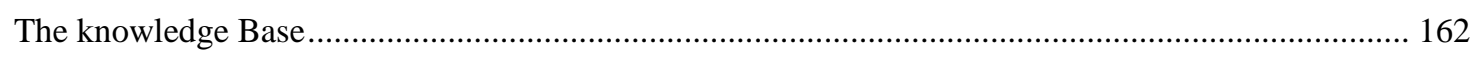

Appendix F ............................................................................................................................... 169

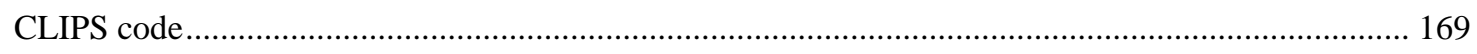

Appendix G..................................................................................................................... 176



Appendix H........................................................................................................................ 180

Site investigation Report: Locust Rd. and Ireland Rd Report 1........................................................ 180

Appendix I ............................................................................................................................ 187

Site investigation Report: Locust Rd. and Ireland Rd Report 2 ….................................................. 187 


\section{LIST OF FIGURES}

Figure 2-1 Cycle of the HEP (Tarko Andrew P., Mayank Kanodia, 2004)..................... 13

Figure 2-2 Collision diagram (LTAP Hazard Elimination Study)................................. 14

Figure 2-3 HEP - Safety review process (Tarko, Andrew P., Mayank Kanodia, 2004) .. 17

Figure 2-4 Example of the Checklist (Hazard Elimination Study for Smith and Rogers



Figure 2-5 Insufficient sight distances (Williamson County RSA, Illinois 2006)........... 24

Figure 2-6 SINDI structure (http://www.infra.kth.se/ctr/publikationer/ctr1999_08.pdf). 28

Figure 2-7 SINDI system (http://www.infra.kth.se/ctr/publikationer/ctr1999_08.pdf).... 29



Figure 3-2 Primary Contributing Circumstances (INDOT- Accident Master Record

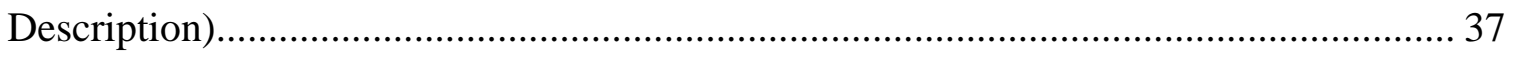

Figure 3-3 Performance operating characteristic (POC) ............................................ 40

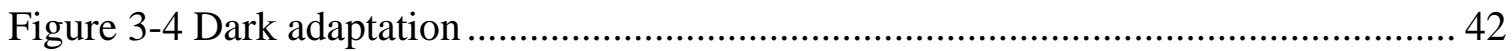

Figure 3-5 Knowledge base representation.............................................................. 44

Figure 3-6 High layer of the knowledge representation ............................................ 46

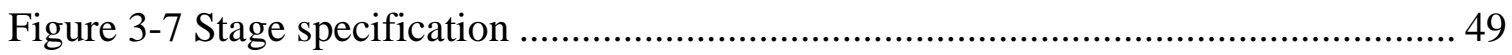

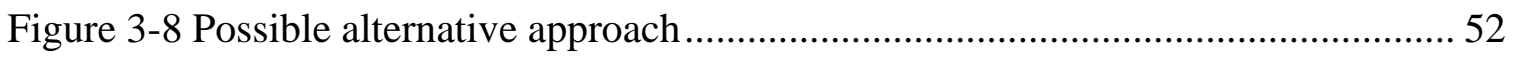

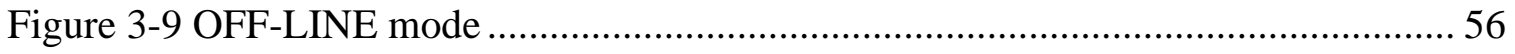



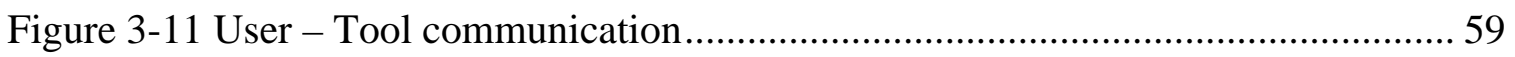

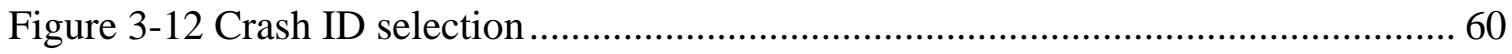

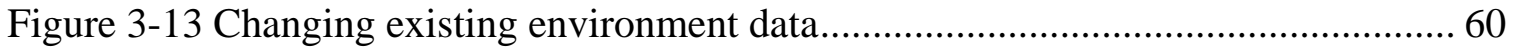

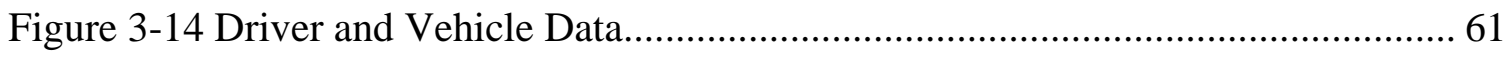

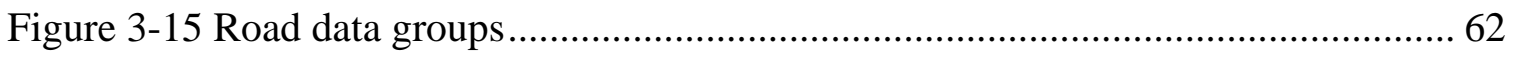

Figure 3-16 Driveways, Shoulders, Road Site and Median Data .................................. 62

Figure 3-17 Results by Contributing factors of Crashes............................................. 63

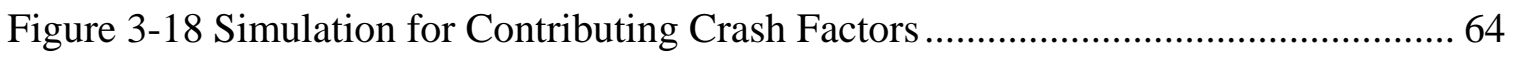

Figure 3-19 Three layers of crash occurrences ......................................................... 70

Figure 3-20 Human information process (modification) .......................................... 71 
Figure 3-21 The RSA - check list (LTPA, 2006) …………………………………....... 73

Figure 3-22 First level of the knowledge.................................................................... 75

Figure 3-23 Structure representation of the knowledge................................................... 76

Figure 3-24 Tree structure (example C- Adverse weather) …………………………...... 77

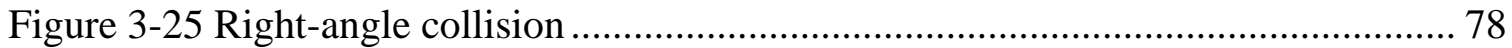

Figure 3-26 Night time collisions ............................................................................ 79

Figure 3-27 Example of the knowledge path................................................................ 79

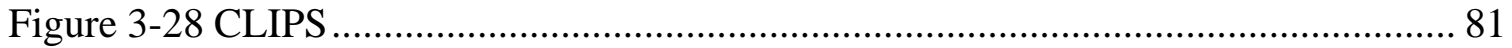

Figure 3-29 Main menu .......................................................................................... 82

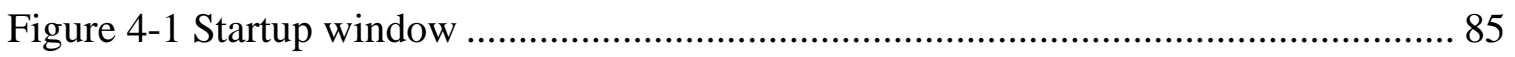



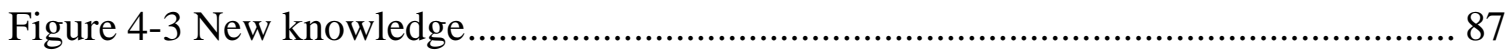

Figure 4-4 Investigation Window ………………………......................................... 88

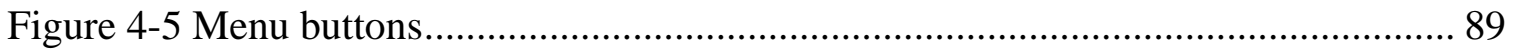

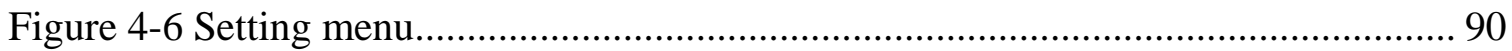

Figure 4-7 Report Menu................................................................................................ 91

Figure 4-8 Report window ................................................................................ 92

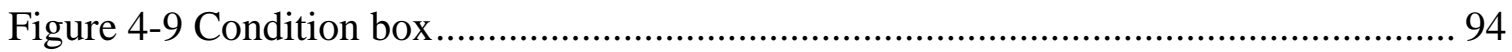

Figure 4-10 Driveways Collisions condition .................................................................. 95

Figure 4-11 Processed text box.......................................................................................... 96

Figure 4-12 Right-angle Collisions window............................................................... 97

Figure 4-13 Stop Sign Not Missing window .................................................................. 98

Figure 4-14 Stop sign visible window …………............................................................. 99

Figure 4-15 Insufficient Sight Distance From The Minor Road....................................... 100

Figure 4-16 Poor horizontal/vertical alignment window ................................................ 101

Figure 4-17 The Insufficient Gaps In The Priority Traffic condition.............................. 102

Figure 4-18 Warning window .................................................................................... 103

Figure 4-19 Inadequate Pavement Marking condition window......................................... 104

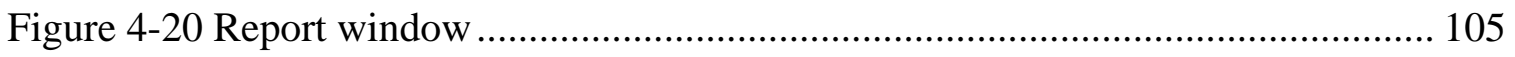

Figure 5-1 Location: Cartersburg Road and CR 200 South............................................. 108

Figure 5-2 The RSIT - preliminary analysis for Cartersburg Road and CR 200 South. 109 


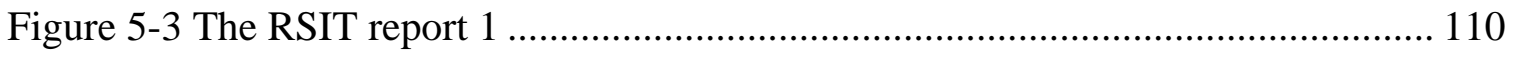

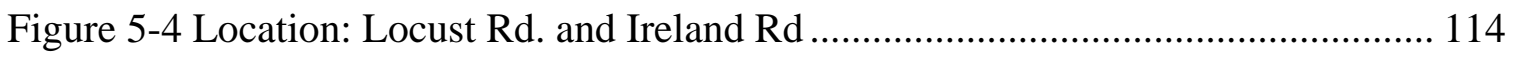

Figure 5-5 The RSIT - preliminary analysis for Locust Rd. and Ireland Rd ................ 115

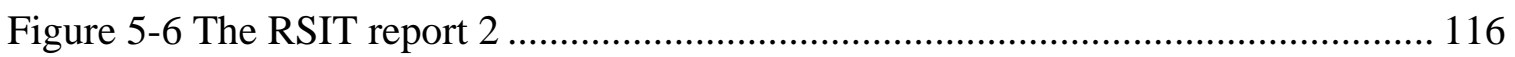




\section{LIST OF TABLES}

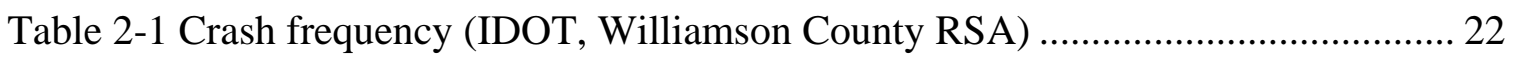

Table 2-2 Severity rating (IDOT, Williamson County RSA) .......................................... 22

Table 2-3 Crash risk assessment (IDOT, Williamson County RSA).............................. 23

Table 2-4 Example of the rash risk assessment (IDOT, Williamson County RSA)........ 24



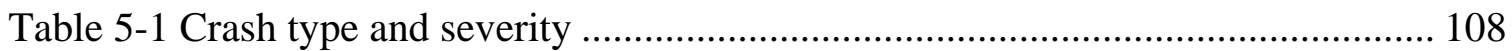

Table 5-2 The investigation team vs. the RSIT Cartersburg Road and CR 200 South,

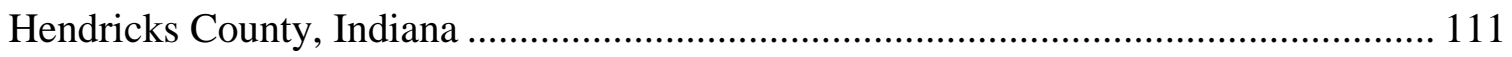



Table 5-4 The RSA team vs. the RSIT Locus Road and Ireland Road is located in St.

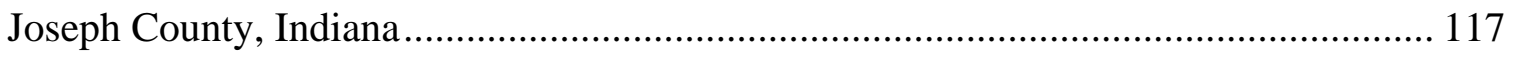

Table 5-5 The RSA team vs. the RSIT (“non-expert” student) Locus Road and Ireland

Road is located in St. Joseph County, Indiana............................................................ 120 


\section{CHAPTER 1 INTRODUCTION}

Road safety has become the major problem in transportation around the world. In the US, 42,643 fatal crashes occurred in 2003. On the U.S. roads every 14 minutes a fatality occurs. Every day more than 100 people die in automobile crashes, and the daily financial loss is $\$ 630$ million. Specialists in different areas of science are constantly trying to improve road safety through safer cars, road geometry, and traffic control, as well as through a better understanding of driver behaviors.

A great deal of past research has tried to determine the most significant aspects of safety, and driver error has been found to be the most important factor of traffic safety. More than 80 [\%] of all crashes are causes by drivers, and information found in crash databases confirms that drivers determine their individual perceptions of risk, which contributes in many cases to various driver errors.

The most challenging task for traffic safety engineering is to determine the most significant cause of each crash and thereby increase safety by thorough evaluation at the crash site. Since driver errors are the main cause of crashes, we should focus on human characteristics and try to understand why drivers make errors.

The most difficult part of crash investigation is determining the cause of each crash; therefore, the investigators try to connect the hypothetical driver behaviors leading to the reported crashes with the roadway features that might play a causal role in the crash occurrence.

Due to the lack of suitable tools, investigative teams have to rely on their experience and judgment. This task may be overwhelming, particularly for inexperienced investigators. Experienced investigators often may have difficulties in connecting various pieces of information and knowledge due to the high level of uncertainty, the high complexity of safety impacts, and the gaps in what is known about driver performance during the crash occurrence. Human factor science can provide important information about driver perception, attention, and response mechanisms.

It is possible that in some cases an investigative team adheres to its past experience, routine actions, and past findings that do not necessarily reflect the causes at the currently investigated site. One of the tempting shortcuts is limiting the investigation 
to roadway deficiencies understood as deviations from the design standards. Although a roadway that does not meet the design standards is likely to exhibit excessive risk for crashes, many times there are additional contributing factors. Furthermore, roadways designed according to the design standards may experience a high number of crashes.

Road safety audits introduced in the U.S more than 10 years ago address future safety problems in the early stages of highway projects (i.e., planning and design). They use safety checklists that organize an audit of the design documentation. The Purdue team has developed a comprehensive checklist as a part of the Indiana guidelines for safety improvements. Although checklists bring organization to a site investigation, there are better ways of assisting investigation teams.

The most difficult task for the investigation team is to connect various pieces of information, including road geometry, traffic control, and driver characteristics, as well as environmental conditions that can create potential safety problems. Additional uncertainty is caused by the lack of data or the impossibility of reconstructing the real time crash situation, which increases the complexity of the problem.

Large numbers of collisions occur and they need to be investigated, which creates for the investigation team additional time pressure, thereby sometimes resulting in inadequate solutions and overlooking important crash factors, as well as insufficient use of the checklist. To make the investigation process more efficient, a computer tool was developed. This tool is intelligent, easy to follow, and provides an understandable way to connect large amounts of information from different areas of science (road geometry, traffic control and human factors).

Crashes can occur at different points of the transportation infrastructure (e.g., on the freeway, an urban road or at intersections). Each time a driver needs to change the current speed, a different action, or a distraction from the environment can contribute to inadequate decisions. For instance, there are more sources of information at intersections that drivers must process than on a freeway so the perception, cognition, and action stages of a driver could be easily disturbed by large amounts of information or temporary inattention, thereby contributing to a crash situation.

For the purpose of this project and the available time, we will focus on the twoway stop controlled (TWSC) intersections. It should be pointed here that the software 
which was developed could be adjusted in the future to determine the most significant causes of crashes at other intersections types as well as on road segments.

One of the important parts of human information processing is to better understand human perception, decision-making, and reasoning, as well as execution. All of this information was implied in the developed knowledge-based system, which by using the DSS (Decision Support System), created the final product.

The objective of this research is to develop an interactive site investigation tool that can guide a site investigator through data collection and perform automated reasoning from provided information about crashes and roadways.

The final product of this research, the knowledge-based system, browses through various sets of information represented in the structure of the tree of events, and by connecting between the facts and the rules returns the possible safety improvements.

The tool is suitable for users who have some transportation background and some experience in site investigation. To make this software user-friendly, however, a manual for users without a transportation background is provided. This tool is meant for education purpose as well to identify possible roadway improvements.

The traffic data needed are prompted by the tool in order to conclude about the possible causes of the reported crashes. The tool user has full control of each analysis stage and can choose to pass over part of the examination as well as to adjust the investigation structure.

The proposed procedure provides crash analysis techniques with the significant difference that no analysis of skid marks and no interviews of the crash victims or witness need to take place. This approach yields multiple possible crash countermeasure scenarios with the evaluated role of the roadway and the control system. The presented approach is retrospective because it ties the scenarios with the actual crashes that have happened in the past. A retrospective approach is strongly justified by the fact that the site is investigated due to the experienced crashes and that crash data brings extremely valuable information.

The tool was developed to be used at the portable station (laptops, Tablets PC), as well as at the permanent station. 
This research report is organized into six chapters. Additional material included graphs, plots, tables, and software documentation, as well as the software shell found in the appendix.

The first chapter provides an overview of the motivation, scope, and objective of the research. In the second chapter the state-of-the-art and practice, and an overview of actual and propose safety investigation tools are provided. Existing methods and proposed improvements are also discussed. Chapter 3 focuses on the proposed method. The developed stages are described and different approaches are presented with detailed explanation of the concept including the final method, justification, and user and developer specification. Chapter 4 provides a full description of the proposed software implementation, including a user manual. An evaluation is provided in Chapter 5, as well as a summary of the results and important findings. 


\section{CHAPTER 2 REVIEW OF SITE INVESTIGATION METHODS}

In this chapter actual methods that are used to investigate hazardous locations are presented.

Significant numbers of crashes occur each year that require investigation by traffic experts in order to determine hazardous locations and potential road inadequacies. The investigation process depends on the method used. This chapter will present an overview of existing and propose procedures that can be used to determine potential road deficiencies.

In Indiana, the Hazard Elimination Program (HEP) was implemented and safety guidelines for this program have been developed. The guidelines provide an organized structure of the safety management program which includes an analytical tool to identify hazardous locations, determine roadway deficiencies, propose safety improvements, and perform an economic analysis of the findings (Tarko and Kanodia, 2004).

The structure of the HEP (Hazard Elimination Program) is shown in Figure 2-1.

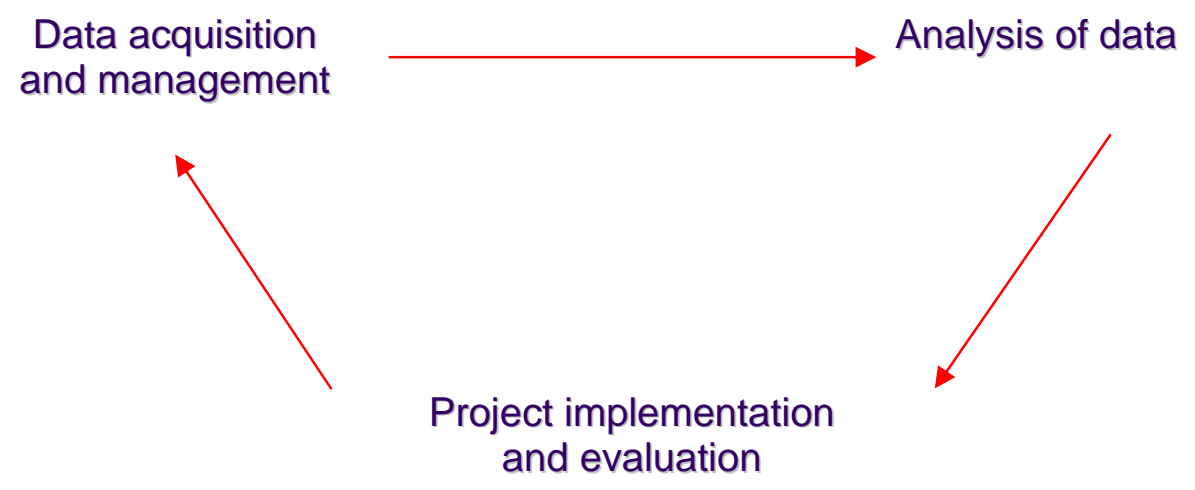

Figure 2-1 Cycle of the HEP (Tarko and Kanodia, 2004)

Data acquisition and management consist of collecting, filling, sharing, and summarizing data. The crash data collected at a crash scene are sent to the Indiana State Police and are entered into a crash database. Each state is required to collect, maintain, 
and share its crash data with public agencies. The Indiana Department of Transportation (INDOT) crash database is often the starting point for site investigations in Indiana. To determine whether a location is hazardous, an analysis of existing crash data and crash patterns are required. The collision type, a collision diagram (Figure 2-2), the times collisions occurred, contributing crash factors, weather conditions and any other information which can be extracted from a crash database are critical for all road safety investigations.



Figure 2-2 Collision diagram (LTAP Hazard Elimination Study)

The next step of the HEP is data analysis, which consists of the following:

- $\quad$ Identify high crash locations,

- Determine causes,

- $\quad$ Determine countermeasures,

- $\quad$ Develop safety project,

- $\quad$ Select projects for implementation,

- $\quad$ Implement safety projects, and 
- $\quad$ Conduct post-implementation study.

The first important part for each project is to collect the appropriate information through the use of a database. The Indiana State Police Vehicle Crash Records System contain all crash data for the state of Indiana (INDOT crash database). These data are collected by police officers during crash scene investigation. A standard crash reporting form is shown in Appendix A. The crash reporting form is entered into the database and includes information about the environment, the, driver, the vehicle, pedestrians, and fatalities and injuries.

The next significant database, which includes information about the road inventory, is the Road Inventory Database (RIDB). This database is divided by two parts: description files (DES) and detail files (DET). The first part contains such information as the beginning and end of the road segments. The second part includes more detailed information about the number of lane, shoulders, median width, the AADT (...). Additional data can also be found from the Indiana Bureau of Motor Vehicles, hospitals, or insurance companies.

The investigation process is strongly related to the information found in the crash database so adequate extraction of data is needed.

The next step is to determinate the hazardous location. Because there is a significant number of locations which need improvements, classifying these locations is needed. There are various techniques (Organization for Economic CO-Operation and Development, 1976) for identification of hazardous locations, but one of the most commonly used and introduced in the HEP is the statistical and numerical technique.

The statistical and numerical technique used in the HEP calculates, for example, the index of crash frequency (greater then 2 indicate hazardous location), or crash rate (from user perspective). To measure the difference between the expected and the estimated crash cost, the index of crash cost can be applied (Tarko and Kanodia, TRB, 2004).

Today, by using new technology, selecting high crash location becomes easier and more effective than before. The GIMS (Geographic Information Management System) and the GIS-ALAS (Geographic Information System Accident Analysis and Location System) databases, which are used in the state of Iowa (Souleyrette and Khattak, 2002), help engineers determine the high crash locations. Furthermore; to improve identification 
of hazardous location and roadway deficiencies, GIS and 3-D computers model were proposed (Khattak, TRB 2004). By using the Light Detection and Ranging (LiDAR) system connected with a GIS system, 3-D models of different sections of the road were obtained. These models were visually analyzed to determine the insufficiencies in the sight distance and to propose adequate roadway countermeasures.

Identification of high crash locations becomes one of the significant starting points for a safety management system. Selecting the wrong locations not only wastes time during the detailed analysis of this location, but not selecting significant locations also will eliminate these locations from future considerations. Therefore, an in-depth study of existing methods and a final decision about choosing one of presented methods needs to be carefully made.

One of the last steps during safety investigation is to determine the causes of crashes and propose adequate countermeasures. More detailed discussion about these two phases of the HEP is presented in the next paragraph, the entire safety review process is shown in Figure 2-3. 




Figure 2-3 HEP - Safety review process (Tarko and Kanodia, 2004)

The last part of the HEP is project implementation and evaluation, whereby the crash reduction factor is updated and the project is checked whether it is statistically significant.

The HEP provides a wider tool for safety investigation purpose. It provides guidelines through identification of hazardous locations, safety site investigation and 
determination of a potential road deficiency. In the next paragraph the safety review methods proposed by the HEP and adopted into Road Safety Audits are presented.

\subsection{Overview of existing methods}

The Hazard Elimination Program (HEP) created the framework for a program that can be used for hazard elimination studies. Because the purpose of this research is to develop the knowledge-based system which will point out safety countermeasures, the major focus is to determine roadway deficiencies and proposed roadway improvements.

\subsubsection{Road Safety Audits vs. Road Safety Reviews}

A road safety audit (RSA) is a safety examination of selected intersections by teams that should include specialists in highway safety engineering (NCHRP Report 336, 2003/2004). To improve the investigative process, the safety team should incorporate additional experts outside highway engineering (i.e., human factors experts). The RSA as well as the RSAR (Road Safety Audit Review) have been used since the 1980s. Road safety audits were first time introduced in the U.S. in 1996.

RSAs can be performed at one of these stages:

- Feasibility studies, where hazardous locations and important roadway network elements can be identified;

- Preliminary designs, where specific information for individual intersections is obtainable, such as land and shoulders width, overtaking line, provision for cyclists and pedestrians;

- Detailed design, where all of the specific characteristics for an intersection are described (i.e., line marking, delineation, lighting, landscaping);

- Pre-opening, which includes a check by the safety team of the actual project improvement in different condition (rain, sunshine, etc.);

- In - service, where any problems observed after the road is opened for public use can be identified. 
There are fundamental differences between RSAs and the RSARs (http://www.roadwaysafetyaudits.org/). The RSAR usually is prepared by a smaller team than RSAs. Also, the safety team for a RSAR is involved in the design stage whereas the RSA team is independent of the project design stage. In the case of the RSAR, the safety team focuses on evaluating the design standards whereas the RSA team conducts a field investigation to review all of the design features. Furthermore; the RSA team includes human factors elements to improve roadway safety whereas the RSAR team does not consider driver behavior.

The most fundamental difference between these two site investigation methods is their connection with crash occurrences (time). In the RSAR method, the review process is reactive. To determine hazardous locations statistical methods are studied. The RSA method is proactive as the safety team tries to determine the roadway deficiencies at the time of a specific crash.

The structure of the safety investigation process can be divided into three major stages. The first stage is called preliminary analysis and it helps to plan site investigation. During this stage the safety team collects information about the intersection: type of intersection, the exact location of the intersection, environmental conditions (i.e., school, shopping center, etc.) and any additional data. Probably the most important element of this preliminary stage is the crash data analysis. The crash data are used to determine the predominant crash pattern, weather condition, time of the accident, crash severity, and where the crash occur, as well as to identify the primary contributing circumstances and other useful information.

One of the required steps during preliminary analysis is to prepare the collision diagram (Figure 2-2). This will help find the predominant crash pattern. The time of the accident (night/day) has an important meaning for crash factors and the site investigation should take place at the same specific time. During preliminary analysis when all the data have been prepared, the safety team can pinpoint possible crash scenarios that will provide a better understanding of the crash situation during the site investigation.

The next stage is the site investigation. The investigation team goes to the specific location and determines the existing local conditions. The purpose of this stage is to collect actual information about road conditions, geometry, traffic control, and traffic 
characteristics. In the case of a speed study, the investigator could determine if a speed violation was present by using speed detectors (i.e., laser gun). Collection of the data often requires photographing or videotaping the site. The team may also briefly discuss funding and decide to collect additional data or prepare additional site investigation studies. One of the common practices by the investigation team during this stage of analysis is to follow the checklist (RSA: Local Technical Assistance Program (LTAP), INDOT, IDOT, and NCHRP Synthesis 336 Series). An example checklist is available in Appendix B. The team, by marking the various elements of the checklist, indicates possible roadway deficiencies. A sample checklist prepared during site investigation is shown in Figure 2-4.

\section{Safety Review Check List}

\section{Roadway Segment}



\section{Figure 2-4 Example of the Checklist (Hazard Elimination Study for Smith and Rogers Road, Indiana, 2006)}

Probably the most difficult task during site investigation and post-analysis is determining possible improvements. A significant amount of information may be obtained from the preliminary analysis and during the site investigation, and combined together, they may create a very large set of possible crash scenarios. Especially when the human factors are considered, which is the case in almost $85 \%$ of all accidents, the investigation process can become an overwhelming task even for the experts. The 
multiplicity of past crashes and a typically large number of local characteristics to consider create a time pressure, which may contribute to inadequate solutions, overlooking important crash factors, and inadequate use of the checklist. Furthermore; the impossibility of reproducing the actual crash conditions and the uncertainty which comes from lack of data, creates an additional difficulty for safety teams and may lead to inappropriate safety countermeasures. Therefore, the investigation team has to spend a significant amount of time during the site investigation and to the team must contain experts from areas outside traffic engineering, such as human factors experts.

The last stage of the safety investigation process is a post-analysis study. The safety team upon completion of the site investigation discusses all the findings and determines the safety deficiency. The common problem in the post-analysis study is the significant number of roads deficiencies and classifying them. One finding can create more safety problems than another, and not all are the most critical for specific crash conditions. It should be pointed that a different range of treatments could have roadway deficiencies which lead to fatal crashes or a different one could lead to PDO collisions.. In the next step the propose countermeasures and discussion of the eventual additional study are prepared. To classify the road deficiencies, the frequency and severity rating can be used (practice by IDOT in the developing and existing condition). By using the frequency rating the total number of crashes that occur on specific intersection or road segments can be classified as shown in Table 2-2. 
Table 2-1 Crash frequency (IDOT, Williamson County RSA)

\begin{tabular}{|c|c|c|c|}
\hline \multicolumn{2}{|c|}{ ESTIMATED } & \multirow{2}{*}{$\begin{array}{l}\text { EXPECTED CRASH FREQUENCY (per } \\
\text { audit item) }\end{array}$} & \multirow{2}{*}{$\begin{array}{l}\text { FREQUENCY } \\
\text { RATING }\end{array}$} \\
\hline EXPOSURE & PROBABILITY & & \\
\hline high & High & \multirow{2}{*}{10 or more crashes per year } & \multirow{2}{*}{ Frequent } \\
\hline medium & High & & \\
\hline high & Medium & \multirow{3}{*}{1 to 9 crashes per year } & \multirow{3}{*}{ Occasional } \\
\hline medium & Medium & & \\
\hline low & High & & \\
\hline high & Low & \multirow{2}{*}{$\begin{array}{c}\text { less than } 1 \text { crash per year, but more than } \\
1 \text { crash every } 10 \text { years }\end{array}$} & \multirow{2}{*}{ Infrequent } \\
\hline low & Medium & & \\
\hline medium & Low & \multirow{2}{*}{ less than 1 crash every 10 years } & \multirow{2}{*}{ Rare } \\
\hline low & Low & & \\
\hline
\end{tabular}

The severity rating is obtained by combining the typical crashes expected with the expected crash severity, for example, a crash that involves high speed and a heavy vehicle can have an expected crash severity of probable fatality or incapacitating injury (Table 2-3).

Table 2-2 Severity rating (IDOT, Williamson County RSA)

\begin{tabular}{|c|c|c|}
\hline $\begin{array}{c}\text { TYPICAL CRASHES EXPECTED } \\
\text { (per audit item) }\end{array}$ & $\begin{array}{c}\text { EXPECTED CRASH } \\
\text { SEVERITY }\end{array}$ & $\begin{array}{c}\text { SEVERITY } \\
\text { RATING }\end{array}$ \\
\hline \hline $\begin{array}{c}\text { crashes involving high speeds or heavy } \\
\text { vehicles, pedestrians, or bicycles }\end{array}$ & $\begin{array}{c}\text { probable fatality or } \\
\text { incapacitating injury }\end{array}$ & High \\
\hline $\begin{array}{c}\text { crashes involving medium to high speed; } \\
\text { head-on, crossing, or off-road crashes }\end{array}$ & moderate to severe injury & High Moderate \\
\hline $\begin{array}{c}\text { crashes involving medium to low speeds; } \\
\text { left-turn and right-turn crashes }\end{array}$ & $\begin{array}{c}\text { minor to moderate injury } \\
\text { crashes involving low to medium speeds; } \\
\text { rear-end or sideswipe crashes }\end{array}$ & $\begin{array}{c}\text { property damage only or } \\
\text { minor injury }\end{array}$ \\
\hline
\end{tabular}

By combining the severity rating and the frequency rating, the crash risk assessment is obtained. Levels D, E, and F represented the highest crash risk and safety implementation is needed as shown in Table 2-4. 
Table 2-3 Crash risk assessment (IDOT, Williamson County RSA)

\begin{tabular}{|l|c|c|c|c|}
\hline \multirow{2}{*}{$\begin{array}{c}\text { FREQUENCY } \\
\text { RATING }\end{array}$} & \multicolumn{4}{c|}{ SEVERITY RATING } \\
\cline { 2 - 5 } & Low & Low Moderate & High Moderate & High \\
\hline Frequent & C & D & E & F \\
\hline Occasional & B & C & D & E \\
\hline Infrequent & A & B & C & D \\
\hline Rare & A & A & B & C \\
\hline
\end{tabular}

Crash Risk Ratings:
A: lowest risk level
D: moderate-high risk level
B: low risk level
E: high risk level
C: moderate-low risk level
F: highest risk level

During site investigation and post-analysis, the safety team develops a list of all possible safety issues. This list is evaluated according to the expected safety risk of associated crashes. Risk is defined by the degree of frequency and the severity of the expected crashes for each safety issue and is given an overall rating level as represented in Figure 2-4. The risk is a function of exposure, probability, and consequences and can be obtained by Equation 2-1.

Where:

\section{Risk $=\mathrm{f}(\mathrm{E}, \mathrm{P}, \mathrm{C})$ \\ Equation 2-1 Safety risk}

E - Exposure, (How many users are exposed to the specific risk being assessed),

P - Probability, (The likelihood of a crash occurring),

$\mathrm{C}$ - Consequence (The severity of a crash once it happens).

Additional sum of the exposure and probability gives the frequency.

$\mathrm{E}+\mathrm{P}=$ Frequency

Following is an example using the crash risk assessment technique, the observations for which were made by the safety team at the Illinois Department of Transportation during road safety audits in Williamson County. One of the observations during the site investigation was insufficient sight distance triangles (Figure 2-5). The expected 
frequency and severity were classified as occasional, severe; see below in Table 2-4 what constitutes a high crash rating and level E.

Table 2-4 Example of the rash risk assessment (IDOT, Williamson County RSA)

\begin{tabular}{|c|c|c|c|}
\hline Expected Frequency & Expected Severity & Risk Rating & E \\
\hline Occasional & Severe & High & \\
\hline
\end{tabular}

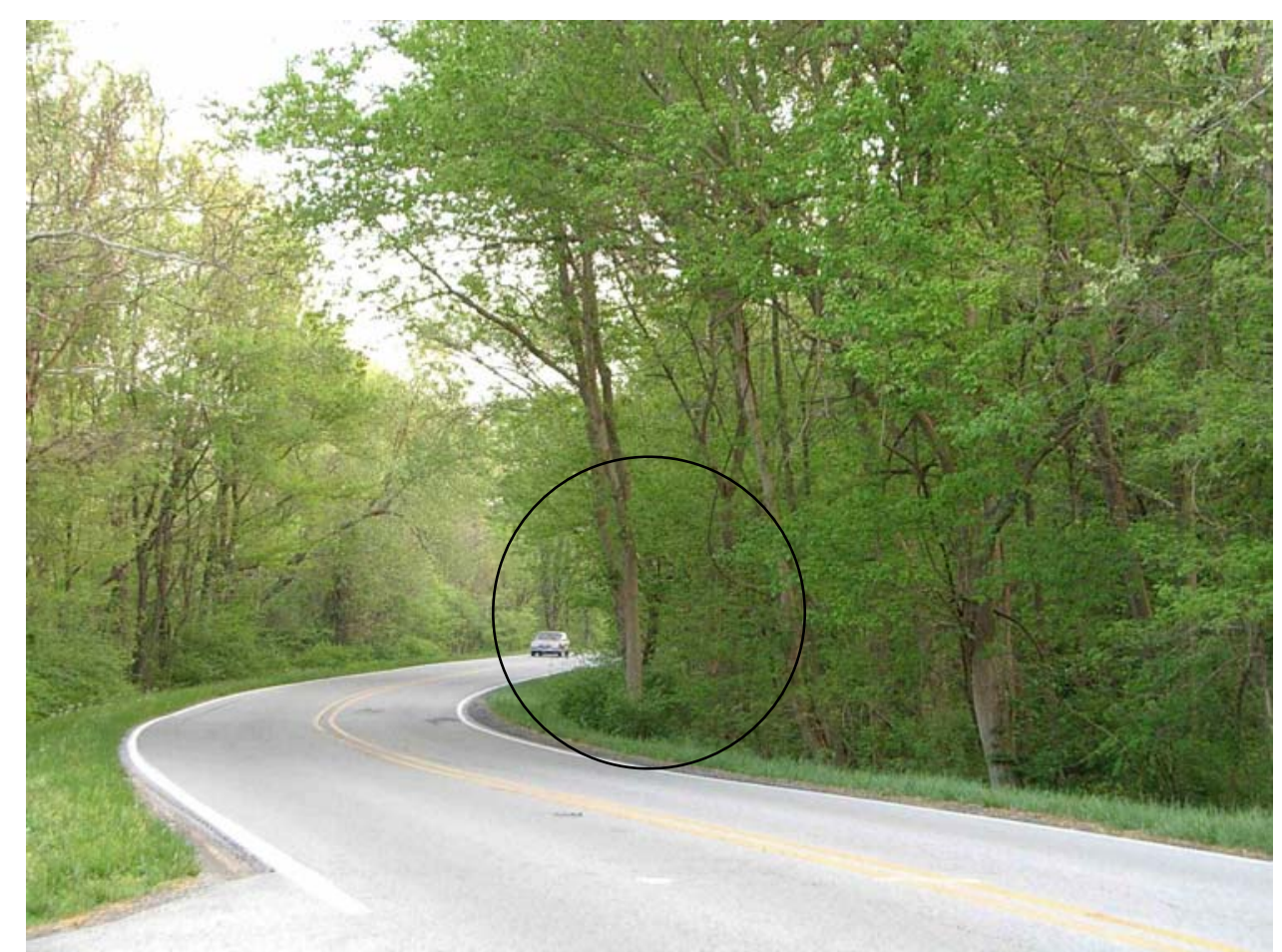

Figure 2-5 Insufficient sight distances (Williamson County RSA, Illinois 2006)

Because the insufficient sight distances represented level $\mathrm{E}$, this observation had to be considered. Therefore the following suggestion was proposed: "Clear vegetation, including strategic tree removal, relocate signs, and re-grade slopes or reduce crests to establish sight distance (Examples: Quarter Horse Road, Cochran),” (RSA, Williamson County, Illinois).

Depending on the final recommendations of the safety investigation, additional engineering studies could be proposed, which could included a volume study, spot speed study, and travel time and delay study, as well as a roadway and intersection capacity study and a gaps study. 
Roadways that exhibit a high number of crashes are investigated to identify the probable causes of the crashes and to propose adequate roadway improvements. The essence of the investigation task is to connect the hypothetical driver behaviors leading to the reported crashes with the roadway features that might play a causal role during the crash occurrence. Due the lack of suitable tools, investigative teams have to rely on their experience and judgment. This task may be overwhelming, particularly for inexperienced investigators. Experienced investigators often may have difficulties in connecting various pieces of information and knowledge due to the high level of uncertainty, the high complexity of safety impacts, and the gaps in what is known about driver performance during the crash occurrence. It is possible that in some cases an investigative team adheres to its past experience, routine actions, and past findings that do not necessarily reflect the causes at the currently investigated site. One of the tempting shortcuts is limiting the investigation to roadway deficiencies understood as deviations from the design standards. Although a roadway that does not meet the design standards and is likely to exhibit excessive crash risk, many times additional factors contribute. Furthermore, roadways designed according to the design standards also may experience a high number of crashes for various reasons.

Time pressures or inadequate use of existing safety investigation tool (i.e., checklist) may create insufficient safety improvements.

An overview of the represented methods, their weaknesses, and possible improvements are discussed in the summary of this chapter.

\subsubsection{IHSDM Intersection Diagnostic Review Model}

The IHSDM (Interactive Highway Safety Design Model), (http://www.tfhrc.gov/safety/ihsdm/pubs/02045/) was proposed to improve intersection geometry on rural two-lane highways. This project is base on the Intersection Diagnostic Review Model (IDRN). The IDRN model combines the potential intersection design problems and proposed adequate countermeasure.

The fundamental part of the model is the IDRN knowledge-based system. This knowledge base includes all the basic geometry components and traffic control design. 
The knowledge base is made not by implementation of a type of "if-then" scenario, but by the engineering models. The goal of each model is to calculate one or more evaluation parameters. These parameters are compared with the standards to evaluate intersection geometry.

They identified more than 100 design problems. These problems were addressed with engineering models that included:

- $\quad$ SSD (stopping sight distance),

- $\quad$ DSD (decision sight distance),

- $\quad$ ISD (intersection sight distance),

- $\quad$ Horizontal curve design.

These models were used later to evaluate 27 concerns, which are related to the intersections and to each approach.

The goal of using each engineering model is calculate the specific value for each problem as shown in the example below (Equation 2-3).

Model: Intersection Sight Distance for Case B1- Left Turn From Minor Road

$$
I S D=0.278 \mathrm{Vt}
$$

Where:

\section{Equation 2-3 ISD}

ISD = intersection sight distance (m)

$\mathrm{V}=$ initial speed $(\mathrm{km} / \mathrm{h})$

$\mathrm{t}=$ time gap (s)

After calculating the ISD $_{\text {des }}$ user obtains the intersection sight distance limited by the vertical geometry, the critical time gap, and, in the last step, decelerates at the sight obstruction.

In the next step the evaluation of the intersection sight distance are prepared. To obtain the ISD, two variables are uses:

- $\quad$ The effective speed for which ISD is provided,

- $\quad$ User response about clearance of sight distance (obstruction present).

After this calculations the possible improvement are presented. 
In final representation of the project, the software implementation was presented (http://www.wsdot.wa.gov/eesc/design/ihsdm/Documents/getstarted.pdf).

This project contains a sufficient knowledge base to check the geometry design for each approach as well as for all intersections. The knowledge base is supported in the engineering models that consist of the most importance factors which have to be checked for geometry design standards. Information about the actual obstruction of the intersection sight distance is derived by the user. This situation creates a more effective tool and gives more adequate findings.

The IHSDM model, as well as the RSAs, contains one common element: these two methods identify potential roadway deficiencies and propose appropriate countermeasures. In the RSAs the safety team determines the safety issue itself based on their experience and knowledge. However, the IHSDM model is more sophisticated and includes a knowledge-based system where the geometry elements which can affect safety are described.

Because driver error is the cause of more than $85 \%$ of all crashes, the next presented model focuses on driver behavior to determine the contributing causes of crashes.

\subsection{Proposed procedure of safety investigation}

One of the methods in the developing phase, is the Safety INDIcator (SINDI) micro-simulation model of driver behaviors, which originates in Sweden (http://www. infra.kth.se/ctr/projekt/sindi/beteendedel/BehavPart.htm).

To evaluate the traffic safety effects, two approaches were used:

- $\quad$ Analytical approach, where factors such as speed, time gaps, road surface, and conditions are used to determine the causes of crashes; and

- $\quad$ Traffic safety panel approach, where the causes of crashes are determined by understanding human behaviors. 
The SINDI model is proposed for use in the development and implementation stages. The major idea behind this Swedish model is a connection between the microlevel driver simulation models with the macro level by introducing the safety indicator.

In this project the main parts of system are presented in Figure 2-6.

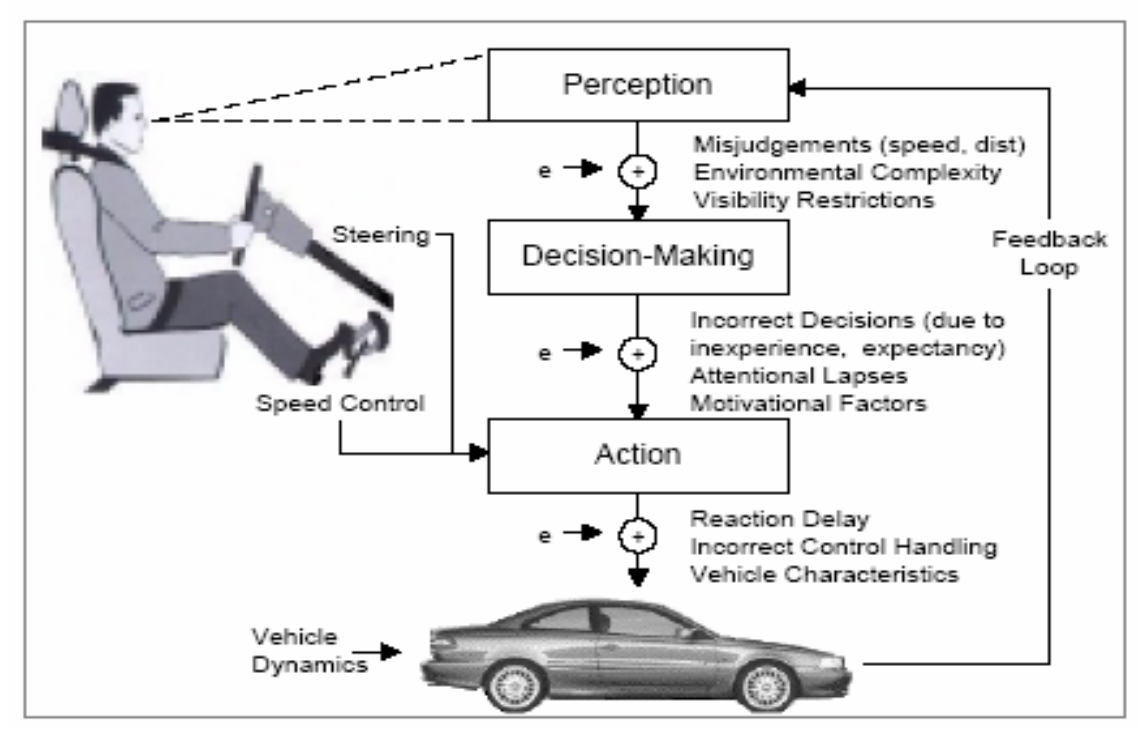

Figure 2-6 SINDI structure (http://www.infra.kth.se/ctr/publikationer/ctr1999_08.pdf)

In this project it was determined that changes in human perception, cognition, and action can contribute to crash occurrences. To better understand how drivers respond and take action, a simulator was created.

After collecting and identifying the human characteristics the traffic safety expert system obtained potential safety improvements.

This process is presented in Figure 2-7. 


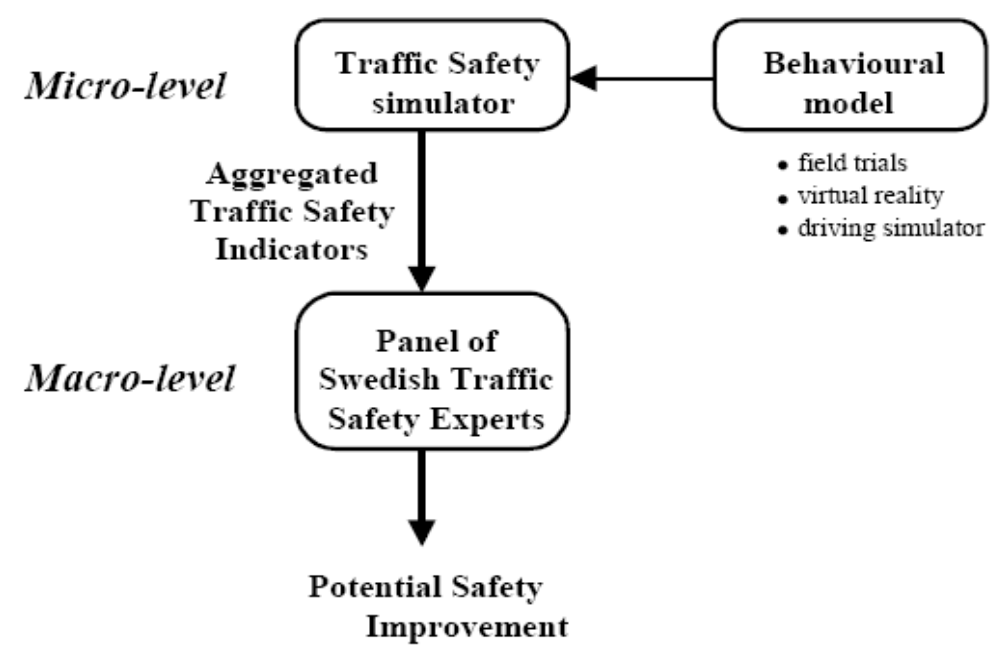

Figure 2-7 SINDI system (http://www.infra.kth.se/ctr/publikationer/ctr1999_08.pdf)

The SINDI model focuses strongly on each stage of human information processing: perception, cognition, and action. The critical point in the presented project was the obtained errors which can be created by drivers in each stage of human information processing.

After determining driver behaviors at the micro level in the traffic safety simulator, the aggregated traffic safety indicators are proposed. At the macro level, the safety expert system determines the potential safety improvement.

Because of large volume of information focusing on human behaviors, this project dealt only with a particular intersection or roundabout. The complexity required involvement of specialists from different areas of science, including the Center for Traffic Engineering and Traffic Simulation at KTH, Stockholm, and Traffic and RoadUser Behavior Department at VTI, Linköping.

The SINDI model considered one important element that was not considered in previous methods in detailed - driver behavior. This idea was applied to identify traffic safety concerns by focusing on the drivers' characteristics in the early stages seems to be very useful and is required to adequately address the safety issue.

\subsection{Summary of site investigation methods}


Roadway safety has become the most fundamental element of transportation safety.

The last five years do not indicate increasing crashes occurrences, but the total number of crashes that do occur is a most important problem. Different methods were presented here to improve the investigation and remediation of roadways deficiencies. One of the methods (RSA), by identifying in the preliminary stage potential crash patterns, investigates the intersection to determine possible safety countermeasures. The most challenging task for the safety team is to connect various pieces of information to determine crash causes and propose safety improvements. Because the total number of facts, that have to be considered increase, especially in the case of the human factors and the uncertainty (lack of data), the safety investigation process becomes overwhelming, even for experiences investigators. The most important finding, the proposed safety countermeasures, as well as identification of the roadway deficiencies, is based on human expert judgment and knowledge. Sometimes the findings are related to human behavior experts' past experiences and not always do they point out the most significant issue for each particular intersection. Strictly following the geometry standards also does not always render the most efficient solution. It has been proven that an intersection which is designed according to standards can still experience crashes. Additionally, the size of the team and the areas of interest of the safety team member should be diverse so that experts from different fields are involved into the safety investigation process (i.e., highway engineering, human factors, planning).

The lack of well organized knowledge from different areas of science about the factors that can contribute to a crash situation creates significant discomfort for investigators and often judgment is the basis of the final safety findings. To organize safety audits a checklist was proposed (Tarko and Kanodia, 2004; NCHRP Synthesis 336 Series, 2004). These checklists provide a general overview of potential roadway problems. The safety team during the site investigation marks the elements of the checklists that adequately describe the actual roadway conditions. However, the checklist is a flat list of roadway deficiencies that can contribute to safety problems, which can create multiple problems for safety team. At first the safety team has to follow all of the elements in the checklist even if some of these elements are not adequate for some 
particular location. The user does not know if the first set of possible problems indicates the safety issue or if the last part of the checklist contains the most fundamental findings. Furthermore, the large number of roadways elements that could indicate safety issues need to be investigated can create a time pressure on the safety team and insufficient use of the checklist.

To address the above problems, the new method, in an intelligent way, organizes the roadway safety deficiencies and proposes only safety improvements which are adequate to the actual roadway conditions. This method decreases the time spent on the safety investigation process as well as the size of the team. The smaller team size is due to the fact that the knowledge is organized and developed into the knowledge-based system and represents various areas of sciences: traffic engineering, human factors, roadway geometry, traffic control (...). The idea behind a knowledge-based system was introduced in the methods presented here: ISHDM and the SINDI. Unfortunately, each of the methods covers only a part of the entire knowledge, respectively: geometry elements and human factors issues. Furthermore, these methods are meant for use in the developing stages. The additional lack of the ability to update the knowledge (on the user level) can possibly create problems in the future and decrease the efficiency of the proposed methods. It has to be pointed that the wrong method of updating knowledge can result in a completely unstructured knowledge base and could deviate from the expected findings.

Developing a tool such as proposed in this current research can provide very flexible and understandable knowledge with the flexibility of updating (by an expert) the final knowledge and even develop a user's own knowledge base. The powerful and open structure of such a developed tool, as well as a user-friendly interface and understandable representation of proposed countermeasures would create an efficient tool for the safety investigation process. A detailed description of the developed tool is presented in the next chapter. 


\section{CHAPTER 3 METHODOLOGY}

The discussion of existing and proposed methods pointed out the lack of an adequate solution that can be effectively and efficiently used by the safety team during site investigation. The lack of in-depth knowledge of the actual circumstances leading to past crashes increases the complexity of the problem. Current practice, despite the best effort of investigating teams, relies a great deal on the teams' experience and judgment, which may not be sufficient given the limited data, the complexity of roadway-drivervehicle interactions, and the large number of possible scenarios leading to crashes.

A computer-based method is needed that utilizes all of the pieces of information known about the local conditions, the circumstances of the recorded crashes, and our current knowledge of driver behavior and performance related to crash occurrence. Modern data-mining and information technology tools can assist in extracting the maximum information about possible roadway-related causes of crashes.

By connecting driver behaviors, road geometry, and other information related to the safety issue, the knowledge base is developed. The knowledge, which becomes the fundamental element of the developed tool, connects various pieces of information and facts into rules to derive final possible roadway improvements.

The starting point for developing the model is to understand the problem scope, and collect data and additional information which create the backbone for the knowledge base. The structure of the knowledge represents an unstructured knowledge base and a structured knowledge base. Each of the structures is discussed in detail and the final method concept with the structured knowledge base is justified and described. The overview of the existing computer shell that can be used to implement the method is presented. To organize the structure of this chapter; the following phases are proposed.

The problem description, method scope, and collection of the data, as well as additional required information are first discussed. Then knowledge structure phase is described, which contains a description of the methods tested to derive the knowledge structure and the uncertainty representation. A discussion of the computer tool methods follows, which includes the study of existing computer tool shell methods and its 
implementation (user manual and software - structure). Finally, the chapter ends with an overview of the problem scope and the proposed equivalent and more effective approach.

\subsection{Method with unstructured knowledge base}

\subsubsection{Method scope and description}

Roadways that exhibit high numbers of crashes are investigated to identify the probable causes of the crashes and to propose adequate roadway improvements. The essence of the investigation task is to connect the hypothetical driver behaviors leading to the reported crashes with the roadway features that might play a causal role during the crash occurrence. It is possible that in some cases an investigative team adheres to its past experience, routine actions, and past findings that do not necessarily reflect the causes at the currently investigated site. One of the tempting shortcuts is limiting the investigation to roadway deficiencies understood as deviations from the design standards. Although a roadway that does not meet the design standards is likely to exhibit excessive risk of crashes, many times additional factors contribute. Conversely, roadways designed according to the design standards also may experience a high number of crashes.

Because intersections are the sites that most often raise safety concerns and require the most complex analyses, the developed method focuses on intersections. The knowledge base is for a two-way stop controlled intersection. The knowledge consists of a large set of information, which is required to develop efficient knowledge base system (Brown, David C, 1989). The developed computer-based tool utilizes all of the pieces of information known about the local conditions, the circumstances of the recorded crashes, and our current knowledge of driver behavior and performance related to the crash occurrence. The final tool is developed as a decision support system (DSS) (Awad 1996), which proposes a set of possible roadways improvements.

One of the fundamental elements of the proposed computer-based system is the knowledge base. To create the most efficient knowledge base, a variety of information should be included. The most fundamental parts of the knowledge should be based on the human information process (i.e., Proctor, Robert W., Trisha Van Zandt, 2004). 
Additional information collected from road safety guidance (i.e., NCHRP Report 500 Series, 2003), low cost improvements guidance (Primer, Latham, and Trombly 2003), human experts (INDOT RSA, IDOT RSA 2006), geometry standards (Robertson, Hummer, and Nelson. 1994), and the road safety investigation process were included inside the final structure. More detailed explanation of the developed knowledge and information follow.

Because the knowledge can be organized using different approaches, the following study focuses on the unstructured knowledge. By using unstructured knowledge, all possible connections between the starting point and the final goal are derived. In an open structure (unstructured) the knowledge does not determine any organized set of connections between the facts. This increases the number of rules (number of possible solution) and creates more flexible knowledge.

\subsubsection{The knowledge}

The knowledge in most of the expert systems (Awad, Elias M., 1996) becomes the fundamental element. It reflects the actual knowledge of the problem and combines different types of information from various correlated areas of science. The knowledge in this study is created based on the elements of human factors, road geometry, and road safety.

\section{Road safety and geometry}

Due to its high level of complexity, the knowledge base is usually one of the largest components of the system. The starting point for describing the knowledge base is to determine the types of crashes and analyze the crash database (INDOT crash database). 
Table 3-1 Crashes by Relation to Junction, Traffic Control Device, and Crash Severity (FHWA, Safety facts 2004)

\begin{tabular}{|c|c|c|c|c|c|}
\hline \multirow{2}{*}{$\begin{array}{l}\text { Relation to } \\
\text { Junction }\end{array}$} & \multicolumn{4}{|c|}{ Traffic Control Device } & \multirow[b]{2}{*}{ Total } \\
\hline & None & Traffic Signal & Stop Sign & OtheriUnknown & \\
\hline \multicolumn{6}{|c|}{ Fatal Crashes } \\
\hline Nonjunction & 25,388 & 77 & 164 & 1,665 & 27,294 \\
\hline \multicolumn{6}{|l|}{ Junction: } \\
\hline Intersection & 1,695 & 2,270 & 2,902 & 244 & 7,111 \\
\hline Intersection Related & 635 & 506 & 258 & 109 & 1,508 \\
\hline OtheriUnknown & 1,810 & 44 & 63 & 423 & 2,340 \\
\hline Total & 29,528 & 2,897 & 3,387 & 2,441 & 38,253 \\
\hline \multicolumn{6}{|c|}{ Injury Crashes } \\
\hline Nonjunction & 708,000 & 4,000 & 1,000 & 75,000 & 786,000 \\
\hline \multicolumn{6}{|l|}{ Junction: } \\
\hline Intersection & 87,000 & 250,000 & 174,000 & 20,000 & 531,000 \\
\hline Intersection Related & 93,000 & 175,000 & 33,000 & 16,000 & 317,000 \\
\hline Other:Unknown & 172,000 & 15,000 & 12,000 & 30,000 & 228,000 \\
\hline Total & $1,059,000$ & 444,000 & 219,000 & 139,000 & $1,862,000$ \\
\hline \multicolumn{6}{|c|}{ Property-Damage-Only Crashes } \\
\hline Nonjunction & $1,778,000$ & 11,000 & 1,000 & 174,000 & $1,964,000$ \\
\hline \multicolumn{6}{|l|}{ Junction: } \\
\hline Intersection & 143,000 & 335,000 & 248,000 & 42,000 & 768,000 \\
\hline Intersection Related & 211,000 & 478,000 & 111,000 & 56,000 & 857,000 \\
\hline OtheriUnkenown & 499,000 & 57,000 & 39,000 & 98,000 & 692,000 \\
\hline Total & $2,632,000$ & 881,000 & 398,000 & 369,000 & $4,281,000$ \\
\hline \multicolumn{6}{|c|}{ All Crashes } \\
\hline Nonjunction & $2,511,000$ & 15,000 & 1,000 & 250,000 & $2,777,000$ \\
\hline \multicolumn{6}{|l|}{ Junction: } \\
\hline Intersection & 232,000 & 588,000 & 425,000 & 62,000 & $1,306,000$ \\
\hline Intersection Related & 305,000 & 654,000 & 144,000 & 72,000 & $1,175,000$ \\
\hline OtheriUnkenown & 672,000 & 72,000 & 50,000 & 128,000 & 923,000 \\
\hline Total & $3,721,000$ & $1,328,000$ & 621,000 & 511,000 & $6,181,000$ \\
\hline
\end{tabular}


Additional data included in the database are the types of crashes in 1998-1999 (Figure 3-1 indicates the various significant causes of crashes).

\section{Type of Crashes}
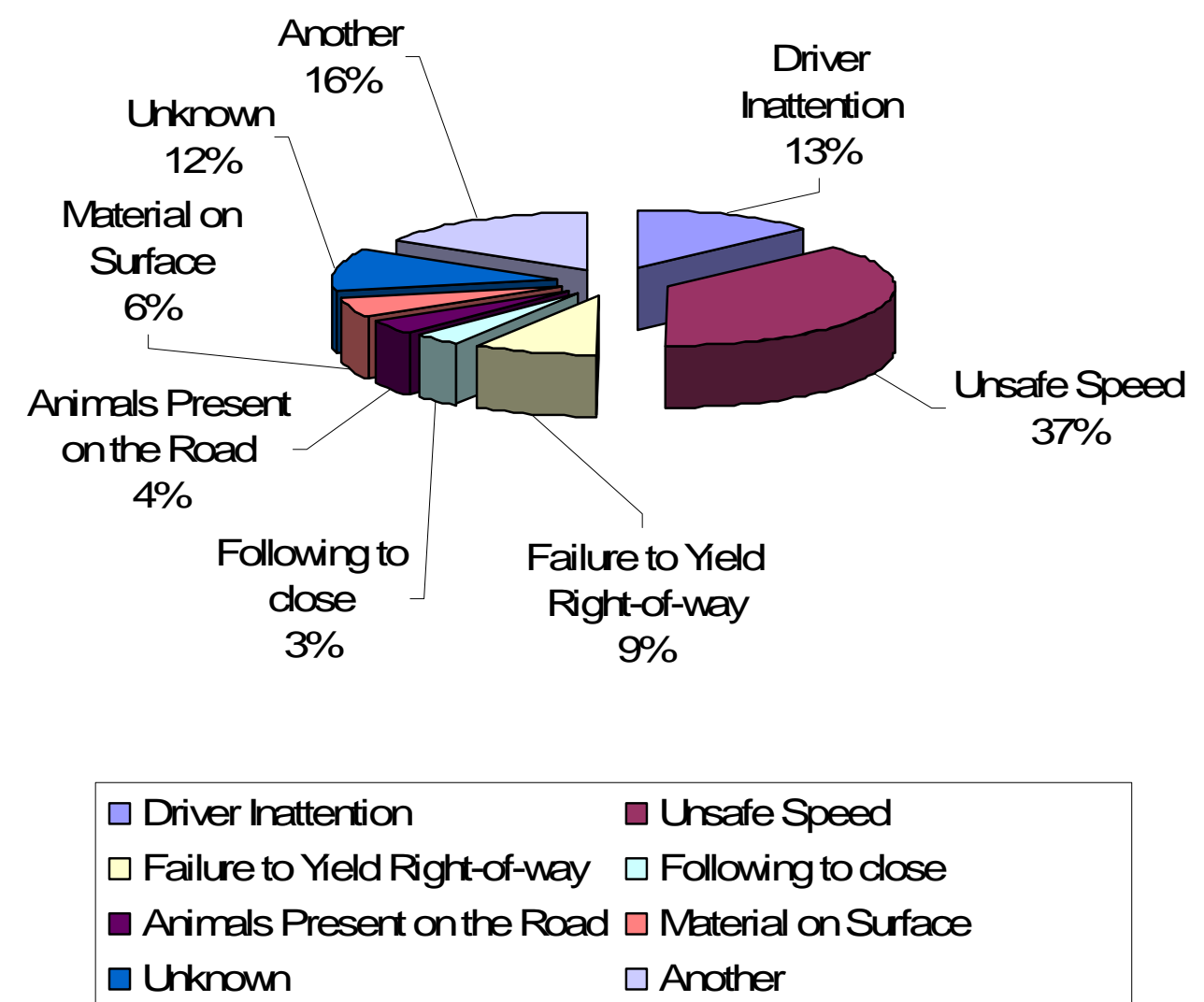

Figure 3-1 Causes of crashes

Studying the crash types has significant meaning for the structure and organization of the knowledge base. The most important causes of crashes were studied in more detail in this research to understand the causes of these accidents. An example of the potential crash factors that was reported by police officers is presented in Figure 3-2. Typically, a crash database contains information such as:

a) Environment record: describes circumstances, location, and surrounding conditions of the accident; 
b) Vehicle record: describes the vehicle and the circumstances of the accident unique to each vehicle;

c) Driver record: describes the driver, license, injury, and alcohol/drug test information for each driver;

d) Pedestrian record: describes the pedestrian, injury, and alcohol/drug test information for each pedestrian;

e) Injury record: describes the injured person (other than a driver or pedestrian: injury and alcohol/drug test information).

\begin{tabular}{|c|c|c|}
\hline \multirow{31}{*}{ Primary Contributing $c$} & \multicolumn{2}{|l|}{ Circumstance } \\
\hline & 901 & Alcoholic Beverage \\
\hline & 902 & Illegal Drugs \\
\hline & 903 & Prescription Drugs \\
\hline & 904 & Driver Apparently Asleep \\
\hline & 905 & Driver Inattention \\
\hline & 906 & Driver Illness \\
\hline & 907 & Unsafe Speed \\
\hline & 908 & $\begin{array}{l}\text { Failure to Yield Right-of- } \\
\text { Way }\end{array}$ \\
\hline & 909 & Disregarded \\
\hline & & Signal/Regulatory Sign \\
\hline & 910 & Left of Center \\
\hline & 911 & Improper Passing \\
\hline & 912 & Improper Turning \\
\hline & 913 & Improper Lane Usage \\
\hline & 914 & Following Too Closely \\
\hline & 915 & Unsafe Backing \\
\hline & 916 & Wrong Way on one Way \\
\hline & 917 & Pedestrian Actions \\
\hline & 918 & Passenger Distraction \\
\hline & 919 & $\begin{array}{l}\text { Violation of D L } \\
\text { Restrictions }\end{array}$ \\
\hline & 920 & Engine Failure or Defective \\
\hline & 921 & $\begin{array}{l}\text { Accelerator Failure or } \\
\text { Defective }\end{array}$ \\
\hline & 922 & Brake Failure or Defective \\
\hline & 923 & Tire Failure or Defective \\
\hline & 924 & $\begin{array}{l}\text { Headlight Defective or Not } \\
\text { On }\end{array}$ \\
\hline & 925 & Other Lights Defective \\
\hline & 926 & Steering Failure \\
\hline & 927 & Window/Windshield Defective \\
\hline & 928 & Oversize/Overweight \\
\hline & 929 & Insecure/Leaky Load \\
\hline
\end{tabular}

Figure 3-2 Primary Contributing Circumstances (INDOT- Accident Master Record Description) 
Especially for the purpose of this research, the environmental, vehicle, and driver records are essential. In these records the following information can be found: the weather condition, type of intersection, road classification, time of the accident, type of accident, lighting condition, road surface type, road surface condition, or driver restriction.

Combining the crash causes information with the environmental conditions can create the following connection: the most common cause of crashes is driver inattention, which can be related to such environmental conditions as bad weather, clutter of information (urban intersection), and nighttime condition. This type of connection creates the knowledge base.

The starting point of the investigation process is to focus on available data, most of which comes from the crash database. This stage is correlated with the preliminary analysis. Therefore, the types of accidents, weather conditions, lighting conditions, number of lanes, and additional road geometry elements are used in the first stage of the knowledge development process.

After determining the types of crashes and additional roadways elements, the geometry countermeasures are applied (i.e., NCHRP Report 500 Series, 2003; Primer, Latham, and Trombly 2003). An example of geometry countermeasures that can be applied to the final knowledge structure is the pavement condition. Some crashes are caused by inadequate pavement conditions and to improve this situation various pavement improvements can be applied (ARA Inc. ERES Consultant Division, 2003). Improving horizontal and vertical alignment are other examples.

The most fundamental challenge in all expert systems is how to connect all of the available data in some understandable structure which provides sufficient solutions. To create the connection of the geometry elements and the road safety information, the major focus is made around driver behaviors. Driver characteristics and behaviors are contributing factors in almost 80 [\%] of all crashes so a detailed study is needed in order to develop the knowledge base. 


\section{Human factors}

Driving involves many different tasks: tracking, decision-making, navigation, adherence to regulations and warnings, tending environmental and mechanical systems within the cab, communication, (...) and watching for various events that may occur inside and outside the vehicle (Wiener, 1984).

The most significant factor in crashes is driver error. Error was defined by Senders and Moray (1991) as an action not intended by the actor; not desired by a set of rules or an external observer; or that led the task or system outside its acceptable limits.

Human factors are a part of a large system (i.e., road, car, driver, and environment). The eventual crash is caused by the failure of one or more elements belonging to the system. Driver errors are divided into two main groups: operator error and design error (Park1987). Additionally, the environment error (lower predictable error) can be defined. The operator error could be considered as a driver error (i.e., inattention, asleep), and the design error could be connected with the car and road design policy.

The operator error is often linked to the capacity of the human brain (Salvendy 1997). Humans can process only a certain number of problems at the same time at the same level of accuracy. Adding more tasks increases the probability of making an error. For example let us use two tasks: driving and using a cell phone. When a driver has only one problem or just one task to solve, the time needed to perform this task is lower than when the number of tasks increases. This situation is described by performance operating characteristic (POC). 


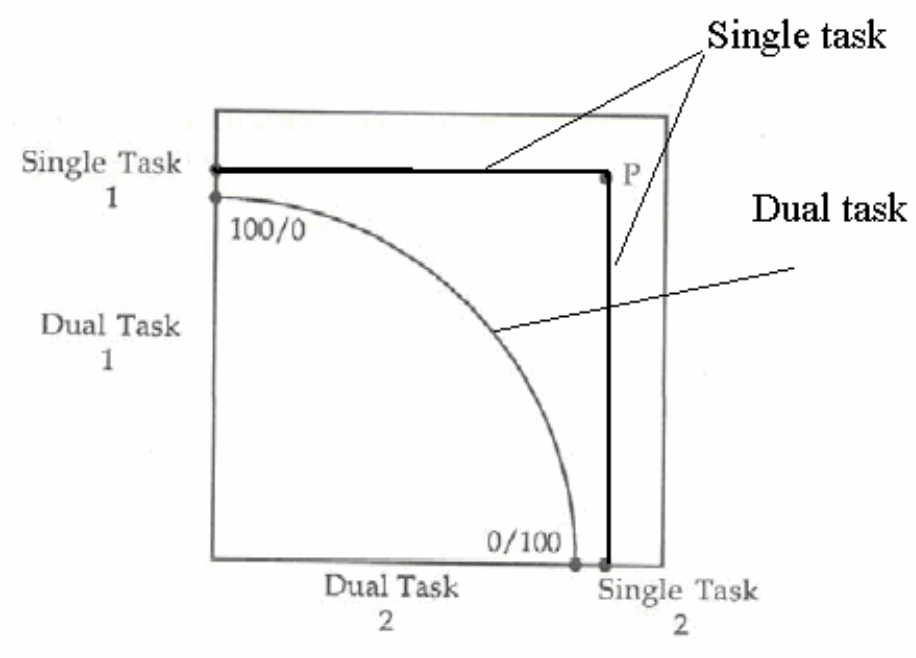

Figure 3-3 Performance operating characteristic (POC)

In Figure 3-3 task 1 is plotted as a function of task 2. Single task performances are represented by single points - single task 1 and single task 2. Points 0/100 and 100/0 indicate when 100 [\%] attention was directed toward task 1 or task 2.

If only one task is performed, it will be represented by a straight line from point single task 1 to point $P$ and for single task 2 to point $P$. Dual task performance will suffer and is shown by the curve on the plot above. The difference between point $\mathrm{P}$ and the curve is called the cost of concurrence. This cost represents how much the performance will decrease by adding additional tasks.

Generally, humans cannot complete two tasks as efficiently as one task. This situation could have significant meaning for drivers when their attention is divided by talking with a passenger or talking on a cell phone. More accidents occur because of inattention; therefore, this problem is an important one and is implemented inside the final knowledge base.

To better understand the issues of error, let us classify all these errors into groups. The main two groups of errors are presented below (Senders and Moray., 1991).

The first group consists of phenomenological errors, where errors are directly connected with events where they were observed. 
The second group is connected with human information processing and the stage where the errors occurred. Because of this, it can be shown that drivers can fail during the perception stage, the cognition stage or in the last stage - the action stage. Drivers can be involved in crash situation by failing in the perception stage (driver does not see a stop sign), in the cognition stage (driver fails to understand the yield the right-of-way law), or in the action stage (instead of decelerating, the driver presses the acceleration pedal), This error classification is applied as the fundamental structure of the proposed knowledge base (Figure 3-5). The reason for this approach is that in order for a driver to avoid a crash (failure), all three stages of human information processing must be accomplished successfully.

Information which reaches the human decision stage comes from different sensors, but for traffic specifically, there are two important sources of information: visual and audio. It was found that 90 [\%] of all information which process drivers are related to visual system (Olson 1996). The perception stage can be affected by improving roadway signage. Different types and size of warning and regulatory signs and the visibility of these signs can affect driver perception. This situation becomes more critical in nighttime hours when visibility can have a more significant impact. Because some crashes occur during night conditions, darkness and light adaptability are added to the knowledge structure. For instance, driving on a sunny day and entering a dark tunnel can cause "blindness" in the first second or so, however, after a few minutes the ability to see in the darkness improves. After around eight minutes, additional improvement can be observed, until around 45 minutes when the sensitivity to light is almost 100,000 times greater than when the dark place was entered (Wickens, Gordon, and Liu, 1998), (Figure 3-4). 


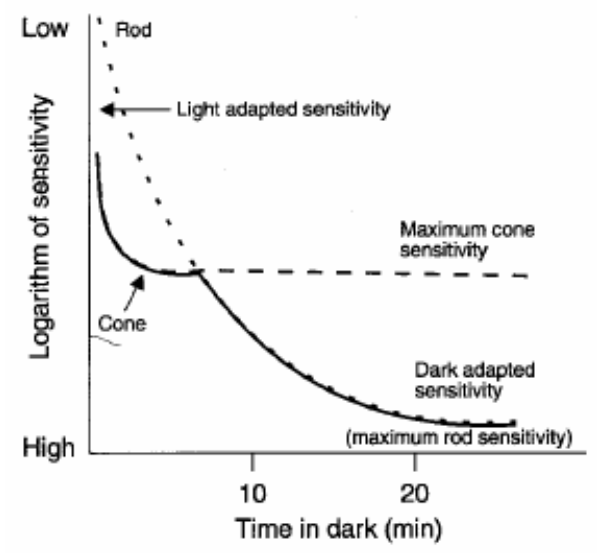

Figure 3-4 Dark adaptation

Perception is a significant issue in crashes. Often a driver will report that he did not see the car or the sign. This problem is related to distinguishing the difference between the target and the background. The possibility for differences between the background and the target seems to be especially significant in the city at intersections where numerous of the information must be processed by drivers (Olson 1996). Targets and backgrounds could be seen differently if:

- $\quad$ The target and background are receiving different luminance,

- $\quad$ The background is greatly removed from the target,

- $\quad$ The background contains a light source,

- $\quad$ The target and background have different reflectivity.

Sometime decreases visibility between the target and the background is related to reflectivity. Research by the Society of Automotive Engineers showed that $40 \%$ of garments had reflectivity of less than $5 \%$, and more than $60 \%$ of garments had reflectivity less than $10 \%$. A difference also could be observed between summer and winter clothing.

Driver perception is the first and most important element in the driving information stage. Others stages are strongly related to the information received during the driver perception stage. Findings from the perception stage are added to the developed knowledge base. An example of the rules which created the knowledge and 
which are connected with the perception stage is: If a stop sign is not visible, then remove, clean, or relocate the stop sign.

Another critical element of intersection deficiencies is insufficient intersection sight distances. This situation is related to the perception stage as well. To improve visibility at the intersection, the following countermeasures can be applied: remove object obstruction (cut trees, restrict parking close to intersection).

The next important element of human information processing where the driver can fail is driver cognition. Solving problems and decisions-making, especially under uncertainty, is strongly dependent upon various factors and can vary for each individual. These factors can include social pressure, illusion of control, emotional stress, and time pressure. The mode of data presentation or illusory correlation can easily affect the decision stage. It is obvious that traffic engineering cannot change emotional driver stress or social pressure, but a safety specialist who knows how drivers make decisions can improve the roadways characteristics to help drivers decrease the decision-making time and increases the effectiveness of their decisions. An example of a finding from the cognition stage, which is added into the final knowledge base system, is the clutter of information. In the case of an urban intersection, the probability of existing different information which is not related to traffic control (advertisements) is higher than at a rural intersection. Information clutter distracts drivers and can contribute to crash situations.

Driver reaction time is another factor that has a direction connection. A study by Gazis (1960) on driver reaction time for a changing yellow light indicated that the response time in this case ranged from 0.6 to 2.4 seconds. This study was continued by Wortman and Matthias (1983), which showed that the $85^{\text {th }}$ percentile perception response time was between 1.5 and 2.1 seconds. The next important element of driver reaction is decision sight distances. The decision sight distance is defined as the distance required for a driver to detect an unexpected difficulty, recognize the dangerous situation, and react adequately. If the road geometry does not allow drivers some specific time for reaction, they will fail in the action stage. Horizontal or vertical curves located closely to an intersection is an example. 


\subsubsection{The knowledge representation and structure}

The road geometry elements and additional road factors affect each driver stage and can contribute to crash occurrences. By identifying the elements which create potential problems for each of the human information process stages, possible countermeasures can be identified.

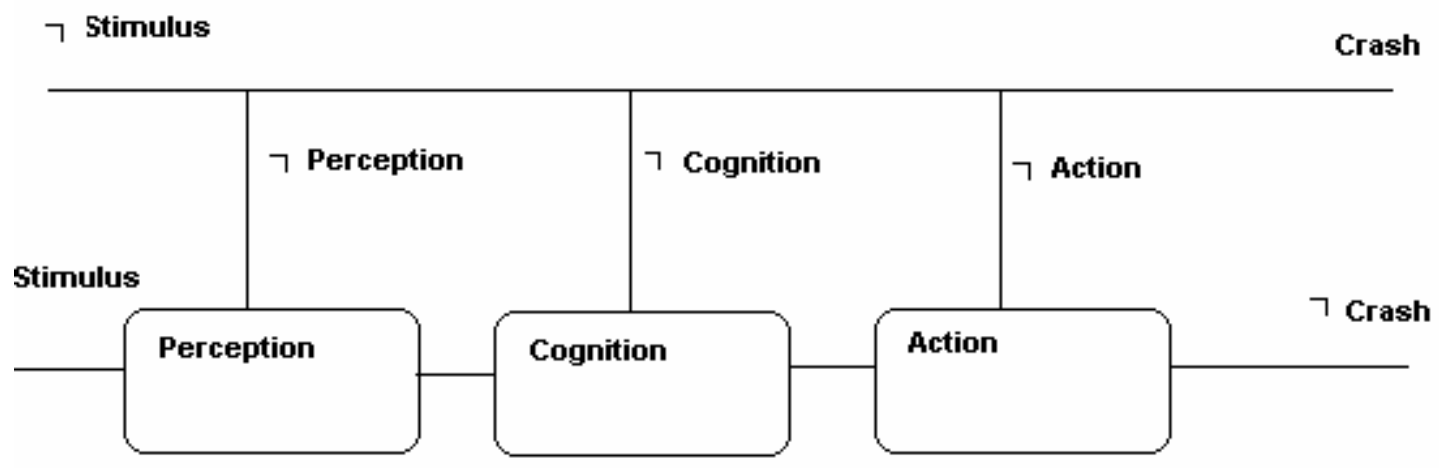

Figure 3-5 Knowledge base representation

Representation of failure in each stage is represented by the symbol $\neg$ logic "NOT."

The first part of the proposed model is the stimuli. When the stimuli are too weak or do not exist (i.e. a tree is covering the stop sign), it can create a potential crash situation. Without information from the environment, a driver cannot process.

Because the major scope of this research is the two-way stop controlled intersection, let us focus on the situation when a driver approaches an intersection on the minor road and there is no stop sign. In this case, the driver will never consider stopping at the intersection and by failing to stop will create a crash situation.

The next step is the perception stage. In this stage, error could occur because of problems with sensors (visual or auditory sensor problem). Even when a stop sign is visible, people with eye problems cannot recognize it and this will contribute to a crash scenario.

After the perception stage, information reaches the cognition stage. Cognition errors could occur because of large amounts of information, disturbed environmental signals, or human brain limitation. 
The last stage at which errors could occur is the action stage. Even if a driver perceives and makes adequate decisions, failure can occur (to stop a car, the driver should press brake but instead presses the accelerator pedal).

By using the human factors approach, we can identify driver errors which are the causes of crashes. To decrease the impact of driver errors, the intersection geometry design as well as traffic control must be evaluated. Only by changing the geometry or the traffic control can the driver behavior be affected. For example, if a cause of a crash was misperceiving the stop sign, traffic engineers must improve the visibility of the sign (i.e., place it on both sides of the road, add roadway horizontal signing, or improve maintenance.

.The second layer of the knowledge base is a connection with the time and space of the driving situation. A driver approaching an intersection goes through the following stages: pre-approach, approach, and passing. These stages can have important meaning in avoiding crash situations, especially in the case when no advance information is present and driver awareness of a two-way stop controlled intersection is inadequate.

The important element of the knowledge base is driver awareness. Usually a crash at an intersection occurs between a major driver and a minor driver. The most common type of intersection crash is a right-angle collision. To present the issue behind driver (major and minor) awareness, let us focus on this type of collision. If the minor driver fails in each of the processing stages and enters the intersection without stopping, the collision can be still avoided because of adequate awareness of the major driver. The major driver therefore can make an evasive maneuver and avoid a collision.

Because the knowledge is represented in natural language programming, the following structure of representation is applied: "IF (...) THEN (...)". The hundreds of possible connections by using the formula above create the knowledge. The knowledge can be perceived from two different approaches: the general approach and the detailed approach. In the general approach the knowledge represents the total scope and idea of the searching process and methodology used. In the detailed approach the specific connections between the individual parts of the knowledge are presented. 
The structure of the knowledge represents all possible connections between the starting point and two possible outputs: a crash or crash avoidance. The general structure is presented in Figure 3-6.

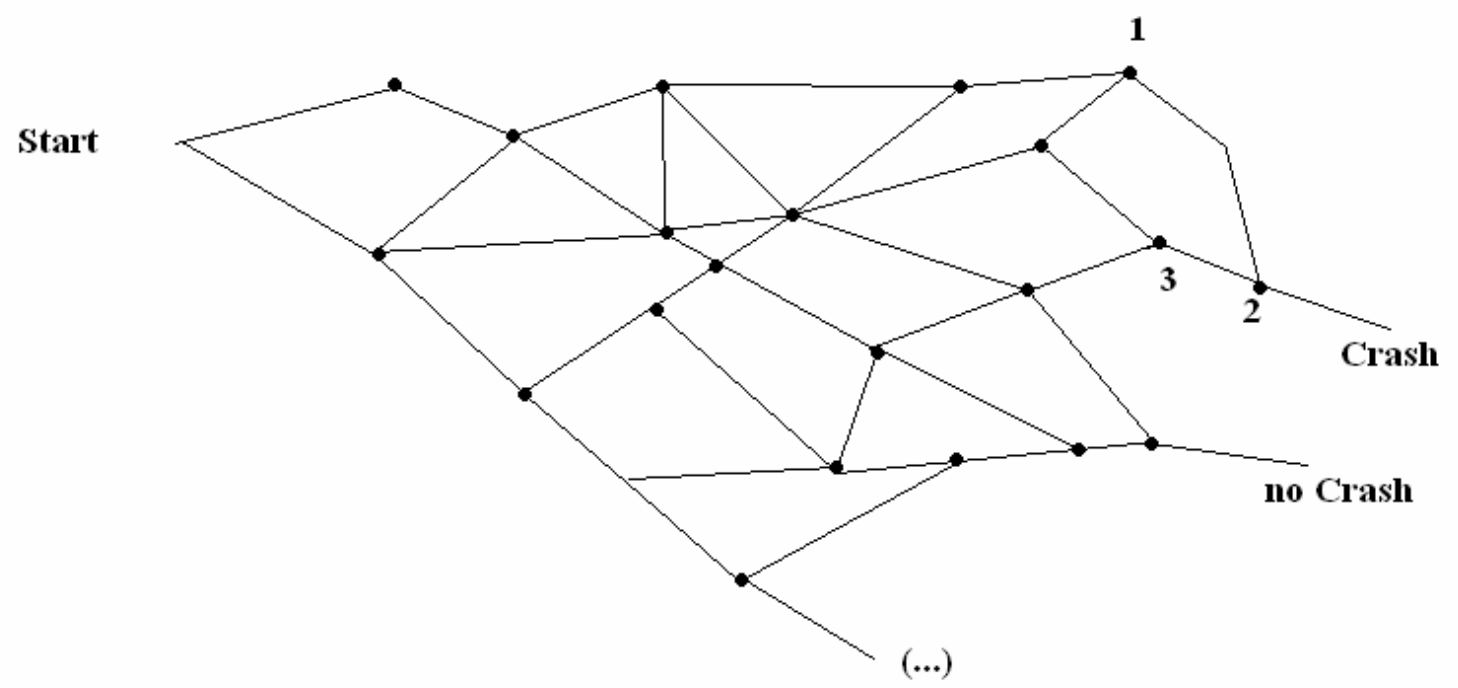

Figure 3-6 High layer of the knowledge representation

The three points (1, 2, and 3) in Figure 3-7 represented the detailed relationship inside the knowledge. These points create one of the possible connections:

- $\quad \operatorname{crash}(L o c a t i o n, y e s)$ - point 2

- danger(Dr_id,Road_Object,Location,yes) - point 1

- evasive_manouver(Dr_id,Location,Action,no) - point 3

The expression “crash(Location,yes)” is built with the "crash” predicates/relation that have two arguments: the variable "Location" and the constant "yes." The variable “Location” can be represented by a different constant (i.e.,. intersection between state road and north road. Therefore "crash(Location,yes)" which is expressed in natural language programming (Dougherty, Ray C., 1994) means that a crash occurred at some location. Points 1 and 2 are coded in a similar fashion.

The connection between points can be expresses as following:

crash(Location,yes) :- danger(Dr_id,Road_Object,Location,yes), evasive_manouver(Dr_id,Location,Action,no).

The above expression can be read as: "crash at some location occurs if danger for driver (x) made by road object $(\mathrm{x})$ at location $(\mathrm{x})$ exist and the same driver at the same 
location does not prepare adequate maneuver to avoid crash." The starting point of developing the knowledge base is to define crash. The next step is to provide which factors can imply this crash. In this case, there is danger and evasive maneuver. A danger could be all road objects which can cause a dangerous situation on the road. As another example, let us consider the danger as a vehicle queue. Consideration of the vehicle queue as a danger comes from fact that one of the most frequent types of crash (next to the right-angle collision) is the rear-end collision. Evasive maneuvers can happen only if it is intended by the driver and it is possible. By intended evasive maneuver, we understand that the danger was perceived. If the danger is perceived, the evasive maneuver can occur. This is represented by symbolic expression below:

evasive_manouver (Dr_id, Location, Action, yes):evasive_manouver_intended(Dr_id,Location, Action, yes), evasive_manouver_possible( Dr_id, Location, Action, yes).

Possible maneuvers can also indicate the condition on the road. Even if a driver makes correct decision and execution, the road condition may not allow successful completion of the evasive maneuver. By road condition, we understand there may be oil on the road, slippery road (...). The evasive maneuver intended and the danger recognizable can be defined as follow:

evasive_manouver_intended (Dr_id,Location,stopping,yes):danger_recognizable(Dr_id,Road_Object,Location,yes).

danger_recognizable(Dr_id,Road_Object,Location,yes):danger_perceive(Dr_id,Road_Object,Location,yes),driver_performance(Dr_id,yes).

The searching process tried to match facts which are provided by the investigator in the preliminary stage and during the site investigation stage to define the rules and to determine how many possible paths will imply crash situation. The non-crash situation is used in the simulation stage which will be discussed in detail in the computer tool specifications section.

The next difficulty in the development process of the knowledge base is the uncertainty representation. 
In the real world uncertainty is dealt with often and this applies especially when determining crash countermeasures. The safety team often has to assume some facts to determine the final roadways improvements.

\subsubsection{Uncertainty representation}

For this research, in order to compensate for the lack of certain knowledge, human expert opinion is needed, whereby the uncertainty can be determined. However, what may be important to one expert may not be so important to others.

To efficiently deal with uncertainty, different methods are recommended. One of the most popular uncertainty methods is the probabilistic approach. One example of the probabilistic approach is the Bayesian theory. Berger (1985) and Luger (2003) indicate that probability $\mathrm{P}\left(\mathrm{H}_{\mathrm{i}} \mid \mathrm{O}_{1}, \mathrm{O}_{2}, \ldots, \mathrm{O}_{\mathrm{m}}\right)$ can be expressed as the conditional probability of $\mathrm{P}\left(\mathrm{O}_{1}, \mathrm{O}_{2}, \ldots, \mathrm{O}_{\mathrm{m}} \mid \mathrm{H}_{\mathrm{i}}\right), \mathrm{i}=1,2, \ldots, \mathrm{n}$, and probability a priori $\mathrm{P}\left(\mathrm{H}_{\mathrm{i}}\right)$.

Each uncertainty theory as well as this one have their own disadvantages. Using Bayesian theory has different restrictions:

- The relationships of the evidence with the various hypotheses must be known.

- All relationships between the evidence and the hypotheses must be calculated (example: determining $P($ crash $\mid$ young $)=\frac{P(\text { crash }) * P(\text { young } \mid \text { crash })}{P(\text { young })}$ is difficult to find probability $\mathrm{P}$ (young | crash).

- Rebuilding the probability table is necessary if new relationships between the evidence and the hypotheses are discovered.

There are fundamental difficulties behind the Bayesian theory (as well as other uncertainty approaches. Dempter-Shafer, Bayesian Belief Network (Shoham 1994 and Ginsberg 1993) has insufficiencies in the obtained solution. By using Bayesian principals, the final solution (value) can be far away from the expected value.

Consequently, using this kind of uncertainty reasoning for this research did not seem appropriate. 
The first prototype of the knowledge base representation was made based on the uncertainty representation by the Certain Factor (Luger 2002 and Jerzy 2004) and the human information process. To develop this prototype all information available in the crash database was used. Three stages of intersection approach were provided: preapproach, approach, and passing. Each stage was based on the human factors and was divided into four parts which are connected to each other. Failure at each of these stages could automatically indicate a crash and contributing geometry factors which need to be changed can be provided. If the critical value is below a certain level, the final information from each stage was added to new stage as shown in Figure 3-7.

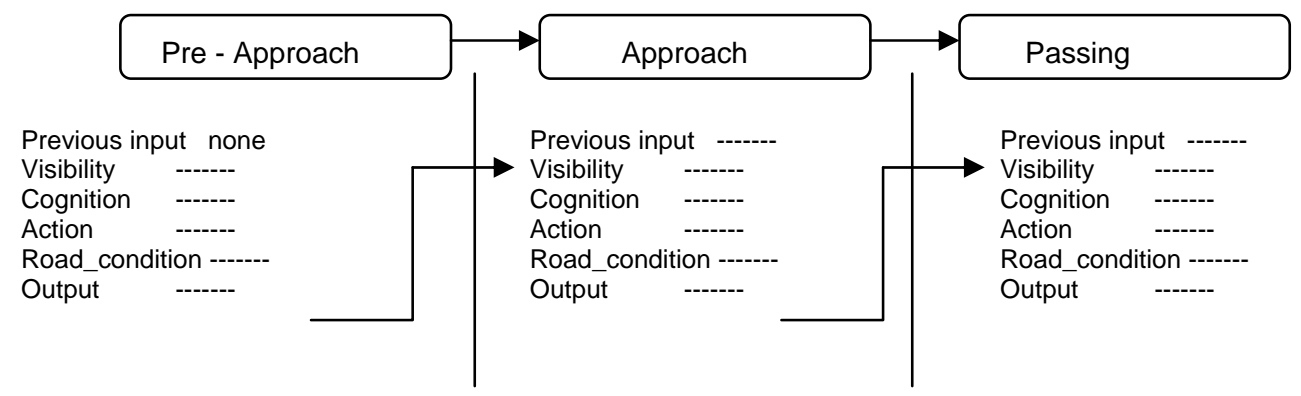

Figure 3-7 Stage specification

Symbol (value) "-----“indicates degree of belief of each stage and each parts of human information process.

For the purpose of this prototype, the following remarks were made:

- Degree of belief: <-1,1>,

- Parallel connection between facts.

Were:

$$
\begin{array}{ll}
- & \text { Strongly disagree }<-1,-0.8> \\
\text { - } & \text { Disagree }<-0.8,-0.3> \\
\text { - } & \text { Unknown }<-0.3,0.3> \\
\text { - } & \text { Agree }<0.3,0.8> \\
\text { - } & \text { Strongly agree }<0.8,1>
\end{array}
$$

For Certain Factors CF $>0$ it was used: 
CF1 $>0$, CF2 $>0$ :

- $\quad \mathrm{CF} 1+\mathrm{CF} 2-\mathrm{CF} 1 * \mathrm{CF} 2$

$\mathrm{CF} 1>0, \mathrm{CF} 2<0$ :

$-\quad \frac{C F 1+C F 2}{1-M I N(|C F 1|,|C F 2|)}$

$\mathrm{CF} 1<0, \mathrm{CF} 2<0$ :

- $\quad \mathrm{CF} 1+\mathrm{CF} 2+\mathrm{CF} 1 * \mathrm{CF} 2$

If one of the outputs indicates a strong belief, this information is enough to derive a crash at that particular stage and stop the process. If the output indicates another value, this information is provided as an input to the next stage.

The part which describes the perception stage (visibility of the object/danger which caused the crash) is defined as follows:

“object_not_visible if information_clutter, bad_weather_condition, season_effect, poor_light_condition,poor_car_condition, poor_road_condition”.

The above statement can be expressed as: "Object is not visible if following information is present: clutter of information, bad weather condition, season effect, poor light condition, poor car condition, and poor road condition.”

The system tries to derive information about the visibility of the object, asks the user/investigator in the field to describe the degree of belief. In this case, the system could ask the user to describe the belief that clutter information was present. The user could choose one of the five choices: strongly disagree, disagree, unknown, agree, and strongly agree, or ask about help, where additional information to be checked is presented. As an example, to derive the presence of information clutter, additional information about the population, urban indicator, locality, or constructions are checked.

After assigning a specific value for each of the stages, the final degree of belief is obtained. If the final remarks indicate a strong belief in crash occurrence, the contributing factors that caused this crash are derived.

Using the specific degree of belief has a very important problem with regard to assigning a specific value or meaning to each variable; therefore, using it for this 
particular problem seems to be inefficient (this determination was made during the testing phase).

\section{Possible alternative uncertainty approach}

To efficiently deal with the uncertainty problem, a possible alternative approach was introduced. By using this theory, we avoid assigning unknown facts to the value (or representation of the value in fuzzy reasoning (Adamski, 2004), such as high, middle, low). In this case all possible scenarios are implemented in the knowledge base. Using this approach, we reduce the knowledge base file as well as we reject scenario which never will happen but will be required to be implemented according to probabilistic theory.

This possible alternative approach provides the user three possible choices in the case of uncertain information. The investigator will have three answer choices: "yes," "no,” or "I don’t know.” By answering “yes” or "no,” the user will be directed to one particular path for the next step of searching for the solution. In the case of "I don't know," both the "yes" and "no" paths will be followed. This approach leaves the final decision to the user, which always in the case of unknown information will have the possibility to reject the solution. This situation should give more expected solutions because the final decision is left to the user. The proposed approach is presented in Figure 3-8. 


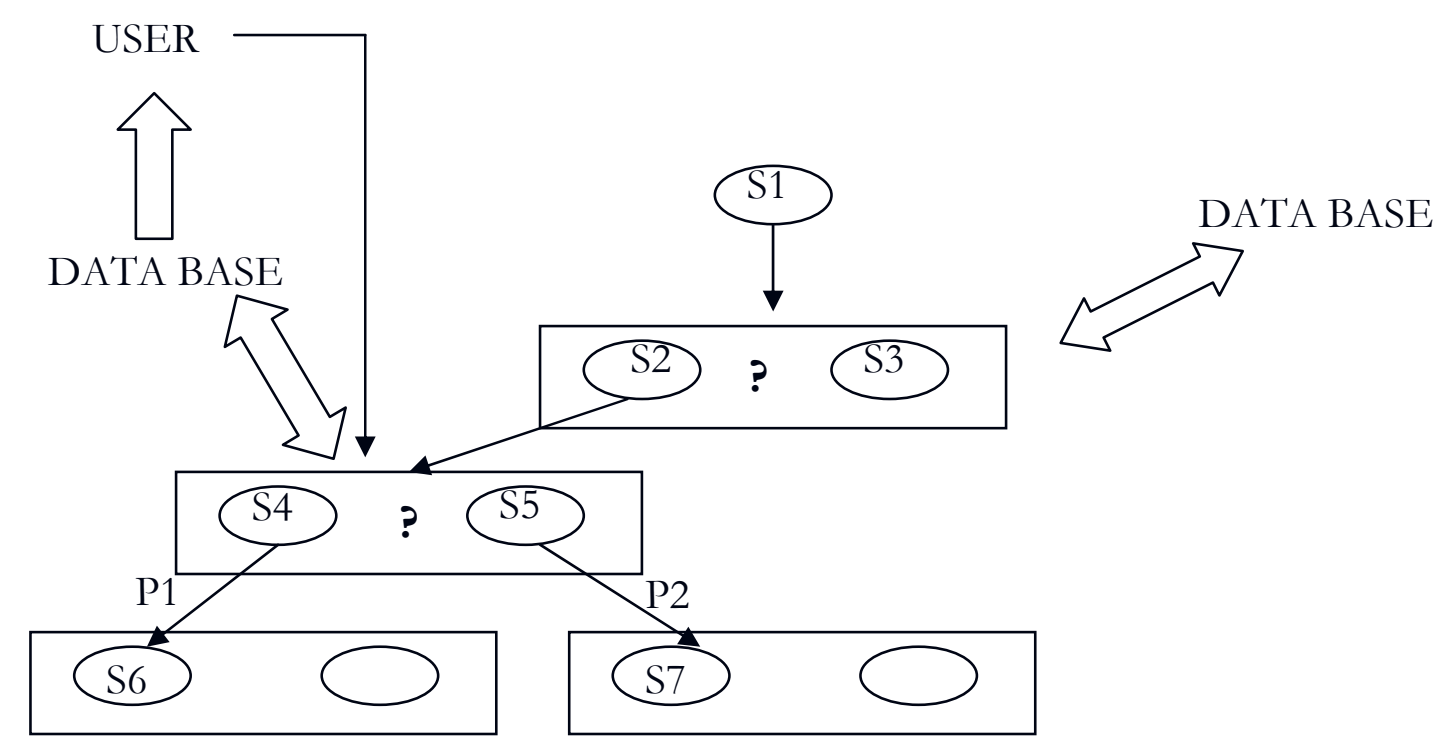

Figure 3-8 Possible alternative approach

The starting point is situation S1 (Situation 1). This situation could imply two possibilities: S2 and S3. The question is which path should be followed in the next step, and the software will try to obtain information from the database. If in the database the situation S2 can be found, then the software will choose this situation and proceed to the next step. A similar situation then can occur in the next step, namely, the user chooses between S4 and S5. If the algorithm cannot find information about S4 or S5 in the database, then it will ask the user to provide the missing information. The user will have three choices: provide information about S4, about S5, or answer "I don't know." If the user chooses S4, for example, then P1 (Possibility 1) will be applied, or if S5 is chosen, then possibility P2 will be used. If "I don't know" is chosen, then P1 and P2 will be chosen simultaneously.

By using this possible alternative approach, the final decision is left to the user to define the certainty of information about some facts. If the user cannot define some facts, two possible paths are implemented. In this way a specific value is not assigned to each fact initially, but rather the focus is only on the possible scenarios.

This approach is much closer to the human decision-making in the case of uncertainty. Understanding uncertainty can be different depending on the time, the 
information available, and others situations which are unknown during development of the knowledge base. The software therefore is less artificial and will return more understandable results.

\subsubsection{The computer tool specification}

An expert system can be developed by using different high level programming languages, such as. $\mathrm{C}++$ or LISP. The most significant difference between these languages is the way they represent the knowledge. Each language has its own representation and destination. Today many different tools are available to constrain expert systems: OPS5, KEE, ART, SALT, MED2, DNA, OPAL (Martyna, 2004). Each tool is dedicated to special purpose, such as medicine or mathematic. Some of them could be used to generate knowledge (general tools), another may be for a special purpose (problem-specific tools).

The choice of tools or languages is determined by the specific purpose of the generated knowledge base as well as for the rules generated. In order to deal with a very universal problem of developing a traffic safety expert system for site investigation, the language chosen should enable building a universal system from the beginning.

From natural language programming we can distinguish this kind of language as:

- CLIPS, is an expert system tool developed by the Software Technology Branch (STB) at the NASA/ Lyndon B. Johnson Space Center. It was released in 1986 and has been continually refined and improved.

CLIPS represents (human) knowledge in three ways:

1. Rules for experience-based, heuristic knowledge,

2. Def-functions and generic functions for procedural knowledge,

3. OO programming, also for procedural knowledge.

One of the weaknesses of CLIPS seems to be the lack of a graphic interface, which would enable a user-friendlier environment (a previous study developed a graphical interface, but it remains to be a separate program). 
- $\quad$ Jess (Java Expert System Shell). JESS is also an expert system shell and it is based on CLIPS. JESS was originally a clone of the essential core of CLIPS but has begun to "acquire a Java-influenced flavor of its own," according to the authors, “and JESS is convenient for giving Java applets and applications the ability to "reason" (Van Laerhoven, 1999).

To summarize, CLIPS is still more complete and stable than JESS, but this might change in the future since the JESS package is being improved constantly. Also, JESS also utilizes Java, which in the long run might prove to be a big advantage over CLIPS.

An overview of all actual tools for expert system programming is available in Appendix C.

One of the well known natural language programs is Programming in Logic (Prolog), which was developed in the 1970s to use logic as a programming language (Deransart 1996, Merritt 1989, and Shoham1994). This language was evaluated by adding additional elements: logic programming with horn clauses, fully object-oriented, object predicate values, algebraic data-typed, controlled non-determinism integrated fact databases, automatic memory management, and support directly linked with $\mathrm{C} / \mathrm{C}++$. From the programmer's point of view, especially when dealing with a large object-orientated system, the object predicate values and horn clauses seem to be very helpful.

General Visual Prolog v6.2 (http://www.visual-prolog.com/), which was used for a purpose of this project contains:
a) Graphic Development Environment
b) Compiler
c) Linker
d) Debugger

By using the Graphic Development Environment, Visual Prolog is user-friendly, which helps the programmer track the entire programming process and enables using windows and a graphic interface. The Visual Prolog graphic interface contains the following elements. 
- A tree representation of the modules, including files and resources in the project window that help to group project items into packages and thus gives an extra level of abstraction.

- The text editor supports convenient text editing and browsing to declarations and implementations.

- The dialog editor provides standard controls to design dialogs.

- The menu editor allows creation of both pull-down and pop-up menus.

- The toolbar editor allows creation of various kinds of toolbars.

- The graphics editor is a convenient tool for creating, viewing, and editing icons with cursors and small bitmaps.

- The build facility supports inserting the necessary packages and includes directives.

- The browse facilities supports search for specific entities, "go to definition" and "go to declaration."

Because of these elements, Visual Prolog was adopted as an adequate language to develop the expert system for the site investigation process of this research. As most all systems do, Visual Prolog has one disadvantage (i.e., the lack of uncertainty reasoning. However, a well developed algebraic data type user (programmer) can implement this element in the process.

The starting point in the investigation process is the preliminary analysis so the same structure therefore was applied to the developed expert system. During this stage the collection of all existing data is required. The actual road data can be checked against either the full list of geometry standards or the typical standards.

By the first option, the user will have to answer the questions which the software will ask, and will always have three possible answer choices: “yes,” "no," or "unknown”. The second option gives the user full freedom to define the road geometry. By choosing this option, the user can provide the data from different information sets which include the road geometry, environment, and driver factors. This possibility allows the user to provide only data which are known and save the time required to prepare the investigation. 
After providing the geometry factors, the software compares this information with the human information process and it will point out some geometry specifications which could be changed for the road improvement.

After the contributing factors of crashes are suggested, the software allows evaluation of countermeasures by using simulation. During the simulation, new questions to users are provided and the final remarks, which confirm that this particular factor was the most important cause of crashes or another factor is presented.

To increase the flexibility and effectives of the software, the major phases of the investigation process were successfully applied by developing three different stages of communication with users.

The first stage - preliminary analysis - requires providing road geometry and traffic control information. After the user determines the available data and chooses the stage off-line, the software will provide the set of possible roadways deficiencies. When there is limited information (no data from the site investigation), the software will try to determine the contributing causes of crashes without asking the user to provide additional information. The structure of the off-line mode is presented in Figure 3-9. (ESSI is an acronym for Expert System for Site Investigation.)
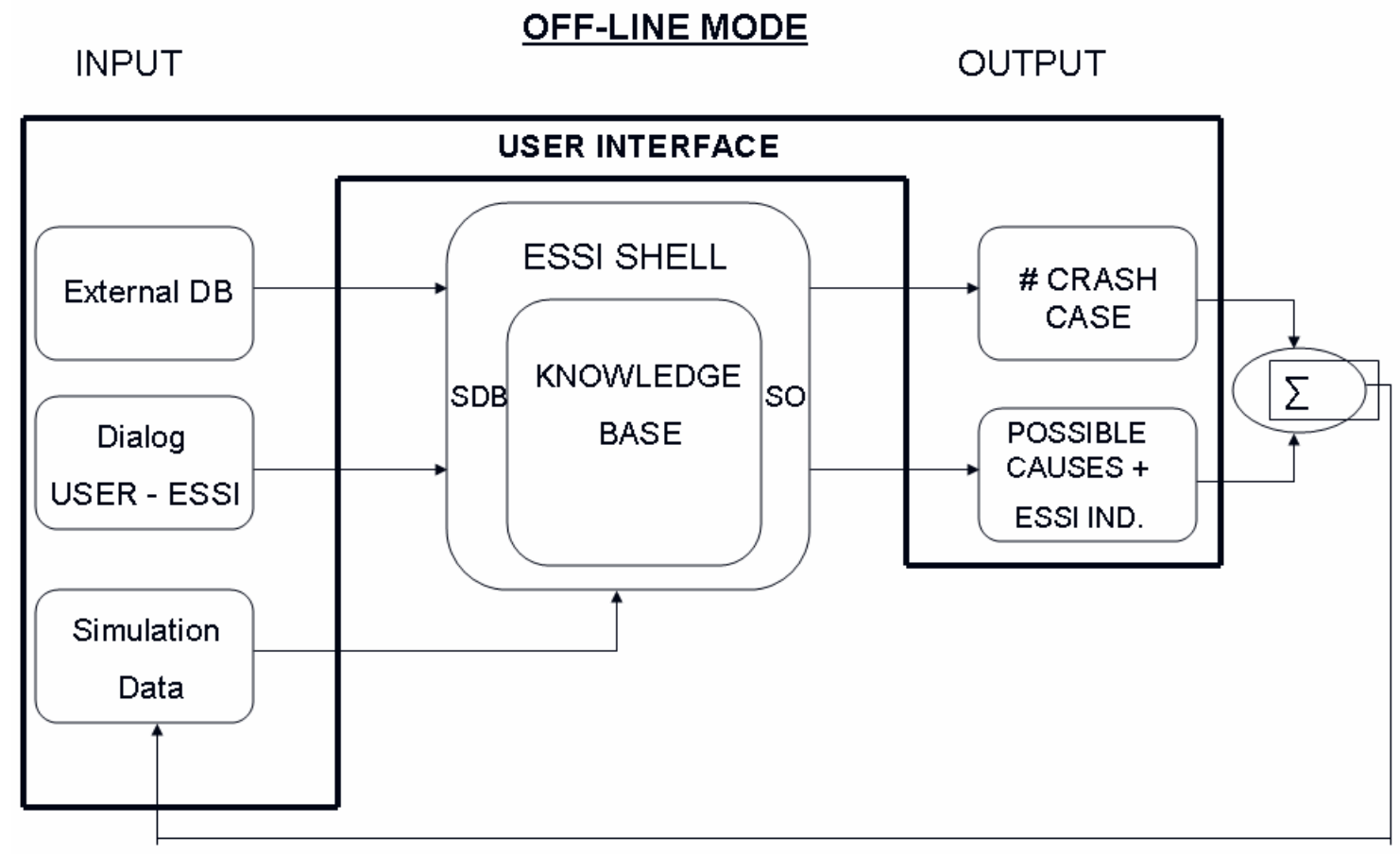

Figure 3-9 OFF-LINE mode 
In the off-line mode, the software allows the user to load an external database and the dialog between the user and the tool is initiated by the user. After providing all the data the user can save - Save Data Base (SDB) - the data in an external file for further use or can run the software to determine the cause of a crash. If ESSI has enough information, the causes and adequate improvement are provided. This function helps investigators better prepare for site investigation by pointing out some potential roadway deficiencies which should be checked first during the site investigation. After determining the possible solutions, the user has the opportunity to use simulation to obtain possible countermeasures. The simulation tool allows the user to virtually see the potential roadway deficiencies and then run the whole process again to determine how effective the previous findings were. To evaluate the significances of each improvement, the total numbers of crashes before simulation and after are combined. If before simulation the total number of paths which derive crash is " $x$ " and after simulation becomes " $\mathrm{x}-\mathrm{y}$," significant improvement is indicated. This information is presented by the ESSI indicator (ESSI IND).

The next stage of the investigation process is the site investigation. In this stage the proposed tool can work in the on-line mode. 


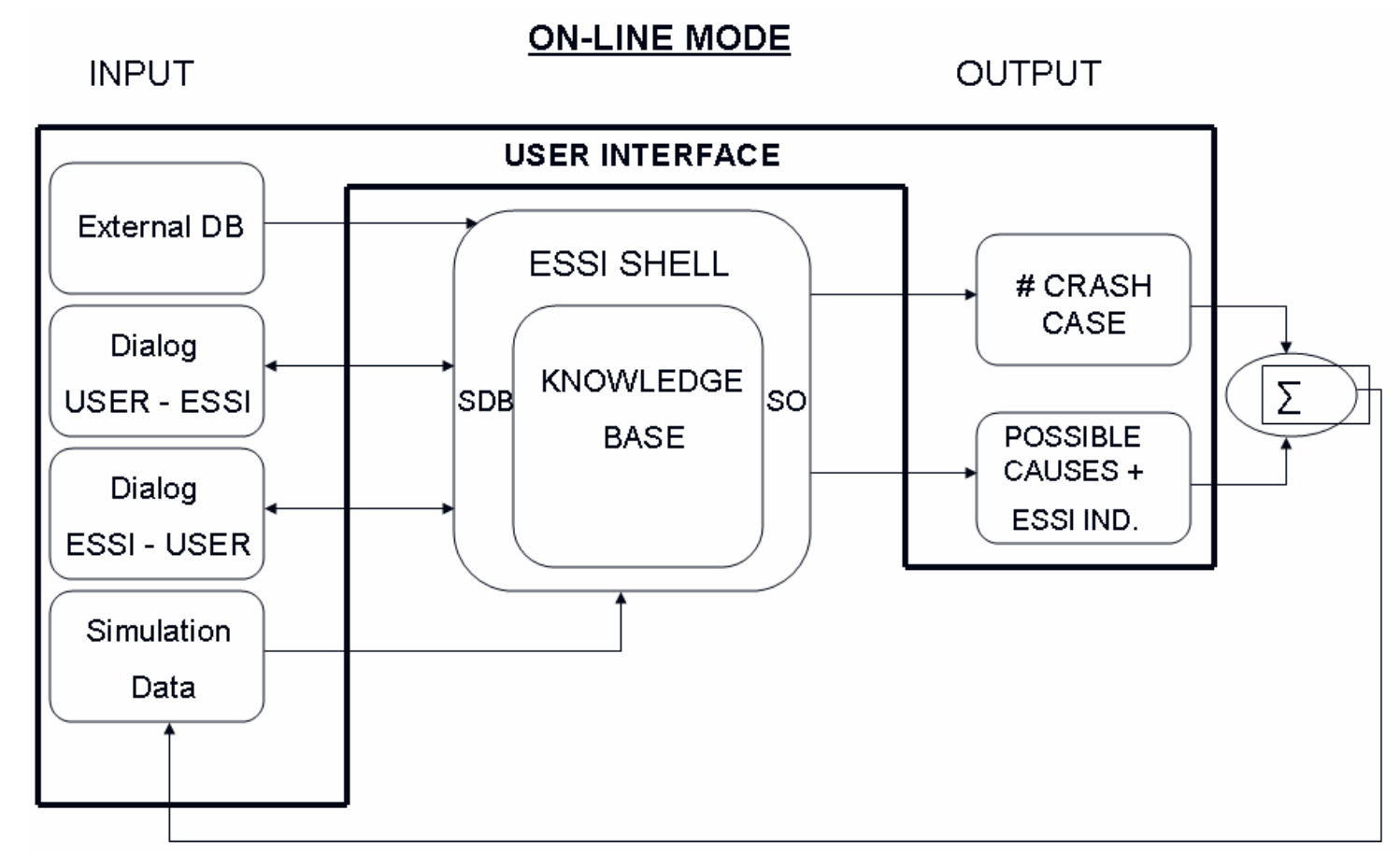

Figure 3-10 ON-LINE mode

In the on-line mode presented in Figure 3-10 compared to the off-line mode, the dialog between ESSI and the user is provided.

After determining all the data (external file data, dialog user ESSI), the investigator can determine the most significant causes of the crash. If the tool during processing determines there is a lack of certain knowledge, the query will be presented automatically to the user. The user can provide data or decide that these particular data are unknown. After the user determines that the data are adequate, the software will continue deriving the crash and follow the user path. If the user cannot determine the data, all possible paths are chosen. After providing the required data, the possible causes are presented. The next step is to run the simulation to check how many crashes could be obtained after virtually fixing roadway deficiencies which could have caused the crash situation. Evaluation of the results is made by ESSI IND.

The most important element of the final tool which creates efficient communication between the user and the software is the graphic user interface. In this tool two major interactions were obtained (user-tool and tool-user) as shown in Figure 3-11. 

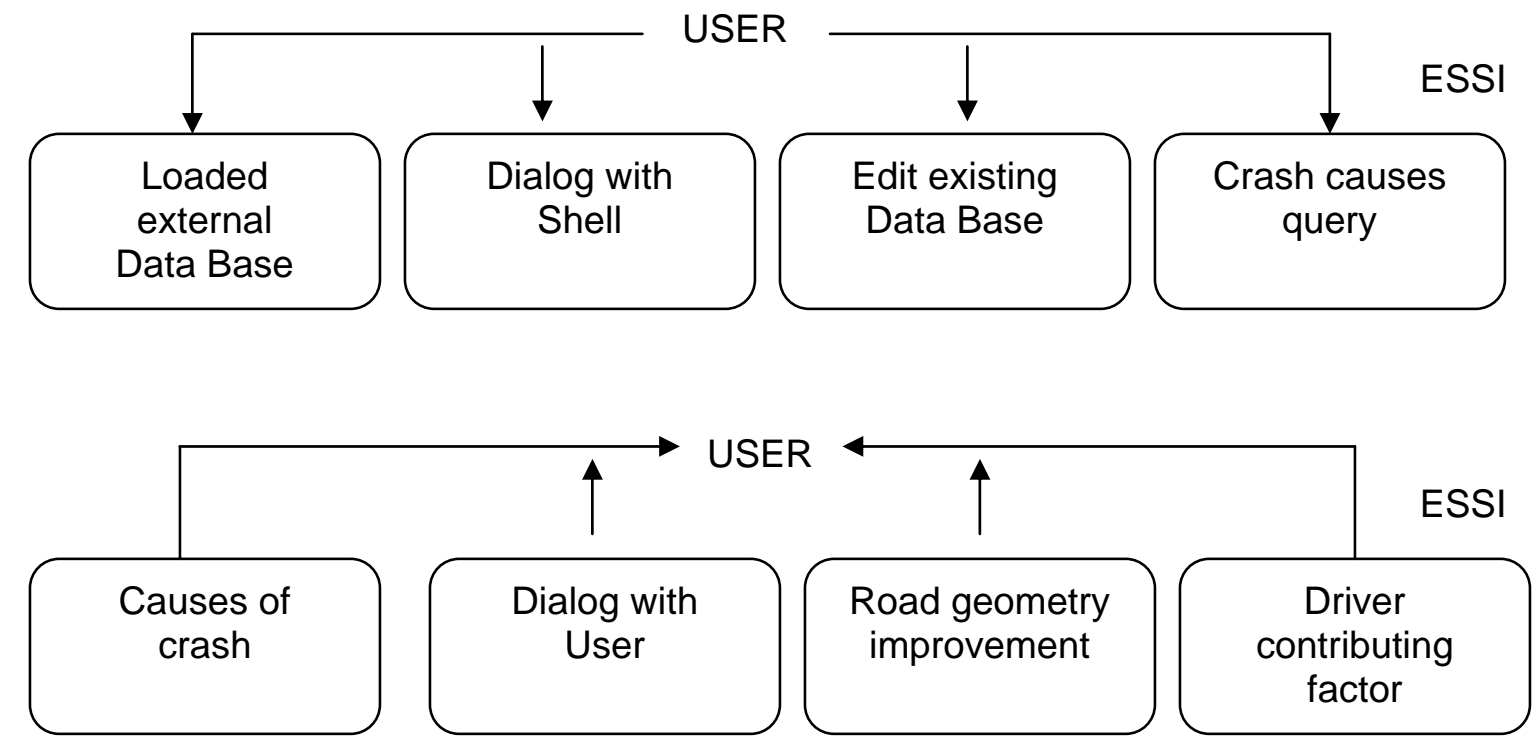

Figure 3-11 User - Tool communication

The dialog between the user and the tool can be initiated by the user or by the software. In the first situation, the user in all three stage of the investigation process (preliminary analysis, site investigation, post-analysis) can initiate the dialog for providing additional data. The dialog can be initiated by the user because of the necessity of checking the geometry design standard, which is connected with an approach; therefore, starting point in the case of providing additional geometry information is choosing the approach. The standard four types of approaches are implemented: South Band, North Band, West Band, East Band approach. Because different crashes contain different roadway information, the first steps in executing the proposed tool are the preliminary analysis and determining the crash ID, and all available data which are assigned to each individual crash (Figure 3-12). 


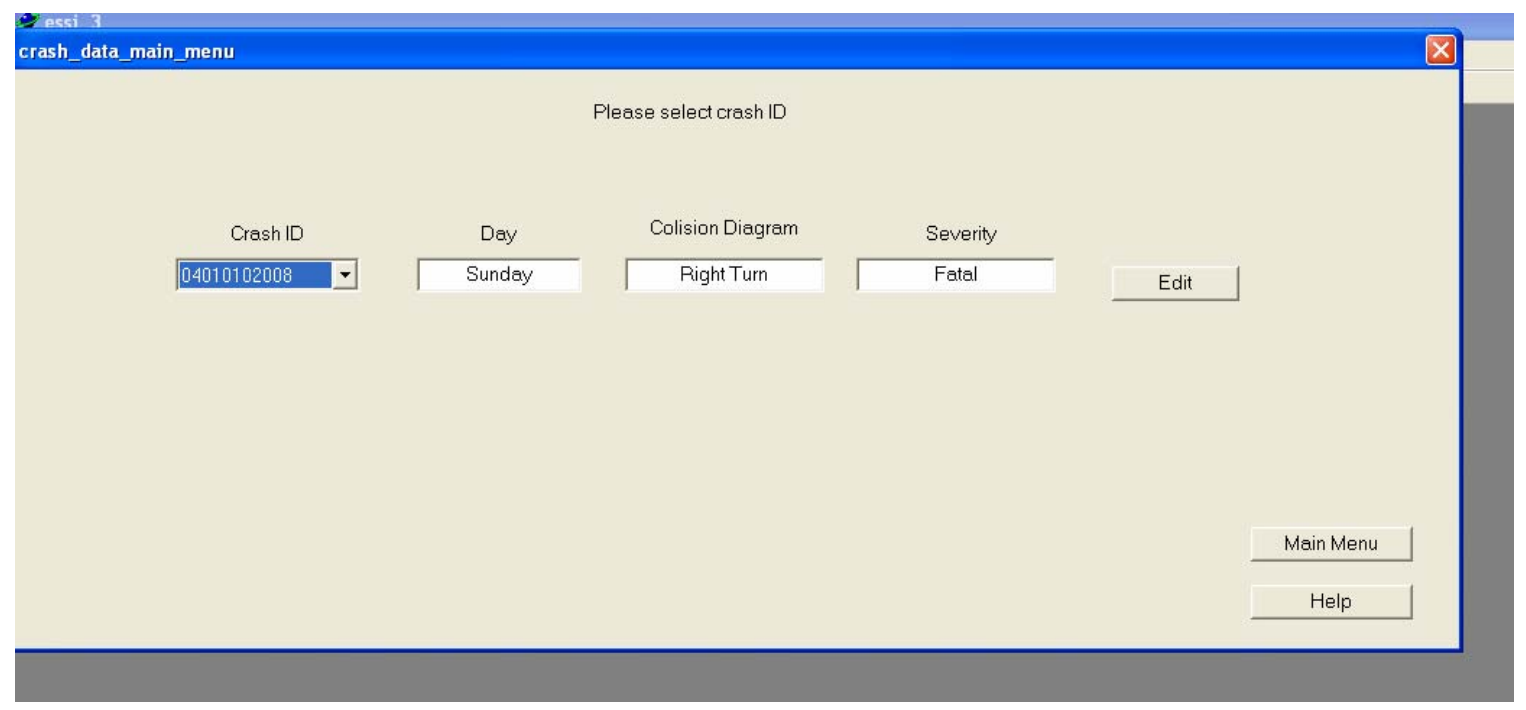

Figure 3-12 Crash ID selection

After determinate the crash ID, the user has the option to provide crash data information from two major groups:

- $\quad$ Environmental

- $\quad$ Driver and Vehicle Data.

These two groups reflects the possible sets of information which can be found from crash data records and can be used by the software to determine the possible solutions.

By choose the environmental possibility a new screen as shown in Figure 3-13 appears.

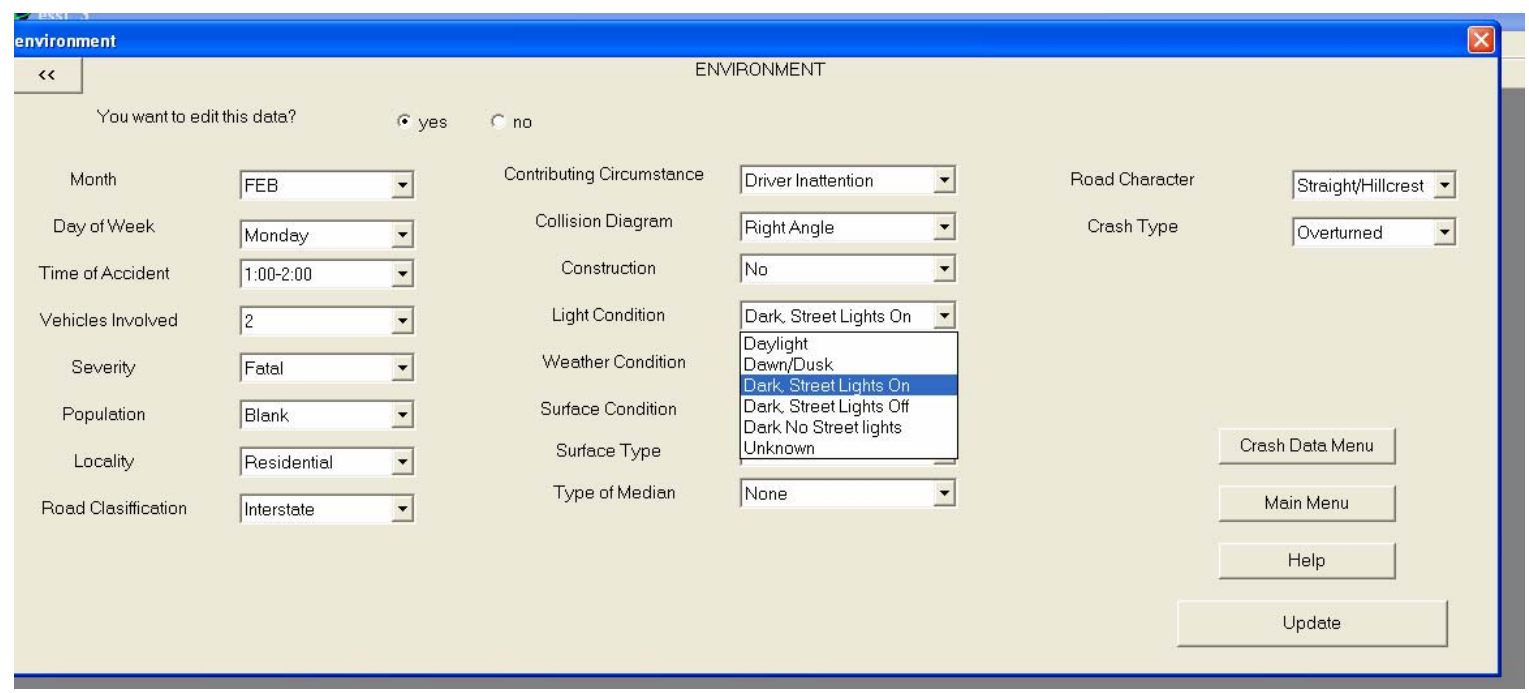

Figure 3-13 Changing existing environment data 
In a similar way, the driver and vehicle data can be edited by the user (Figure 3-14).

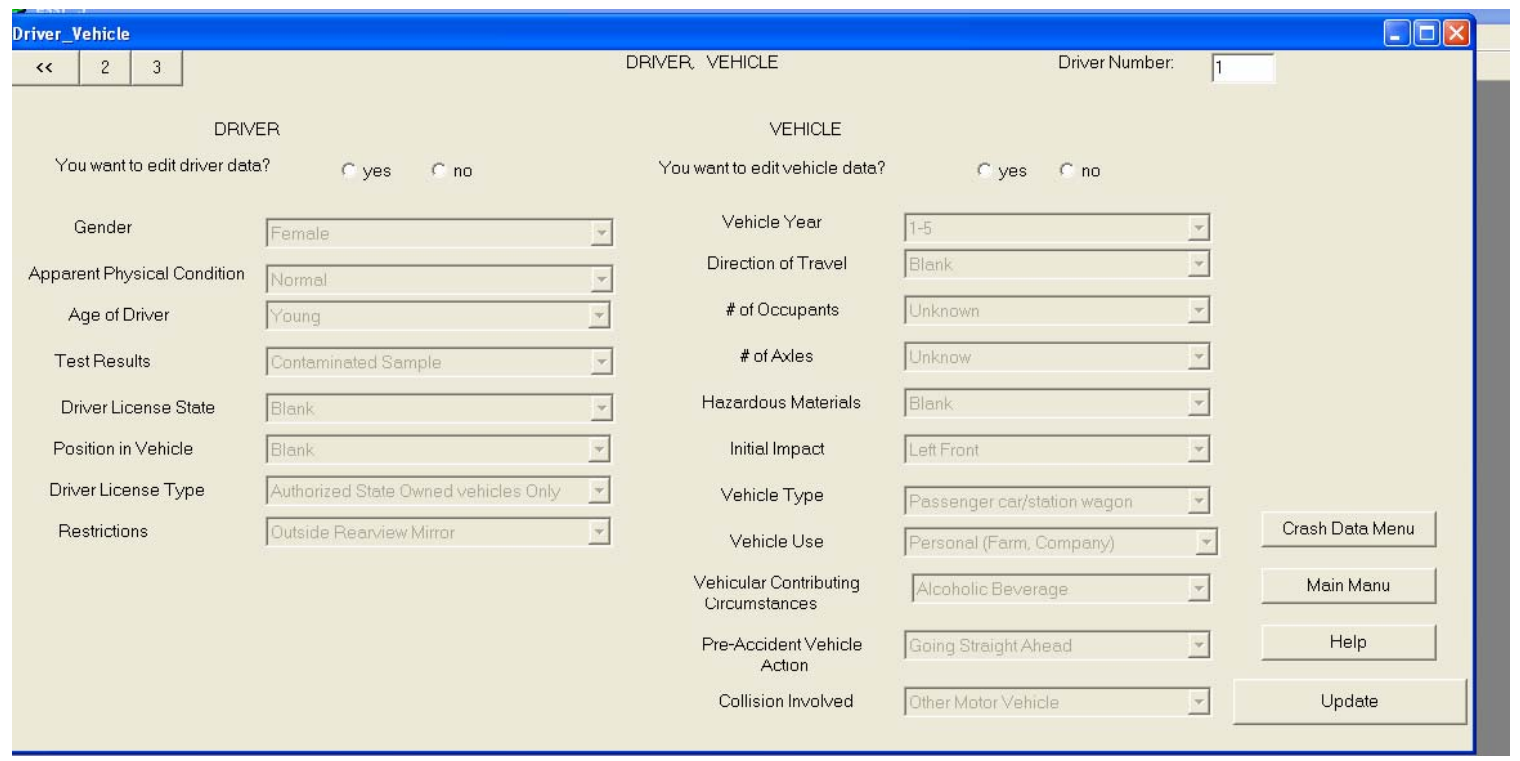

Figure 3-14 Driver and Vehicle Data

After the environmental and driver and vehicle information are provided, the preliminary analysis is completed. The next step is the site investigation process, where the investigation team visits the site to check the actual road conditions. This process using the propose tool is divided into five categories (Figure 3-15) which can help organize the knowledge:
a) Lanes and Pavement
b) Driveways, Shoulders, Road Site and Median
c) Signs, Traffic Control
d) Sight Distance, Light Condition, Drainage
e) Road User, Environment. 


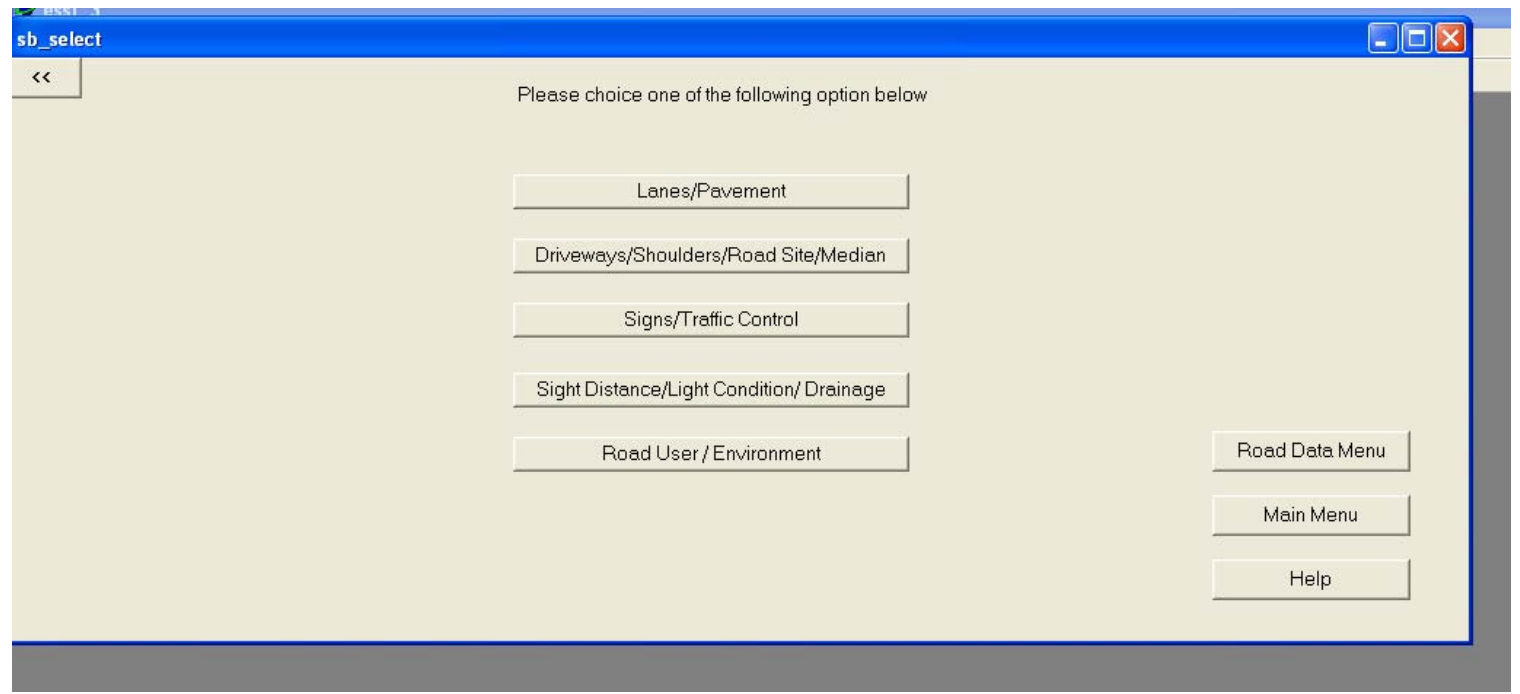

Figure 3-15 Road data groups

To illustrate the idea behind each category, the Driveways, Shoulders, Road Site and Median category is presented in Figure 3-16.

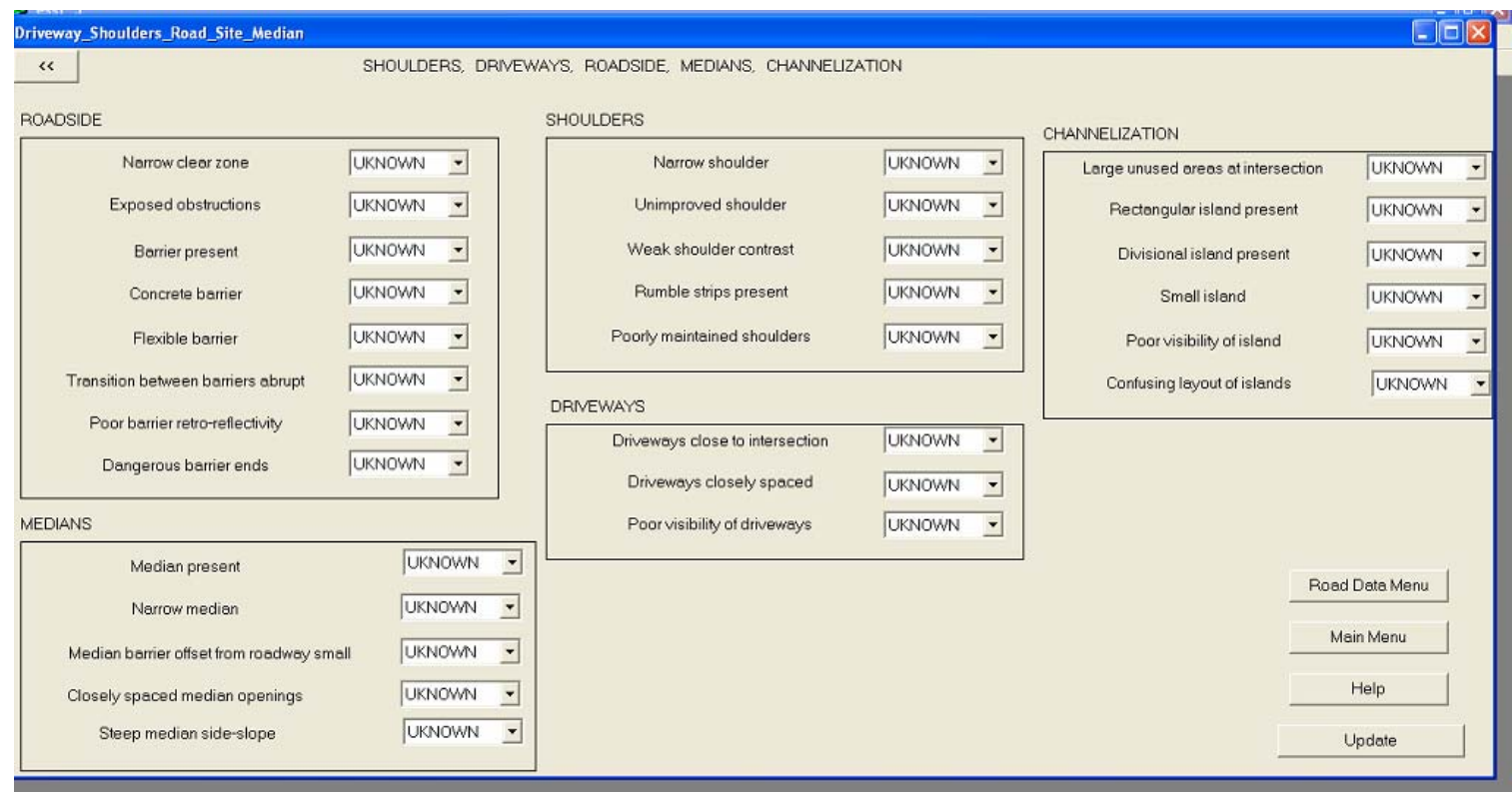

Figure 3-16 Driveways, Shoulders, Road Site and Median Data

In this category the user can provide three different answers for items in question during the investigation, such as "narrow clear zone." The user has one of the following choices for response: yes/ no/unknown. If the user chooses "yes," "narrow clear zone" will be added to the knowledge base; but if the user chooses "no," the knowledge added 
will be "adequate clear zone." Finally, if the user chooses "unknown," the two above facts will be applied to the knowledge base.

User can update all the information in each stage. After collecting all the required information, the software provides the contributing crash factors in two categories:

- Results by contributing crash factors

- Results by crash

As an example, if the user wants the results for all types of crashes and sorts these solutions by the contributing crash factors, the following window is presented (Figure 3-17):

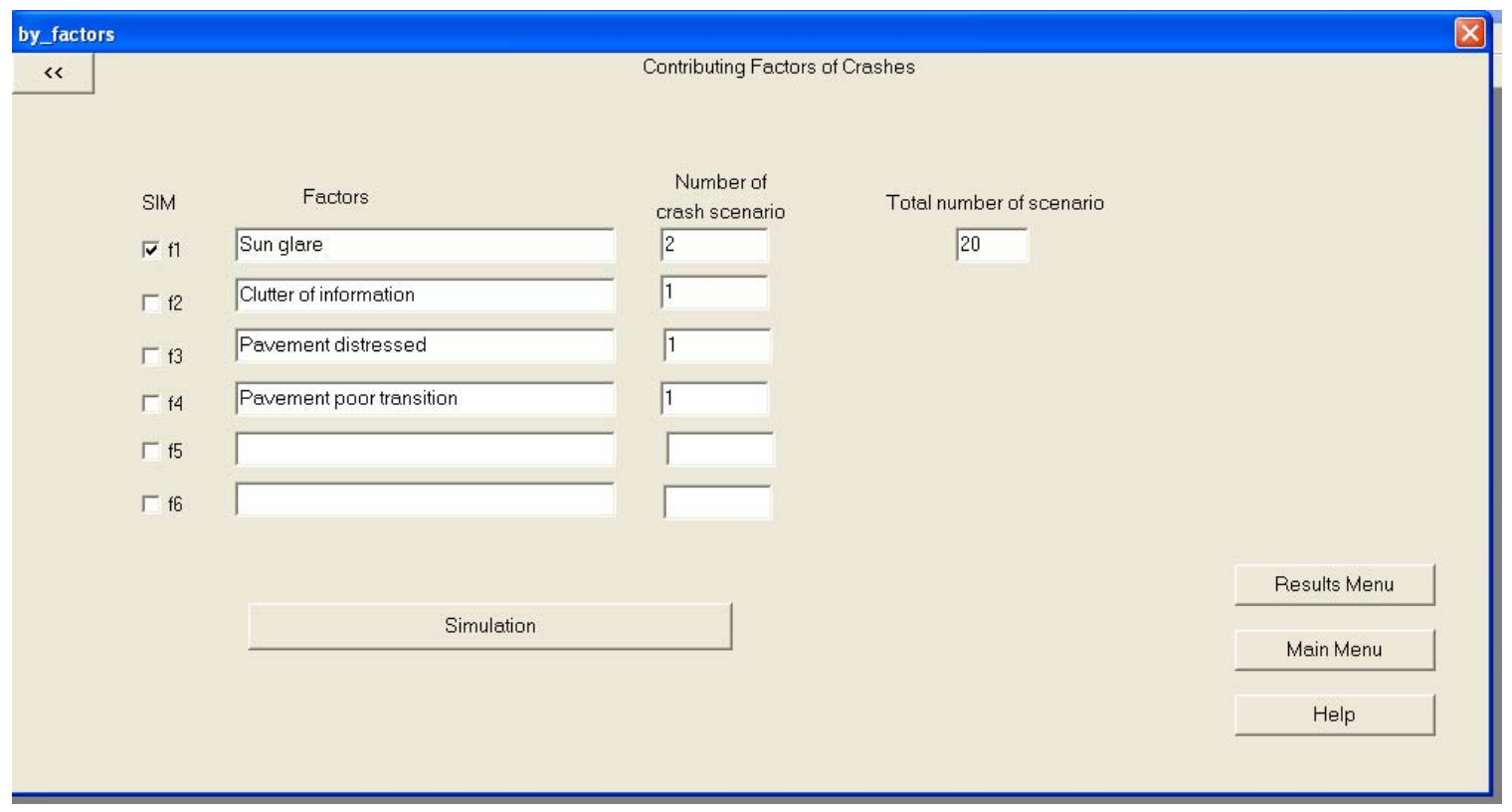

Figure 3-17 Results by Contributing factors of crashes

In the example above, the tool, by searching for all possible connection inside the knowledge base, found that sun glare was a contributing crash factor in two cases and additional factors such as clutter of information or poor pavement transition contributed to single crash scenarios. The total number of scenarios which imply the crash in the example above was 20. One of the most important function of evaluation the findings is the simulation of the propose solution. The user, by marking one of the simulation (SM) factors (f), (e.g., in Figure 3-17 "f1" was marked) can virtually fix this roadway insufficiency and by obtaining simulations check the importance of this 
one particular factor in all crash scenarios. After the simulation is obtained, the reduction of crashes is calculated (Figure 3-19).



Figure 3-18 Simulation for Contributing Crash Factors

It was found in the example that by updating a sun glare problem (i.e., by installing better visible signs), the number of scenarios implying crash decreased to from 20 to 14.

The final step of the software process is to prepare the report from the site investigation process. The major parts of the final report are the time of the investigation, the investigation team, the location, the weather conditions, and the proposed countermeasures.

\subsection{Evaluation of the proposed method}

The proposed computer tool was evaluated and adequate changes were proposed. The most complicated aspect of the tool is development of the knowledge base. Since a great deal of information is considered from such areas as human factors, road geometry, 
traffic control, and environmental condition, the total number of possible scenarios rapidly increases. Linking together the driver characteristics with additional information as discussed in the methods concepts, creates potential difficulty for the final description of the knowledge base. The lack of a knowledge structure which generates an "open mind" development process creates in the testing and evaluation phase the difficulty to describe in a logical way the connection between the facts and the rules which lead to possible solution. The backward chaining, which in the development stage gives more freedom to create and describe the knowledge by allow more flexibility to connection between facts, creates in the final process multiple problems. Those problems come from fact that in a previous approach backward chaining was used as the starting point to determine the goal. The goal was indicated by two scenarios: crash and crash avoidances. This approach can be successfully applied in the case where no additional data about facts are available. This approach does not focus much on the data collection process, because the knowledge does not have a structure where the level of presenting rules and facts will have impact on the final findings. The most powerful idea for trying to follow proposed approach was to create the most flexible knowledge base free of a past experiences structure and connection between the facts. The knowledge base can search from all possible rules, therefore, even impossible or less likely situations can be applied to the knowledge structure to derive a final solution.. The high level of complexity of the proposed approach was discussed with artificial intelligence specialists and this large structure of knowledge will have its own impact in time and representation of the final solutions.

The next problem encountered during the testing phase was the time necessary to searching and the efficiency of providing data and solutions. The backbone of the proposed knowledge was based on detailed study and analysis of the human information process. The most challenging part of the process of developing the knowledge was focusing on the human characteristics, especially the decision-making process. The effort to describe the possible connection between human information processing and additional environmental conditions, as well as road geometry and control elements, brings increased time needed for searching the knowledge and difficulty in presenting the proposed change in the road structure in an easy and user-friendly way. The final 
consistencies of the knowledge become questionable. Because of the large number of possible scenarios and the possible paths which can connect each fact in the multiple scenarios, the difficulty in evaluating the proposed knowledge increased. All of the problems described above increased dramatically when the possible alternative approaches were applied. In this situation, the number of possible scenarios increased, in order to provide more proposed solutions, which were not always real world situations. Furthermore the knowledge base maintenance became a significant problem.

The next evaluation step was to indicate the functionality of providing facts. In the proposed approach, this idea was divided into two groups in order to reduce the amount of time users have to spend in providing data. This solution helps users but still does not solve the problem in the most efficient way. To improve this situation a change in the searching process was needed.

Due to the problems that occurred in the testing phases, a change in the approach was required. It is critical to understand that the previous approach provided significant knowledge for the knowledge base development process which in some level was applied to the new method (method with structured knowledge base). The previous findings were extremely helpful for the new methodology which is a clearer and more understandable representation of the knowledge base and the final product.

\subsection{Method with structured knowledge base}

Based on the findings of the previous chapter, an alternative method is proposed.. Because most of the problems encountered in the previous method with the knowledge structure were due to backward chaining, in the final method forward chaining therefore was used. In this new methodology knowledge acquisition was the most time consuming process. Forward chaining required much more organized knowledge than backward chaining utilized in the previous approach. Detailed knowledge was needed from different sources of information. Human factor processing was used in this approach also; therefore, the driver three-stage model was the most fundamental element of the 
knowledge. The structured knowledge base, as well as the previous unstructured knowledge, was developed for a two-way stop controlled intersection.

To makes the knowledge more efficient, understandable, and user-friendly, the Hierarchical Document System ver.0.3.4 was used (HDS). This tool provides very flexible knowledge representation in the path (note) and the final solution, as well as comments. The final knowledge was organized by the HDS software and returned the input file to the Road Safety Investigation Tool (RSIT). The graphic user interface was created using Visual Basic software. The starting point of the final product was implementing the knowledge inside the CLIPS software but a user-friendly interface was lacking to merge implementation toward Visual Basic. The major advantage of the presented tool is the flexibility of developing its own knowledge as well as editing the existing knowledge. The user can update the knowledge by using the HDS software and work on the knowledge within a convenient graphic shell.

\subsubsection{Knowledge acquisition}

The structured knowledge was acquired based on various types of information. In general, the sources of information can be divided as follows:

- Human factors area (Fuller and Santos 2002). The human information process Figure 3-6), guidance for driver behaviors;

- Safety facts, included study of the crash data base, and the crash facts;

- Road safety area, included road safety guidance, examples of the check list, and the structure of the Road Safety Audits (RSA);

- The final report of the RSA (LTAP, INDOT), which included the roadways deficiencies and propose solution;

- The observations of the safety specialist team during real-time safety investigation (Indiana Department of Transportation, Illinois Department of Transportation);

- Road geometry study. 
Knowledge acquisition is one of the most important elements of the expert system development process. The knowledge acquisition process is the most complicated element in the whole structure of the knowledge base system due to the fact that, in general, it is very difficult to obtain the knowledge.

The most powerful source of information at this stage is a human expert, but it is difficult to convert the knowledge of an expert into an efficient tool. This process becomes more complicated realizing how vast an expert's knowledge may be. Often the knowledge which experts have is difficult to express, and it can also be a task to find adequate and valuable experts in some areas.

The next source of information is an in-depth study of the interest area. In this case the information comes from publications and other different sources. There exist different techniques of knowledge acquisition (KA) (http://www.epistemics.co.uk/Notes/63-00.htm). The first technique is call protocol-generation (Ericson and Simon 1984) and is a connection of various types of interviews (unstructured, semi-structured, and structured), as well as reporting and observational techniques.

The protocol analysis technique (Cordingley, 1989) was the second useful technique for the knowledge acquisition process in this project. It is based on analysis of existing sources of information such as books, safety guidance, or other text-based information.

The next technique is the hierarchy generation technique. By using this methodology, the classification of the knowledge is by decision trees or other hierarchical structures.

The fourth technique of the KA is the matrix-based technique. This method "involves the construction of grids indicating such things as problems encountered against possible solutions." (http://www.epistemics.co.uk/Notes/63-0-0.htm).

The sorting techniques allow comparing the way humans order different concepts and compare them

The knowledge acquisition process was based on three different techniques to develop the final structure of the knowledge. The first technique: the protocol analysis technique extracts the most useful information from various sources such as: 
NCHRP Report 500 Series, Volume 5 “A Guide for Addressing Unsignalized Intersection Collisions”. Transportation Research Board, Washington, D.C., 2003.

Andrew P. Tarko, Mayank Kanodia. "Hazard Elimination Program Manual on Improving Safety of Indiana Road Intersection and Section”. FHWA/IN/JTRP-2003/19, Purdue University, West Lafayette, February 2004.

DCHRP Synthesis 336 Series, "Road Safety Audits, A Synthesis of Highway Practice.” Transportation Research Board, Washington, D.C., 2004.

Examples of the information which was extracted from the major sources above are presented in Table 3-2.

Table 3-2 Extracted part of the knowledge

\begin{tabular}{|c|c|c|c|}
\hline \multirow[t]{2}{*}{ B5 } & $\begin{array}{l}\text { A } \\
\text { rear_end_collision_related_to_spee } \\
\text { d_different_turning_left_onto_high } \\
\text { way(yes), } \\
\text { divided_highway_present(yes). }\end{array}$ & $\begin{array}{l}\text { A. Not enough space to } \\
\text { 1. Ncelerate. } \\
\text { 2. Significant number of } \\
\text { trucks. } \\
\text { 3. High speed condition. }\end{array}$ & $\begin{array}{l}\text { A } \\
\text { 1. Provide left- } \\
\text { turn } \\
\text { acceleration } \\
\text { lanes }\end{array}$ \\
\hline & $\begin{array}{l}\text { B } \\
\text { rear_end_collision_related_to_spee } \\
\text { d_different_turning_left_onto_high } \\
\text { way(yes), } \\
\text { divided_highway_present(no). }\end{array}$ & $\begin{array}{l}\text { B } \\
\text { 1. Lack of space for driver to } \\
\text { choice adequate gap. }\end{array}$ & $\begin{array}{l}\text { B } \begin{array}{l}\text { Improve } \\
\text { visibility }\end{array} \\
\text { 2. Restrict } \\
\text { turning. }\end{array}$ \\
\hline \multirow[t]{2}{*}{ B6 } & $\begin{array}{l}\text { A } \\
\text { collision_major_turning_right_follo } \\
\text { wing(yes),major_right_turn_lane_e } \\
\text { xist(no). }\end{array}$ & $\begin{array}{l}\text { A. } \\
\text { 1. High speed condition. } \\
\text { 2. Significant number of } \\
\text { vehicle turning right. }\end{array}$ & $\begin{array}{l}\text { A. Install } \\
\text { right-turn } \\
\text { lanes. }\end{array}$ \\
\hline & $\begin{array}{l}\text { B } \\
\text { collision_turning_right_through_co } \\
\text { mming_from_left_cross_street(yes), } \\
\text { major_right_turn_lane_exist(no). }\end{array}$ & $\begin{array}{l}\text { B } \\
\text { 1. Lack of visibility } \\
\text { 2. Significant number of } \\
\text { turning vehicle. }\end{array}$ &  \\
\hline
\end{tabular}


The full table of the knowledge extracted from the presented above sources is shown in Appendix D. The table above is divided into four columns. The first column indicates the strategy number (NCHRP Report 500 Series, 2003), and input information was assigned to each strategy. Input information is defined as all possible situations which can imply the specific strategy (i.e., B5 - "Provide left-turn acceleration lanes at divided highway intersection T”). Next to the input information, the crash causes are presented, which represent the possible causes of specific types of collisions. In the last column the possible solutions are proposed. Additional information from past road safety audits, as well as the road geometry characteristics, are used to describe the final knowledge.

For better organization of the method the protocol analysis technique determines the final knowledge in three major layers. The fundamental assumption, which was made to describe the potential problems for TWSC intersection, is based on dividing all of the crash factors into three layers (Figure 3-19). The first layer represented the road geometry and traffic control. Inside this layer the following factors are present: lane width, shoulder width, pavement marking, channelization, type of control, traffic control maintenance, speed condition, horizontal and vertical alignment (...). (See knowledge structure in Appendix E).

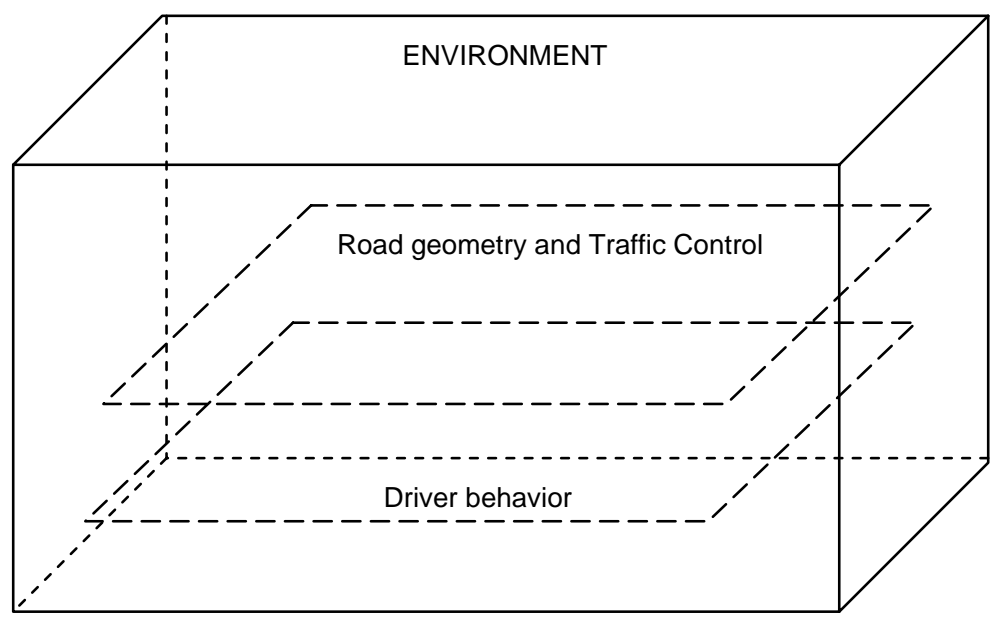

Figure 3-19 Three layers of crash occurrences 
The second layer represents driver behavior. The significant amount of time which was spent on the previous approach where the human factors became the backbone of the knowledge is applied as well to the final method. The protocol analysis technique is used as in the previous approach to determine the most important driver characteristics. Since a driver error seems to be the major causes of all crashes, the driver behavior layer has a very important impact during developing the knowledge base.

Driver behavior can be represented as a three-stage model as shown in Figure 3-20.

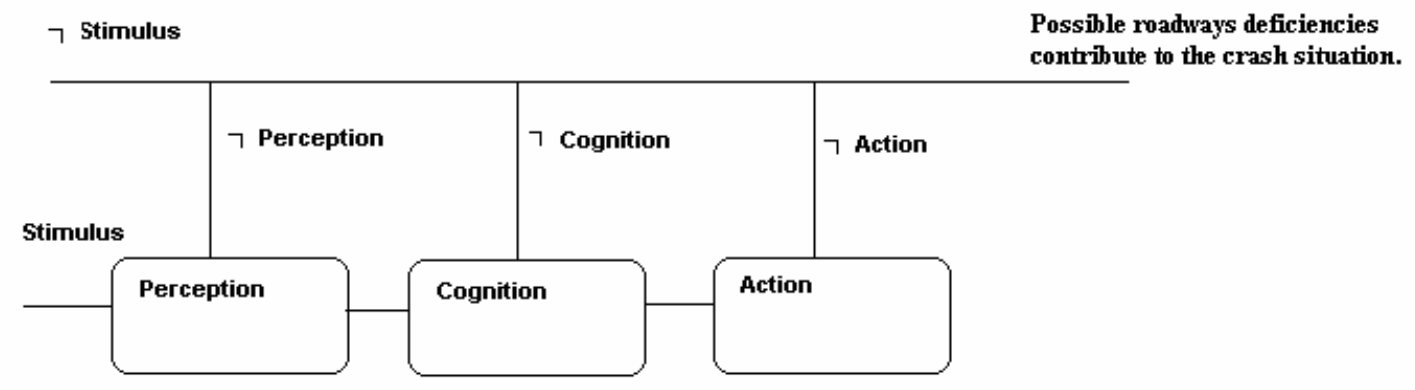

Figure 3-20 Human information process (modification)

If a stimulus is not present (i.e., stop sign is missing), then the lack of this information could lead to a crash. If a signal is present, but the driver fails in the perception stage (i.e. stop sign obstruction), this can leads to a crash as well. If traffic control exists and is perceived and recognized, the driver could still fail in the action stage (i.e., slippery road or mechanical problem).

The main approach taken was to describe the knowledge and focus on driver characteristics. To represent the results of driver characteristics combined with the road geometry and traffic control, let us focus on one type of collision: right-angle collisions for TWSC intersections. In this type of intersection, the first element which can potential cause crashes is failure to stop. The question becomes “Why driver didn't stop?” There are different causes for stop failure, but one of the most fundamental is because the driver does not know to stop (i.e. ,no perception signal was present), which could be caused, for example by a missing stop sign. If there is no stop sign, the driver will not consider stopping. Proposing a possible solution to this situation is simple: “Install stop sign.” Let us consider now a situation where the source of information (stop sign) exists. It is never 
guaranteed that the driver will perceive the stop sign for example, a stop sign is present, but trees obstruct it. Thus, the next step would be to determine if the stop sign is visible or not. In the case of lack visibility of the stop sign, we should look for causes which create insufficient visibility (i.e., "inappropriate stop sign maintenance" or "poor horizontal/vertical alignment” (...).

The next step in the knowledge acquisition process was based on the observational techniques employed, which was done during two road safety investigations. The first was conducted by the Indiana Department of Transportation, and the second by the Illinois Department of Transportation. By observing the safety teams during their work, useful information and techniques were applied to the final structure of the knowledge base. The first step of a RSA is the preliminary investigation phase where there is discussion of the actual road crash characteristics. During this stage, the site investigation plan is prepared. The safety team tries to obtain the location, the type, and time of the collision. These findings were applied to the final structure of the searching process for the knowledge (please see the knowledge representation paragraph). The next step is the actual site investigation whereby the safety team collects additional data. During the investigation stage, the safety team tries to collect various pieces of information that indicate a probable safety deficiency. This collection of the data can be organized using the checklist shown in Figure 3-21 (Tarko and Kanodia. 2004) or the field observation findings can be collected by the individual team members. 
Facality Type:

Location: Smith Road / Rogers Road

Date:

18-Jan-05 Time:

Moving Lanes

Lane widths are inadequate for vehicle classes common to location

Number of lanes are inadequate for traffic

Lanes abrubtly end

\section{Auxiliary / Turning Lanes}

Inadequate advance warning of lane drop

Auxiliary lane lengths are inadequate

Taper lanes and not properly marked or inadequate length

Driveways and Parking

Driveways too closely spaced

Inadequate visibilty of driveways

Parked cars limit visiblity

Curb and / or Shoulders

Curbs are improperly installed - height and width

Curbs are not delineated adequately

Curbs show evidence of off tracking

Shoulder widths are inadequate

Inappropriate shoulder surface

Rumble strips not installed properly or as warranted

Shoulders are poorly maintained

Insufficient contrast of shoulder

Horizontal and Vertical Alignment

Horizontal or vertical alignment affect visibilty

Abrubt change in elevation

Inadequate visibilty at sag or crest curves

Inadequate or excessive superelevation

Curves present that cause sliding in adverse weater conditions
Page: $\quad 1$ of 3

1:30 PM Weather: Sunny
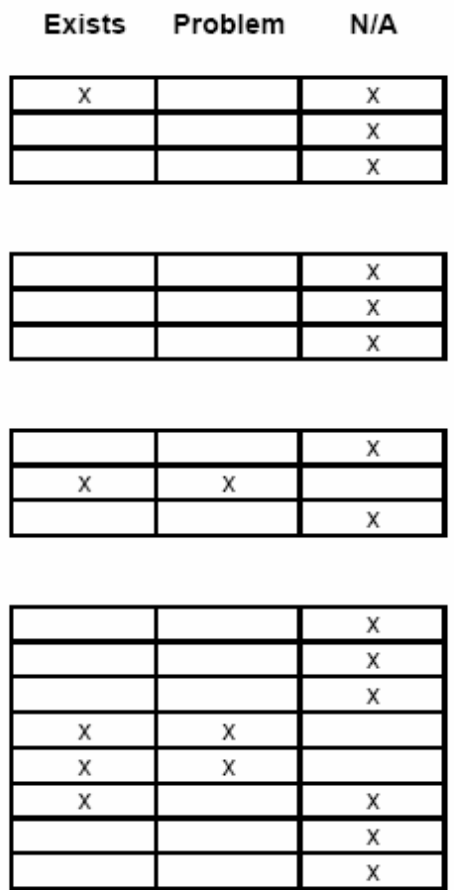

\begin{tabular}{|c|c|c|}
\hline$x$ & $x$ & \\
\hline$x$ & $x$ & \\
\hline$x$ & $x$ & \\
\hline$x$ & $x$ & \\
\hline$x$ & $x$ & \\
\hline
\end{tabular}

Figure 3-21 The RSA - check list (LTPA, 2006)

The last stage is the post-analysis phase where the safety team discusses the findings and proposes adequate countermeasures. High-crash locations are investigated to determine potential road improvements. The most difficult task for the safety team is to link various road characteristics, traffic control, and other relevant local conditions with an excessive level of risk. The lack of in-depth knowledge of the actual circumstances leading to past crashes increases the complexity of the problem. The multiplicity of past crashes and a typically large number of local characteristics to consider create a time pressure, which may contribute to inadequate solutions, overlooking important crash 
factors, and inadequate use of the checklist. Developed knowledge, based on described information can provide the user more flexible and understandable knowledge representation than the checklist.

The findings of the safety investigation team, especially the connection of various pieces of information, were successfully applied to the final knowledge base as well as to the computer-based tool.

\subsubsection{Knowledge representation and structure}

Most of the difficulty in the previous approach was related to backward chaining and the specific structural representation of the knowledge (Ohsuga 1990). In the proposed method, representation of the knowledge was obtained by using the hierarchically generation technique. Forward chaining can be successful, especially in cases where a multiple solution is expected. In the propose method the goal is to obtain the possible solutions that can be applied to different road conditions. Because the goal (possible solutions) is unknown before the knowledge structure is developed and the input information is available, forward chaining can create an efficient structure of the knowledge that is understandable easily followed by the user.

The developed knowledge has it own structure where the level of each individual fact can affect the final solution. By this approach, the flexibility of the knowledge is reduced but a user-friendly explanation of the structure is applied. The final structure of the knowledge is organized by different levels which represent the hierarchical structure of the knowledge. The information initially presented to the user has a higher level of importance than information at the next level. For example, one of the first questions which the software will address to the user is not the width of the shoulders but the type of crashes. Because the starting point of the knowledge becomes the most critical, it needs to be carefully determined. This tool is developed to help investigators determine the potential roadways deficiencies so it therefore must mimic the decision process in each of the investigation stages by the investigation team. Therefore, the starting level of the knowledge was divided into five groups:

- Crash types, 
- Time of collision,

- Weather conditions,

- Pedestrians/bicycle collisions,

- Intersection inconspicuous.

The first group contains different types of collision (i.e., rear-angle collision, rightangle collision, etc. (...). In real world situations, different types of crashes can occur on each specific two-way stop controlled intersection, therefore, in the first level of the decision tree, the user has various choices which are presented in Figure 3-22.

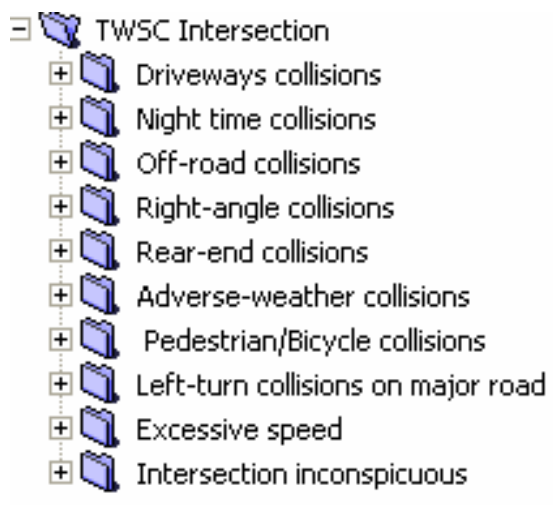

Figure 3-22 First level of the knowledge

By using proper questions and adequate structure of the knowledge, we avoided asking question which would never apply. This situation is presented in Figures 3-23a and b. Elements "C" are present in the entire branches in the last step (Level III) of the tree structure, therefore, these elements can be implemented one level above (Level II) as it is presented in Figure 3-23b. 
a)

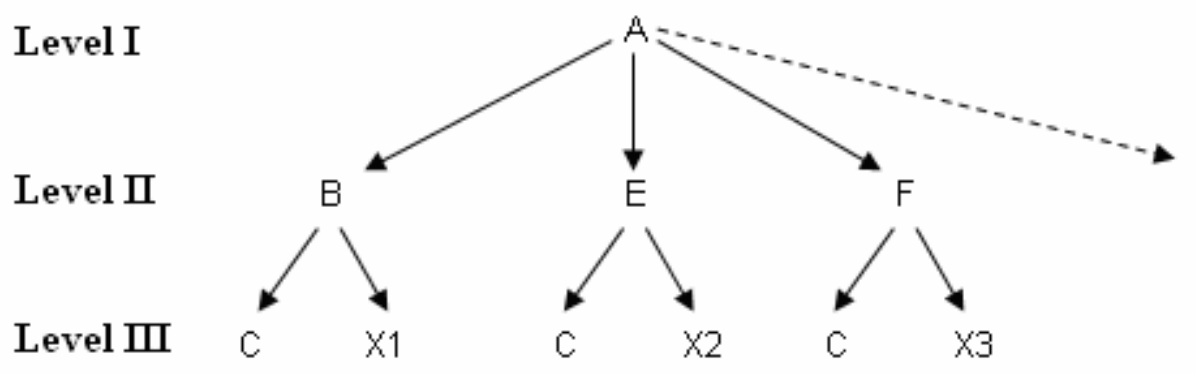

b)

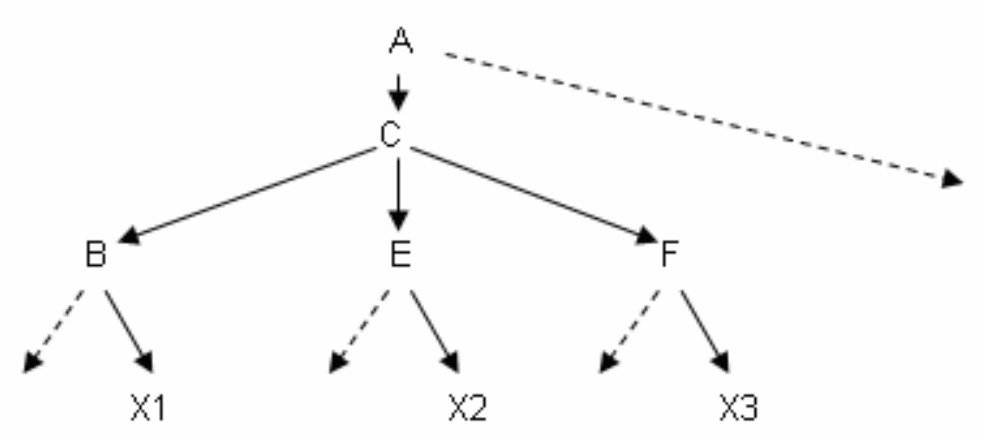

Figure 3-23 Structure representation of the knowledge

The general idea behind searching the structure of the decision tree is to give users as much flexibility as possible, for example, by allowing multiple choices. According to Figures 3-23a and b, users can choose F, E, and B at the same time. In this case all child nodes are explored by using FIFO (first in first out) queuing theory. When the user chooses F, E and B, then the first processed are F, next E, and the last B.

If one of the child nodes occurs often, as shown in Figure 3-23a, the decision tree can be redesigned (Figure 3-23b). Sometimes, one of the elements of the decision tree can be a common part in whole structure (i.e., adverse weather conditions). Adverse weather can affect all types of crashes: rear-end collision, pedestrians, or right-angle collision (...). Therefore, we can consider adverse weather conditions as a special node path inside the structure of the decision tree (Figure 3-24). Because of multiple choices, users always have the possibility to simultaneously choose several of factors which are important for specific hazardous locations (i.e., adverse weather conditions and rear-end collisions). 


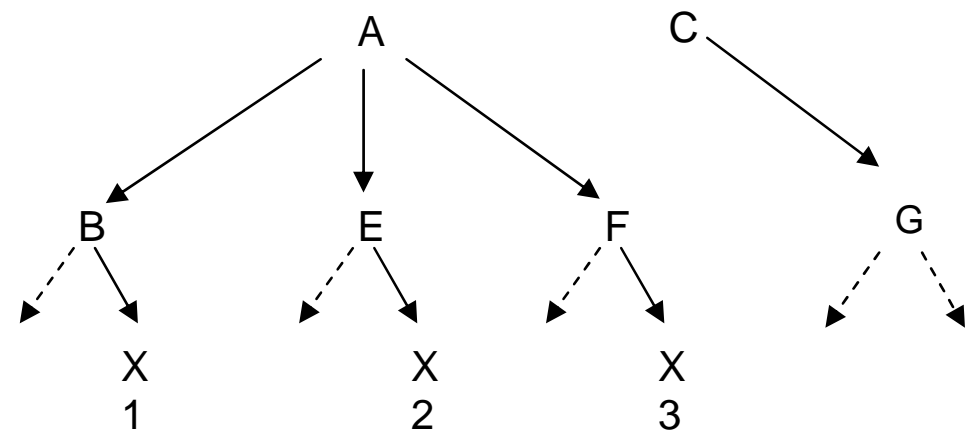

Figure 3-24 Tree structure (example C- Adverse weather)

For better understanding of the structure (tree representation) of the knowledge the following example discusses it in more detail. This example focuses on the most critical type of the crash: right-angle collision. The first step is to indicate that situation under consideration is the right-angle collision. Next, the two possible causes which are determined by the user in real-time investigations are: "stop sign missing" and "stop sign not missing." It was presented before that the first elements that have to exist to avoid a collision is stimuli, which in the present example is a stop sign. If a stop sign does not exist, the following treatment should be applied: "Install a stop sign.” If the stop sign is present, the next level of possible choices is shown to the user. In this level the following information should be obtained:

- $\quad$ Stop sign not visible

- $\quad$ Stop sign visible

This situation is related to the driver information process, where after a stimulus is present the perception stage is considered. If the user chooses "stop sign is not visible," the following choices are applied:

- $\quad$ Improperly maintained stop sign

- $\quad$ Poor horizontal/ vertical alignment

- $\quad$ Stop sign obstruction

- $\quad$ Multiple lanes on approaches 
By this structure it can be easily observed that after determining that the stop sign is not visible (no perception signal), the causes of this situation are proposed. If in the next step the user will choose "stop sign obstruction,", the special treatment "remove the object obstructing the sight of the stop sign." The whole representation of the knowledge for the right-angle collision is presented in Figure 3-25.

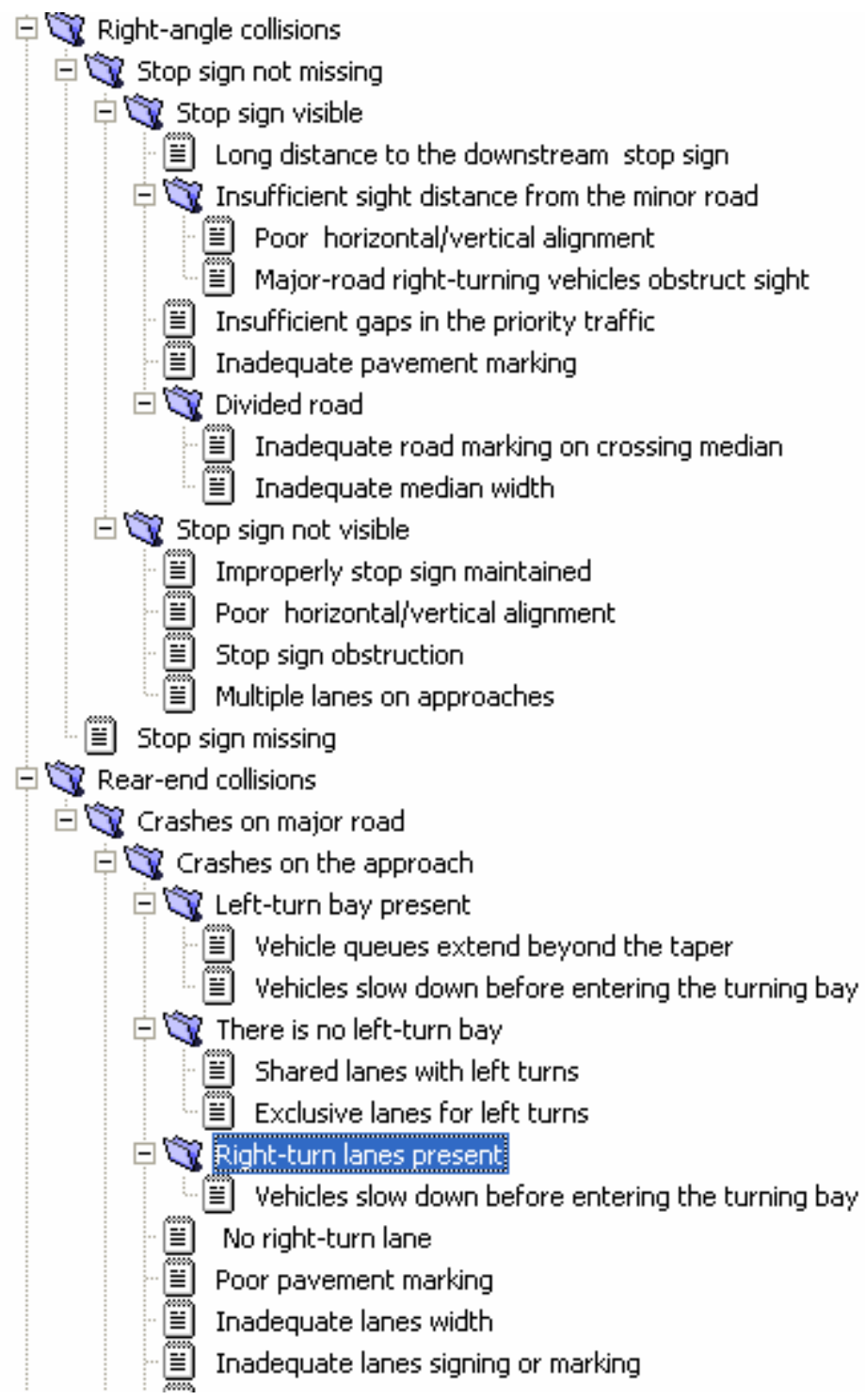

Figure 3-25 Right-angle collision

The same idea for the structure and searching process was applied to other elements. One of them has less complicated structure (i.e., for off-road collisions the second 
level of the structure gives the possible roadway improvements as shown in Figure 326.

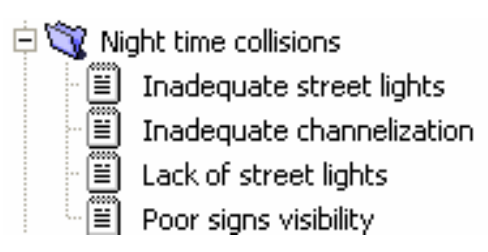

\section{Figure 3-26 Night time collisions}

The complete structure of the knowledge base was added in to attach and it has specific structure (Appendix E). In this structure (which was used as a part of the evaluation) the whole paths are presented. By the whole paths we mean all factors which have to be considered to determine the final improvements. An example of the knowledge representation is shown in Figure 3-27.

\section{Intersection inconspicuous}

\subsection{No advance warning sign}

\#1. Install warning signs in advance of intersections

\subsection{Advance warning sign posted}

\subsubsection{Warning sign poorly visible/recognizable}

10.2.1.1 Improperly warning sign maintained

\#1. Replace, repair, or clean the warning signs

10.2.1.2 Warning sign obstruction

\#1. Relocate the sign to make it visible \#2. Remove the object obstructing sight of the warning sign

10.2.1.3 Visual distraction

Figure 3-27 Example of the knowledge path

In the example shown in Figure 3-27 the part of the knowledge related to "intersection inconspicuous" is presented. The number "10" represents only the serial of the highest structure of the knowledge. The numbers "10.1,” 10.2,” (...) represent the second level of the structure. Finally, the numbers "10.2.1," "10.2.2,” (...), represent the third level of the 
knowledge. The symbol “\#” plus a number (\#1) represents the final possible solution. Let us consider the following example. The propose improvement is \#1: "Install warning signs in advance of intersections.” This improvement was derived because the user indicated "Intersection inconspicuous" at the first level, and in the next level "No advance warning sign.”

By using forward chaining in the proposed structure of the knowledge, searching through all the facts and rules are more user-friendly and more organized. The knowledge is more understandable and easy to follow by the user. In each of the searching stages, even before the final solution is obtained, user has possibility to update the facts previously entered.

Before the final computer tool (implementation language) was proposed, the testing phase of the knowledge was made by using the AI (Artificial Intelligences) natural language programming tool - CLIPS (Ginsberg 1993).

CLIPS was developed by NASA in 1984. The word CLIPS stands for C Language Integrated Production System. This tool was developed for forward chaining. In our method, this approach was used therefore in the testing phases of the knowledge implemented by this software.

The main operating window for CLIPS is presented in Figure 3-28. This window is divided into two major parts. The first part (PART 1) is used to communicate with the user. The second part (PART 2) gives the user the main menu option (i.e. save, open $(\ldots))$. 


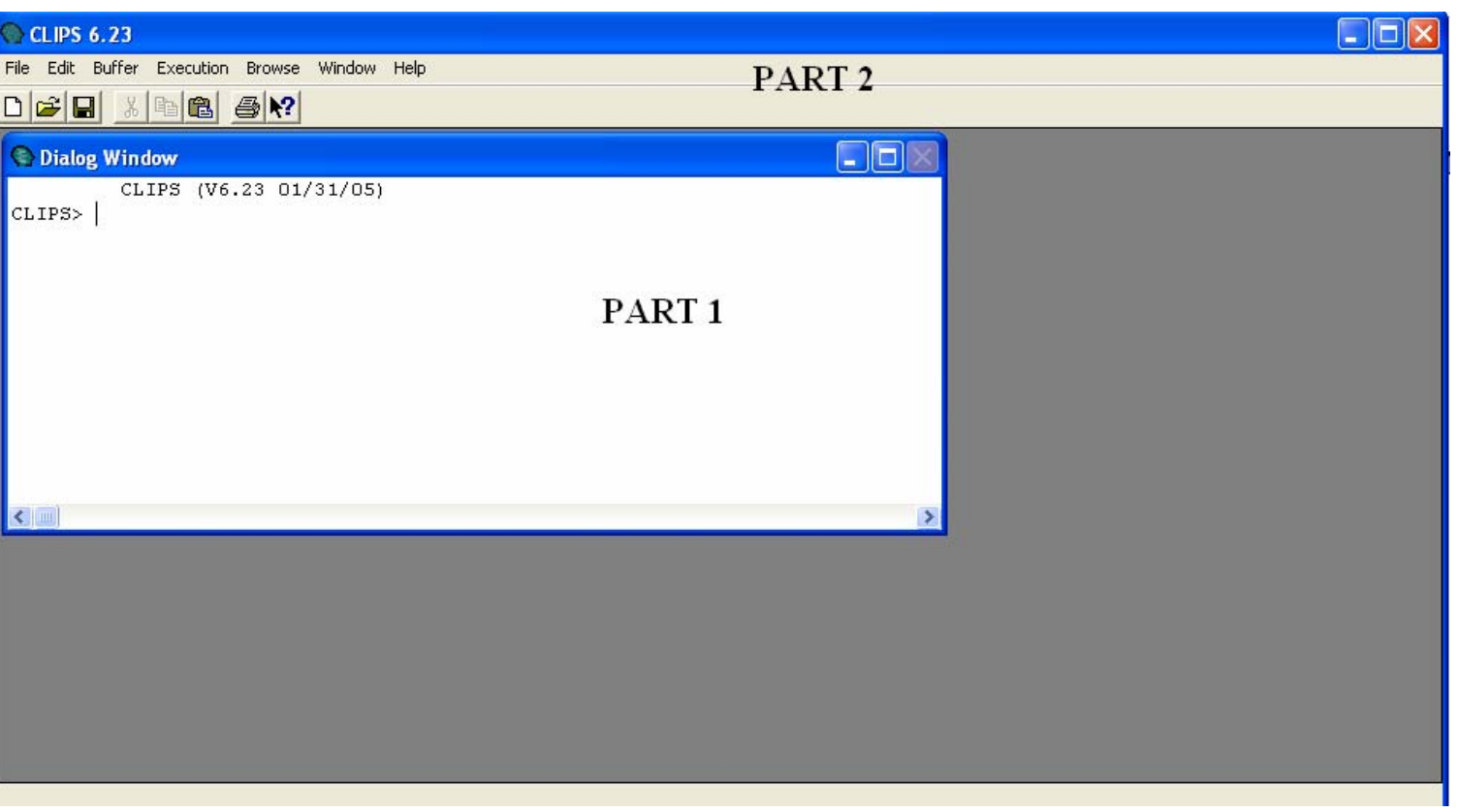

Figure 3-28 CLIPS

The code was written in the text editor (Appendix F) and it was loaded into the software. The starting point is the main menu, where the first level of possible choices is presented to the user. There are ten different choices which the user can follow by typing in the assigned choice letter and by pressing the enter key (Figure 3-29). 


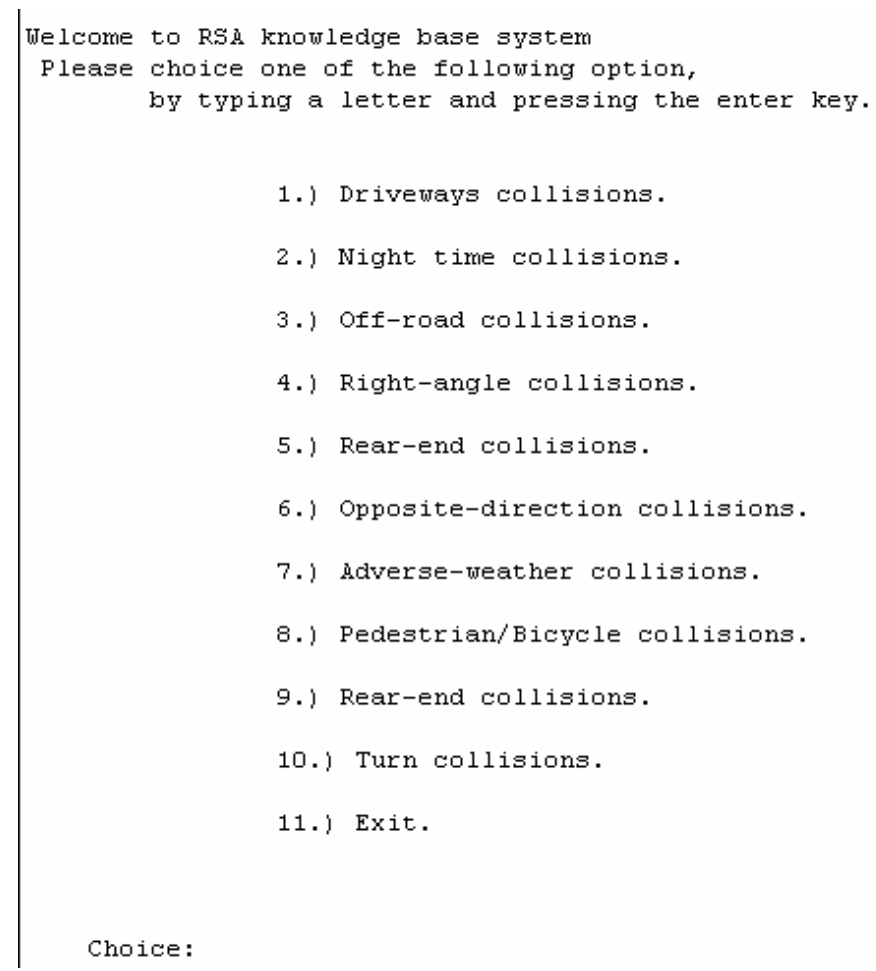

Figure 3-29 Main menu

After executing the first level, the user is taken to the next level of possible choices. In each step, by typing " 0 ” the user can go back one level.

If the user wants to select other solutions after reaching a possible solution, the user can press the enter key to go back to the previous level. This feature allows searching for an alternative solution or multiple solutions.

The testing phase, by using the CLIPS, was conducted on a small part of the knowledge to evaluate the usefulness of the software. Because this tool does not represent the solution in a graphic user interface, the decision was made not use it $i$ the final product, and using Visual Basic and HDS was proposed.

By applying new methodology and a structured knowledge base, the tool returned more understandable results. Furthermore, the knowledge was created by combining various sources of information, which increases the independence of the final findings. The user can easily follow each of the steps during the searching process and countermeasures can be determined which are adequate to actual road conditions The developed knowledge base, by using forward chaining, created a more efficient and flexible structure of the knowledge, which is easier to maintain and update. An additional 
expert system shell was used to represent the final knowledge. The graphic user-friendly interface was obtained by using the Visual Basic language. The functionality of the tool as well as the results from the evaluation phases, confirmed the effectiveness and usefulness of developed tool. The final representation of the computer tool is presented in next chapter. 


\section{CHAPTER 4 THE METHOD IMPLEMENTATION}

The final output of this research is a computer-based system for safety evaluation. During the development stage, different approaches were proposed. The first implementation was made by using the Prolog language (Deransart, Pierre, 1996). Because of complexity of the knowledge structure, and the time needed to evaluate all possible scenarios, the approach was changed to forward chaining where CLIPS was used. CLIPS contains all the functions required to develop a more efficient tool but lacked a user-friendly interface so this approach was discarded as well.

The final proposed knowledge is represented in Visual Basic., which offered the possibility to develop a convenient user-friendly interface (Figure 4-3), and the searching process of the knowledge is easy to follow.

The developed RSIT reads a knowledge base file and provides assistance to the site investigation process by following a decision tree structure. The user follows a logical set of conditions describing the types of collisions at a site, from general conditions to more detailed ones. Each set of conditions (a branch in the decision tree) ends with a set of proposed safety improvements, from which the user selects the most appropriate ones. The program creates a report of the investigation, listing all the condition sets that were selected during the investigation.

\subsection{Description of buttons and commands}

\subsubsection{Startup window}

The starting window of the RSIT program has 4 buttons: "Site Investigation", "Edit Knowledge Base”, "Help", and "Exit Application" (Figure 4-1). 


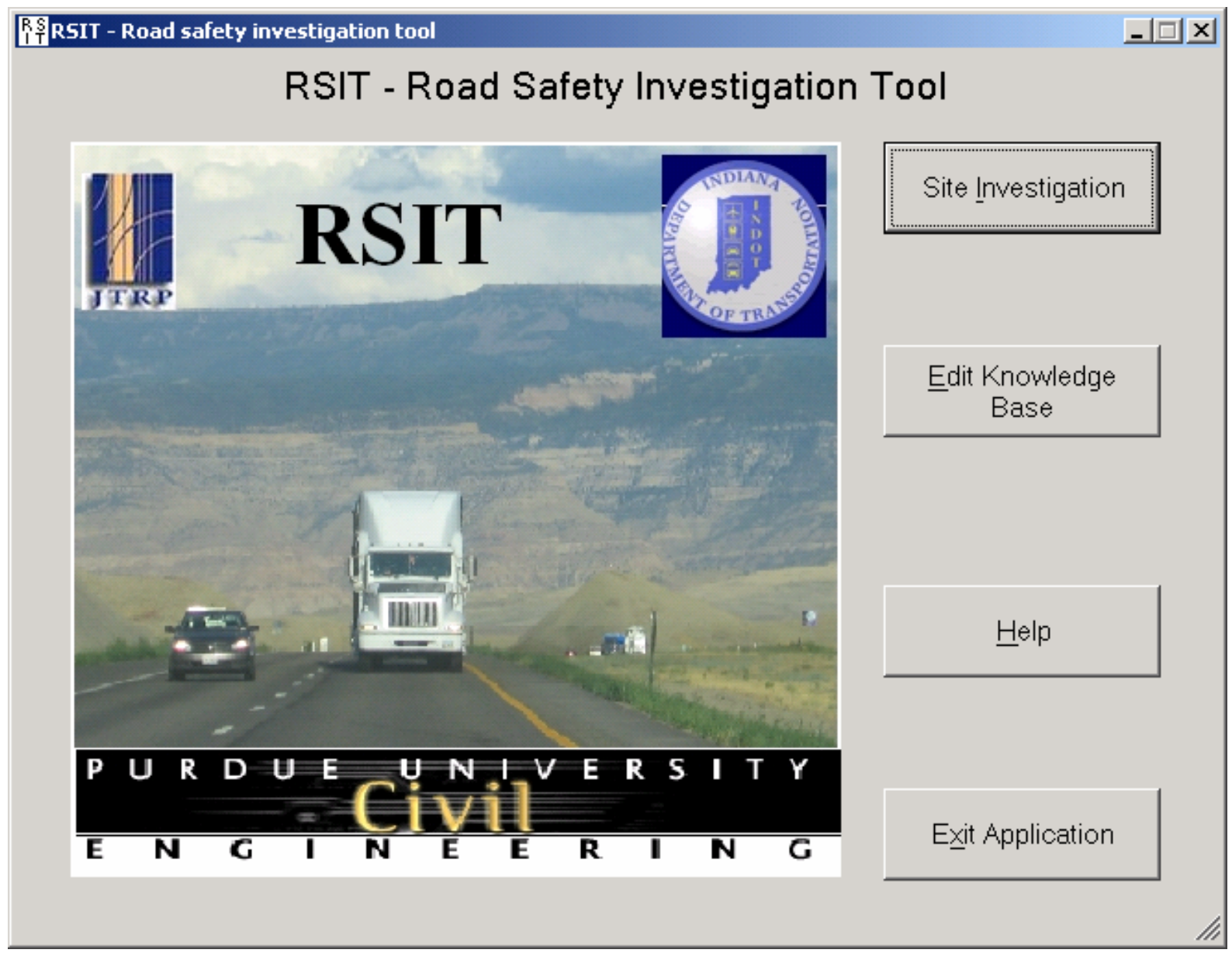

Figure 4-1 Startup window

The "Site Investigation" button will open a new window which allows starting a new investigation, to open an existing investigation, or to view and save the report.

The "Edit Knowledge Base" button opens the Hierarchical Document System (HDS) program (Figure 4-2), which allows the modification of the existing knowledge base: adding, changing, and deleting conditions or set of conditions, proposed safety improvements, and comments. To edit the knowledge the HDS (Hierarchical Document System) software was used, which is distributed on public license and does not require special installation on the PC. For more information about HDS, created by Toshihiro Inoue under a public domain license, go to http://sourceforge.net/projects/hdocsys.

In Figure 4-2 the main menu is presented. It is divided into three major parts. The first part (PART A) represent the knowledge structure, and the second part (PART B) 
represents the possible solutions which are the last elements of each node inside the knowledge. The third part (PART C) contains a standard user menu: save, open, import.

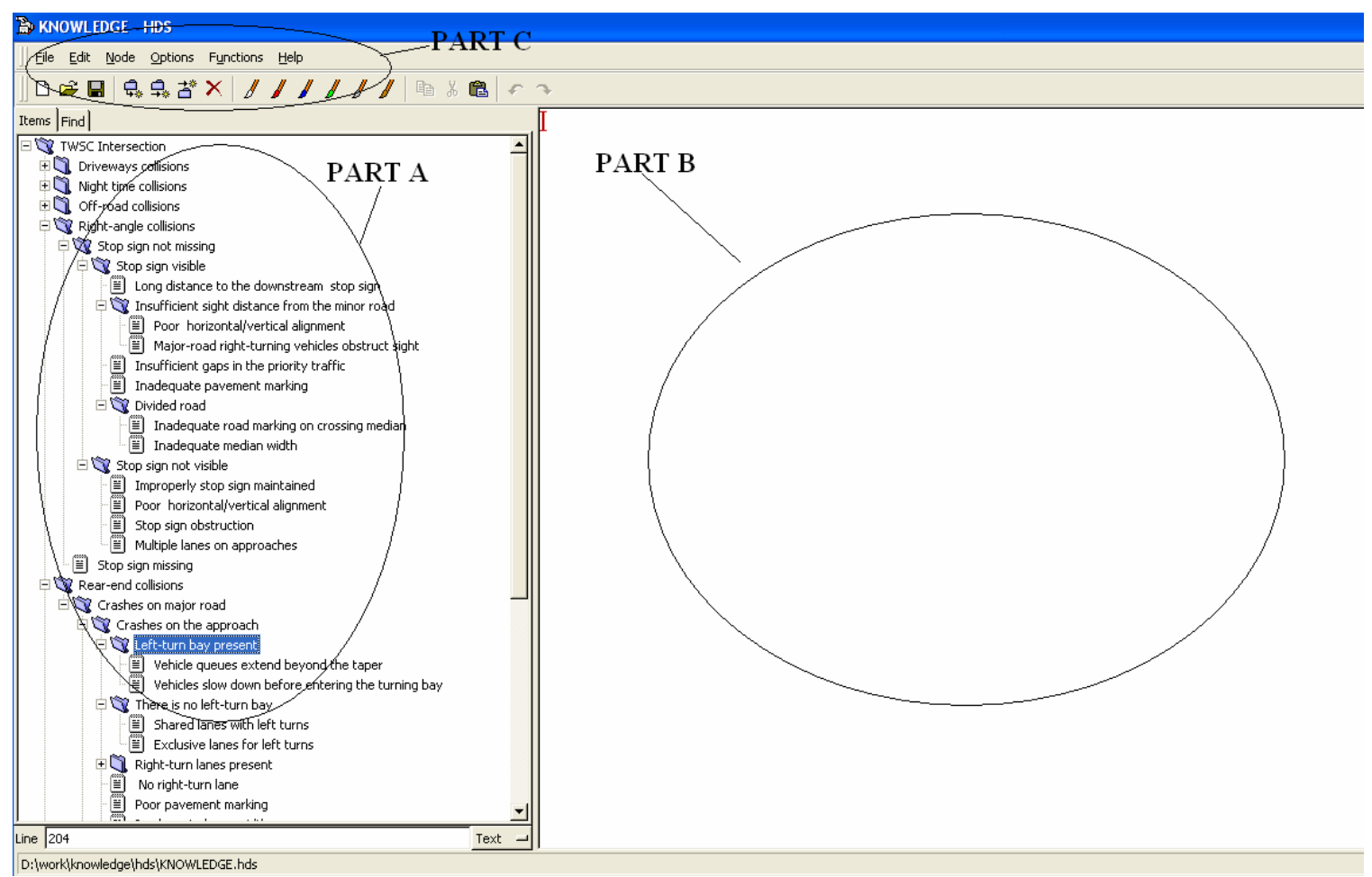

Figure 4-2 HDS windows

To update the existing information, the file containing the knowledge must be loaded (default: knowledge.hds). Next, by double (slow) clicking on each child (node) the name can be updated. The information in PART B is editable in the same way as most editing software (i.e., Microsoft Office or Notepad). To create his own knowledge base, the user must choose "File: New" and by using "File: Node” can add new child or append part of one (Figure 4-3). 


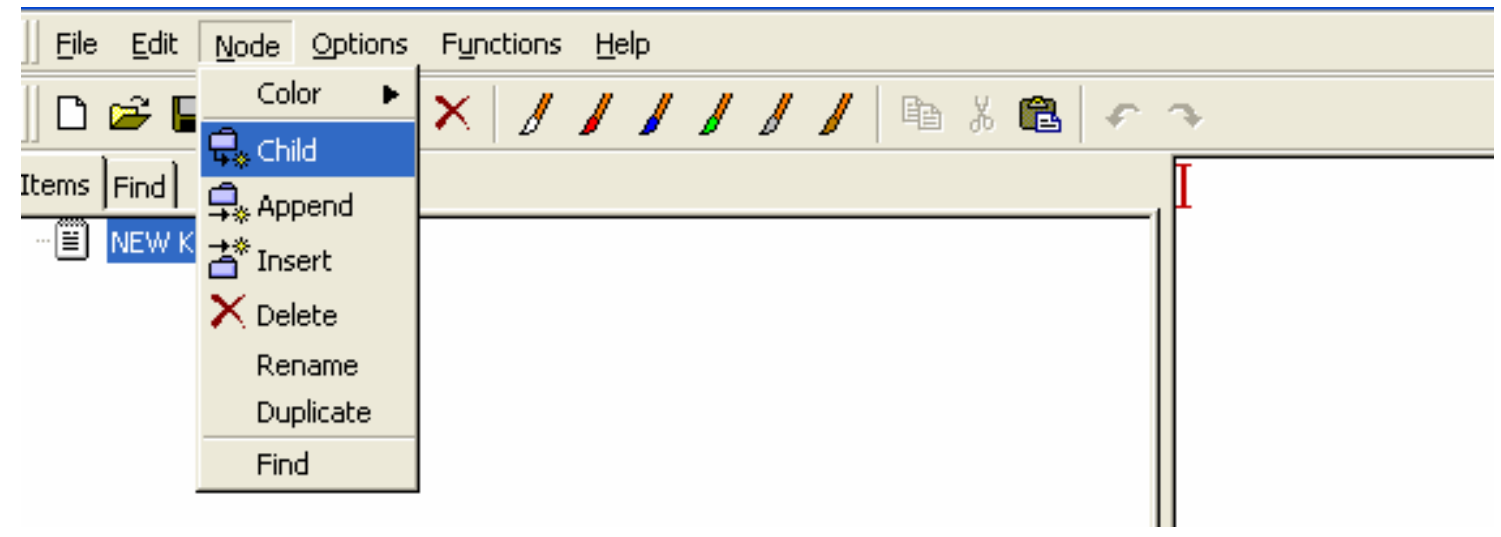

Figure 4-3 New knowledge

The last step after the user knowledge is developed is to export the knowledge to the Visual Basic shell by the function: “Save With, Text File.” This text file will be readable by the RSIT software to derive multiple solutions.

The HDS.exe file opens the HDS program and it should be in the RSIT folder, along with the knowledge.hds file which contains the existing knowledge base. After changes are made, the knowledge base should be saved using the option "Save With ... Text."

The "Help" button opens this window.

The "Exit Application" button will close RSIT application, including all the other windows that were open from the program.

\subsubsection{Investigation window}

\section{File menu}

The window has several regions: the menu and buttons panel on the left, the Conditions list box on the top middle (a check list box, non-editable), the Proposed Safety Improvements list box on the top right (a check list box, non-editable), the Comments text box on the middle right (editable), the Processed (text box, non-editable) and the To Process list box (non-editable) on the bottom. 




Figure 4-4 Investigation Window

The "File" button opens a menu containing "Start New Investigation," "Open Existing Investigation," "Save Investigation," and "Save Investigation As" commands (Figure 45). 


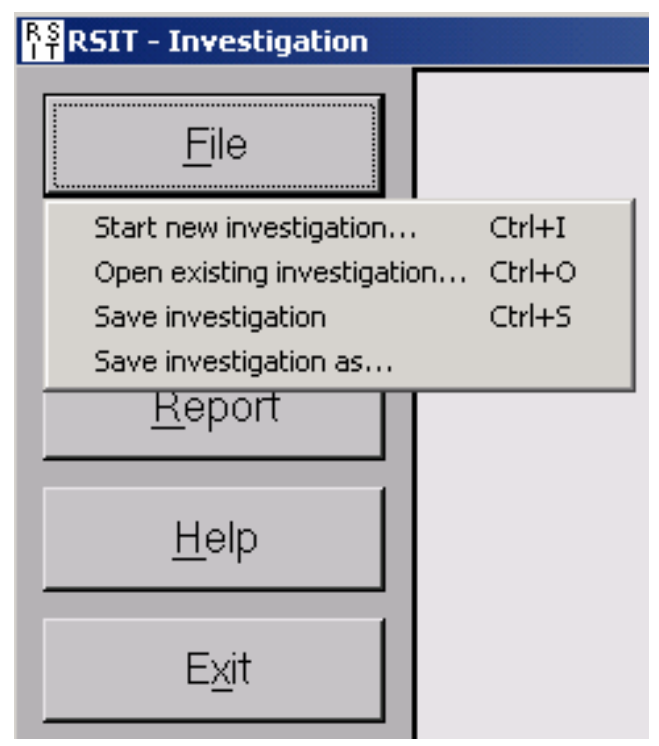

Figure 4-5 Menu buttons

The "Start New Investigation" command opens a window where the user selects an existing knowledge file (output from the HDS program). Then the panel in the middle of the window is populated with the first level conditions. The investigation starts by selecting the appropriate conditions and then going to the next level of condition detail with the "Proceed" button.

The "Open Existing Investigation" command opens a window where the user selects an existing investigation file (saved previously). The window is populated with all the elements of the investigation at the moment when it was last saved.

The "Save Investigation" command allows the saving of the current investigation with a default file name or a new file name. That file name is used when the user wants to open an existing investigation. The "Save Investigation" command in this window has the same functionality as the command in the "File" menu.

\section{Settings menu}

The "Settings" button opens a menu containing commands to change "Background Color" for four different regions of the window (Figure 4-6), "Font" (Figure 4-6) and "Font Color" (Figure 4-6) for two regions of the window and to set the "Auto Save Interval." 

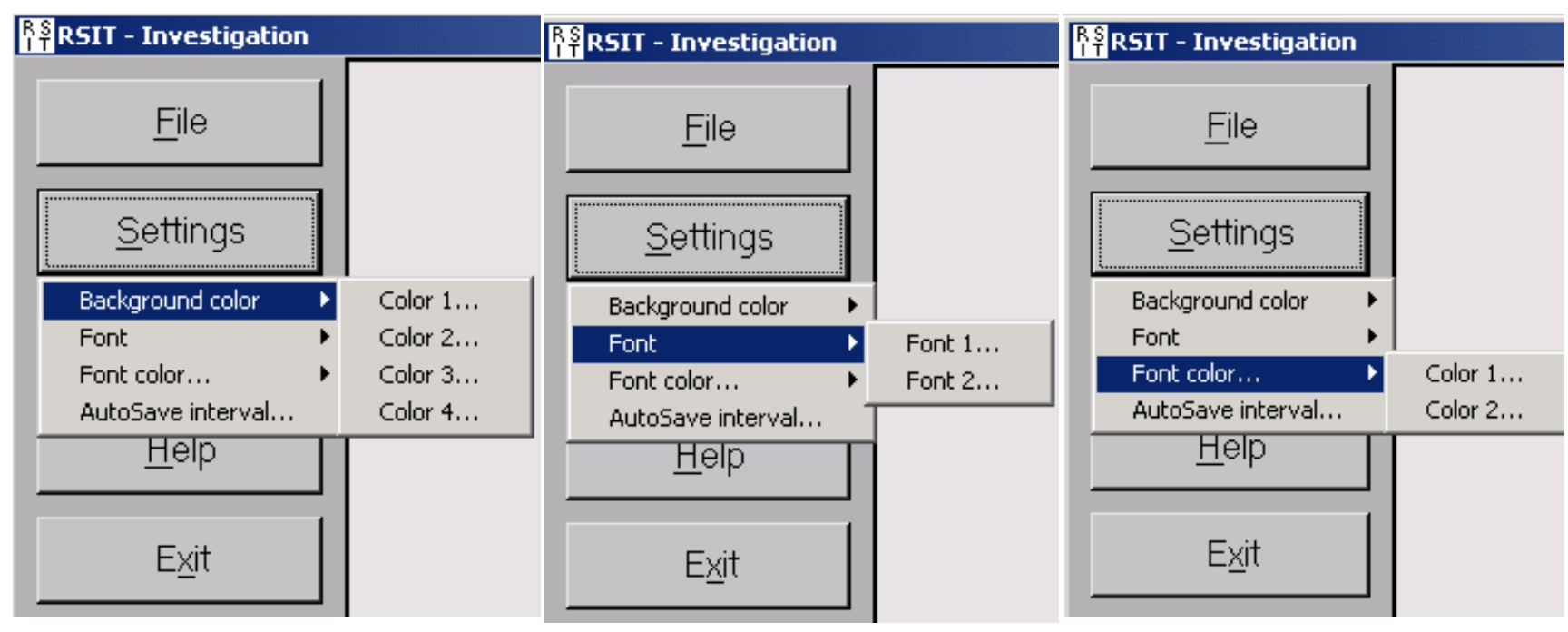

\section{Figure 4-6 Setting menu}

"Background Color" - "Color 1" is used to set the color for most of the window, except for buttons and editable and non-editable boxes.

"Background Color" - "Color 2" is used to set the color for the non-editable boxes.

"Background Color" - "Color 3" is used to set the color for the editable box (Comments).

"Background Color" - "Color 3" is used to set the color for the buttons.

"Font" - "Font 1" is used to set the font for the elements of the window that do not change during the investigation.

"Font" - "Font 2" is used to set the font for the elements of the window that do change during the investigation.

"Font Color" - "Color 1" is used to set the font color for the elements of the window that do not change during the investigation.

"Font Color" - "Color 2" is used to set the font color for the elements of the window that do change during the investigation.

Once colors and fonts are set for different elements of the investigation window, they will be used as default settings for the next investigation sessions.

The "AutoSave Interval" is used to set the investigation auto-save interval, in minutes. The default value is five minutes. If a file name for the investigation file was not specified before, the Save Investigation window will appear in order to do that. 
The size of the investigation window can be changed, by increasing the width and/or the height. The width of the Conditions list box can also be changed by using the splitter area at the right of the list box, and the width of the Proposed Safety Improvements list box and the Comments text box will be changed accordingly. The new sizes will be saved and used as default size settings for the next investigation sessions.

\section{Report menu}

The "Report" button opens a menu containing "View Report," "Save Report," and "Save Report As" commands (Figure 4-7).

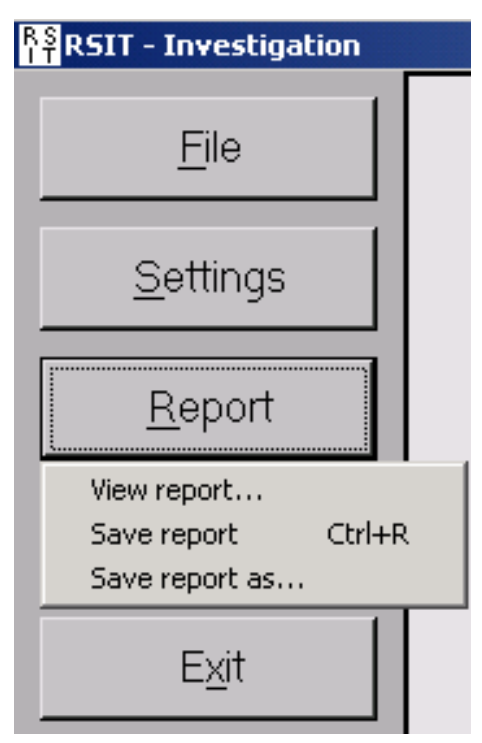

Figure 4-7 Report Menu

"View Report" opens a new window where report information, such as date, location, investigator names can be entered (Figure 4-8). The user also sees the current report text, containing complete condition sets with proposed safety improvements and comments. A "Save Report" button can be used to specify the report file name. 




Figure 4-8 Report window

The "Save Report" command allows the saving of the current report with a default file name or a new file name. The "Save Report" button on the window has the same functionality as the command in the "Report" menu. 
The "Help" button opens this window.

The "Exit" button will close the RSIT Investigation window.

\subsection{Description of investigation steps}

An investigation starts by using the "Open New Investigation" command in the File menu and selecting the knowledge base file. This will display a list of the first level conditions in the Conditions list box (Figure 4-9).

The Proceed button will be used to navigate the knowledge base, and at each step the user can select conditions and proposed safety improvements for a set of conditions and add or edit comments. The conditions' selections are reflected in the Processed text box, where the current set of conditions is displayed and in the To Process list box, where conditions that were selected previously and are not processed yet are listed. The current condition is displayed at the top of the Conditions list box. Marking and adding comments are related to the current condition.

The user can add comments in the Comments text box or edit the existing comments and use the Add Comment To Report check box if the new or edited comments have to be added to the report.

The Mark check boxes can be used to assign colors to some of the conditions. The marked color will be displayed for that condition in the Processed text box.

The user can go back to the upper level of conditions by using the Back button and unselect some of the previously selected conditions or select new conditions. Each click on the Back button will move one level up, until the first level is reached.

A sample investigation is presented in the following sequence of RSIT screen shots to illustrate the necessary steps to complete an investigation and the various features of the program.

The result of the "Open New Investigation" command is a display of the first level conditions. Two conditions, Driveways Collisions and Right-angle Collisions are selected from the Conditions list box (Figure 4-9), and the Proceed button is clicked. The 
first of the two conditions will be the starting of the path (set of conditions) that will be followed until a list of Proposed safety improvements is displayed.

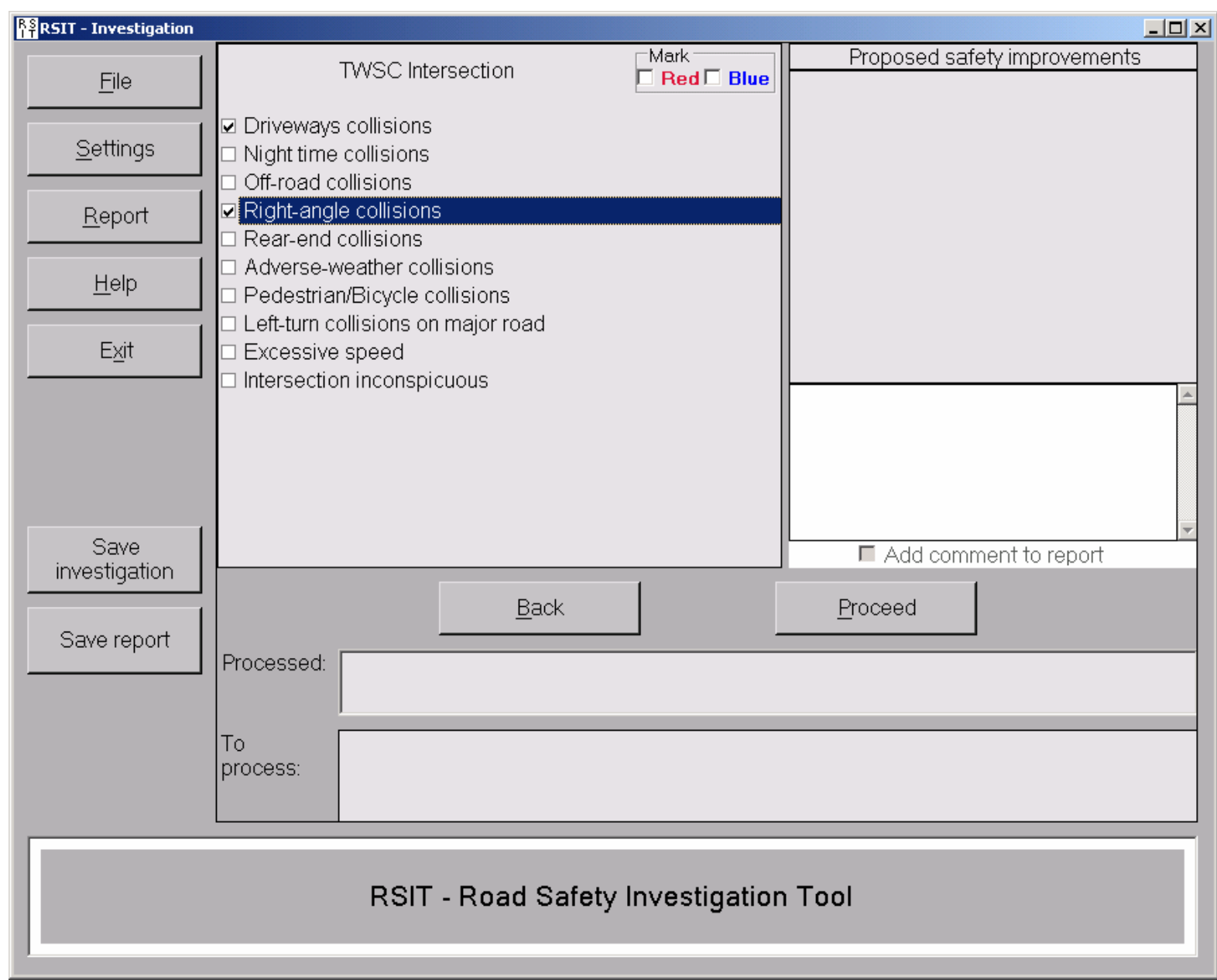

\section{Figure 4-9 Condition box}

The window is updated to show the next level of conditions corresponding to Driveways Collisions (Figure 4-10). In this case, it is only one condition, Driveways Close To Intersection, which is listed in the Conditions list box. The list is labeled with the condition from the upper level Driveways Collisions, which also is listed in the Processed text box. The second selected condition from the upper level, Right-angle Collisions is listed now in the To Process list box. The Proposed Safety Improvements list box and the Comment text box are empty. A comment (Comment 1 ) is added in the Comment text box and the Add Comment To Report check box is checked. This will be reflected in the report (Figure 4-20). To continue, the Proceed button is clicked. 


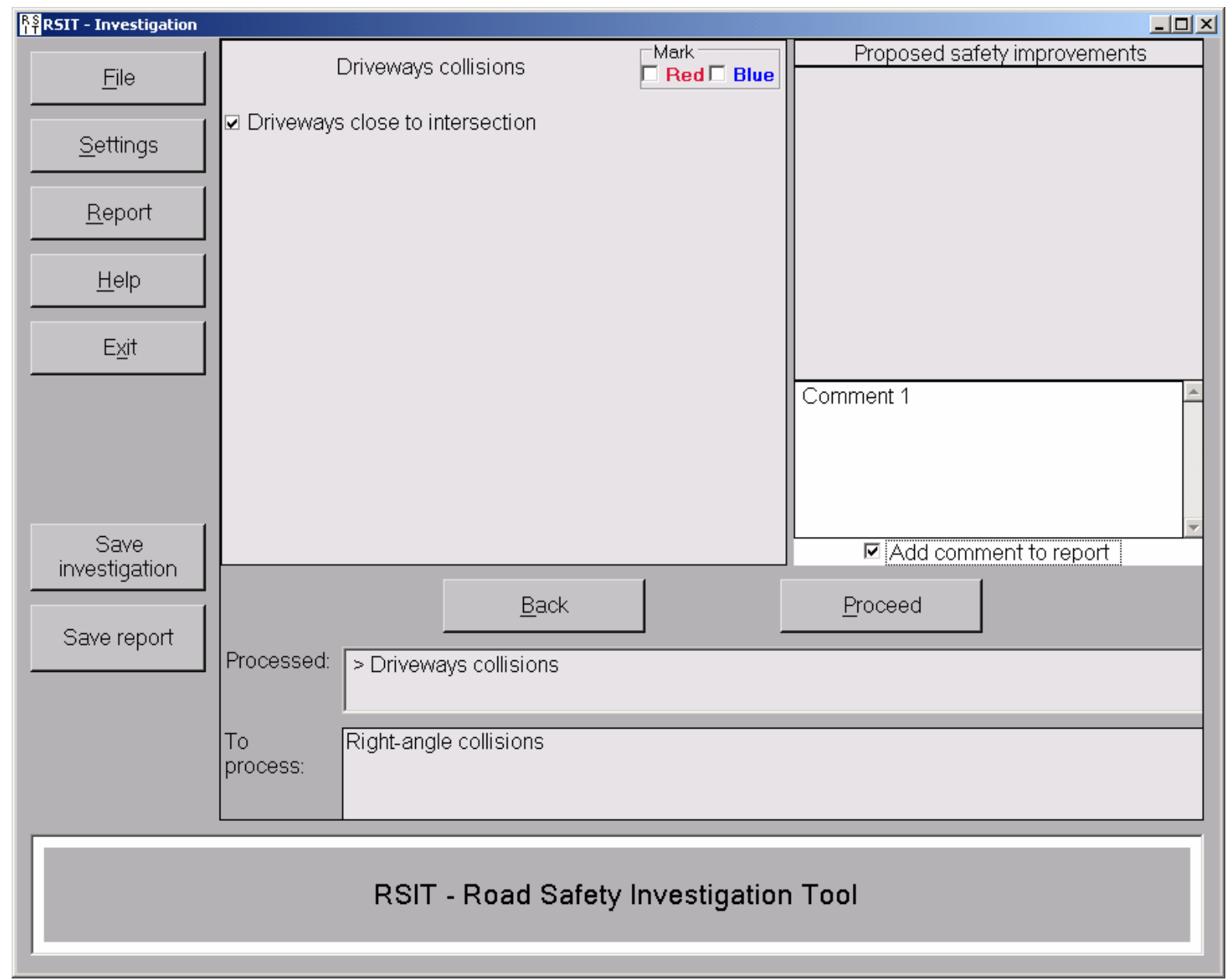

\section{Figure 4-10 Driveways Collisions condition}

The updated window has the Driveways Close To Intersection as a label for the Conditions list box and the list box is empty, and this condition name is also added to the Processed text box (Figure 4-11). The Proposed Safety Improvements list box has a list of seven items and three of them are selected by the user. An existing comment is displayed in the Comment text box and a second one (Comment 2) is added by the user. While the existing comment will always be added to the report, the comment added by the user is added only if the Add Comment check box is checked.

A set of conditions, the associated Proposed Safety Improvements and any existing and added comments are considered fully processed when the Processed button is clicked one more time. At this moment they will be visible in the Report window when 
using the View Report command. If no other condition is listed in the To Process list box, the investigation is considered completed. In this case, Right-angle Collisions condition will be processed next, after the Proceed button is clicked.

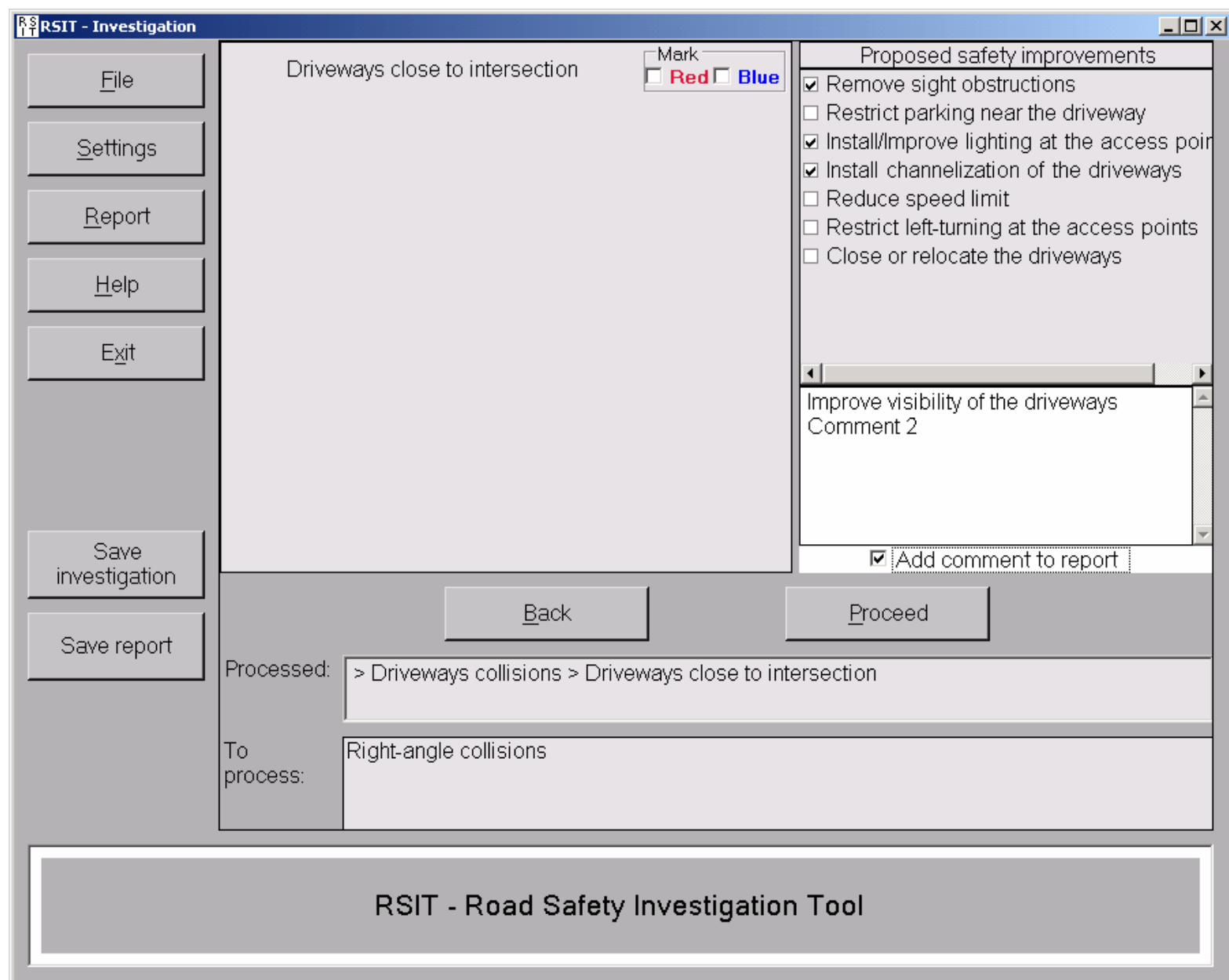

\section{Figure 4-11 Processed text box}

The next window shows two conditions listed in the Conditions list box, under the Rightangle Collisions label (Figure 4-12). The first one, Stop Sign Not Missing, is selected by the user. The Mark Red button is also checked, and it is used to mark the first selected condition in the Conditions list box. 


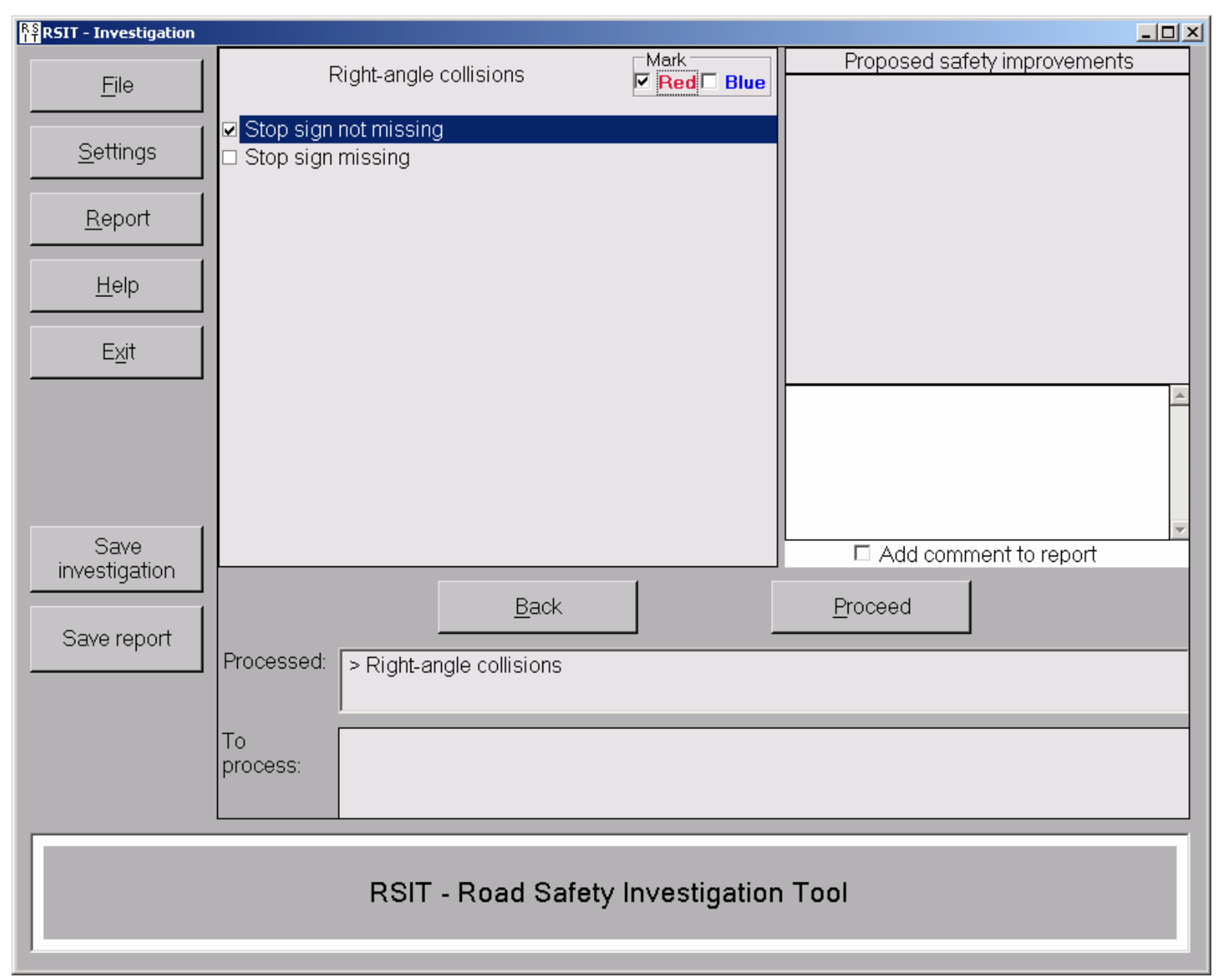

\section{Figure 4-12 Right-angle Collisions window}

The next window shows two conditions corresponding to the Stop Sign Not Missing condition, and the first one Stop Sign Visible is selected by the user (Figure 4-13). In the processed list, the current condition is marked in red, according to the Mark selection done previously. In this window, the Mark Blue is checked. 


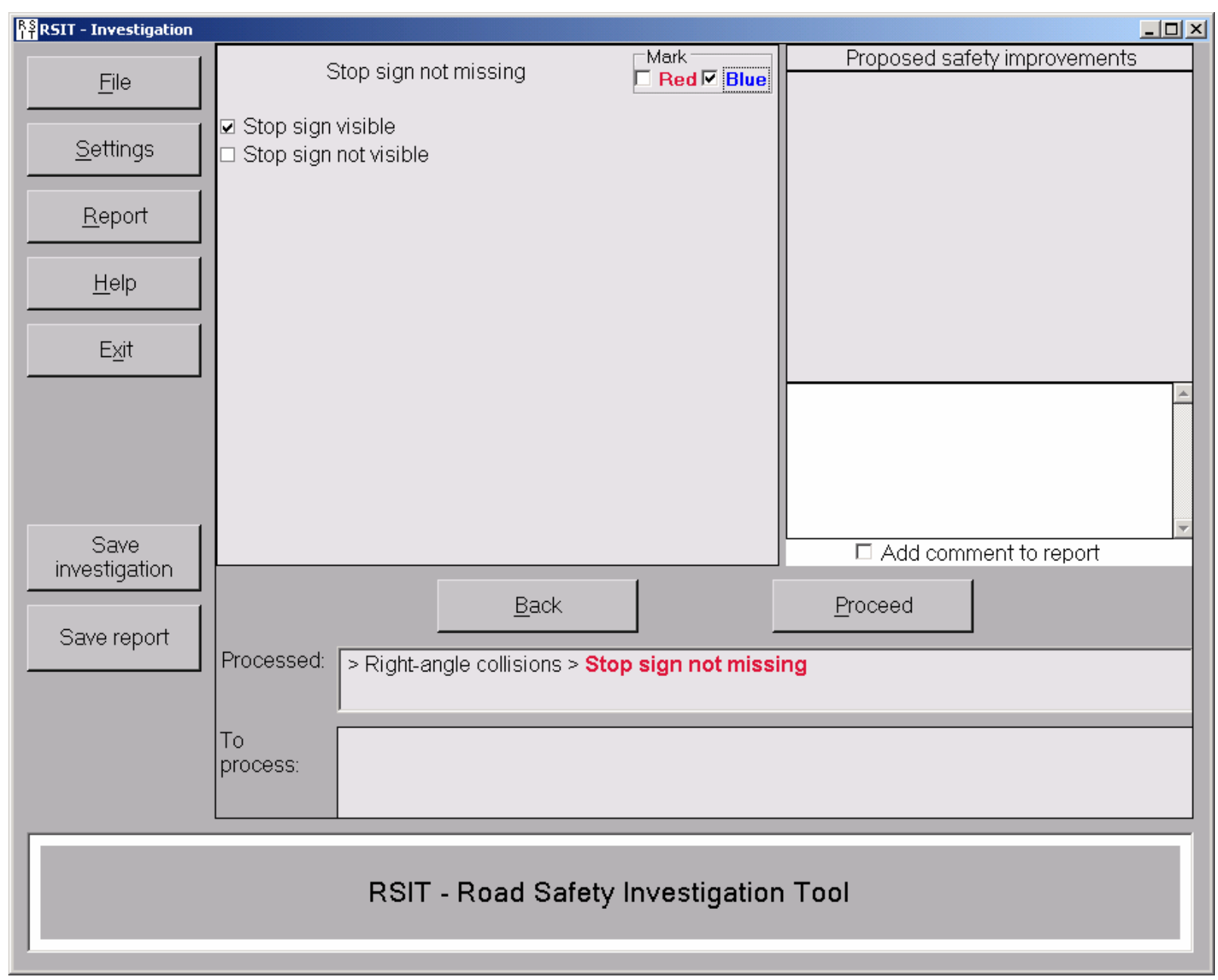

Figure 4-13 Stop Sign Not Missing window

The next window shows the last condition in the Processed text box colored in blue, as marked in the previous step (Figure 4-14). The Stop Sign Visible condition has a list of five associated conditions and the user is selecting three of them. The Proceed button moves to the next level, following the set of conditions determined by the first selected condition in the list of Conditions. 




Figure 4-14 Stop sign visible window

This window (Figure 4-15) shows two new conditions corresponding to Insufficient Sight Distance From The Minor Road condition, and the first one is selected by the user. The other two conditions selected at the upper level are added to the To Process list box. The investigation continues with the Proceed command. 




Figure 4-15 Insufficient Sight Distance From The Minor Road

The Poor Horizontal/Vertical Alignment condition does not have any subsequent conditions and it has a proposed safety improvement, which is selected by the user (Figure 4-16). The full list of conditions leading to this proposed safety improvement is listed in the Processed text box (five conditions). When Proceed is clicked, the investigation goes to the first condition listed in the To Process list box. 


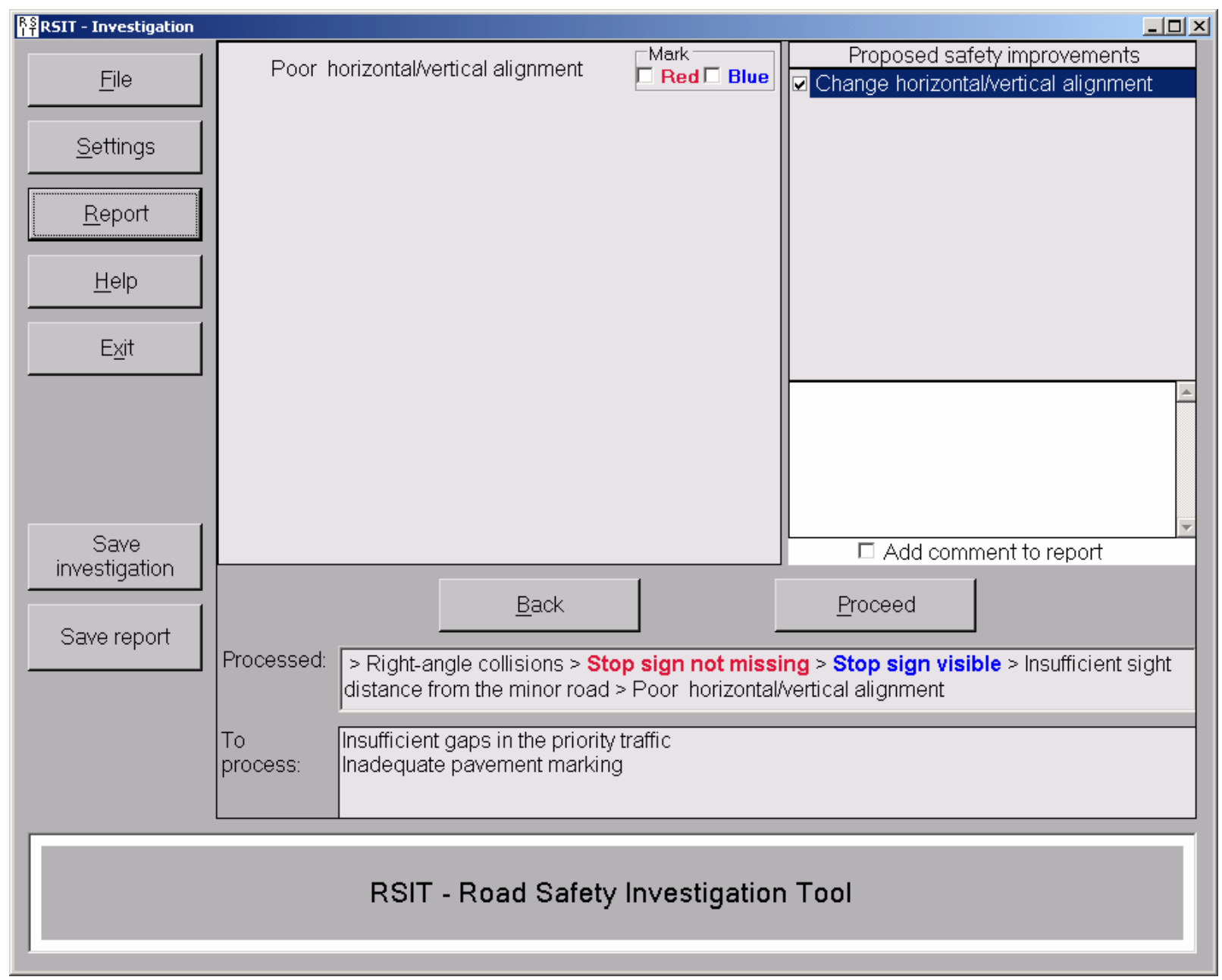

Figure 4-16 Poor horizontal/vertical alignment window

The Insufficient Gaps In The Priority Traffic condition has two proposed safety improvements (Figure 4-17). The To Process list box has one condition left. The Processed text box has two previously marked conditions still displayed in their respective colors.

If the user is not selecting any of the proposed safety improvements and the Proceed button is clicked, then a message box is displayed. 


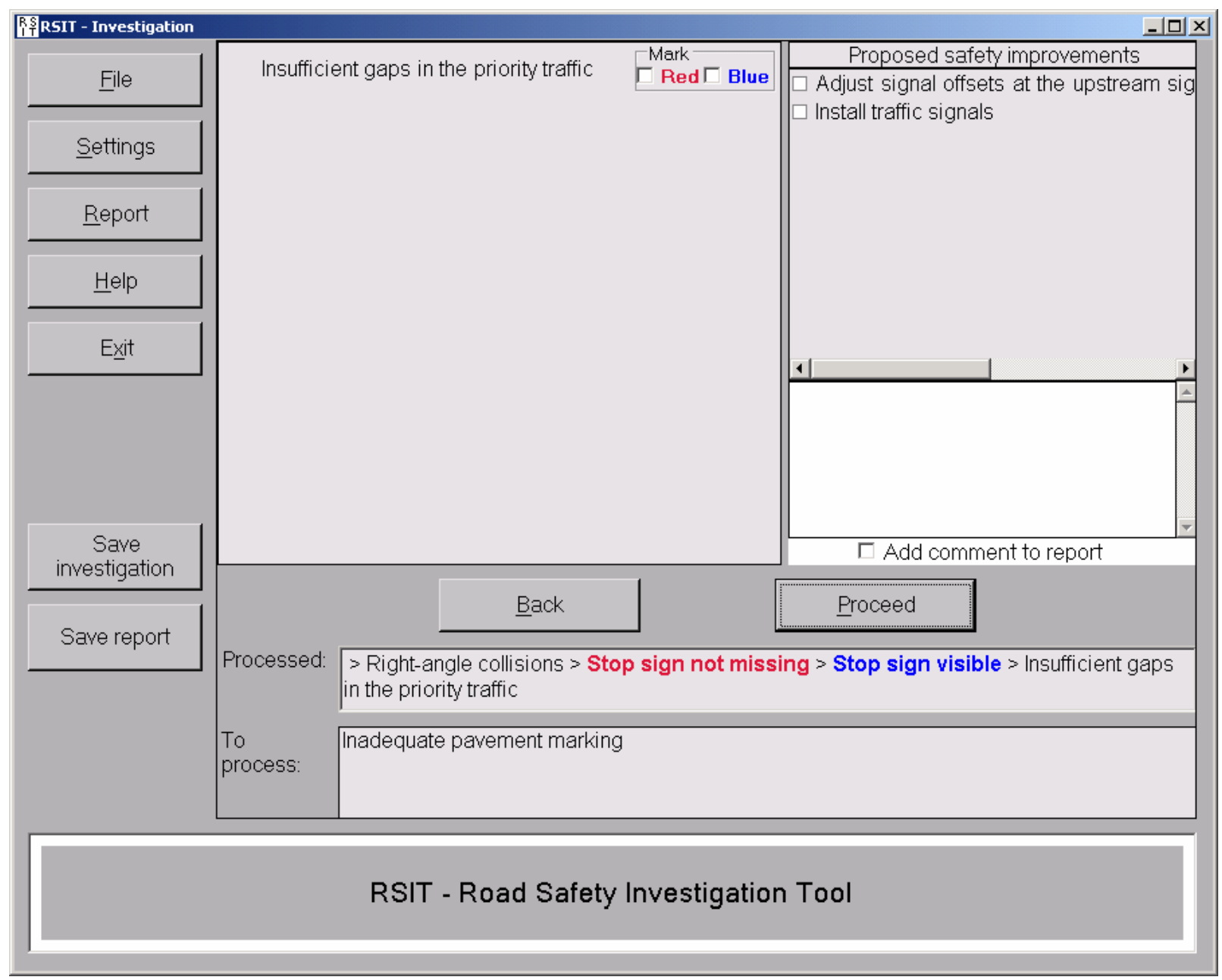

Figure 4-17 The Insufficient Gaps In The Priority Traffic condition

The message box gives the user the option of going back to select a safety improvement: "No proposed safety improvement was selected. Do you want to select one?” (Figure 4-18). If Yes is clicked, the window does not change and the user can make a selection and then proceed as usual.

If No is clicked, the current set of conditions (listed in the Processed text box) will not be saved in the report. If No is clicked and the Add Comment To Report is checked, then the current set of conditions is saved to the report.

After No is clicked in the message box, the first available condition in the To Process list box will be processed next. 


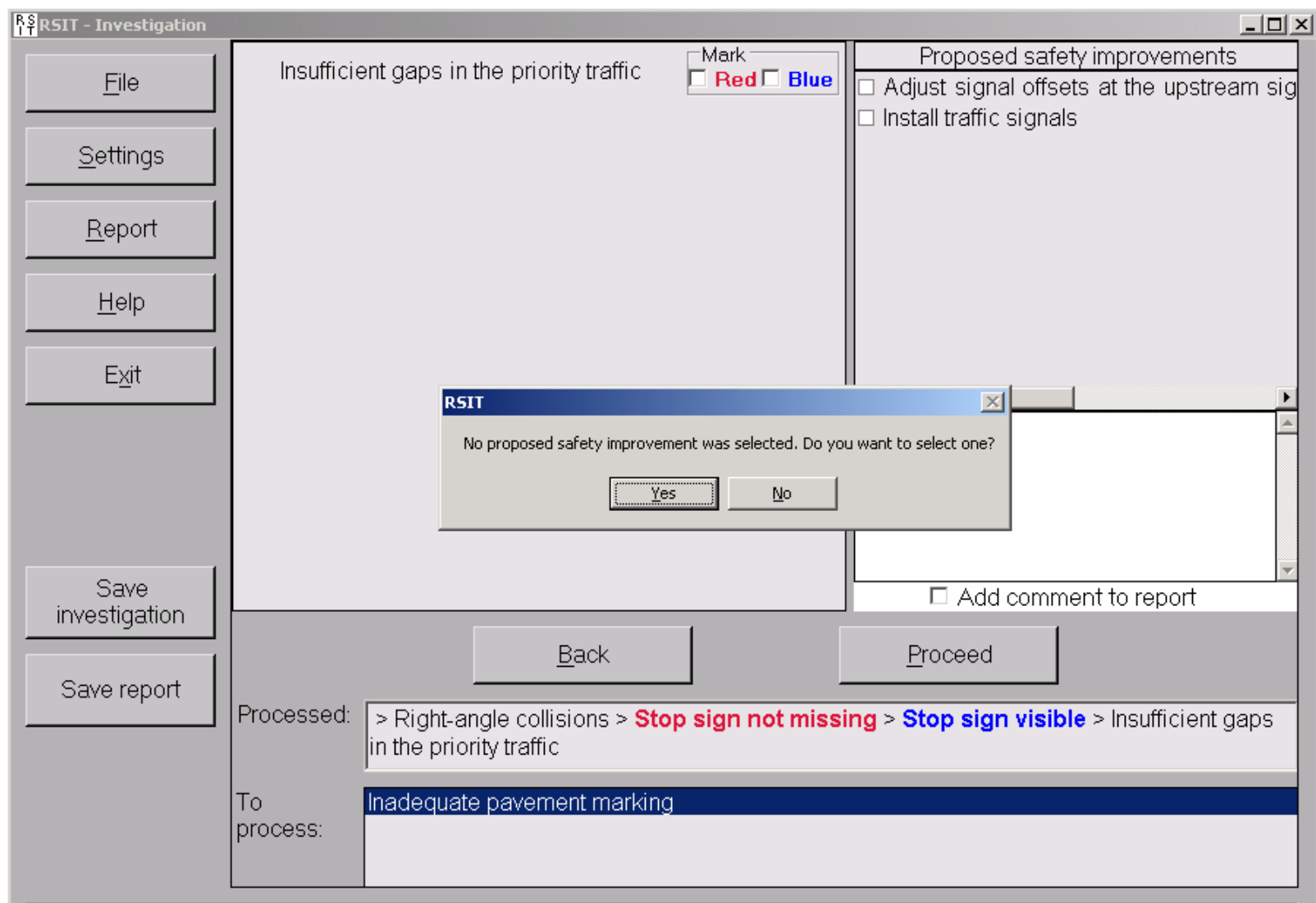

RSIT - Road Safety Investigation Tool

Figure 4-18 Warning window

The Inadequate Pavement Marking condition has a proposed safety improvement which is selected by the user (Figure 4-19). Because no other condition is listed in the To Process box, when Proceed is clicked the investigation is considered complete.

The user can go to upper levels using the Back button and make changes to previous selections and thus change the investigation. The changes will be reflected in the report and the investigation log. 




Figure 4-19 Inadequate Pavement Marking condition window

If the View Report command is used at the end of the sample investigation, then the report looks as in Figure 4-20, with three sets of conditions, some with additional comments (Conditions 1), and some with no proposed safety improvements (Conditions 2) or comments (Conditions 2 and 3). The report elements, (jurisdiction, facility type, location, etc.), should also be added in order to generate a complete report.

The evaluation of the tool is discussed in Chapter 5, which includes the user interfaces as well as the final knowledge testing. 


\section{Site Investigation Report}

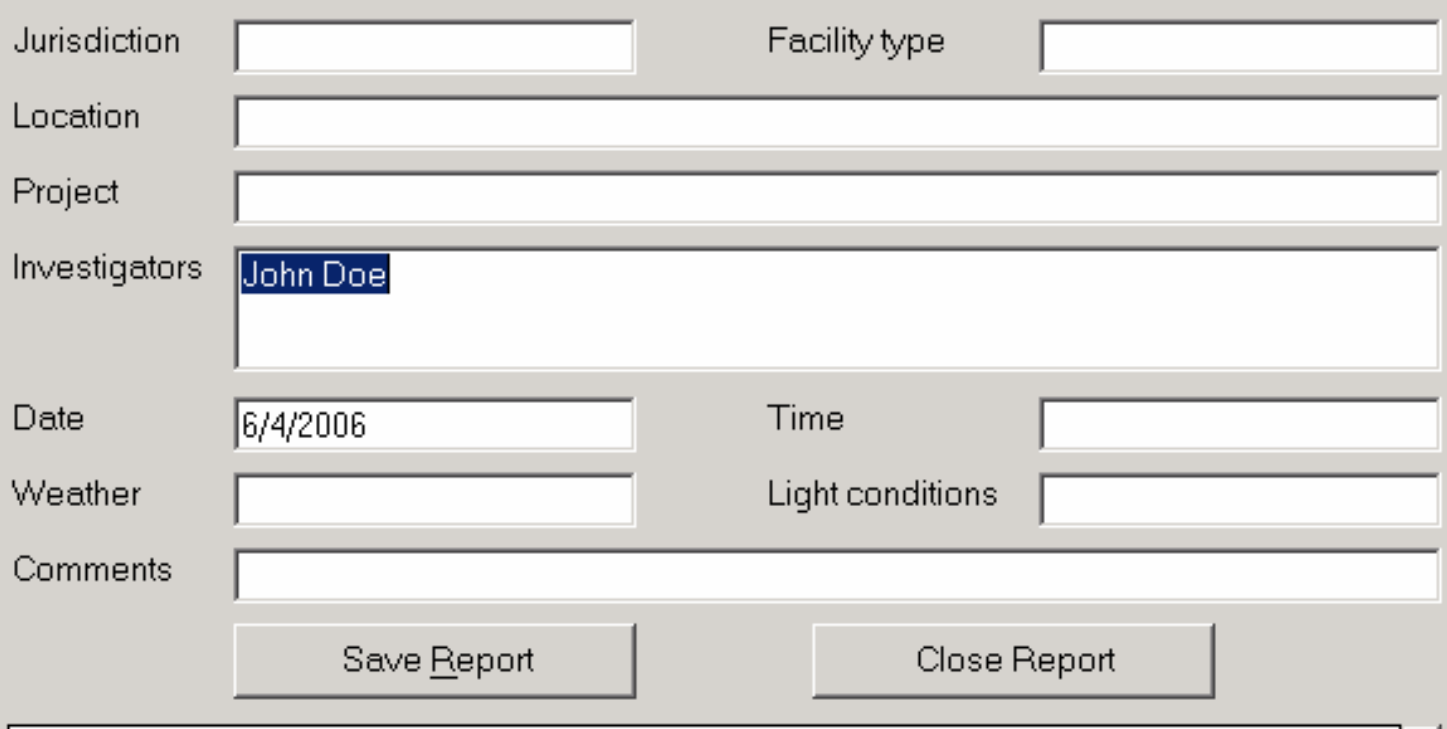

Conditions 1

Driveways collisions (Comment 1). Driveways close to intersection

Proposed safety improvements

1 Remove sight obstructions

2 Install//mprove lighting at the access points

3 Install channelization of the driveways

Comments

Improve visibility of the driveways

Comment 2

Conditions 2

Right-angle collisions, Stop sign not missing, Stop sign visible, Insufficient gaps in the priority traffic

Proposed safety improvements

Comments

Conditions 3

Right-angle collisions, Stop sign not missing. Stop sign visible, Inadequate pavement marking

Proposed safety improvements

1 Provide adequate delineation for left-turns at the intersection (markers or lines)

Comments

Figure 4-20 Report window 


\section{CHAPTER 5 METHOD EVALUATION}

The proposed methods included two major elements: the knowledge and the software implementation. By combining these two parts, we developed a very efficient and user-friendly tool. This tool gives the user flexibility during investigation process and an understanding of each individual phase. The user can update exiting knowledge or add personal comments or suggestions during site investigation. Furthermore, the proposed solution does not have to be the final solution and users can include thier own countermeasures which may be more adequate according to actual road conditions.

\subsection{The Evaluation Phases}

To verify the usefulness of the proposed tool, a testing phase was conducted. The testing and evaluation were based on a comparison of the findings from actual road safety investigations in Indiana with a road safety investigation (the same location) obtained using the RSIT. To evaluate the computer tool two road safety investigations (final report and real time investigations) were used:

- $\quad$ Cartersburg Road and CR 200 South, Hendricks County, Indiana

- $\quad$ Locust Rd. and Ireland Rd, St. Joseph County, Indiana

The evaluation process was divided into three phases.

The first phase included extracting crash data information from the road safety investigation final report (LTAP); an analysis of the crash pattern, time of the accident, and additional information obtained from the crash database and actual environmental condition (i.e., two-way stop controlled intersection, road names, AADT, (...)). To avoid bias, the previous findings from both investigations were not analyzed. Before the site investigation with RSIT we were informed that one of the intersections (Cartersburg Road and CR 200 South, Hendricks County, Indiana) was changed and updated to a fourway stop control intersection. Regardless of this change, for the testing phase (mostly for the potential code errors), we decided to evaluate this intersection by using the RSIT software. 
The first stage is similar to the preliminary analysis stage in a RSA. Findings from this phase can be applied directly to the RSIT software and saved for future site investigations.

The second phases included an on-site investigation, where additional data were collected and applied to the RSIT software. Additional data and comments were added to the final report. The pictures and videos to visually specify the safety problems and concerns were collected. During this phase the final propose solutions were obtained and the preview of the final report was proposed.

The last stage included post-analysis, which summarized the final conclusions included in the report, as well as a comparison with the previous road safety report.

Because one of the advantages of the software was the assumption that it could be used by individuals without significant transportation background, the Purdue part-time student worker for this research project was used in the site investigation of the intersection between Locust Rd. and Ireland Rd, St. Joseph County, Indiana. Additionally, both intersections were investigated by the author of this report.

\subsection{The RSIT evaluation}

\subsubsection{Cartersburg Road and CR 200 South, Hendricks County, Indiana}

The intersection of Cartersburg Road and the CR 200 South is an actual four-way stop controlled intersection. This intersection is located on the southern limits of the Town of Danville in central Hendricks County (Figure 5-1). 


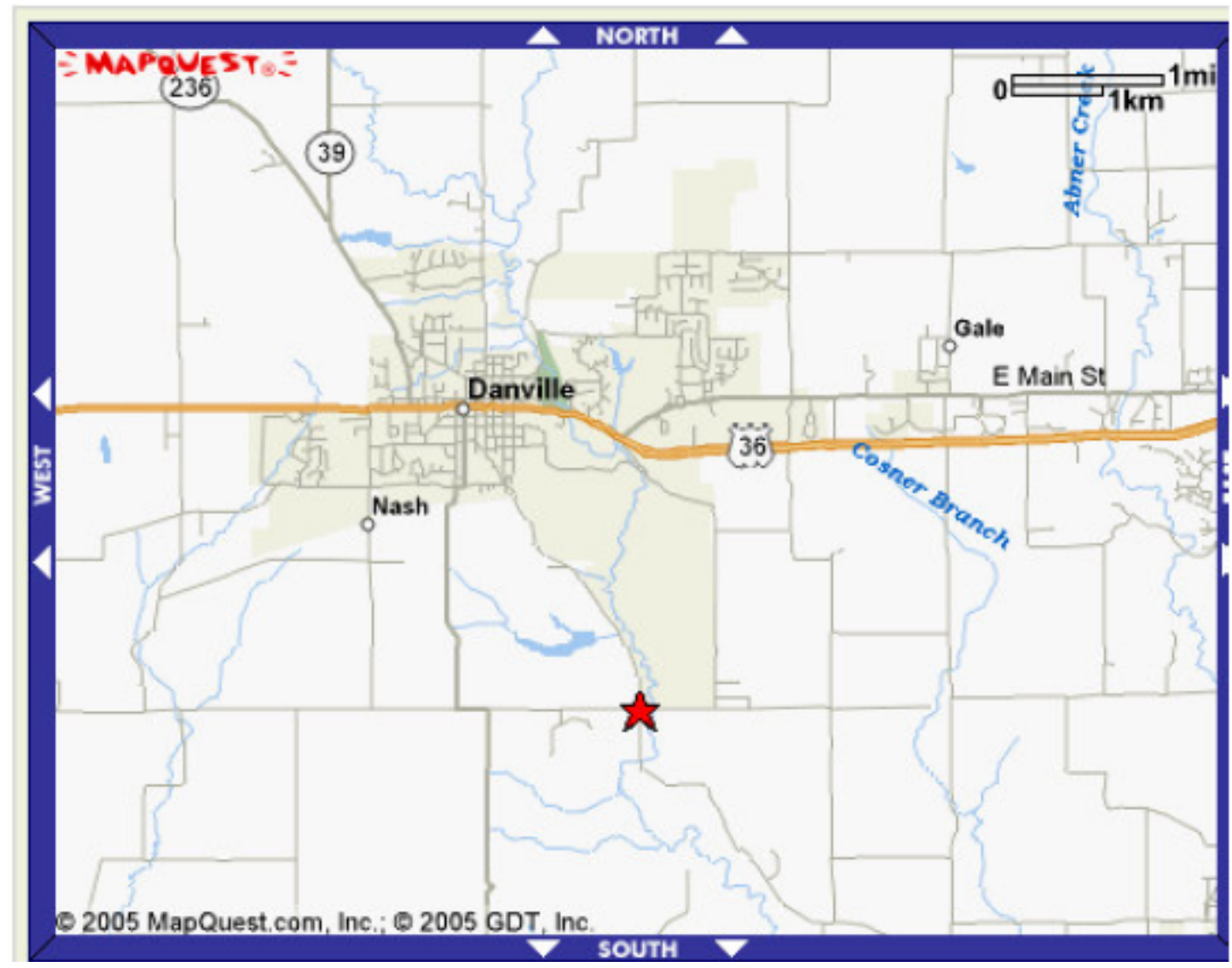

Figure 5-1 Location: Cartersburg Road and CR 200 South

Since as a result of a road safety investigation on January 20 2005, this intersection was converted from a two-way stop controlled intersection into a four-way stop controlled intersection, this part of the evaluation was based on the assumption that the two-way stop control type was not changed (only for software testing phases). More powerful findings were obtained from the second intersection site investigation.

Before the site investigation was conducted, the crash database was analyzed. Available crash data (INDOT, LTAP) indicated that during a two-year period (20012002) eight crashes occurred, including one fatal crash. The crash types were as follow:

- 5 total right-angle collision, included 1 fatal,

- 1 left-turn collision,

- 2 run-off road collision,

A detailed description of the crash type is shown in Table 5.1. (LTAP final report)

Table 5-1 Crash type and severity (LTAP) 


\begin{tabular}{|l|c|c|c|c|}
\hline \multicolumn{7}{|c|}{$\begin{array}{c}\text { Crash Type and Severity } \\
\text { Cartersburg Road and CR 200 South }\end{array}$} \\
\hline Crash Type & PDO & Injury & Fatality & Total \\
\hline Right Angle & 3 & 1 & 1 & 5 \\
\hline Left Turn & 0 & 1 & 0 & 1 \\
\hline Run Off & 2 & 0 & 0 & 2 \\
\hline Totals & $\mathbf{5}$ & $\mathbf{2}$ & $\mathbf{1}$ & $\mathbf{8}$ \\
\hline
\end{tabular}

It was found that the fatal crash occurred on January 3, 2001, which for this location indicated a high probability of bad weather conditions (lacking that data, we based this on assumption). One of the crashes (right-angle) occurred during nighttime conditions: time of accident 9:00 pm on January 22, 2002. Using all collected data, the preliminary analysis was obtained by using the RSIT software (Figure 5-2).

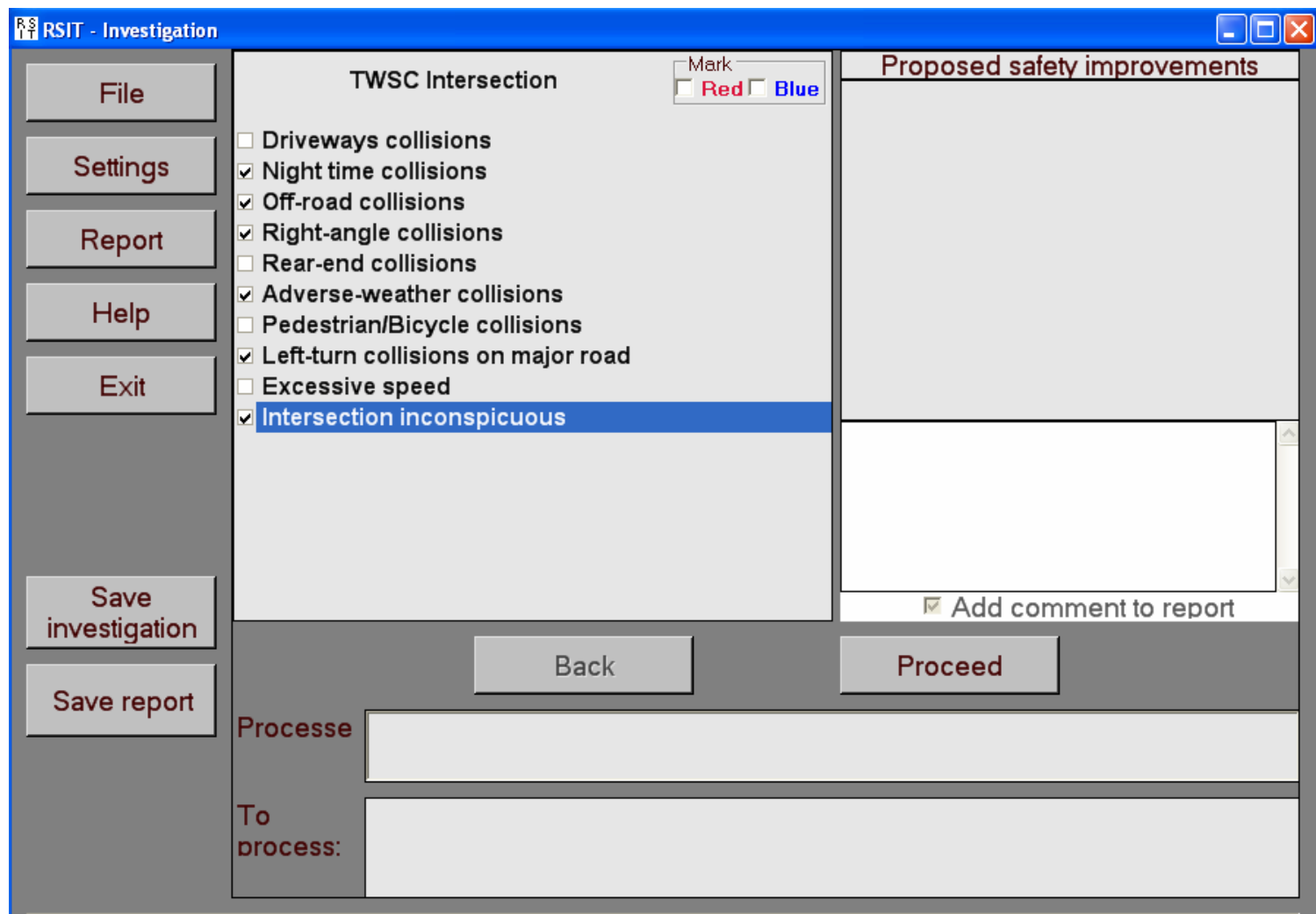

\section{RSIT - Road Safety Investigation Tool}

Figure 5-2 The RSIT - preliminary analysis for Cartersburg Road and CR 200 South 
The next phase was the site investigation, which was conducted on May 26, 2006 at 10:00 AM. The detailed investigation information is shown in Appendix G. The RSIT was run and by collecting additional data, the final proposed solutions with comments were obtained (Figure 5-3).

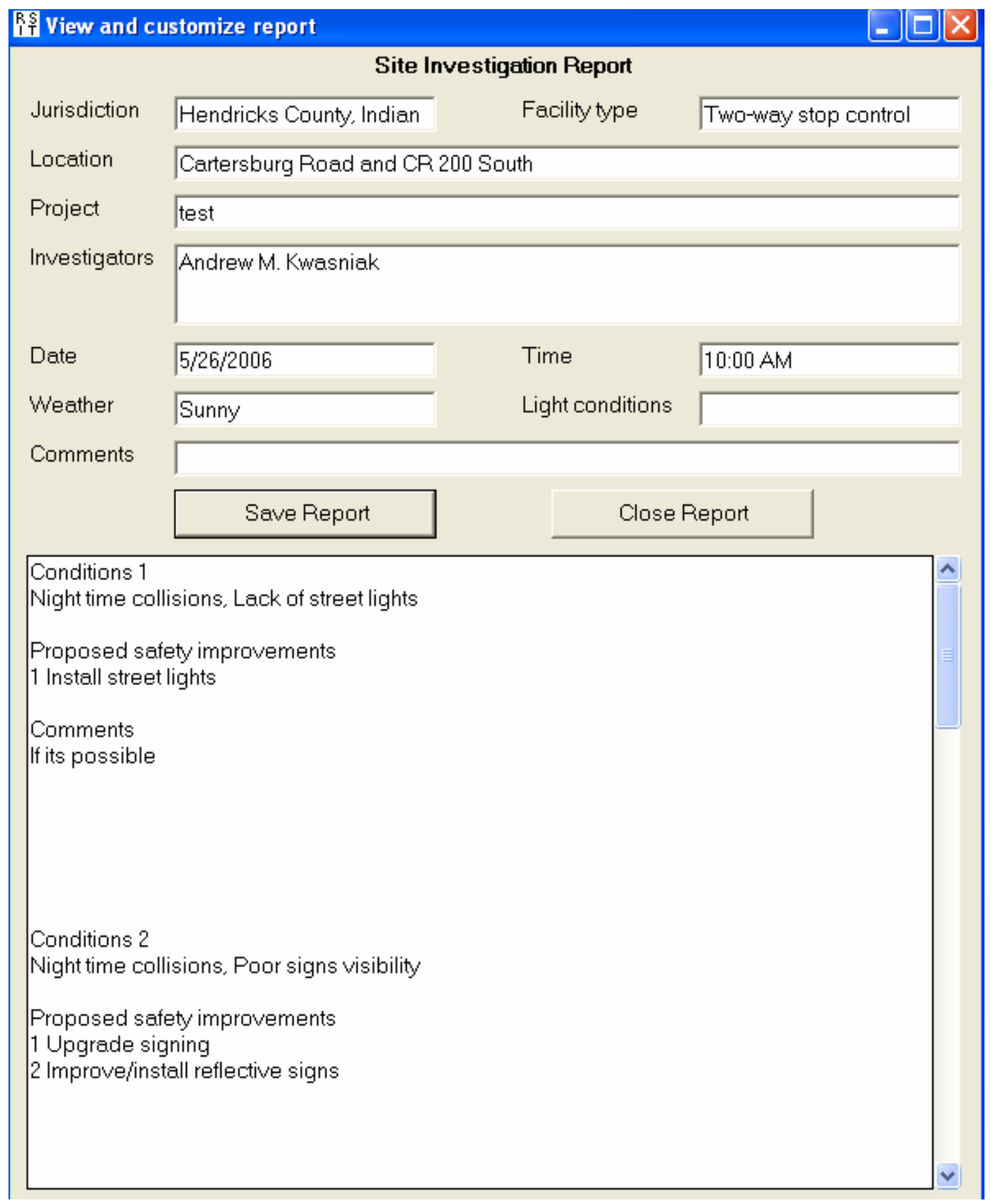

Figure 5-3 The RSIT report 1 
The comparison between the findings from the road safety investigation and the investigation with the RSIT software is shown in Table 5-2.

Table 5-2 The investigation team vs. the RSIT Cartersburg Road and CR 200 South, Hendricks County, Indiana

The RSA without THE RSIT

- Prepare and pass an ordinance to change the intersection to four-way stop controlled.

- Increase the size of the stop signs to a minimum of 30-inches. In addition, include the "all-way" supplementary plaque to the stop signs. Add supplementary stop signs on the left side of each approach for conspicuity.
The RSA with the RSIT

[Nofindings]

Conditions 4

Right-angle collisions, Stop sign not missing, Stop sign not visible, Improperly

stop sign maintained

Proposed safety improvements

1 Replace, repair, or clean the sign

Comments:

Increase visibility of the stop sign

Conditions 7

Intersection inconspicuous, Advance warning sign posted, Warning sign poorly visible/recognizable, Improperly warning sign maintained

Proposed safety improvements

1 Replace, repair, or clean the warning signs

Conditions 8

Intersection inconspicuous, Advance warning sign posted, Warning sign poorly visible/recognizable, Warning sign obstruction

Proposed safety improvements

1 Relocate the sign to make it visible

2 Remove the object obstructing sight of the warning sign

Comments

Trees can obstruct the signs 
- Obtain a right of entry from the property owner on the southeast quadrant to perform clearing in order to provide adequate intersection sight distance.

- Reconstruct Cartersburg Road from the existing intersection to approximately 1100 linear feet north of the existing intersection. Reconstruction is required in order to eliminate the significant vertical grade change that currently limits the intersection sight distance and stopping sight distance. Plans for reconstruction should consider the required turn radius needed by a truck under stopped condition

[No findings]
[No findings]

Conditions 6

Left-turn collisions on major road, Undivided highway, Poor visibility of opposite vehicles, Poor horizontal/vertical alignment

Proposed safety improvements

1 Change horizontal/vertical alignment (See picture)

Conditions 1

Night time collisions, Lack of street lights

Proposed safety improvements

1 Install street lights

Comments

If it's possible

Conditions 2

Night time collisions, Poor signs visibility

Proposed safety improvements

1 Upgrade signing

2 Improve/install reflective signs

Conditions 3

Off-road collisions, Inadequate shoulders width

Proposed safety improvements 1 Increase width of the shoulders

Comments

No shoulder present on the Cartersburg Road toward North were two run-off collision occur. (See attach picture)

Conditions 5

Adverse-weather collisions, Snow/Slush/Ice 


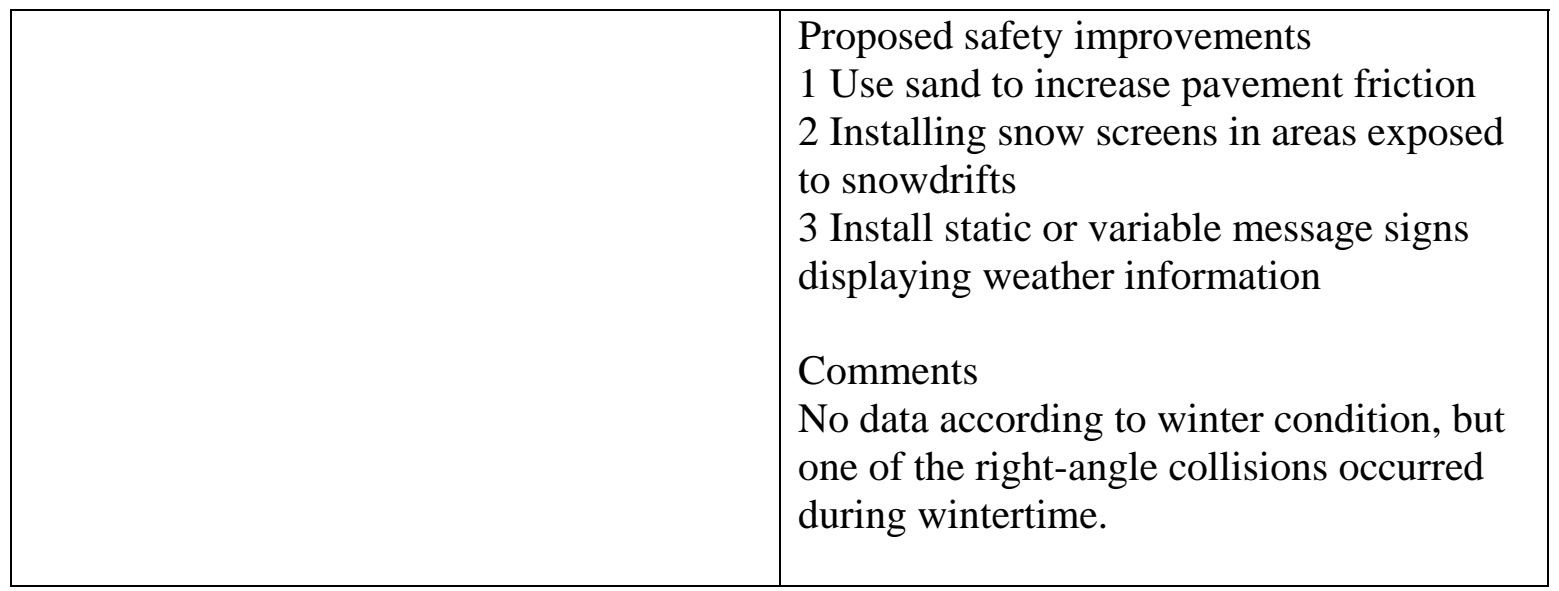

This final report and comparison between the findings from the RSA without the RSIT and with RSIT indicate similarities in the proposed solution. Additionally, the RSIT obtained possible solutions for adverse weather condition (the one fatal crash occurred on January 3, 2001), nighttime collision (one of the right-angle crashes occurred at 9:00 pm during the winter season), and the off-road collision with proposed upgrade shoulders. The RSIT does not propose changing this intersection into a four-way stop controlled intersection. It must be remembered that this site investigation with the RSIT software was done on already upgraded intersection and it was base on some assumptions. More detailed and more useful evaluation was obtained in the next safety investigation on Locust Rd. and Ireland Rd, St. Joseph County, Indiana.

\subsubsection{Locust Rd. and Ireland Rd, St. Joseph County, Indiana}

The intersection of Locus Road and Ireland Road is located in St. Joseph County, Indiana. It is a two-way stop controlled intersection. The stop control intersection is on the Locust Road. The major approach is Ireland Road, and the posted speed limit 55 mph. The location of this intersection is shown in Figure 5-4. 


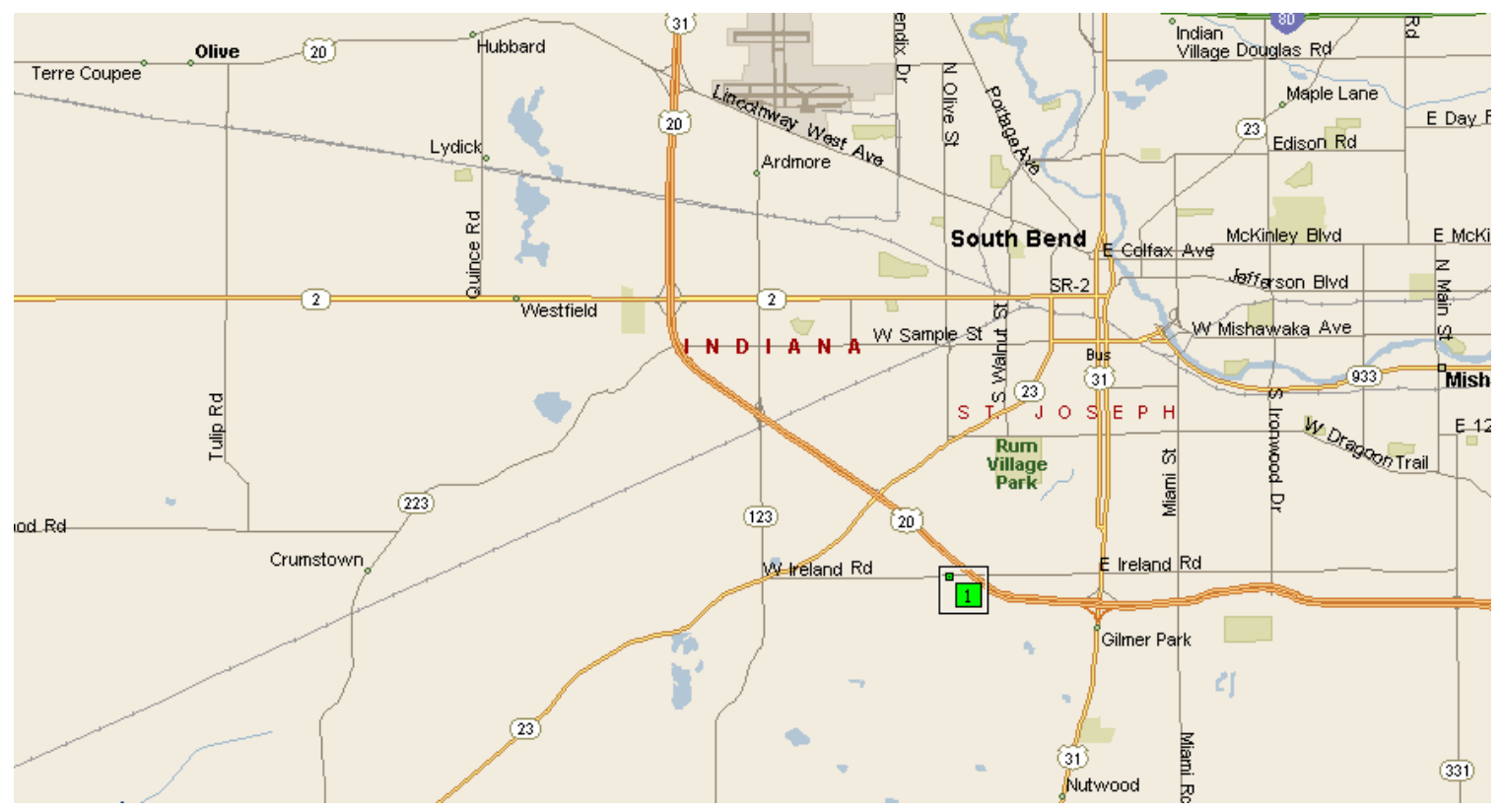

Figure 5-4 Location: Locust Rd. and Ireland Rd

The analysis of the crash database (LTAP) information from 2001 and 2003-2004 (crash data from 2002 was not adequate for actual conditions due to road construction) indicated a total of 18 crashes. Around $44 \%$ of all crashes occurred during night/dusk/dawn conditions. Right-angle collision was the most significant crash type on the analyzed intersection. The summary of the crash report is show in Table 5-3 (LTAP). The findings from the RSA which was obtained by the safety specialists were not implemented. This situation created a perfect occasion for testing the proposed computer tool.

Table 5-3 Crash type and severity (LTAP)

Locust Rd. @ Ireland.Rd. Intersection: 3-Year Crash Type Summary (2001, 2003-2004)

\begin{tabular}{|l|l|l|l|l|l|l|l|l|l|l|l|l|l|l|}
\hline Crash Type & \multicolumn{3}{|c|}{ Personal Injury } & \multicolumn{3}{c|}{ Property Damage } & \multicolumn{3}{c|}{ Fatality } & \multicolumn{3}{c|}{ Total } \\
\hline & 2001 & 2003 & 2004 & 2001 & 2003 & 2004 & 2001 & 2003 & 2004 & 2001 & 2003 & 2004 \\
\hline Rear End & & & & & 2 & & & & & & 2 & \\
\hline Right Angle & 1 & & 2 & & 2 & 2 & & & 1 & 1 & 2 & 5 \\
\hline Side Swipe & & & & & 1 & & & & & & 1 & \\
\hline $\begin{array}{l}\text { Turning } \\
\text { Movement }\end{array}$ & & & 1 & & & 2 & & & & & & 3 \\
\hline Other & & & 1 & 1 & & 2 & & & & 1 & & 3 \\
\hline Totals & 1 & & 4 & 1 & 5 & 6 & & & 1 & 2 & 5 & 11 \\
\hline
\end{tabular}


The investigation process with the RSIT software was conducted by two Purdue students, the author of this report and a person with no advanced knowledge of the traffic safety area. The explanation of the functionality of the software to the student without transportation background required approximately 30 minutes. After that time she was able to adequately use the RSIT software. The final summary of this investigation was compared with findings from the RSA without the RSIT tool. The site investigation with the RSIT was obtained by the author of this report and by the student without advanced transportation knowledge.

Utilizing all the collected data, the preliminary analysis was obtained with the RSIT software (Figure 5-5) by the author of this report.

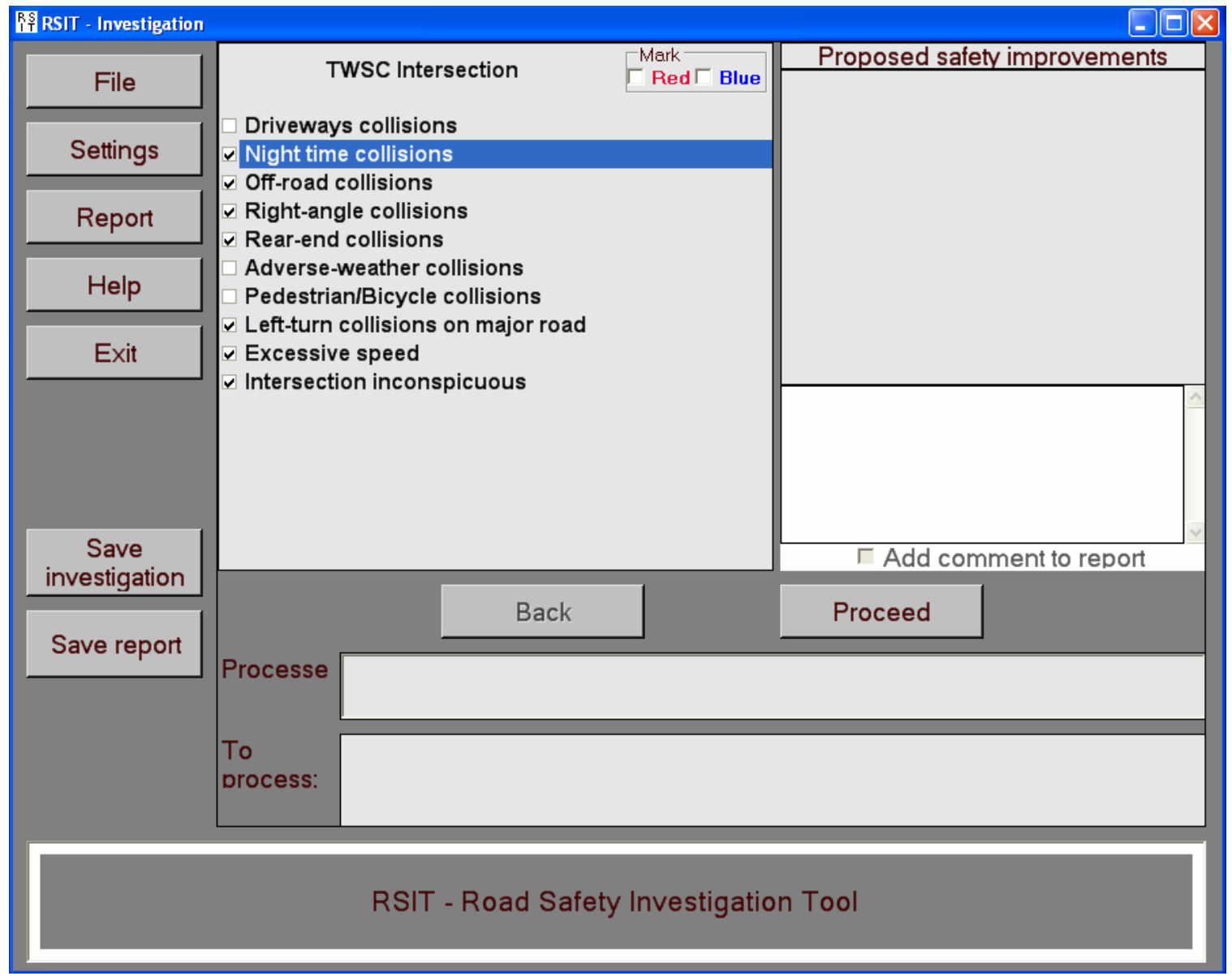

Figure 5-5 The RSIT - preliminary analysis for Locust Rd. and Ireland Rd

The site investigation was conducted on May 26, 2006 at 4:00 PM. The detailed information is shown in the final report from the investigation. The RSIT was run and by 
collecting additional data, the final proposed solutions with comments were obtained (Figure 5-6).

\section{RS View and customize report}

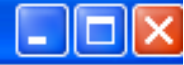

\section{Site Investigation Report}



Conditions 1

Night time collisions, Lack of street lights

Proposed safety improvements

1 Install street lights

Conditions 2

Night time collisions, Poor signs visibility

Proposed safety improvements

1 Upgrade signing

2 Improve/install reflective signs

Conditions 3

Off-road collisions, Inadequate pavement marking

Proposed safety improvements

1 Install reflectorized pavement marking

Figure 5-6 The RSIT report 2 
The final findings from this site investigation are shown in Appendix H. The comparison between the findings from the RSA and the investigation with the RSIT software by the author of this report is presented in Table 5-4.

Table 5-4 The RSA team vs. the RSIT Locus Road and Ireland Road is located in St. Joseph County, Indiana

The RSA without THE RSIT - Deficiencies in the geometric configuration on the
north leg of Locust Road

- $\quad$ Right-of-Way Acquisition \& Services

- Mobilization/Demobilization \& Clearing Right-of-Way

- Common Excavation \& Grading

- Pavement Replacement \& Widening

- Drainage Improvements

- Signage Upgrade, Pavement Marking Upgrade, Intersection Lighting

- Existing Municipal Water relocation

- Landscape Restoration \& Maintenance of Traffic
The RSA with the RSIT

Conditions 5

Right-angle collisions, Stop sign not missing, Stop sign visible, Insufficient sight distance from the minor road Proposed safety improvements

Comments

Increase visibility toward west Ireland $\mathrm{Rd}$. from the North side of the Locust Rd. (See picture) Problem with vertical alignment

Conditions 8

Right-angle collisions, Stop sign not missing, Stop sign not visible, Improperly stop sign maintained

Proposed safety improvements 1 Replace, repair, or clean the sign

Conditions 9

Right-angle collisions, Stop sign not missing, Stop sign not visible, Stop sign obstruction

Proposed safety improvements 1 Remove the object obstructing the sight of the stop sign

Comments

See picture

Conditions 12

Intersection inconspicuous, No advance warning sign 


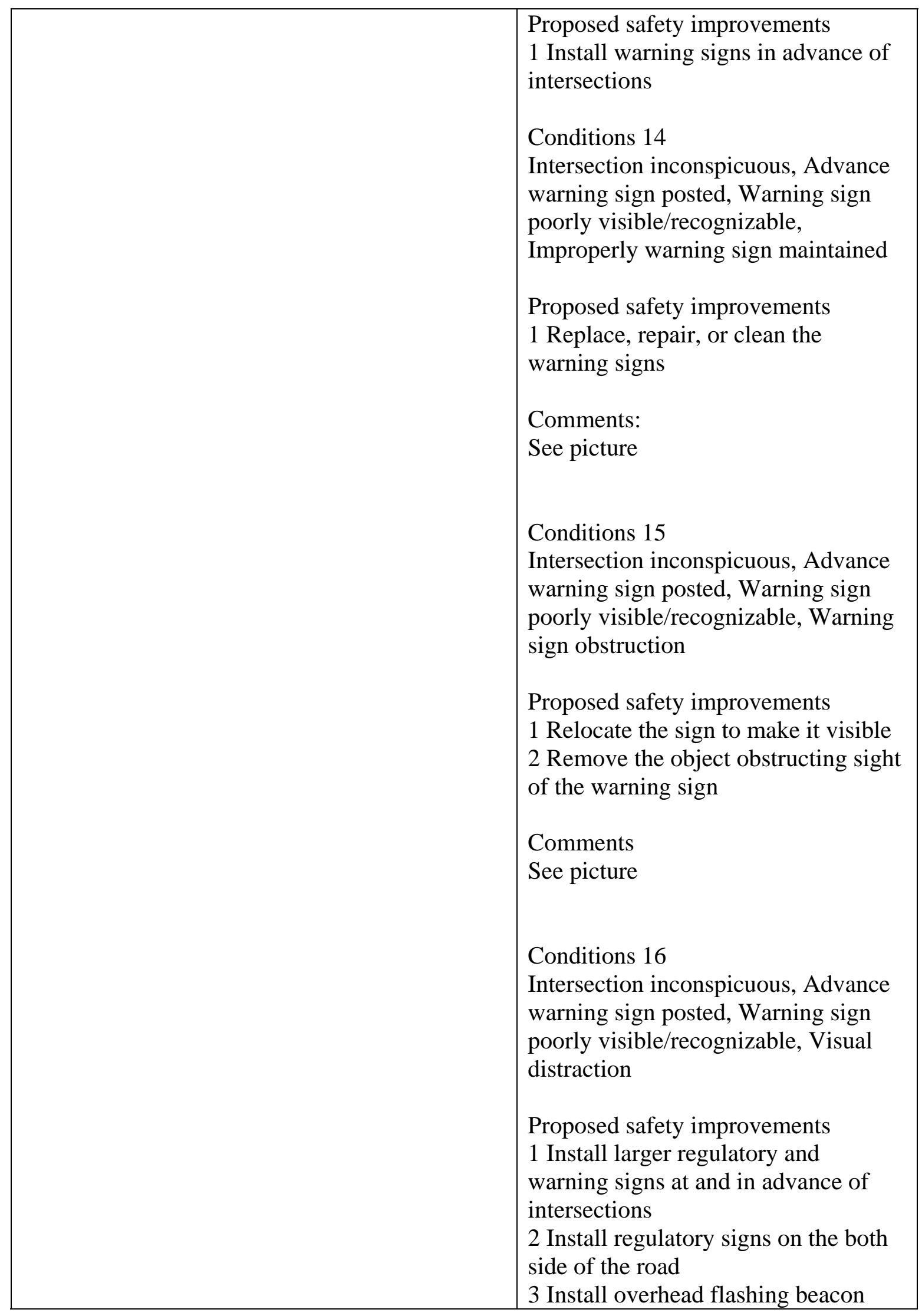




\begin{tabular}{|c|c|}
\hline & $\begin{array}{l}\text { lights } \\
4 \text { Provide on-pavement horizontal } \\
\text { signing }\end{array}$ \\
\hline - Installation of lighting & $\begin{array}{l}\text { Conditions } 1 \\
\text { Night time collisions, Lack of street } \\
\text { lights } \\
\text { Proposed safety improvements } \\
1 \text { Install street lights } \\
\text { Conditions } 2 \\
\text { Night time collisions, Poor signs } \\
\text { visibility } \\
\text { Proposed safety improvements } \\
1 \text { Upgrade signing } \\
2 \text { Improve/install reflective signs } \\
\text { Comments } \\
\text { The investigation should take place } \\
\text { additional during night time } \\
\text { condition. But because of time } \\
\text { possibility we assume according to } \\
\text { shape of the signs that this will be an } \\
\text { issue. }\end{array}$ \\
\hline - Addition of roadway illumination & $\begin{array}{l}\text { Conditions 1, conditions } 2 \\
\text { plus additional: } \\
\text { Conditions } 3 \\
\text { Off-road collisions, Inadequate } \\
\text { pavement marking } \\
\\
\text { Proposed safety improvements } \\
1 \text { Install reflectorized pavement } \\
\text { marking }\end{array}$ \\
\hline [No findings] & $\begin{array}{l}\text { Conditions } 11 \\
\text { Left-turn collisions on major road, } \\
\text { Inadequate pavement marking } \\
\text { Proposed safety improvements } \\
1 \text { Provide adequate turning markers or } \\
\text { pavement markings }\end{array}$ \\
\hline
\end{tabular}




\begin{tabular}{|c|c|}
\hline [No findings] & $\begin{array}{l}\text { Conditions } 4 \\
\text { Off-road collisions, Inadequate } \\
\text { shoulders width } \\
\text { Proposed safety improvements } \\
1 \text { Increase width of the shoulders } \\
\text { Comments } \\
\text { Especially for the Ireland road toward } \\
\text { East. (See picture) Shoulders are not } \\
\text { consistent }\end{array}$ \\
\hline
\end{tabular}

Additionally, the safety investigation by the "non-expert" student was obtained and the comparison between the RSA without RSIT tool is shown in Table 5-5.

\section{Table 5-5 The RSA team vs. the RSIT (“non-expert” student) Locus Road and Ireland Road is located in St. Joseph County, Indiana}

\section{The RSA without THE RSIT} - Deficiencies in the geometric configuration on the
north leg of Locust Road

- $\quad$ Right-of-Way Acquisition \& Services

- Mobilization/Demobilization \& Clearing Right-of-Way

- Common Excavation \& Grading

- Pavement Replacement \& Widening

- Drainage Improvements

- Signage Upgrade, Pavement Marking Upgrade, Intersection Lighting

- Existing Municipal Water relocation

- Landscape Restoration \& Maintenance of Traffic

- Improvement in the intersection advance warning

\section{The RSA with the RSIT}

Conditions 6

Right-angle collisions, Stop sign not missing, Stop sign visible, Insufficient sight distance from the minor road, Poor horizontal/vertical alignment

Proposed safety improvements

1 Change horizontal/vertical alignment

Comments

Locust road - toward South
Conditions 10

Intersection inconspicuous, Advance warning sign posted, Warning sign poorly visible/recognizable, 


\begin{tabular}{|c|c|}
\hline & $\begin{array}{l}\text { Improperly warning sign maintained } \\
\text { Proposed safety improvements } \\
1 \text { Replace, repair, or clean the } \\
\text { warning signs } \\
\text { Comments } \\
\text { All approach signs. } \\
\text { Conditions } 11 \\
\text { Intersection inconspicuous, Advance } \\
\text { warning sign posted, Warning sign } \\
\text { poorly visible/recognizable, Warning } \\
\text { sign obstruction } \\
\text { Proposed safety improvements } \\
1 \text { Relocate the sign to make it visible } \\
2 \text { Remove the object obstructing sight } \\
\text { of the warning sign } \\
\text { Comments } \\
\text { On the main road toward East. } \\
\text { Conditions } 12 \\
\text { Intersection inconspicuous, Advance } \\
\text { warning sign posted, Warning sign } \\
\text { poorly visible/recognizable, Visual } \\
\text { distraction } \\
\text { Proposed safety improvements } \\
1 \text { Install larger regulatory and } \\
\text { warning signs at and in advance of } \\
\text { intersections } \\
2 \text { Install regulatory signs on the both } \\
\text { side of the road } \\
3 \text { Install overhead flashing beacon } \\
\text { lights } \\
4 \text { Provide on-pavement horizontal } \\
\text { signing } \\
\text { (a) }\end{array}$ \\
\hline - Installation of lighting & $\begin{array}{l}\text { Conditions } 1 \\
\text { Night time collisions, Lack of street }\end{array}$ \\
\hline
\end{tabular}




\begin{tabular}{|c|c|}
\hline & $\begin{array}{l}\text { lights } \\
\text { Proposed safety improvements } \\
1 \text { Install street lights } \\
\text { Conditions } 2 \\
\text { Night time collisions, Poor signs } \\
\text { visibility } \\
\text { Proposed safety improvements } \\
1 \text { Upgrade signing } \\
2 \text { Improve/install reflective signs }\end{array}$ \\
\hline - Addition of roadway illumination & $\begin{array}{l}\text { Conditions } 2 \\
\text { Night time collisions, Poor signs } \\
\text { visibility } \\
\text { Proposed safety improvements } \\
1 \text { Upgrade signing } \\
2 \text { Improve/install reflective signs }\end{array}$ \\
\hline [No findings] & $\begin{array}{l}\text { Conditions } 3 \\
\text { Off-road collisions, Fix object close } \\
\text { to traveled way } \\
\text { Proposed safety improvements } \\
1 \text { Remove or relocate the object } \\
\text { Comments } \\
\text { trees }\end{array}$ \\
\hline [No findings] & $\begin{array}{l}\text { Conditions } 5 \\
\text { Off-road collisions, Inadequate } \\
\text { shoulders width } \\
\text { Proposed safety improvements } \\
1 \text { Increase width of the shoulders } \\
\text { Comments } \\
\text { The pavement on the shoulders is not } \\
\text { constant, with different materials on } \\
\text { the WB. }\end{array}$ \\
\hline
\end{tabular}




\begin{tabular}{|l|l|}
\hline [No findings] & $\begin{array}{l}\text { Conditions 7 } \\
\text { Left-turn collisions on major road, } \\
\text { Undivided highway, Poor visibility of } \\
\text { opposite vehicles, Opposite left turn } \\
\text { vehicles obstruct visibility } \\
\text { Proposed safety improvements }\end{array}$ \\
\hline [No findings] & $\begin{array}{l}\text { Conditions } 9 \\
\text { Excessive speed, Posted speed limit } \\
\text { Proposed safety improvements } \\
\text { Comments } \\
\text { High speed on the major road. }\end{array}$ \\
\hline
\end{tabular}

\subsection{Summary of the evaluation stage}

The evaluation stage included three major discussions. The first phase consisted of the testing of the software's usefulness (checking for errors) and user-friendly interface. This testing was based on the investigation of the intersection between Cartersburg Road and CR 200 South. Additionally, some comparisons between the propose solutions by the RSIT and the expert team were obtained, but part of the evaluation process was not fully adequate because of the fact that this intersection already had been changed and updated.

The second part of the testing included the comparison between the expert findings and the RSIT proposed countermeasures from the investigation of the intersection between Locust Road and Ireland Road. In this part, the RSIT was used by the author of this report.

The third part included investigation of the same intersection as in part two, but the major comparison was based on the findings from the safety expert investigation process and the "non-expert" student who used the RSIT.

The first phase of the software evaluation pointed out additional issues with the software. Several errors occurred during the investigation when updated information was added after the evaluation section (no fully functional "BACK" function as well as a lack 
of capability of saving middle stage comments). In general, the user-friendly interface was positively evaluated and providing the user with a view of existing and proposed searching stages was valuable. The user can easily follow the existing investigation searching process and has full flexibility to change the order of the stages viewed. The possibility to change the settings of the software was very useful, especially on a sunny day where the visibility of the software on the computer screen may not be adequate. Additional updating of the computer screen could be implemented. Because of the size of the laptop which was used to run the RSIT in the field, the future merge into the Personal PC Tablets can increase effectiveness of the proposed method. During the testing phase it was proven that the functionality of the menu was compatible with well known software (i.e., Microsoft Office), which increased the effectiveness of using the tool and decreased the user's learning time. A very useful function of the RSIT is the possibility to add comments during the investigation stages.

The RSIT found additional improvements that were not proposed by the safety team. The first of these countermeasures are related to the nighttime collision. The RSIT proposed installing street lights (if possible), upgrading signing, and improving/installing reflective signs. These findings seem to be very important because one fatal crash occurred at night. Additionally, increasing the shoulder width was proposed by the RSIT, which could be related to the run-off collisions that occurred at this intersection. The RSIT obtained one more findings according to the winter crash condition which was found from the crash database. The proposes solutions indicate various countermeasures such as use sand to increase pavement friction, install snow screens in areas exposed to snowdrifts, and install static or variable message signs displaying weather information.

Other findings by the RSIT and the safety team are similar. The final conclusion from this safety investigation with the RSIT indicated similarities with the final solution. Furthermore, the proposed tool indicated additional possible improvements which were not indicated by the safety team. The major difference probably stems from the fact that this intersection was already upgraded, which is connected to the lack of proposed solutions by the RSIT according to the change from $\mathrm{z}$ two-way stop controlled intersection to a four-way stop controlled intersection. More adequate findings were found during testing the RSIT on the second intersection. 
The second phase of testing was an evaluation of the software on the intersection between Locust Road and Ireland Road in St. Joseph County, Indiana. This phase of evaluation was focused mainly on the knowledge. The major findings from the safety team indicated a deficiency in the geometry structure on the north leg of Locust Road. The RSIT found the same deficiencies and proposed a change in the horizontal/vertical alignment (the problem is connected with the vertical alignment). The safety team proposed additional improvements in the intersection advance warning, compared to the RSIT, which indicated a more detailed list of solution to this problem:

- Install warning signs in advance of intersections,

- Replace, repair, or clean the warning signs,

- Relocate the sign to make it visible (comments: Ireland toward East),

- Remove the object obstructing sight of the warning sign (comments: Ireland toward East),

- Install larger regulatory and warning signs at and in advance of intersections,

- Install regulatory signs on both sides of the road,

- Install overhead flashing beacon lights,

- Provide on-pavement horizontal signing.

The safety team proposed additional installation of the lighting which was emphasized as well by the RSIT. Furthermore, additional roadway illumination was proposed by the safety team and by the RSIT.

The RSIT indicated additional roadways improvements which were not indicated by the safety team:

- Provide adequate turning markers or pavement markings,

- Increase width of the shoulders (comments especially for the Ireland road toward East. (See picture) Shoulders are not consistent).

The RSIT's conclusions and proposed solutions were similar to those of the safety team. The major focus of the safety team was to improve the vertical alignment on the Locust road (north leg), which was emphasized as a possible improvement by the RSIT. All additional findings which the safety team indicated were also obtained by the RSIT and were more detailed. The RSIT found more issues to investigate at the intersection 
which were not mentioned by the safety team. These problems seem to be reasonable according to actual road conditions and the crash type (i.e., left-turn collision or sideswipe crash).

The last, third phase of the evaluation process was a comparison between the findings obtained by the safety team and the "non-expert" student who used the RSIT.

The four groups of findings from the safety team investigation process which included the following information were indicated by the "non-expert" student with the RSIT software as well.

- Deficiencies in the geometric configuration on the north leg of Locust Road,

- Improvement in the intersection advance warning,

- Installation of lighting,

- Addition of roadway illumination.

Only the first finding was emphasized in less detailed as the safety team, but the general improvement in the vertical alignment was proposed (Figure 5-5). The "non-expert" student had the following additional findings not obtained by the safety team:

- Fix object close to the driveways, solution: Remove or relocate the object (comments: trees),

- Inadequate shoulders width, solution: Increase width of the shoulders (comments: The pavement on the shoulders is not constant, with different materials on the WB),

- Opposite left turn vehicles obstruct visibility, solution (none),

- Excessive speed on the major approaches.

In all of the evaluations phases the possible proposed solutions by the RSIT appear to be very closely related to the countermeasures obtained by the safety team. It was shown especially in regard to the evaluation of the Locust Road and Ireland Road intersection that all of the possible solutions pointed by the safety team were determined also by the RSIT. In fact, the RSIT provided more detailed explanations and countermeasures, which was enhanced by the RSIT allowing the addition of comments so the final solutions actually fit the road conditions. The RSIT provided more possible solutions and scenarios than the investigation by the safety team. The additional solutions appear to be adequate 
as well, especially considering the specific road deficiencies that contribute to a particular type of crash. The final report, which is automatically generated by the software, provided a simple and understandable explanation of the proposed solutions with the comments.

The next important aspects of the RSIT that was observed was its suitability of use by inexperienced (safety area) individuals. The solutions obtained by the "non-expert" student are very similar to the findings from the experts.

The RSIT, by combining a well organized knowledge base with a user-friendly interface and a real time overview of the investigation stage, provides a unique tool to improve roadway deficiencies. 


\section{CHAPTER 6 CONCLUSIONS}

A summary of the research findings, conclusion and recommendations for future research are presented in this chapter.

\subsection{Research Summary}

High-crash locations are investigated to determine potential road improvements. The most difficult task is to link various road characteristics, traffic control, and other relevant local conditions with an excessive level of risk. The lack of in-depth knowledge of the actual circumstances leading to past crashes increases the complexity of the problem. To organize a site investigation into a well-organized and systematic process, checklist is used; a Purdue research team in a previous project developed such checklist (Tarko and Kanodia 2004). The multiplicity of past crashes and a typically large number of local characteristics to consider creates a time pressure, which may contribute to inadequate solutions, overlooking important crash factors, and an inadequate use of the checklist.

A computer-based method was used to utilize all the pieces of information known about the local conditions, circumstances of the recorded crashes, and our current knowledge of driver behavior and performance-related to crash occurrence. Modern datamining and technology information tools assisted in extracting the maximum information about possible roadway-related causes of crashes.

Different approaches were adapted to achieve the final tool. The first and most fundamental task was to describe the scope of the knowledge that becomes the base of the tool. The knowledge was built based on the following information: (a) human factors area (b) safety facts (crash data base) (c) road safety area (included road safety guidance, examples of the checklist, and the methodology behind the RSA process; (d) RSA final reports; (e) observation of the safety specialist team during real time safety investigation (Indiana Department of Transportation, Illinois Department of Transportation); and (f) road geometry studies. From all the presented sources of information, the human factor area was studied in more detailed because of the fact that drivers cause more than $80 \%$ of all crashes. The road geometry elements which can affect each of the human information 
processing stages (perception, cognition, and action) were adapted to the final knowledge base. These three stages of human information processing also became the backbone for the knowledge structure.

The most difficult task was to select the knowledge structure. The starting approaches included uncertainty implementation with the certain factors and backward chaining. The first difficulty was connected with the knowledge structure. The idea was to describe almost all possible scenarios which can lead to crash situation and by matching the rules with facts to derive the propose roadway improvements was found to be too complex to be implemented. The high level of complexity was created by the human characteristics which can lead to crash situation. Furthermore, the number of possible scenarios radically increases when less information was presented. The uncertainty creates an additional set of rules which are related to the proposed modal logic. For testing purposes, a prototype of the computer tool was developed. This tool was based on the Visual Prolog shell. The prototype of the computer tool implemented in Visual Prolog confirmed that the total time spent on processing all possible scenarios under uncertainty was overwhelming. The lack of organization of the knowledge which generates the "open mind" development process created in the testing and evaluation phase difficulty in describing in a logical way the connection between the facts and the rules which lead to possible solution. The issue of maintenance also arose. Backward chaining, which in the developing stage gives more freedom to create and describe the knowledge by allowing more flexibility to connect between facts, creates in the final process multiple problems. By using backward chaining, the user must provide all possible data before the algorithm will be executed. This creates additional discomfort for the user to provide some part of data that may not be used in the execution stage. To more efficiently deal with the entire problem, forward chaining with certain information was proposed.

The final method provides a more understandable structure of the knowledge and more efficient representation of the rules and facts. The knowledge acquisition processes of protocol analysis, hierarchy generation technique, and protocol generation technique were adopted. The presented knowledge was descried for a two-way stop controlled intersection. The previous findings especially included human factors, which were used 
for the knowledge derivation process. Because the forward chaining approach was used, where the starting points are the known facts, the hierarchical structure was required. By using the protocol analysis technique, especially the crash database study, the first level of the knowledge structure was obtained. The first level is related to different crash situations, where the following sets are defined: collision types, adverse weather conditions, time of collision, and intersection inconspicuous. Additional pedestrians and bicycle collisions were also specified. This selection mirrors the preliminary analysis phase of the road safety investigation process where the safety team determines the specific types of crash and additional environment conditions. Furthermore, the protocol analysis technique allowed extracting information from different sources, such as safety guidance, road safety final reports, driver behavior studies, and low-cost road improvements references. The protocol generation technique was used during the two road safety investigations, where the decision-making process by the safety specialist was observed and analyzed. Finally, the hierarchical generation technique, in connection with the human information process, created the final knowledge structure. The four stages of the driving process were addressed. Because in each stage, the driver can fail, the possible solution of improve road geometry, traffic control, and environmental conditions were developed. To more efficiently represent the structure of the knowledge, the Hierarchical Document System (HDS) was adopted. The HDS was used as a part of the final tool to edit and evaluate existing knowledge and create the user's own knowledge.

The forward chaining required a specific type of shell for implementation. Different types of shell were investigated, and CLIPS was proposed. One of the disadvantages of using CLIPS was lack of a graphic user interface. To improve this situation, the Visual Basic structure was proposed. Visual Basic provides a more flexible, efficient, and convenient user-friendly graphic representation. A final RSIT was developed that provides a real time information system about the processing stage. The user receives information about the actual processing stage as well as a stage that is waiting in the queue to be processed. At the same time, different elements of the knowledge can be marked and checked later in a special type of sequence. This sequence was based on the queue theory FIFO (First in First out). The RSIT is highly flexible and allows users to change an already defined process as well as search back and forward for 
described knowledge and update it. The user can add personal comments at each of the processing stages. An added convenience of RSIT is an automatically generated report.

\subsection{Conclusions}

The proposed site investigation tool can guide an investigation team through a sequence of checks and determine the probable roadway factors contributing to crash occurrence. Even though the tool is complex, it has an easily understandable knowledge structure represented by a user-friendly interface. It is flexible and increases the efficiency of site investigation and contributes to more effective findings. Furthermore, RSIT allows editing and changing the knowledge, which can bring additional flexibility. The tool structure and functionality is easy to understand and during the evaluation and testing phases takes about 30 minutes to explain its operation to a "non-expert." RSIT provides a more detailed explanation for each individual roadway deficiency compared to the findings from the road safety report (based on the evaluation). By using the RSIT software the time spent on the investigation process should decrease.

One of the difficulties for the safety team was to connect various pieces of information to derive the final improvements. Using RSIT enables obtaining all possible adequate solutions based on real facts. Additionally, it was shown that the presented prototype of the RSIT described more roadways deficiencies than the safety team. This confirms previous statement that even experienced investigators can overlook important factors.

An important advantage of RSIT is that the investigation process can be conducted by a team or an individual. The implemented knowledge can decrease the size of the team, which usually should contain specialists from different areas: geometry, safety, and human factors. In addition, the final report, which is generated automatically, presents in an easy and understandable way the searching process including users comments and the proposed final solutions.

The proposed road safety investigation tool RSIT creates a very convenient way for investigators to more efficiently and in a user-friendly environment obtain the 
roadways deficiencies without overlooking important factors which can possible save lives.

\subsection{Future Research}

RSIT requires future additional testing on a wider scale. The proposed tool and the knowledge input focused on a two-way stop controlled intersection in this project. To create a more efficient tool, additional types of roadway segments should be included. The future development process should focus on signalize intersections, four-way stop controlled intersection, road segments, and railroad crossings.

A user's manual should be prepared for those with little experience in high-crash sites investigation. The future improvements of the software could include reporting more efficiently the components of the roadway geometry and traffic control that most likely contributed to the recorded crashes. Additional improvements could be adopting more graphic representation in the actual processing stage and additional evaluation of proposed knowledge for other roadway elements.

To increase RSIT's flexibility and efficiency, integration with the crash database should be implemented, which could decrease the time spent on extracting useful information from the database and make this software more convenient. Furthermore, uncertainty representation should be implemented. The graphic user interface can be changed to use some well known and user-friendly web interactive design styles. The purchase and testing of personal PC tablets (http://www.tabletpclounge.com/) for using the software in the field would make the site investigation process more user-friendly and flexible. 


\section{List of references}

1) Adamski Andrzej, Habdan-Wojewodzki Seweryn "Incident detection by fuzzy logic approach” Krakow 2004.

2) Aemal J. Khattak, "Data Visualization in Highway Safety Assessment", Transportation Reseach Board, 2004

3) Awad, Elias M., "Building expert systems: principles, procedures, and applications" Minneapolis/St. Paul West Pub. Co., c1996.

4) Berger, James O., "Statistical decision theory and Bayesian analysis" New York: Springer-Verlag, c1985.

5) Bratko, Ivan, "Prolog programming for artificial intelligence" Harlow, England; New York: Addison Wesley, 2001.

6) Brown, David C., Chandrasekaran B., "Design problem solving: knowledge structures and control strategies” London: Pitman; San Mateo, Calif.: M. Kaufmann Publishers, 1989.

7) Collins, H. M. (Harry M.), "Artificial experts: social knowledge and intelligent machines” Cambridge, Mass.: MIT Press, c1990.

8) Cordingley, E. S. "Knowledge acquisition techniques for knowledge-based systems," D. Diaper (ed.), Knowlege elicitation principles, techniques and applications, Ellis Horwood Limited, Chichester, 1989, UK, pp. 89-173.

9) Deransart, Pierre, "Prolog: the standard: reference manual" Berlin; New York: Springer, c1996.

10) Dougherty, Ray C., "Natural language computing: an English generative grammar in Prolog” Hillsdale, N.J.: Lawrence Erlbaum Associates, 1994.

11) Ericson, K. A. and Simon, H. A. (1984). "Protocol Analysis: verbal reports as data" MIT Press, 1984, Boston.

12) Fuller R., Santos J. A., "Human factors for highway engineers" Amsterdam; New York: Pergamon, 2002.

13) Gabriel, Richard F., "What engineers and managers need to know about human factors” Warrendale, Pa.: SAE International, c2003. 
14) Ginsberg, Matthew L., "Essentials of artificial intelligence” San Mateo, CA: Morgan Kaufmann Publishers, c1993.

15) Illinois Department of Transportation "Williamson County, Road Safety Audits" Illinois, April 2006.

16) Indiana Department of Transportation, Crash Data Base (1996-2004).

17) Kandel Abraham “Fuzzy expert systems” Boca Raton, FL: CRC Press, c1992.

18) Keele, Steven W., "Attention and human performance” Pacific Palisades, Calif., Goodyear Pub. Co. [1973].

19) Liu, Puyin., "Fuzzy neural network theory and application” River Edge, NJ : World Scientific, c2004.

20) Luger, George F., "Artificial Intelligence: structures and strategies for complex problem solving." $4^{\text {th }}$ Edition. Harlow, England; New York: Addison-Wesley, 2002.

21) Martyna Jerzy "Inteligentne systemy wspomagania decyzji” PK, Krakow 2004.

22) Merritt, Dennis, "Building expert systems in Prolog” New York: Springer-Verlag, c1989.

23) NCHRP Report 500 Series, Volume 5 "A Guide for Addressing Unsignalized Intersection Collisions”. Transportation Research Board, Washington, D.C., 2003.

24) NCHRP Synthesis 336 Series, "Road Safety Audits, A Synthesis of Highway Practice.” Transportation Research Board, Washington, D.C., 2004.

25) Olson, Paul L., „Forensic Aspects of Driver Perception and Response”. Tucson, AZ: Lawyers \& Judges Pub. Co., c1996.

26) Organization for Economic CO-Operation and Development Paris 1976 "Hazardous road location identification and counter measures”.

27) Park, Kyung S. (Kyung Soo), "Human reliability: analysis, prediction, and prevention of human errors” Amsterdam; New York: Elsevier; New York, NY: Distributors for the U.S. and Canada, Elsevier Science Pub. Co., 1987.

28) Primer A., Latham, F.E. and J.W. Trombly "Low Cost Traffic Engineering Improvements”. FHWA-OP-03-078. Federal Highway Administration, Washington, D.C., April 2003.

29) Proctor, Robert W., Trisha Van Zandt. "Human factors in simple and complex systems”. Boston: Allyn and Bacon, c1994. 
30) Reginald R. Souleyrette, Aemal Khattak "Systematic Identification of High Crash Location” Transportation Research Board, 2002.

31) Robertson, H.D., J.E. Hummer, and D.C. Nelson. Manual of Transportation Engineering Studies. Institute of Transportation Engineers, Washington, D.C., 1994.

32) Salvendy Gavriel "Handbook of human factors and ergonomics” New York: J. Wiley, c1997.

33) Senders, John W., Neville P. Moray. "Human error: cause, prediction, and reduction / analysis and synthesis.” Hillsdale, N.J.: L. Erlbaum Associates, 1991.

34) Shoham, Yoav, "Artificial intelligence techniques in Prolog” San Mateo, Calif.: Morgan Kaufmann Publishers, c1994.

35) Tarko Andrew P., Mayank Kanodia "Effective and Fair Identification of Hazardous Locations” Transportation Reseach Board, 2004

36) Tarko, Andrew P., Mayank Kanodia., "Hazard Elimination Program - Manual on Improving Safety of Indiana Road Intersection and Section”. FHWA/IN/JTRP2003/19, Purdue University, West Lafayette, February 2004.

37) The Indiana LTAP Center "Hazard Elimination Study for Cartersburg Road and CR 200 South Hendricks County” Indiana, March 2005.

38) The Indiana LTAP Center "Hazard Elimination Study for Locust Rd. @ Ireland Rd St.Joseph County, Indiana” Indiana, March 2005.

39) The Indiana LTAP Center "Hazard Elimination Study for Smith Road and Roger Road Indiana” Indiana, January 2006.

40) Wagman, Morton, "The human mind according to artificial intelligence: theory, research, and implications” Westport, Conn.: Praeger, 1999.

41) Wickens, Christopher D., Sallie E. Gordon, Yili Liu, "An introduction to human factors engineering” New York: Longman, c1998.

42) Woodson, Wesley E., "Human factors design handbook: information and guidelines for the design of systems, facilities, equipment, and products for human use" New York: McGraw-Hill, c1992.

43) http://archives.cnn.com/2002/TECH/ptech/11/14/tablet.pc/index.html

44) http://safety.transportation.org/guides.aspx

45) http://www.aarp.org/life/drive/ 
46) http://www.commonkads.uva.nl/frameset-commonkads.html

47) http://www.dot.gov/

48) http://www.epistemics.co.uk/Notes/55-0-0.htm

49) http://www.epistemics.co.uk/Notes/63-0-0.htm

50) http://www.epistemics.co.uk/Notes/63-0-0.htm

51) http://www.fhwa.dot.gov/

52) http://www.infra.kth.se/ctr/publikationer/ctr1999_08.pdf

53) http://www.infra.kth.se/ctr/publikationer/ctr2000_08.pdf).

54) http://www.roadwaysafetyaudits.org/

55) http://www.tabletpclounge.com/

56) http://www.tfhrc.gov/safety/ihsdm/pubs/02045/

57) http://www.visual-prolog.com/

58) http://www.wsdot.wa.gov/eesc/design/ihsdm/Documents/getstarted.pdf 


\section{APPENDICES}




\section{Appendix A}

\section{Indiana Officer's Standard Crash Report}

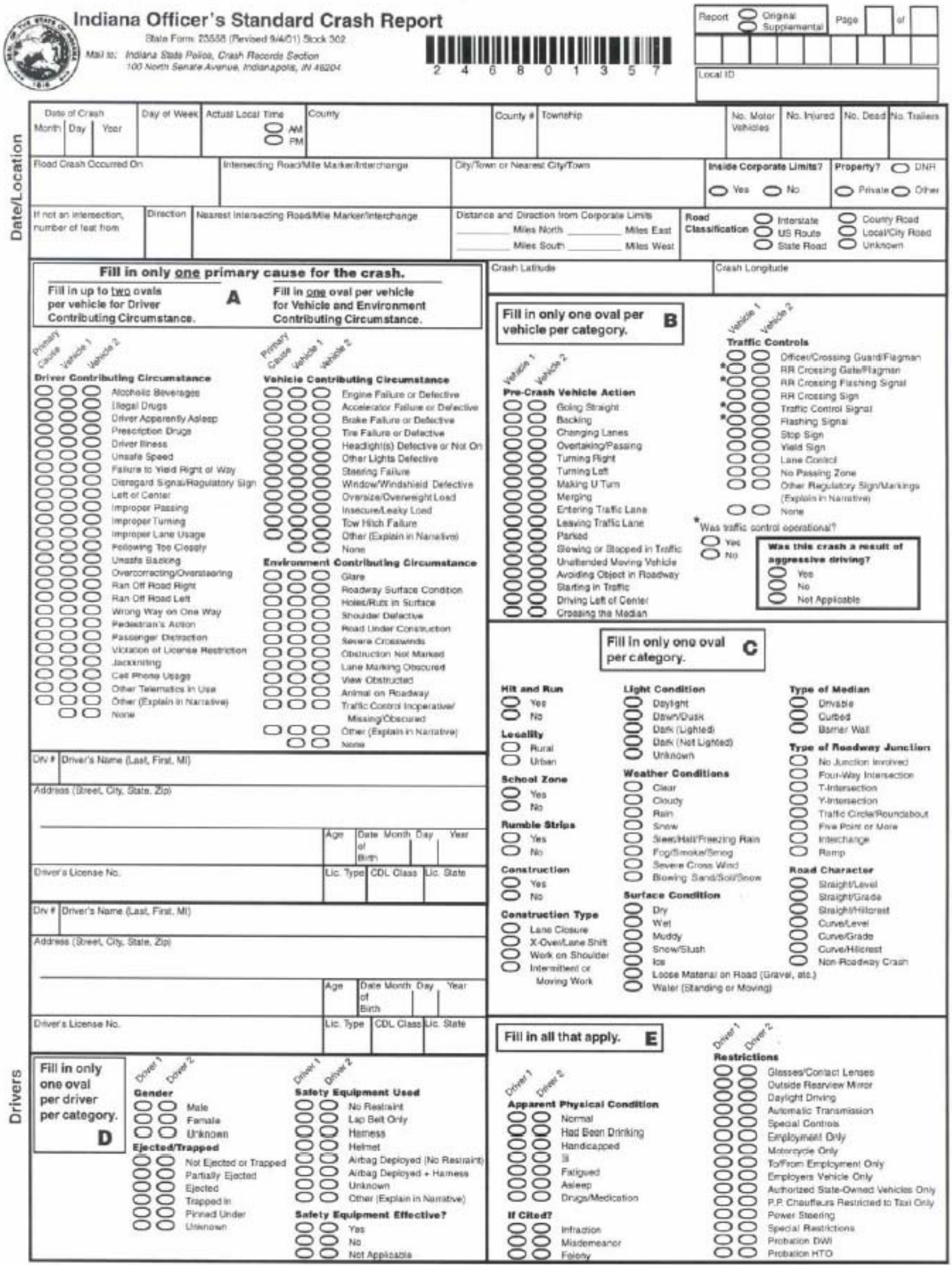




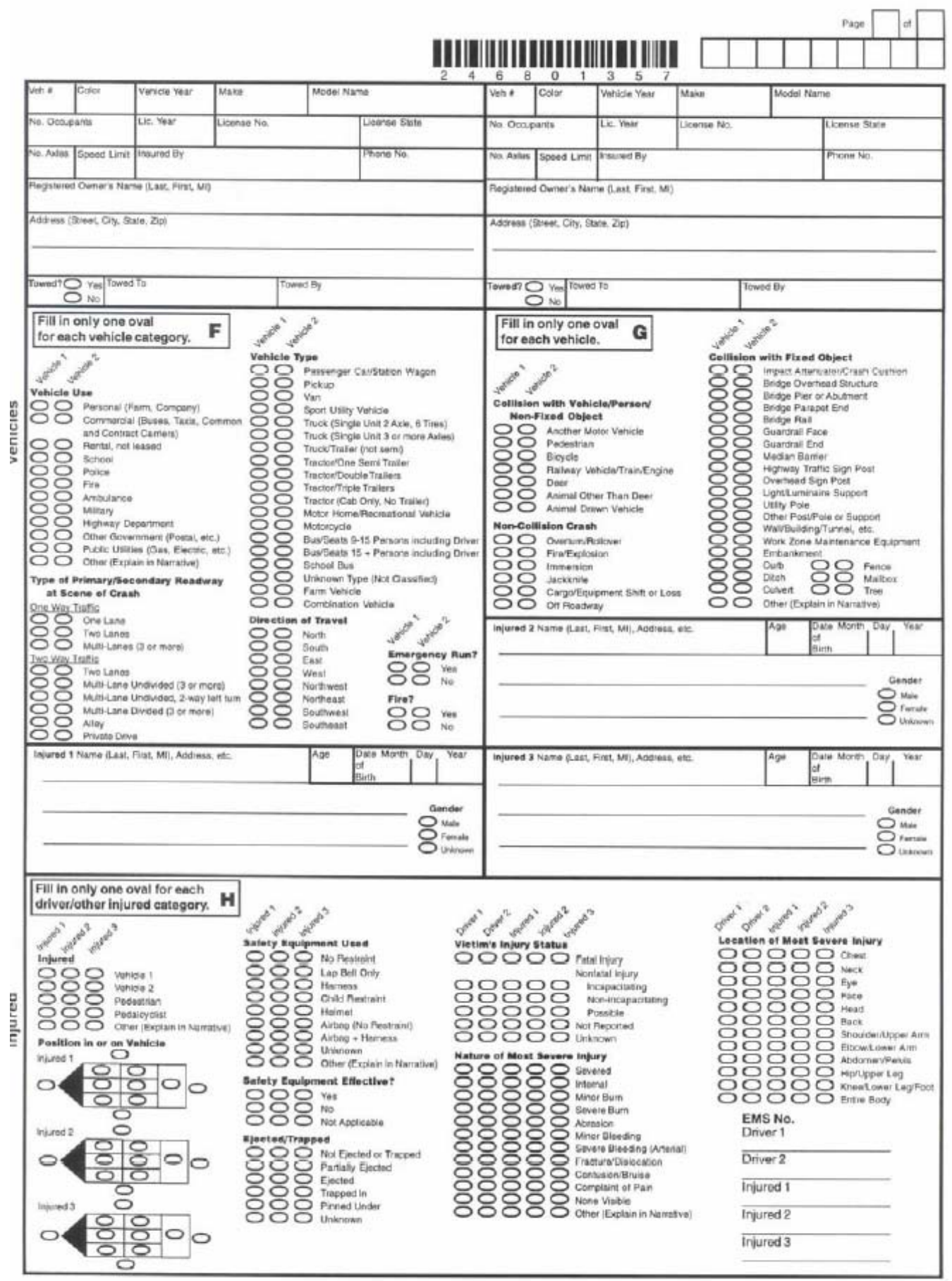














\section{Appendix B}

\section{The Check List (only first sheet (52))}



causes causes

Group A

Moving lanes

Lane widths are inadequate for vehicle classes that are common to the location Number of lanes inadecuate for traffic

Readability

Lanes end abruptly without prior waning (laces are not aligned)

Auriliary/Turning Lanes

Inadequate advance waming of lave drops

Driveways

Inproper location of driveways(e.g. driveways are too close to the intersection)

Driveways are closely spaced.

Inadequate visibility of driveways

Shoulders

Shoulder width inadequate for vehicle classes that are common to the intersection

Inappropriate sboulder surfacing

Rumble strips not installed where warranted

Sbotilders are poorly maintained.

Insufficient contrast of shoulders

Horizontal and vertical aligument

Horizontal or vertical aligument affect the visibility of the intersection

Is location free of abnupt changes in elevation

Inadequate visibility at sag and crest curves 


\title{
Appendix C
}

\section{Natural language programming tools overview}

\author{
FREE TOOLS
}

- BABYLON

o Description: This is a modular, configurable, hybrid environment for developing expert systems. It provides the following knowledge representation formalisms: frames, rules, logic (Prolog) and constraints. It requires Common Lisp.

o Platforms: Mac, and UNIX.

o Source: The latest version is available from ftp.gmd.de.

o Reference: Additional information is available from ftp.gmd.de

o Contact: juergen.walther@gmd.de

- ES

o Description:The ES Expert system development tool supports backward/forward chaining, and fuzzy set relations.

o Platforms: PC.

o Source: The latest version is available from ftp.uu.net.

o Reference: For additional information see the October/November 1990 issue of BYTE.

- GEST (Generic Expert System Tool)

o Description: This shell can be used in a variety of problem domains and supports backward and forward chaining. Its knowledge representation schemes include frames, rules and procedures. Support is also present for fuzzy logic and certainty factor maintenance. It includes a blackboard architecture. The user interface utilizes the Symbolics windowing system and is menu and mouse driven.

o Platforms: Symbolics Lisp Machines, Genera 7.2.

o Source: N/A.

o Contact: john.gilmore@gtri.gatech.edu.

- CLIPS (C Language Integrated Production System)

o Description: A forward-chaining rule-based tool written in C by NASA. It can be easily embedded in other applications and includes an objectoriented language called COOL.

o Platforms: DOS, Windows, VMS, Mac, and UNIX.

o Source: The latest version is available from the CMU AI Repository or Nortwestern University.

o Reference: Additional information is available at www.tnt.unihannover.de

- Contact: For problems with usage or installation of CLIPS contact NASA's Client/Server Systems Branch Help Desk.

- DYNACLIPS (DYNAamic CLIPS Utilities) 
- Description: A number of tools are available to be linked with CLIPS. DYNACLIPS is a set of blackboard, dynamic knowledge exchange, and agent tools implemented as a set of libraries that can be linked with CLIPS.

o Platforms: Same as CLIPS.

- Source: The latest version is available from the CMU AI Repository.

- Reference: Additional information is available from the $\underline{\mathrm{CMU} \mathrm{AI}}$ Repository.

o Contact: cengelog@escmail.orl.mmc.com.

- FuzzyCLIPS

o Description: This version of CLIPS provides handling of fuzzy concepts and reasoning, in addition to the other CLIPS features.

- Platforms: Same as CLIPS.

o Source: The latest version is available from the National Research Council of Canada.

o Reference: Additional information is available from the National Research Council of Canada.

o Contact: fzclips@ai.iit.nrc.ca.

- RT-Expert for DOS, Personal Edition

o Description: A rule-based system with allows for integration of the expert system with $\mathrm{C}$ or $\mathrm{C}^{++}$code.

o Platforms: DOS.

- Source: N/A.

- Reference: N/A.

o Contact: Integrated Systems Inc., 3260 Jay Street, Santa Clara, CA 95054, Phone: (408) 980-1500, Fax: (408) 980-0400, E-mail: rtis@world.std.com.

COMERCIAL TOOLS

- Aion Development System (ADS)

o Description: It supports forward and backward chaining, an object oriented knowledge representation, graphics, and calls to/from other languages (C, Pascal, ...).

- Platforms: DOS, OS/2, SunOS, Microsoft Windows, and VMS.

- Source: N/A.

- Reference: N/A.

o Contact: Aion Corporation, 101 University Avenue, Palo Alto, CA 94301, Phone: (800) 845-2466, (415)328-9595, Fax: (415) 321-7728.

- Analyser

o Description: Machine-learning software, an add on to XpertRule, that uses genetic algorithms to optimize solutions.

o Platforms:

- Source: N/A.

o Reference: Additional information is available from www.attar.com

o Contact: Attar Software, P.O.Box 68, Harvard, MA 01415-0068, Phone: (508) 456-3946, Fax: (508) 456-3946. 


\section{- ART*Enterprise}

o Description: An integrated C++ based development tool for building expert systems. Its graphical development environment supports rule based and case based reasoning (CBR), OOP, DBMS integration and GUI creation.

o Platforms: Windows (3.1, 95, NT), OS/2, UNIX (AIX, HP-UX, Solaris)

o Source: N/A.

o Reference: Additional information is available from www.brightware.com.

o Contact: Brightware, Inc., 350 Ignacio Blvd., Novato, CA 94949, Phone (800) 532-2890, (415) 884-4744, Fax: (415) 884-4740, Email: info@brightware.com.

\section{- Doctus KBS}

o Description: Knowledge-Based Expert System Shell 'Doctus' uses deduction also called Rule-Based Reasoning and induction, which is the symbolic version of Case-Based Reasoning, enhanced with reduction. The Knowledge Import component of the system is designed to retrieve both soft and hard information from external sources, which makes it appropriate for data mining. Doctus is also equipped to export knowledge in various forms of intelligent agents via its Knowledge Export module.

o Platforms: MS Windows

o Source: Demo version of the software can be downloaded from www.doctus.info. There is also direct access to demo of the Intelligent Executive Portal and to the demo of the Knowledge Factory..

o Reference: Additional information is available from www.doctus.info.

o Contact: viktor@doctus.info.

\section{- EXSYS Professional}

o Description: An easy to learn rule-based expert system shell and an excellent educational tool which comes with many examples and a good tutorial on developing expert systems. It features backward and forward chaining, blackboarding, fuzzy logic, and frames. SQL interface and linking to database and spreadsheet programs such as Lotus 1-2-3 is supported.

o Platforms: DOS, Windows, Macintosh, UNIX, and VAX.

o Source: A demo is now available at http://www.multilogic.com/

o Reference: Additional information is available at http://www.multilogic.com/

o Contact: MultiLogic Inc., 2000 Minnesota World Trade Center, 30 East 7th Street, St. Paul, MN 55101-4901, Phone:(612)228-7090, Fax:(612)228-7072. Email: productinfo@multilogic.com

\section{- EXSYS RuleBook}

o Description: Development tool that allows the building of expert systems using tree diagrams.

o Platforms: Windows, Macintosh.

o Source: A demo is now available at http://www.multilogic.com/ 
- Reference: Additional information is available at http://www.multilogic.com/

o Contact: MultiLogic Inc., 2000 Minnesota World Trade Center, 30 East 7th Street, St. Paul, MN 55101-4901, Phone:(612)228-7090, Fax:(612)228-7072. Email: productinfo@multilogic.com

\section{- EXSYS Linkable Object Modules}

o Description: Allows customization of EXSYS programs, addition of up to 100 user-defined $C$ functions, embed neural networks, and add DDE links to other programs.

o Platforms: DOS, Windows, Macintosh.

o Source: N/A.

o Reference: Additional information is available at http://www.multilogic.com/

o Contact: MultiLogic Inc., 2000 Minnesota World Trade Center, 30 East 7th Street, St. Paul, MN 55101-4901, Phone:(612)228-7090, Fax:(612)228-7072. Email: productinfo@multilogic.com

\section{- KEE (Knowledge Engineering Environment)}

o Description: KEE supports a variety of knowledge representation schemes including object-oriented frame language. The inference engine supports both forward and backward chaining. It allows for linking to several data bases. Its interactive graphics interface is one of the most sophisticated available among expert system tools.

o Platforms: PC, VAX, Sun.

- Source: N/A.

- Reference: N/A.

o Contact: IntelliCorp, Inc., 1975 El Camino Real West, Suite 101, Mountain View, CA 94040-2216, Phone: (415)965-5700/5500, Fax: (415) 965-5647.

- $\quad$ M.4

o Description: An expert system development tool that includes support for rule-based procedural control and object-oriented representation. Provides interface to Visual Basic and Visual C++ and supports forward and backward chaining and DDE and DLL support.

o Platforms: DOS, Windows, Sun, and Mac.

o Source: N/A.

o Reference: Additional Information is available at: http://www.teknowledge.com:80/M4/

o Contact: Teknowledge Corporation, 1810 Embarcadero Road, Palo Alto, CA 94303, Phone: (800)285-0500, (415) 424-0500, Fax: (415)493-2645, Email: aterry@teknowledge.com.

\section{- Nexpert Object}

o Description: An expert system development tool with a graphical user interface. It features a rule-based and object-based inference engine. It allows for the interfacing with databases, programming languages and other applications.

o Platforms: DOS, Mac, UNIX, and VMS. 
o Source: N/A.

o Reference: N/A.

o Contact: Neuron Data, 156 University Avenue, Palo Alto, CA 94301, Phone: (800)876-4900, (415)321-4488, Fax: (415)321-3728.

\section{- OPS83}

o Description: OPS 83 is a rule based system that is a successor of OPS5. It is written in $\mathrm{C}$ and allows for the integration of applications written in $\mathrm{C}$. OPS 83 supports generalized Forward Chaining, a control structure which allows rules to be more expressive.

o Platforms: DOS, OS/2, VMS, and UNIX.

o Source: N/A.

o Reference: N/A.

o Contact: Production Systems Technologies, Inc., 5001 Baum Blvd., Pittsburgh, PA 15213, Phone: (412) 683-4000, Fax: (412) 683-6347.

- $\quad$ RT-Expert

o Description: A rule-based system with allows for integration of the expert system with $\mathrm{C}$ or $\mathrm{C}++$ code.

o Platforms: UNIX, DOS, Windows, and VMS.

o Source: N/A.

o Reference: N/A.

o Contact: Integrated Systems Inc., 3260 Jay Street, Santa Clara, CA 95054, Phone: (408) 980-1500, Fax: (408) 980-0400, E-mail: rtis@world.std.com.

\section{- XpertRule}

o Description: A windows-based expert system development tool which utilized genetic algorithms for optimization. It generates code in $\mathrm{C}$, Pascal and COBOL.

o Platforms: MS Windows/PC.

o Source: N/A.

o Reference: Additional information is available from www.attar.com

- Contact: USA: Attar Software USA, PO Box 68,

o Contact: Cincom Systems, Inc., 2300 Montana Ave. , Cincinnati, Ohio 45211, Phone: (800) 543-3010, Fax: (513) 481-8332. 


\section{Appendix D}

\section{Knowledge Acquisition Process}

\begin{tabular}{|c|c|c|c|}
\hline $\begin{array}{l}\text { Guidelines } \\
\text { number }\end{array}$ & Input & Causes & $\begin{array}{l}\text { Possible } \\
\text { solution }\end{array}$ \\
\hline A2 & $\begin{array}{l}\text { driveways_near_intersection(yes } \\
\text { ), } \\
\text { high_crash_frequencies_related_ } \\
\text { to_driveways(yes). } \\
\text { driveways_near_intersection(no) } \\
\text { high_crash_frequencies_related_ } \\
\text { to_driveways(yes). }\end{array}$ & $\begin{array}{l}\text { Improperly located } \\
\text { driveway. }\end{array}$ & $\begin{array}{l}\text { 1. Restrict } \\
\text { turning. } \\
\text { 2. Close or } \\
\text { relocate } \\
\text { driveway }\end{array}$ \\
\hline A1 & $\begin{array}{l}\text { driveways_within_250_feet_to_i } \\
\text { ntersection(yes), } \\
\text { high_crash_frequencies_related_ } \\
\text { to_driveways(yes). }\end{array}$ & $\begin{array}{l}\text { Improperly located } \\
\text { driveway. }\end{array}$ & $\begin{array}{l}\text { 1.Close or } \\
\text { relocate } \\
\text { driveway }\end{array}$ \\
\hline \multirow[t]{2}{*}{ B1 } & $\begin{array}{l}\text { A. } \\
\text { major_left_turn_lane_exist(no),c } \\
\text { ollision_major_turning_left_and } \\
\text { _following(yes). } \\
\text { major_left_turn_lane_exist(no),c } \\
\text { ollision_major_waiting_left_and } \\
\text { following(yes). }\end{array}$ & $\begin{array}{l}\text { A } \\
\text { 1. Following driver didn’t } \\
\text { perceive turning vehicle. } \\
\text { 2. High speed condition. }\end{array}$ & $\begin{array}{l}\text { 1. Install left } \\
\text { turn lanes. }\end{array}$ \\
\hline & $\begin{array}{l}\text { B. } \\
\text { major_left_turn_lanes_exist(no), } \\
\text { collision_major_turning_left_op } \\
\text { posing_through(yes). }\end{array}$ & $\begin{array}{l}\text { B } \\
\text { 1. Lack of visibility towards } \\
\text { approaching vehicle. } \\
\text { 2. Driver doesn't have } \\
\text { enough time to select } \\
\text { appropriate gaps. } \\
\text { 3. High speed condition } \\
\text { 4. Lack of visibility of the } \\
\text { intersection }\end{array}$ & $\begin{array}{l}\text { 1. Install left } \\
\text { turn lanes. }\end{array}$ \\
\hline
\end{tabular}




\begin{tabular}{|c|c|c|c|}
\hline B2 & $\begin{array}{l}\text { major_left_turn_lane_exist(yes), } \\
\text { collision_major_waiting_for_tur } \\
\text { n_left_and_following(yes). }\end{array}$ & $\begin{array}{l}\text { 1. Significant number of } \\
\text { turning vehicle. } \\
\text { 2. Turning vehicle queue } \\
\text { outside the turning lanes. }\end{array}$ & $\begin{array}{l}\text { 1.Provide } \\
\text { longer left turn } \\
\text { at the } \\
\text { Intersection }\end{array}$ \\
\hline \multirow[t]{2}{*}{ B3 } & $\begin{array}{l}\text { A. } \\
\text { major_left_turn_lane_exist(yes), } \\
\text { collision_major_turning_left_op } \\
\text { posing_through(yes),sufficient_s } \\
\text { ight_distance_major_left_turnin } \\
\text { g(no). } \\
\text { major_left_turn_lanes_exist(yes) } \\
\text { ' } \\
\text { collision_major_turning_left_op } \\
\text { posing_through(yes),sufficient_s } \\
\text { ight_distance_major_left_turnin } \\
\text { g(no). }\end{array}$ & $\begin{array}{l}\text { A } \\
\text { 1. Block view by } \\
\text { vehicle in opposing } \\
\text { approach. }\end{array}$ & $\begin{array}{l}\text { A } \\
\text { Provide offset } \\
\text { left - turn } \\
\text { lanes. }\end{array}$ \\
\hline & $\begin{array}{l}\text { B. } \\
\text { major_left_turn_lanes_exist(yes) } \\
\text {, } \\
\text { collision_major_turning_left_op } \\
\text { posing_through(yes),sufficient_s } \\
\text { ight_distance_major_left_turnin } \\
\text { g(yes). } \\
\text { major_left_turn_lane_exist(yes), } \\
\text { collision_major_turning_left_op } \\
\text { posing_through(yes),sufficient_s } \\
\text { ight_distance_major_left_turnin } \\
\text { g(yes). }\end{array}$ & $\begin{array}{l}\text { B } \\
\text { 1. Opposing major driver } \\
\text { not aware about } \\
\text { intersection. } \\
\text { 2. Inadequate turning } \\
\text { path. } \\
\text { 3. High speed condition. }\end{array}$ & $\begin{array}{l}\text { B. } \\
\text { 1. Increase } \\
\text { curb radii. } \\
2 . \\
\text { Install/improve } \\
\text { warning signs. } \\
\text { 3. Install } \\
\text { overhead } \\
\text { flashing } \\
\text { beacon. }\end{array}$ \\
\hline
\end{tabular}




\begin{tabular}{|c|c|c|c|}
\hline & $\begin{array}{l}\text { C } \\
\text { major_left_turn_lanes_exist(yes) } \\
\text { rear_end_between_through_on_ } \\
\text { opposing_approach(yes), } \\
\text { sufficient_intersection_sight_dis } \\
\text { tance_major_approach(no). } \\
\\
\text { major_left_turn_lane_opposite_ } \\
\text { approach_exist(yes), } \\
\text { rear_end_between_through_on_ } \\
\text { opposing_approach(yes), } \\
\text { sufficient_intersection_sight_dis } \\
\text { tance_major_approach(no). }\end{array}$ & $\begin{array}{l}\text { C } \\
\text { 1. Block view by } \\
\\
\text { vehicle turning left. }\end{array}$ & $\begin{array}{l}\text { C } \\
\text { Provide offset } \\
\text { left - turn } \\
\text { lanes. }\end{array}$ \\
\hline & $\begin{array}{l}\text { D } \\
\text { major_left_turn_lanes_exist(yes) } \\
\text {, } \\
\text { rear_end_between_through_on_ } \\
\text { opposing_approach(yes), } \\
\text { sufficient_intersection_sight_dis } \\
\text { tance_major_approach(yes). } \\
\text { major_left_turn_lane_opposite_ } \\
\text { approach_exist(yes), } \\
\text { rear_end_between_through_on_ } \\
\text { opposing_approach(yes), } \\
\text { sufficient_intersection_sight_dis } \\
\text { tance_major_approach(yes). }\end{array}$ & $\begin{array}{l}\mathrm{D} \\
\text { 1. Driver not aware about } \\
\text { intersection. } \\
\text { 2. High speed condition }\end{array}$ & $\begin{array}{l}\mathrm{D} \\
\text { 1.Install/impro } \\
\text { ve warning } \\
\text { signs. } \\
\text { 2.Install } \\
\text { overhead } \\
\text { flashing } \\
\text { beacon. }\end{array}$ \\
\hline B4 & $\begin{array}{l}\text { major_left_turn_lane_exist(no), } \\
\text { intersection_type_t(yes), } \\
\text { collision_waiting_for_turn_left } \\
\text { and_following_on_major_road( } \\
\text { yes). }\end{array}$ & $\begin{array}{l}\text { A } \\
\text { 1. Following driver didn't } \\
\text { perceive turning vehicle. } \\
\text { 2. High speed condition. }\end{array}$ & $\begin{array}{l}\text { A } \\
\text { Provide } \\
\text { shoulder area } \\
\text { for the bypass } \\
\text { lane. } \\
\text { Use for low- } \\
\text { volume. }\end{array}$ \\
\hline
\end{tabular}




\begin{tabular}{|c|c|c|c|}
\hline \multirow[t]{2}{*}{ B5 } & $\begin{array}{l}\text { A } \\
\text { rear_end_collision_related_to_s } \\
\text { peed_different_turning_left_ont } \\
\text { o_highway(yes), } \\
\text { divided_highway_present(yes). }\end{array}$ & $\begin{array}{l}\text { A. } \\
\text { 1. Not enough space to } \\
\text { accelerate. } \\
\text { 2. Significant number of } \\
\text { trucks. } \\
\text { 3. High speed condition. }\end{array}$ & $\begin{array}{l}\text { A } \\
\text { 1. Provide left- } \\
\text { turn } \\
\text { acceleration } \\
\text { lanes }\end{array}$ \\
\hline & $\begin{array}{l}\text { B } \\
\text { rear_end_collision_related_to_s } \\
\text { peed_different_turning_left_ont } \\
\text { o_highway(yes), } \\
\text { divided_highway_present(no). }\end{array}$ & $\begin{array}{l}\text { B } \\
\text { 1. Lack of space for driver to } \\
\text { choice adequate gap. }\end{array}$ & $\begin{array}{ll}\text { B } & \text { Improv } \\
& \text { e } \\
& \text { visibilit } \\
& \text { y. } \\
\text { 2. } & \text { Restrict } \\
\text { turning. }\end{array}$ \\
\hline \multirow[t]{2}{*}{ B6 } & $\begin{array}{l}\text { A } \\
\text { collision_major_turning_right_f } \\
\text { ollowing(yes),major_right_turn__ } \\
\text { lane_exist(no). }\end{array}$ & $\begin{array}{l}\text { A. } \\
\text { 1. High speed condition. } \\
\text { 2. Significant number of } \\
\text { vehicle turning right. }\end{array}$ & $\begin{array}{ll}\text { A } & \\
\text { 1. } & \text { Install } \\
& \text { right- } \\
& \text { turn } \\
& \text { lanes. } \\
\end{array}$ \\
\hline & $\begin{array}{l}\text { B } \\
\text { collision_turning_right_through } \\
\text { _comming_from_left_cross_stre } \\
\text { et(yes), } \\
\text { major_right_turn_lane_exist(no) } \\
\text {. }\end{array}$ & $\begin{array}{l}\text { B } \\
\text { 1. Lack of visibility } \\
\text { 2. Significant number of } \\
\text { turning vehicle. }\end{array}$ & $\begin{array}{l}\text { B } \\
\text { 1. Install } \\
\text { right-turn } \\
\text { lanes. }\end{array}$ \\
\hline B7 & $\begin{array}{l}\text { major_right_turn_lane_exist(yes } \\
\text { ), } \\
\text { collision_waiting_for_turn_right } \\
\text { _and_following(yes). }\end{array}$ & $\begin{array}{l}\text { 1. Significant number of } \\
\text { turning vehicle. } \\
\text { 2. Turning vehicle queue } \\
\text { outside the turning lanes. }\end{array}$ & $\begin{array}{l}\text { 1.Provide } \\
\text { longer right } \\
\text { turn at the } \\
\text { Intersection }\end{array}$ \\
\hline B8 & $\begin{array}{l}\text { A } \\
\text { major_right_turn_lane_exist(yes } \\
\text { ), } \\
\text { collision_minor_left_right_throu } \\
\text { gh_major(yes),sufficient_sight_- } \\
\text { distance_minor_crossing_turnin } \\
\text { g(no). }\end{array}$ & $\begin{array}{l}\text { A } \\
\text { 1. Lack of visibility on } \\
\text { the minor road. }\end{array}$ & $\begin{array}{l}\text { 1. Provide } \\
\text { offset } \\
\text { right turn } \\
\text { lanes at } \\
\text { intersectio } \\
\mathrm{n}\end{array}$ \\
\hline
\end{tabular}




\begin{tabular}{|c|c|c|c|}
\hline & $\begin{array}{l}\text { B } \\
\text { major_right_turn_lane_exist(yes } \\
\text { ), } \\
\text { collision_minor_left_right_throu } \\
\text { gh_major(yes),sufficient_sight_ } \\
\text { distance_minor_crossing_turnin } \\
\text { g(yes). }\end{array}$ & $\begin{array}{l}\text { B } \\
\text { 1. High speed condition } \\
\text { 2. Significant number of } \\
\text { vehicle on the minor } \\
\text { road } \\
\text { 3. Lack of awareness } \\
\text { major drivers }\end{array}$ & $\begin{array}{l}\text { B } \\
1 . \\
\text { Install/improve } \\
\text { warning signs. } \\
\text { 2. Install } \\
\text { overhead } \\
\text { flashing } \\
\text { beacon. } \\
\text { 3. Provide } \\
\text { offset right } \\
\text { turn lanes at } \\
\text { intersection }\end{array}$ \\
\hline \multirow[t]{2}{*}{ B9 } & $\begin{array}{l}\text { A } \\
\text { rear_end_collision_related_to_s } \\
\text { peed_different_turning_right_on } \\
\text { to_highway(yes), } \\
\text { sufficient_sight_distance_minor } \\
\text { right_turning(no), } \\
\text { acceleration_lane_present(no). }\end{array}$ & $\begin{array}{l}\text { A. } \\
\text { 1. Lack of visibility for } \\
\text { vehicles turning right. } \\
\text { 2. High speed condition. }\end{array}$ & $\begin{array}{l}\text { A } \\
\text { 1.Improve } \\
\text { visibility } \\
\text { 2. Providing } \\
\text { right-turn } \\
\text { acceleration } \\
\text { lane }\end{array}$ \\
\hline & $\begin{array}{l}\text { B } \\
\text { rear_end_collision_related_to_s } \\
\text { peed_different_turning_right_on } \\
\text { to_highway(yes), } \\
\text { sufficient_sight_distance_minor } \\
\text { right_turning(yes), } \\
\text { acceleration_lane_present(no). }\end{array}$ & $\begin{array}{l}\text { B } \\
\text { 1. High speed condition } \\
\text { 2. Significant number of } \\
\text { trucks. }\end{array}$ & $\begin{array}{l}\text { B } \\
\text { 1. Providing } \\
\text { right-turn } \\
\text { acceleration } \\
\text { lanes }\end{array}$ \\
\hline \multirow[t]{3}{*}{ B10 } & $\begin{array}{l}\text { divided_highway_present(yes), } \\
\text { shoulder_smaller_8feet(yes), } \\
\text { run_off_road_accident(yes). }\end{array}$ & $\begin{array}{l}\text { Lack of space to avoid } \\
\text { hazardous situation }\end{array}$ & $\begin{array}{l}\text { Provide full } \\
\text { width paved } \\
\text { shoulder. }\end{array}$ \\
\hline & $\begin{array}{l}\text { run_off_road_accident(yes), } \\
\text { abrupt_pavement_change_condi } \\
\text { tion(yes). }\end{array}$ & $\begin{array}{l}\text { Inadequate pavement } \\
\text { condition. }\end{array}$ & $\begin{array}{l}\text { 1. Eliminate } \\
\text { dropoff. } \\
\text { 2. Improve } \\
\text { super- } \\
\text { elevation/crow } \\
\mathrm{n}\end{array}$ \\
\hline & $\begin{array}{l}\text { run_off_road_accident(yes), } \\
\text { steeper_sideslope_present(yes). }\end{array}$ & Inadequate sideslope present. & $\begin{array}{l}\text { Repair } \\
\text { sideslope. }\end{array}$ \\
\hline $\begin{array}{l}\mathrm{B} 11 \\
\mathrm{~B} 12\end{array}$ & $\begin{array}{l}\text { collision_related_to_particular_t } \\
\text { urning_movement(yes). }\end{array}$ & $\begin{array}{l}\text { High turning volume. } \\
\text { Lack of visibility }\end{array}$ & $\begin{array}{l}\text { CHECK IF IT } \\
\text { IS POSSIBLE }\end{array}$ \\
\hline
\end{tabular}




\begin{tabular}{|c|c|c|c|}
\hline B13 & $\begin{array}{l}\text { B11 } \\
\text { NOW } \\
\text { we should ask user question: } \\
\text { improving sign distance } \\
\text { practical? } \\
\text { yes/no, } \\
\text { providing left - turn practical? } \\
\text { yes/no } \\
\text { providing shoulder bypass lane } \\
\text { practical? } \\
\text { yes/no } \\
\text { if yes stop and process if no then } \\
\text { go next } \\
\text { and so on.. }\end{array}$ & & $\begin{array}{l}\text { TO: } \\
\text { 1. Improve } \\
\text { sight distance } \\
\text { 2. Provide left- } \\
\text { turn. } \\
\text { 3. Provide } \\
\text { shoulder } \\
\text { bypass lane. } \\
\text { IF NOT } \\
\text { 4. Clearly } \\
\text { signed } \\
\text { Restrict or } \\
\text { prohibition } \\
\text { turning } \\
\text { movement. } \\
\text { 5. Provide } \\
\text { channelization. } \\
\text { 6. Close } \\
\text { Median } \\
\text { Openings } \\
\text { 7. Close or } \\
\text { relocate high } \\
\text { crash } \\
\text { intersection. }\end{array}$ \\
\hline B14 & $\begin{array}{l}\text { collision_related_to_particular_t } \\
\text { urning_movement(yes), } \\
\text { four_leg_intersection_present(ye } \\
\text { s), } \\
\text { low_cross_street_through_volu } \\
\text { me(yes). } \\
\text { Q: maybe change } \\
\text { collision_related_to_particular_t } \\
\text { urning_movement into more } \\
\text { specific crash type } \\
\text { or leave like it is right now and } \\
\text { after added one rule which will } \\
\text { be specify this? }\end{array}$ & High turning volume. & $\begin{array}{l}\text { 1. Convert four } \\
\text { legged } \\
\text { intersections to } \\
\text { two T- } \\
\text { intersection. }\end{array}$ \\
\hline B15 & $\begin{array}{l}\text { high_cross_street_through_volu } \\
\text { me(yes), } \\
\text { offset_t_intersection_present(ye } \\
\text { s). }\end{array}$ & $\begin{array}{l}\text { High through volume on } \\
\text { cross street. }\end{array}$ & $\begin{array}{l}\text { Convert offset } \\
\text { T-Intersection } \\
\text { to four-legged } \\
\text { Intersection. }\end{array}$ \\
\hline B16 & $\begin{array}{l}\text { sufficient_intersection_sight_dis } \\
\text { tance_major_minor(no),awkwar }\end{array}$ & $\begin{array}{l}\text { Wrong design intersection } \\
\text { angle }\end{array}$ & $\begin{array}{l}\text { Realign a } \\
\text { skewed }\end{array}$ \\
\hline
\end{tabular}




\begin{tabular}{|c|c|c|c|}
\hline & $\begin{array}{l}\text { d_sight_lines(yes),skewed_inter } \\
\text { section(yes). }\end{array}$ & & intersection \\
\hline B17 & $\begin{array}{l}\text { accommodating_left_turn_dema } \\
\text { nd_present_minor(yes). } \\
\text { accommodating_left_turn_dema } \\
\text { nd_present_major(yes). }\end{array}$ & $\begin{array}{l}\text { Lack of visibility, } \\
\text { High speed location, } \\
\text { High left turning volume. }\end{array}$ & $\begin{array}{l}\text { Implement } \\
\text { indirect left } \\
\text { turn. }\end{array}$ \\
\hline \multirow[t]{3}{*}{ B18 } & $\begin{array}{l}\text { collision_involed_pedestrain(yes } \\
\text { ), } \\
\text { school_crossing_area_present(n } \\
\text { o). }\end{array}$ & $\begin{array}{l}\text { Inadequate sight distance. } \\
\text { Inadequate pedestrian } \\
\text { protection. }\end{array}$ & $\begin{array}{l}\text { 1. Continuous } \\
\text { sidewalks; } \\
\text { 2. Signed and } \\
\text { marked } \\
\text { crosswalks; } \\
\text { 3. Pedestrian } \\
\text { signs, signals, } \\
\text { and markings; } \\
\text { 4. Sidewalk } \\
\text { set-backs. } \\
\text { 5. Lighting. }\end{array}$ \\
\hline & $\begin{array}{l}\text { collision_involed_pedestrain(yes } \\
\text { ), } \\
\text { school_crossing_area_present(y } \\
\text { es). }\end{array}$ & Inadequate sight distance. & $\begin{array}{l}\text { Install school } \\
\text { zone markings. } \\
\text { Install school } \\
\text { crossing sight. } \\
\text { Install speed } \\
\text { limit sign. } \\
\text { Use school } \\
\text { crossing } \\
\text { guards }\end{array}$ \\
\hline & $\begin{array}{l}\text { collision_involed_pedestrain(yes } \\
\text { ), } \\
\text { long_distance_to_narest_crossw } \\
\text { alk(yes). }\end{array}$ & $\begin{array}{l}\text { Inadequate sight distance. } \\
\text { high number of pedestrians }\end{array}$ & $\begin{array}{l}\text { Install } \\
\text { pedestrian } \\
\text { crosswalk. } \\
\text { Install } \\
\text { pedestrian } \\
\text { actuated } \\
\text { signals. }\end{array}$ \\
\hline B19 & collision_involed_bicycle(yes). & High number of bicycle & $\begin{array}{l}\text { 1. Widen the } \\
\text { outside through } \\
\text { lanes or adding } \\
\text { bike lanes, } \\
\text { 2. Provide } \\
\text { median refuges } \\
\text { at key minor- }\end{array}$ \\
\hline
\end{tabular}




\begin{tabular}{|c|c|c|c|}
\hline & & & $\begin{array}{l}\text { street crossings, } \\
\text { 3. Provide } \\
\text { independent } \\
\text { bicycle/pedestri } \\
\text { an structures } \\
\text { where } \\
\text { necessary, } \\
\text { 4. Replace } \\
\text { poorly designed } \\
\text { drain grates with } \\
\text { bicycle-safe } \\
\text { models, and } \\
\text { 5. Provide } \\
\text { smooth paved } \\
\text { shoulders. }\end{array}$ \\
\hline $\mathrm{C} 1$ & $\begin{array}{l}\text { sufficient_intersection_sight_dis } \\
\text { tance_minor(no), } \\
\text { stop_sign_intersection(yes). } \\
\text { sufficient_intersection_sight_dis } \\
\text { tance_minor(no), } \\
\text { yield_sign_intersection(yes). }\end{array}$ & Lack of visibility & $\begin{array}{l}\text { Remove sight } \\
\text { triangle } \\
\text { obstruction. }\end{array}$ \\
\hline $\mathrm{C} 2$ & $\begin{array}{l}\text { divided_highways_present(yes), } \\
\text { fixed_sight_obstruction_in_med } \\
\text { ian_close_to_intersection(yes). } \\
\text { divided_highways_present(yes), } \\
\text { sufficient_intersection_sight_dis } \\
\text { tance(no). }\end{array}$ & Lack of visibility & $\begin{array}{l}\text { Clear sight } \\
\text { triangle in the } \\
\text { median. }\end{array}$ \\
\hline $\mathrm{C} 3$ & $\begin{array}{l}\text { horizontal_curves_present(yes), } \\
\text { sufficient_intersection_sight_dis } \\
\text { tance(no). } \\
\text { vertical_curves_present(yes), } \\
\text { sufficient_intersection_sight_dis } \\
\text { tance(no). }\end{array}$ & $\begin{array}{l}\text { Lack of visibility due } \\
\text { insufficient vertical } \\
\text { alignment }\end{array}$ & $\begin{array}{l}\text { Change } \\
\text { horizontal and } \\
\text { or vertical } \\
\text { alignment. }\end{array}$ \\
\hline
\end{tabular}




\begin{tabular}{|c|c|c|c|}
\hline C4 & $\begin{array}{l}\text { parking_restricted_sight_distanc } \\
\text { e(yes). }\end{array}$ & $\begin{array}{l}\text { Lack of visibility due } \\
\text { parking. }\end{array}$ & $\begin{array}{l}\text { Enforcement } \\
\text { parking } \\
\text { restriction. }\end{array}$ \\
\hline \multirow[t]{2}{*}{$\begin{array}{l}\text { D1 } \\
\text { D2 }\end{array}$} & $\begin{array}{l}\text { A } \\
\text { sufficient_sight_distance_crossi } \\
\text { ng_manouver(no). }\end{array}$ & $\begin{array}{l}\text { A } \\
\text { Lack of visibility }\end{array}$ & \multirow[t]{2}{*}{$\begin{array}{l}\text { 1.Provide an } \\
\text { Automated real- } \\
\text { Time System to } \\
\text { inform Drivers } \\
\text { of Suitability of } \\
\text { Available Gaps } \\
\text { for Marking } \\
\text { Turning and } \\
\text { Crossing } \\
\text { Maneuvers. } \\
\text { 2. Provide } \\
\text { Roadside } \\
\text { Markers or } \\
\text { Pavement } \\
\text { Markings to } \\
\text { Assist } \\
\text { Drivers in } \\
\text { Judging the } \\
\text { Suitability of } \\
\text { Available } \\
\text { Gaps for } \\
\text { Making } \\
\text { Turning and } \\
\text { Crossing } \\
\text { Maneuvers }\end{array}$} \\
\hline & $\begin{array}{l}\text { B } \\
\text { sufficient_sight_distance_crossi } \\
\text { ng_manouver(yes). }\end{array}$ & $\begin{array}{l}\text { B } \\
\text { Misjudge available gaps }\end{array}$ & \\
\hline D3 & $\begin{array}{l}\text { right_angle_collision_minor_ma } \\
\text { jor(yes), } \\
\text { lack_of_sufficient_gap(yes). } \\
\text { turning_related_collision_minor } \\
\text { major(yes), } \\
\text { lack_of_sufficient_gap(yes). }\end{array}$ & $\begin{array}{l}\text { High major road traffic } \\
\text { To short gaps. }\end{array}$ & $\begin{array}{l}\text { Retime of } \\
\text { Adjacent } \\
\text { Signals to } \\
\text { Create Gaps at } \\
\text { Stop- } \\
\text { Controlled } \\
\text { Intersections }\end{array}$ \\
\hline $\begin{array}{l}\text { E1 } \\
\text { E5 }\end{array}$ & $\begin{array}{l}\text { sufficient_visiblity_to_approach } \\
\text { ing_major_vehicle(no), } \\
\text { rear_end_collision(yes). } \\
\text { sufficient_visiblity_to_approach } \\
\text { ing_major_vehicle(no), }\end{array}$ & $\begin{array}{l}\text { Lack of major driver } \\
\text { awareness of approaching } \\
\text { intersection. }\end{array}$ & $\begin{array}{l}\text { 1. Improve } \\
\text { Visibility of } \\
\text { Intersections } \\
\text { by Providing } \\
\text { Enhanced } \\
\text { Signing and }\end{array}$ \\
\hline
\end{tabular}




\begin{tabular}{|c|c|c|c|}
\hline & $\begin{array}{l}\text { right_angle_collision(yes). } \\
\text { sufficient_visiblity_to_approach } \\
\text { ing_major_vehicle(no), } \\
\text { turning_collision(yes). }\end{array}$ & & $\begin{array}{l}\text { Delineation } \\
\text { 2. Install } \\
\text { Larger } \\
\text { Regulatory and } \\
\text { Warning Signs } \\
\text { at Intersections }\end{array}$ \\
\hline E2 & $\begin{array}{l}\text { high_night_collision_present(ye } \\
\text { s), } \\
\text { rear_and_collision(yes). } \\
\text { high_night_collision_present(ye } \\
\text { s), } \\
\text { right_angle_collision(yes). } \\
\text { high_night_collision_present(ye } \\
\text { s), } \\
\text { turning_collision(yes). }\end{array}$ & $\begin{array}{l}\text { Poor visibility or lighting. } \\
\text { Poor sign quality. } \\
\text { Inadequate channelization or } \\
\text { delineation. }\end{array}$ & $\begin{array}{l}\text { 1.Improve } \\
\text { Visibility of } \\
\text { the } \\
\text { Intersection by } \\
\text { Providing } \\
\text { Lighting }\end{array}$ \\
\hline E3 & $\begin{array}{l}\text { sufficient_traffic_controle_mino } \\
\text { r_road_visibility(no), } \\
\text { high_minor_road_speed(yes). }\end{array}$ & $\begin{array}{l}\text { Driver on the minor } \\
\text { approach unaware of } \\
\text { intersection present. }\end{array}$ & $\begin{array}{l}\text { 2. Install } \\
\text { Splitter Islands } \\
\text { on the Minor- } \\
\text { Road } \\
\text { Approach } \\
\text { to an } \\
\text { Intersection }\end{array}$ \\
\hline $\begin{array}{l}\text { E4 } \\
\text { E6 }\end{array}$ & $\begin{array}{l}\text { collision_related_to_traffic_cont } \\
\text { rol_violations(yes). } \\
\text { poor_traffic_control_recognition } \\
\text { (yes). }\end{array}$ & $\begin{array}{l}\text { Inadequate visibility of } \\
\text { traffic control, traffic control } \\
\text { violations }\end{array}$ & $\begin{array}{l}\text { 1. Provide a } \\
\text { Stop Bar (or } \\
\text { Provide a } \\
\text { Wider Stop } \\
\text { Bar) on } \\
\text { Minor-Road } \\
\text { Approaches } \\
\text { 2. Call } \\
\text { Attention to } \\
\text { the } \\
\text { Intersection by } \\
\text { Installing } \\
\text { Rumble Strips } \\
\text { on Intersection } \\
\text { Approaches }\end{array}$ \\
\hline E7 & $\begin{array}{l}\text { divided_highways_present(yes), } \\
\text { rear_end_collision_major(yes), }\end{array}$ & $\begin{array}{l}\text { Lack of driver awareness of } \\
\text { the intersection. }\end{array}$ & $\begin{array}{l}\text { 1. Provide } \\
\text { Dashed }\end{array}$ \\
\hline
\end{tabular}




\begin{tabular}{|c|c|c|c|}
\hline & $\begin{array}{l}\text { sufficient_visiblity_to_approach } \\
\text { ing_major_vehicle(no). } \\
\text { divided_highways_present(yes), } \\
\text { right_angle_collision(yes), } \\
\text { sufficient_visiblity_to_approach } \\
\text { ing_major_vehicle(no). } \\
\\
\text { divided_highways_present(yes), } \\
\text { turning_collision(yes), } \\
\text { sufficient_visiblity_to_approach } \\
\text { ing_major_vehicle(no). }\end{array}$ & & $\begin{array}{l}\text { Markings } \\
\text { (Extended Left } \\
\text { Edgelines) for } \\
\text { Major-Road } \\
\text { Continuity } \\
\text { Across the } \\
\text { Median } \\
\text { Opening at } \\
\text { Divided } \\
\text { Highway } \\
\text { Intersections }\end{array}$ \\
\hline $\begin{array}{l}\text { E8 } \\
\text { E9 }\end{array}$ & $\begin{array}{l}\text { rear_end_collision_minor(yes), } \\
\text { sufficient_visiblity_to_approach } \\
\text { ing_minor_vehicle(no). } \\
\text { right_angle_collision(yes), } \\
\text { sufficient_intersection_visiblity_ } \\
\text { minor_vehicle(no). } \\
\text { turning_collision(yes), } \\
\text { sufficient_intersection_visibility } \\
\text { _minor_vehicle(no). } \\
\text { rear_and_collision_minor(yes), } \\
\text { long_stretch_of_highway_witho } \\
\text { ut_stop(yes). } \\
\text { right_angle_collision(yes), } \\
\text { long_stretch_of_highway_witho } \\
\text { ut_stop(yes). } \\
\text { turning_collision(yes), } \\
\text { long_stretch_of_highway_witho } \\
\text { ut_stop(yes). }\end{array}$ & $\begin{array}{l}\text { Lack of driver awareness of } \\
\text { the intersection. (stop } \\
\text { control). }\end{array}$ & $\begin{array}{l}\text { 1. Provide } \\
\text { Supplementary } \\
\text { Stop Signs } \\
\text { Mounted Over } \\
\text { the } \\
\text { Roadway } \\
\text { 2. Provide } \\
\text { Pavement } \\
\text { Markings with } \\
\text { Supplementary } \\
\text { Messages, } \\
\text { Such as STOP } \\
\text { AHEAD }\end{array}$ \\
\hline
\end{tabular}




\begin{tabular}{|c|c|c|c|}
\hline E10 & $\begin{array}{l}\text { high_collision_location_related_ } \\
\text { right_of_way(yes), } \\
\text { stop_control_sign(yes), } \\
\text { adequate_stop_sign_maintenanc } \\
\text { e(no). }\end{array}$ & $\begin{array}{l}\text { Lack visibility of the stop } \\
\text { sign. }\end{array}$ & $\begin{array}{l}\text { 1.Provide } \\
\text { Improved } \\
\text { Maintenance of } \\
\text { Stop Signs }\end{array}$ \\
\hline E11 & $\begin{array}{l}\text { right_angle_collision(yes), } \\
\text { sufficient_intersection_sign_info } \\
\text { rmation(no) }\end{array}$ & $\begin{array}{l}\text { Lack of driver awareness of } \\
\text { the intersection on major and } \\
\text { minor(stop controlled) } \\
\text { approach. }\end{array}$ & $\begin{array}{l}\text { 1.Install } \\
\text { Flashing } \\
\text { Beacons at } \\
\text { Stop- } \\
\text { Controlled } \\
\text { Intersections } \\
\text { (minor and/or } \\
\text { major } \\
\text { approach). }\end{array}$ \\
\hline F1 & $\begin{array}{l}\text { collision_related } \\
\text { to_high_volume_intersection(ye } \\
\text { s). } \\
\text { collision_related_to_medium_vo } \\
\text { lume_intersection(yes). }\end{array}$ & & $\begin{array}{l}\text { 1.Before } \\
\text { considering } \\
\text { install } \\
\text { signalization try } \\
\text { to identify } \\
\text { appropriate } \\
\text { alternative } \\
\text { design traffic } \\
\text { control methods. }\end{array}$ \\
\hline F2 & $\begin{array}{l}\text { right_angle_collision(yes), } \\
\text { turning_collision(yes), } \\
\text { moderate_relatively_balanced_v } \\
\text { olume_on_approaches(yes), } \\
\text { all_way_stop_control_present(n } \\
\text { o). }\end{array}$ & $\begin{array}{l}\text { Sight distance restriction. } \\
\text { High through and turning } \\
\text { volume. }\end{array}$ & $\begin{array}{l}\text { 1.Use all-way } \\
\text { stop control } \\
\text { intersection. }\end{array}$ \\
\hline F3 & $\begin{array}{l}\text { moderate_relatively_balanced_v } \\
\text { olume_on_approaches(yes), } \\
\text { rear_end_collision(yes). } \\
\text { moderate_relatively_balanced_v } \\
\text { olume_on_approaches(yes), } \\
\text { rear_collision_location(yes). }\end{array}$ & Lack of driver awareness. & $\begin{array}{l}\text { 1. Alternative } \\
\text { solution to } \\
\text { signalize } \\
\text { intersection: } \\
\text { design } \\
\text { roundabout. }\end{array}$ \\
\hline G1 & $\begin{array}{l}\text { collision_related_to_stop_sign_ } \\
\text { violations(yes). }\end{array}$ & Driver irresponsibility. & $\begin{array}{l}\text { 1. Provide } \\
\text { Targeted } \\
\text { Enforcement }\end{array}$ \\
\hline
\end{tabular}




\begin{tabular}{|c|c|c|c|}
\hline & & & $\begin{array}{l}\text { to Reduce Stop } \\
\text { Sign } \\
\text { Violations }\end{array}$ \\
\hline G2 & $\begin{array}{l}\text { high_collision_location(yes). } \\
\text { (I will connect this with G1). }\end{array}$ & $\begin{array}{l}\text { Lack of safety problem } \\
\text { understanding by drivers. }\end{array}$ & $\begin{array}{l}\text { 1. Provide } \\
\text { Targeted } \\
\text { Public } \\
\text { Information } \\
\text { and Education } \\
\text { on } \\
\text { Safety } \\
\text { Problems at } \\
\text { Specific } \\
\text { Intersections }\end{array}$ \\
\hline $\begin{array}{l}\mathrm{H} 1 \\
\mathrm{H} 2\end{array}$ & $\begin{array}{l}\text { collision_related_to_speed_viola } \\
\text { tions(yes). } \\
\text { right_angle_collision(yes), } \\
\text { speed_violations_present(yes). } \\
\text { rear_end_collision_minor(yes), } \\
\text { speed_violations_present(yes). } \\
\text { rear_end_collision_major(yes), } \\
\text { speed_violations_present(yes). } \\
\\
\text { turning_collision(yes), } \\
\text { speed_violations_present(yes). }\end{array}$ & $\begin{array}{l}\text { High speed which lead to } \\
\text { collision pattern. }\end{array}$ & $\begin{array}{l}\text { 1.Provide } \\
\text { Targeted Speed } \\
\text { Enforcement. } \\
\text { 2. Provide } \\
\text { Traffic } \\
\text { Calming on } \\
\text { Intersection } \\
\text { Approaches } \\
\text { through } \\
\text { a Combination } \\
\text { of Geometric } \\
\text { and Traffic } \\
\text { Control } \\
\text { Devices }\end{array}$ \\
\hline H3 & $\begin{array}{l}\text { collision_related_to_speed_viola } \\
\text { tions(yes), } \\
\text { collision_near_intersection(yes). }\end{array}$ & $\begin{array}{l}\text { High speed which lead to } \\
\text { collision pattern. }\end{array}$ & $\begin{array}{l}\text { 1. Post } \\
\text { Appropriate } \\
\text { Speed Limits } \\
\text { on Intersection } \\
\text { Approaches }\end{array}$ \\
\hline I1 & $\begin{array}{l}\text { complex_intersection_present(y } \\
\text { es), } \\
\text { collision_related_to_vehicle_pos } \\
\text { itioning_i_e_sideswipe_crashes( } \\
\text { yes). }\end{array}$ & $\begin{array}{l}\text { Inadequate intersection } \\
\text { pavement marking. }\end{array}$ & $\begin{array}{l}\text { 1.Provide Turn } \\
\text { Path Markings }\end{array}$ \\
\hline $\mathrm{I} 2$ & $\begin{array}{l}\text { divided_highway_present(yes), } \\
\text { side_by_side_queuing_collison( } \\
\text { yes). }\end{array}$ & $\begin{array}{l}\text { Driver confusing. } \\
\text { Inadequate intersection } \\
\text { pavement marking. }\end{array}$ & $\begin{array}{l}\text { 1. Provide } \\
\text { Double Yellow } \\
\text { Centerline on }\end{array}$ \\
\hline
\end{tabular}




\begin{tabular}{|l|l|l|l|}
\hline & $\begin{array}{l}\text { divided_highway_present(yes), } \\
\text { angle_stopping_collison(yes). }\end{array}$ & $\begin{array}{l}\text { the Median } \\
\text { Opening of } \\
\text { a Divided } \\
\text { Highway at } \\
\text { Intersections }\end{array}$ \\
\hline I3 & $\begin{array}{l}\text { collision_lead_to_driver_indecis } \\
\text { ion(yes). } \\
\text { or maybe ask: } \\
\text { driver_indecision_present(yes). }\end{array}$ & $\begin{array}{l}\text { Driver confusing by } \\
\text { inadequate intersection } \\
\text { approach marking and } \\
\text { signing. }\end{array}$ & $\begin{array}{l}\text { Assignment } \\
\text { Signing or } \\
\text { Marking at } \\
\text { Complex } \\
\text { Intersections }\end{array}$ \\
\hline EXTRA & $\begin{array}{l}\text { collision_related_to_sleepery_pa } \\
\text { vement(yes). }\end{array}$ & $\begin{array}{l}\text { Wet Pavement } \\
\text { Inadequate drainage }\end{array}$ & $\begin{array}{l}\text { Provide } \\
\text { adequate } \\
\text { drainage } \\
\text { Improve } \\
\text { roadway } \\
\text { crown } \\
\text { Reduce speed } \\
\text { limit }\end{array}$ \\
& & & $\begin{array}{l}\text { Use “slippery } \\
\text { when wet” } \\
\text { sign }\end{array}$ \\
\hline
\end{tabular}




\section{Appendix E}

\section{The knowledge Base}

(Two-way stop-controlled intersections)

\section{TWSC Intersection}

\section{Driveways collisions}

\subsection{Driveways close to intersection}

\# Improve visibility of the driveways \#1 Remove sight obstructions \#2 Restrict parking near the driveway \#3 Install/Improve lighting at the access points \#4 Install channelization of the driveways \#5 Reduce speed limit \#6 Restrict left-turning at the access points \#7 Close or relocate the driveways

\section{Night time collisions}

\subsection{Inadequate street lights}

\#1. Improve street lights \#2. Improve/install reflectorized pavement markers \#3. Remove distracting commercial lights

\subsection{Inadequate channelization}

\#1. Install pavement markings \#2. Improve channelization/delineation

\subsection{Lack of street lights}

$\# 1$. Install street lights

\subsection{Poor signs visibility}

\#1. Upgrade signing \#2. Improve/install reflective signs

\section{Off-road collisions}

\subsection{Fix object close to traveled way}

\#1. Remove or relocate the object \#2. Install an object marker \#3. Install a barrier curb or a guardrail \#4. Add special signing

\subsection{Inadequate lanes width}

\#1. Improve lanes width

\subsection{Inadequate pavement marking}

\#1. Install reflectorized pavement marking 


\subsection{Inadequate shoulders width}

\#1. Increase width of the shoulders

\subsection{Inadequate road alignment}

\#1. Improve alignment

\section{Right-angle collisions}

\subsection{Stop sign not missing}

\subsubsection{Stop sign visible}

\subsubsection{Long distance to the downstream stop sign}

\# Improve driver awareness of the intersection \#1 Provide visible stop bars \#2 Install rumble strips \#3 Provide splitter islands \#4 Install a warning sign about the intersection \#5 Provide pavement marking (stop sign, chevron, etc.)

\subsubsection{Insufficient sight distance from the minor road}

\subsection{Poor horizontal/vertical alignment}

\#1. Change horizontal/vertical alignment

\subsection{Major-road right-turning vehicles obstruct sight}

\# Vehicles in the right-turn lane on the major road block the minor-road drivers' view of traffic approaching on the major road. \#1 Consider moving the right-turn lanes on the major road laterally (ref: NCHRP REPORT 500)

\subsection{Roadside sight obstruction}

\#1. Remove the object obstructing the sight triangle \#2. Trim vegetation \#3. Install corner mirrors \#4. Reduce speed on the major road

\subsection{Multiple lanes on the minor approach}

4.1.1.2.4.1 Sight distance obstructed by other vehicles \#1. Reduce the number of lanes on the minor approach if allowed by capacity \#2. Relocate or split the stopping line \#3. Install a triangular island to relocate the right-turning movement away from other movements \#4. Restrict parking on the approach

\subsubsection{Insufficient gaps in the priority traffic}

\#1. Adjust signal offsets at the upstream signalized intersections to create more gaps \#2. Install traffic signals

\subsubsection{Inadequate pavement marking}

\#1. Provide adequate delineation for left-turns at the intersection (markers or lines)

\subsubsection{Divided road}


4.1.1.5.1 Inadequate road marking on crossing median

\#1. Add stop-lines in the median opening \#2. Improve pavement marking in the median opening

4.1.1.5.2 Inadequate median width

\#1. Widen the median to provide sufficient protection to crossing vehicles

\subsubsection{Stop sign not visible}

\subsubsection{Improperly stop sign maintained}

\#1. Replace, repair, or clean the sign

\subsubsection{Poor horizontal/vertical alignment}

\#1. Change horizontal/vertical alignment

\subsubsection{Stop sign obstruction}

\#1. Remove the object obstructing the sight of the stop sign

\subsubsection{Multiple lanes on approaches}

\#1. Add overhead stop-signs if the percent of tall vehciles is considerable

\subsection{Stop sign missing}

\#1. Install a stop sign

\section{Rear-end collisions}

\subsection{Crashes on major road}

\subsubsection{Crashes on the approach}

\subsubsection{Left-turn bay present}

\subsection{Vehicle queues extend beyond the taper}

\#1. Increase the length of the left turn lanes \#2. Install traffic signals \#3. Install indirect left-turn lanes \#4. Convert the intersection into a roundabout

5.1.1.1.2 Vehicles slow down before entering the turning bay

\#1. Increase the length of the left turn lanes

\subsubsection{There is no left-turn bay}

\subsection{Shared lanes with left turns}

$\# 1$. Install left turn bays if turning volume is considerable

5.1.1.2.2 Exclusive lanes for left turns 
\#1. Install left turn bays

\subsubsection{Right-turn lanes present}

5.1.1.3.1 Vehicles slow down before entering the turning bay

\#1. Increase length of the right turn lanes \#2. Increase radius of the corner curve

\subsubsection{No right-turn lane}

\#1. Install right turn bays if the number of vehicle turning right is considerable \#2.

Increase the turning path radius

\subsubsection{Poor pavement marking}

\#1. Improve pavement marking

\subsubsection{Inadequate lanes width}

\#1. Widen lanes to adequate width

\subsubsection{Inadequate lanes signing or marking}

\#1.Provide adequate lanes signing or marking

\subsubsection{Inadequate shoulders width}

\#1. Increase width of the shoulders

\subsubsection{Intersection type " $T$ "}

\#1. Provide a bypass lane on the approach with left-turn traffic

\subsubsection{Crashes on the exit}

\subsubsection{Considerable turning volume entering the major road}

\#1. Install an acceleration lane

\subsubsection{Considerable number of trucks entering the major road}

\#1. Install acceleration lanes sufficiently long for trucks

\section{Adverse-weather collisions}

\subsection{Fog}

$\# 1$. Install fog - warning signs

\subsection{Snow/Slush/lce}

\#1. Improve winter maintenance preparedness (shorter response time) \#2. Improve winter maintenance methods \#3. Use sand to increase pavement friction \#4. Use salt to prevent snow or ice from forming or from sticking to the road surface \#5. Installing snow screens in areas exposed to snowdrifts \#6. Install static or variable message signs displaying weather information 


\subsection{Slippery pavement (no winter)}

\#1. Overlay pavement (friction course) \#2. Chip and seal or slurry seal approaches \#3.

Groove pavement surface \#4. Provide adequate drainage \#5. Reduce speed limit \#6. Use

"Slippery when wet” sign (temporary)

\section{Pedestrian/Bicycle collisions}

\subsection{Bicycle collisions}

\#1. Widen the outside through lanes or add bike lanes \#2. Provide median refuges \#3. Provide independent bicycle path where necessary \#4. Replace poorly designed drain grates with bicycle-safe types \#5. Provide smooth paved shoulders

\subsection{Pedestrian collisions}

\subsubsection{School zone}

\#1. Install school zone markings \#2. Install school crossing sign \#3. Install speed limit sign \#4. Use school crossing guards

\subsubsection{Long distance between crosswalks}

\#1. Install pedestrian crosswalk \#2. Install pedestrian actuated signals

\subsubsection{Crashes on existing crosswalk}

\#1. Install sidewalk set-backs \#2. Install raised crosswalk \#3. Improve signage and/or marking of the crosswalk \#4. Install a pedestrian overpass or underpass \#5. Install lighting

\section{Left-turn collisions on major road}

\subsection{Divided major road}

\subsubsection{Poor visibility of opposite vehicles}

\subsubsection{Opposite left turn vehicles obstruct visibility}

\#1. Provide offset for left turn lanes on the opposite approaches \#2. Restrict left-turn maneuver \#3. Consider indirect left turns

\subsubsection{Poor horizontal/vertical alignment}

\#1. Change horizontal/vertical alignment

\subsubsection{Median object obstructs sight distance}

\#1. Remove or re-locate the median object obstructing sight of opposite traffic

\subsubsection{Insufficient median width}

\#1. Widen the median width \#2. Properly maintain the striping 


\subsection{Undivided highway}

\subsubsection{Poor visibility of opposite vehicles}

\subsubsection{Opposite left turn vehicles obstruct visibility}

\#1. Restrict left-turn maneuver \#2. Consider indirect left turns

\subsubsection{Poor horizontal/vertical alignment}

\#1. Change horizontal/vertical alignment

\subsection{Pedestrians may block exits on the minor road}

\#1. Increase the crosswalk setback

\subsection{Long queues of left-turn vehicles}

$\# 1$. Convert the intersection to a roundabout if traffic on the minor road is significant \#2.

Consider traffic signals with protected left-turn phase \#3. Consider indirect left-turn movements

\subsection{Inadequate pavement marking}

\#1. Provide adequate turning markers or pavement markings

\section{Excessive speed}

\subsection{Frequent stop sign violations}

\#1. Enforce stop sign compliance

\subsection{No posted speed limit}

\#1. Post an adequate speed limit

\subsection{Posted speed limit}

\#1. Provide targeted speed enforcement \#2. Provide traffic calming on intersection approaches through a combination of geometric and traffic control devices \#3. Post dynamic message sign to display the speed of approaching vehicles. \#4. Post a lower speed limit

\section{Intersection inconspicuous}

10.1 No advance warning sign

\#1. Install warning signs in advance of intersections

\subsection{Advance warning sign posted}

\subsubsection{Warning sign poorly visible/recognizable}

10.2.1.1 Improperly warning sign maintained 
$\# 1$. Replace, repair, or clean the warning signs

\subsubsection{Warning sign obstruction}

\#1. Relocate the sign to make it visible \#2. Remove the object obstructing sight of the warning sign

\subsubsection{Visual distraction}

\#1. Install larger regulatory and warning signs at and in advance of intersections \#2.

Install regulatory signs on the both side of the road \#3. Install overhead flashing beacon lights \#4. Provide on-pavement horizontal signing 


\section{Appendix F}

\section{CLIPS code}






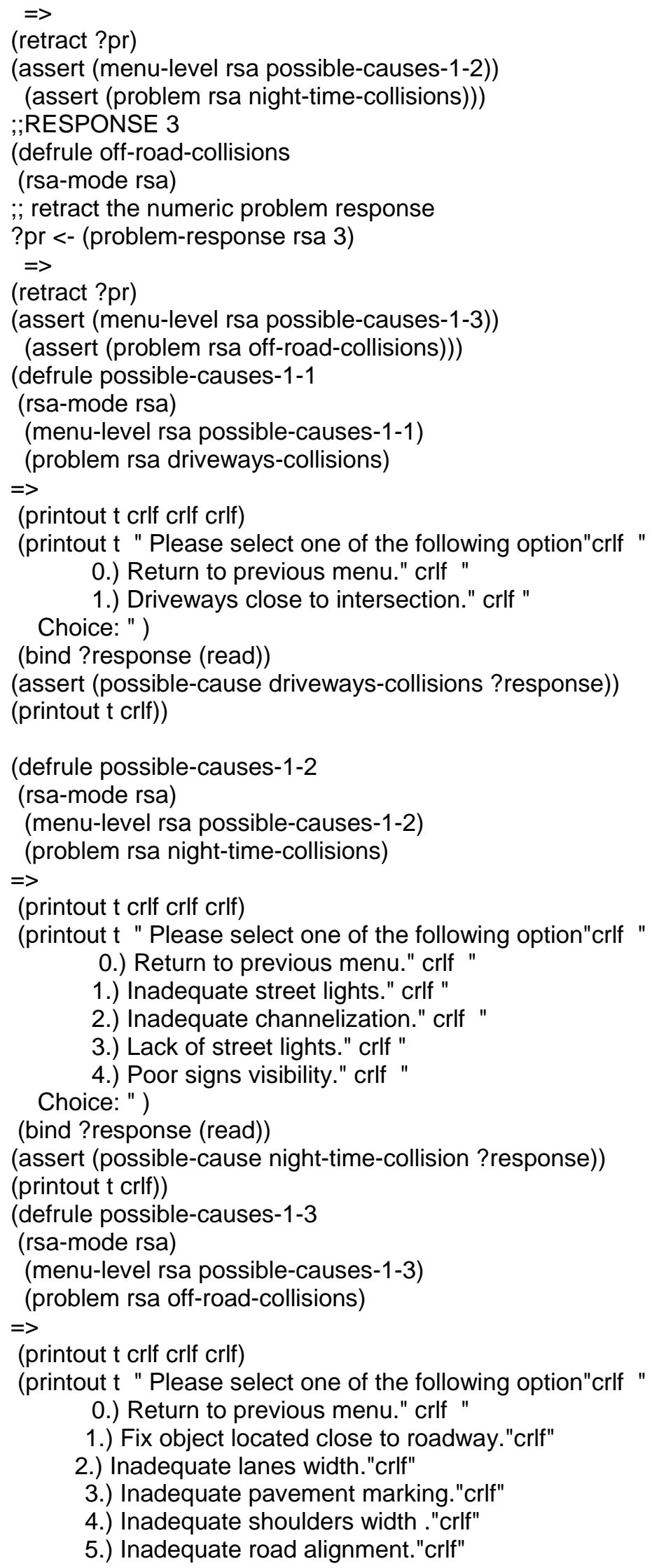




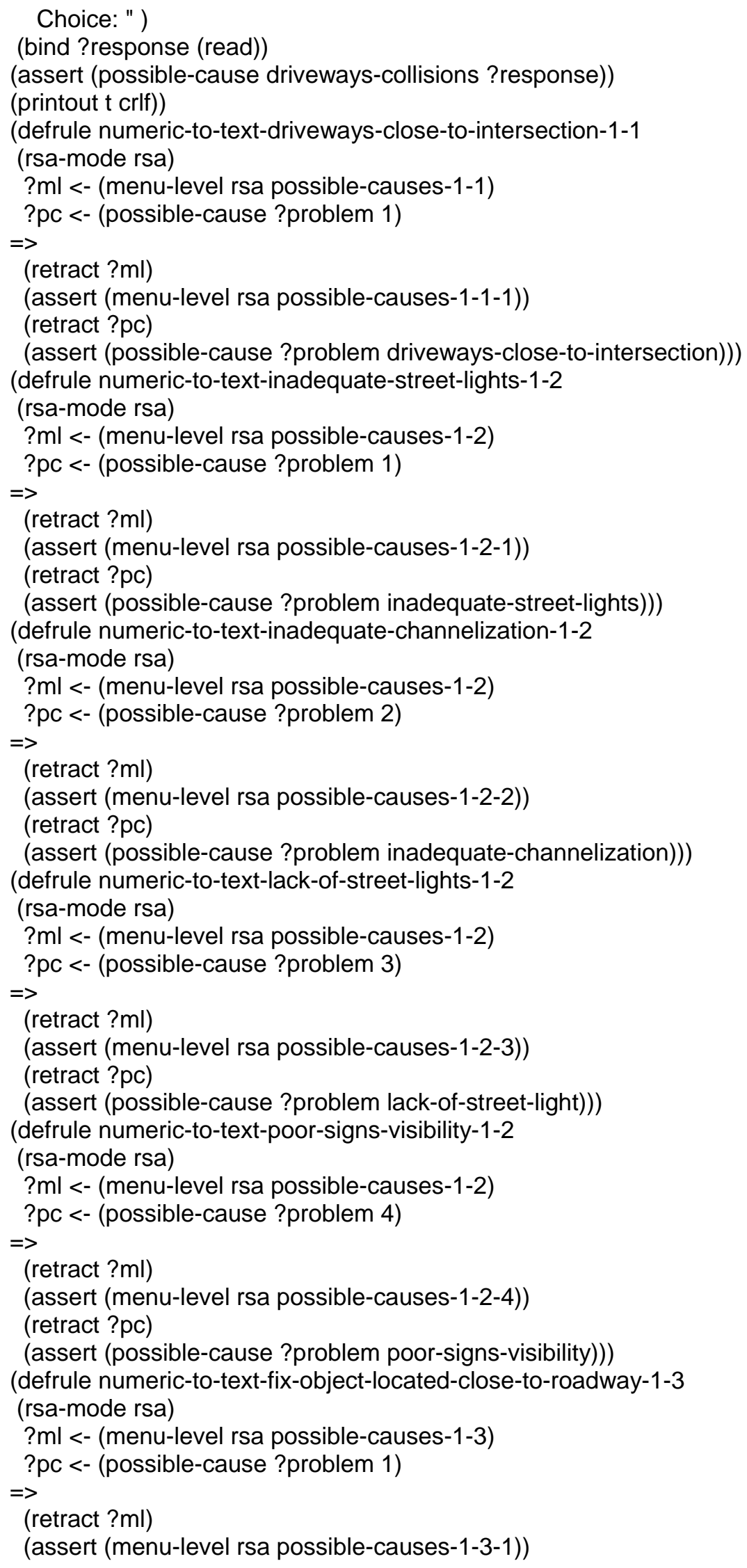




\section{(retract ?pc)}

(assert (possible-cause ?problem fix-object-located-close-to-roadway)))

(defrule numeric-to-text-inadequate-lanes-width-1-3

(rsa-mode rsa)

?ml <- (menu-level rsa possible-causes-1-3)

?pc <- (possible-cause ?problem 2)

$=>$

(retract ?ml)

(assert (menu-level rsa possible-causes-1-3-2))

(retract ?pc)

(assert (possible-cause ?problem inadequate-lanes-width)))

(defrule numeric-to-text-inadequate-pavement-marking-1-3

(rsa-mode rsa)

?ml <- (menu-level rsa possible-causes-1-3)

?pc <- (possible-cause ?problem 3)

$=>$

(retract ?ml)

(assert (menu-level rsa possible-causes-1-3-3))

(retract ?pc)

(assert (possible-cause ?problem inadequate-pavement-marking)))

(defrule numeric-to-text-inadequate-shoulders-width-1-3

(rsa-mode rsa)

?ml <- (menu-level rsa possible-causes-1-3)

?pc <- (possible-cause ?problem 4)

$=>$

(retract ?ml)

(assert (menu-level rsa possible-causes-1-3-4))

(retract ?pc)

(assert (possible-cause ?problem inadequate-shoulders-width)))

(defrule numeric-to-text-inadequate-road-alignment-1-3

(rsa-mode rsa)

?ml <- (menu-level rsa possible-causes-1-3)

?pc <- (possible-cause ?problem 5)

$=>$

(retract ?ml)

(assert (menu-level rsa possible-causes-1-3-5))

(retract ?pc)

(assert (possible-cause ?problem inadequate-road-alignment)))

(defrule possible-causes-of-driveways-close-to-intersection

(rsa-mode rsa)

(menu-level rsa possible-causes-1-1-1)

?pc <- (possible-cause ?problem driveways-close-to-intersection)

$=>$

(retract ?pc)

(printout t crlf crlf crlf)

(printout t "

1. Improve visibility of the driveways."crlf"

1.1 Remove sight obstructions."crlf"

1.2 Restrict parking near the driveway."crlf"

1.3 Install/Improve lighting at the access points."crlf"

2. Install channelization of the driveways. "crlf"

3. Reduce speed limit."crlf"

4. Restrict left-turning at the access points. "crlf"

5. Close or relocate the driveways."crlf" 
Press enter to return to previous menu." crlf)

(bind ?response (readline))

(assert (menu-level rsa possible-causes-1-1)))

(defrule possible-causes-of-inadequate-street-lights

(rsa-mode rsa)

(menu-level rsa possible-causes-1-2-1)

?pc <- (possible-cause ?problem inadequate-street-lights)

$=>$

(retract ?pc)

(printout t crlf crlf crlf)

(printout t "

1. Improve street lights."crlf"

2. Improve/install reflectorized pavement markers."crlf"

3. Remove distracting commercial lights."crlf"

Press enter to return to previous menu." crlf)

(bind ?response (readline))

(assert (menu-level rsa possible-causes-1-2)))

(defrule possible-causes-of-inadequate-channelization

(rsa-mode rsa)

(menu-level rsa possible-causes-1-2-2)

?pc <- (possible-cause ?problem inadequate-channelization)

$=>$

(retract ?pc)

(printout t crlf crlf crlf)

(printout $\mathrm{t}$ "

1. Install pavement markings."crlf"

2. Improve channelization/delineation."crlf"

Press enter to return to previous menu." crlf)

(bind ?response (readline))

(assert (menu-level rsa possible-causes-1-2)))

(defrule possible-causes-of-lack-of-street-light

(rsa-mode rsa)

(menu-level rsa possible-causes-1-2-3)

?pc <- (possible-cause ?problem lack-of-street-light)

$=>$

(retract ?pc)

(printout t crlf crlf crlf)

(printout t "

1. Install street lights."crlf"

Press enter to return to previous menu." crlf)

(bind ?response (readline))

(assert (menu-level rsa possible-causes-1-2)))

(defrule possible-causes-of-poor-signs-visibility

(rsa-mode rsa)

(menu-level rsa possible-causes-1-2-4)

?pc <- (possible-cause ?problem poor-signs-visibility)

$=>$

(retract ?pc)

(printout t crlf crlf crlf)

(printout t "

1. Upgrade signing."crlf"

2. Improve/install reflective signs."crlf"

Press enter to return to previous menu." crlf)

(bind ?response (readline))

(assert (menu-level rsa possible-causes-1-2))) 
(defrule possible-causes-of-remove-or-relocate-the-object

(rsa-mode rsa)

(menu-level rsa possible-causes-1-3-1)

?pc <- (possible-cause ?problem remove-or-relocate-the-object)

$=>$

(retract ?pc)

(printout t crlf crlf crlf)

(printout t "

Press enter to return to previous menu." crlf)

(bind ?response (readline))

(assert (menu-level rsa possible-causes-1-3)))

(defrule possible-causes-of-poor-signs-visibility

(rsa-mode rsa)

(menu-level rsa possible-causes-1-2-4)

?pc <- (possible-cause ?problem poor-signs-visibility)

$=>$

(retract ?pc)

(printout t crlf crlf crlf)

(printout t "

1. Upgrade signing."crlf"

2. Improve/install reflective signs."crlf"

Press enter to return to previous menu." crlf)

(bind ?response (readline))

(assert (menu-level rsa possible-causes-1-2)))

(defrule possible-causes-of-fix-object-located-close-to-roadway

(rsa-mode rsa)

(menu-level rsa possible-causes-1-3-1)

?pc <- (possible-cause ?problem fix-object-located-close-to-roadway)

$=>$

(retract ?pc)

(printout t crlf crlf crlf)

(printout t "

1. Remove or relocate the object."crlf"

2. Install an object marker."crlf"

3. Install a barrier curb or a guardrail."crlf"

4. Add special signing."crlf"

Press enter to return to previous menu." crlf)

(bind ?response (readline))

(assert (menu-level rsa possible-causes-1-3)))

(defrule possible-causes-of-inadequate-lanes-width

(rsa-mode rsa)

(menu-level rsa possible-causes-1-3-2)

?pc <- (possible-cause ?problem inadequate-lanes-width)

$=>$

(retract ?pc)

(printout t crlf crlf crlf)

(printout t "

1. Improve lanes width."crlf"

Press enter to return to previous menu." crlf)

(bind ?response (readline))

(assert (menu-level rsa possible-causes-1-3)))

(defrule possible-causes-of-inadequate-pavement-marking

(rsa-mode rsa)

(menu-level rsa possible-causes-1-3-3)

?pc <- (possible-cause ?problem inadequate-pavement-marking)

$=>$ 
(retract ?pc)

(printout t crlf crlf crlf)

(printout t "

1. Install reflectorized pavement marking."crlf"

Press enter to return to previous menu." crlf)

(bind ?response (readline))

(assert (menu-level rsa possible-causes-1-3)))

(defrule possible-causes-of-inadequate-shoulders-width

(rsa-mode rsa)

(menu-level rsa possible-causes-1-3-4)

?pc <- (possible-cause ?problem inadequate-shoulders-width)

$=>$

(retract ?pc)

(printout t crlf crlf crlf)

(printout t "

1. Increase width of the shoulders."crlf"

Press enter to return to previous menu." crlf)

(bind ?response (readline))

(assert (menu-level rsa possible-causes-1-3)))

(defrule possible-causes-of-inadequate-road-alignment

(rsa-mode rsa)

(menu-level rsa possible-causes-1-3-5)

?pc <- (possible-cause ?problem inadequate-road-alignment)

$=>$

(retract ?pc)

(printout t crlf crlf crlf)

(printout t "

1. Improve alignment."crlf"

Press enter to return to previous menu." crlf)

(bind ?response (readline))

(assert (menu-level rsa possible-causes-1-3)))

(defrule ascend-to-main-menu-1

?ml <- (menu-level rsa possible-causes-1-1)

?pc <- (possible-cause ?problem 0)

$=>$

(retract ?ml)

(retract ?pc)

(assert (menu-level rsa main)))

(defrule ascend-to-main-menu-2

? $\mathrm{ml}<-$ (menu-level rsa possible-causes-1-2)

?pc <- (possible-cause ?problem 0 )

$=>$

(retract ?ml)

(retract ?pc)

(assert (menu-level rsa main)))

(defrule ascend-to-main-menu-3

? $\mathrm{ml}<-$ (menu-level rsa possible-causes-1-3)

?pc <- (possible-cause ?problem 0)

$=>$

(retract ?ml)

(retract ?pc)

(assert (menu-level rsa main))) 


\section{Appendix G}

\section{Site investigation report: Cartersburg Road and CR 200 South}

Site Investigation Report

Jurisdiction: Hendricks County, Indiana Facility Type: Two-way stop control

Location: Cartersburg Road and CR 200 South

Project: test

Investigators:

Andrew M. Kwasniak

Date: 5/26/2006 Time: 10:00 AM

Weather: Sunny Light Conditions:

Comments:

Conditions 1

Night time collisions, Lack of street lights

Proposed safety improvements

1 Install street lights

Comments

If it's possible

Conditions 2

Night time collisions, Poor signs visibility

Proposed safety improvements

1 Upgrade signing

2 Improve/install reflective signs

Conditions 3

Off-road collisions, Inadequate shoulders width

Proposed safety improvements

1 Increase width of the shoulders

Comments 
No shoulder present on the Cartersburg Road toward North were two run-off collision occur. (See attach picture)

\section{Conditions 4}

Right-angle collisions, Stop sign not missing, Stop sign not visible, improperly stop sign maintained

Proposed safety improvements

1 Replace, repair, or clean the sign

\section{Conditions 5}

Adverse-weather collisions, Snow/Slush/Ice

Proposed safety improvements

1 Use sand to increase pavement friction

2 Installing snow screens in areas exposed to snowdrifts

3 Install static or variable message signs displaying weather information

Comments

No data according to winter condition, but one of the right-angle collisions occur during winter time.

\section{Conditions 6}

Left-turn collisions on major road, undivided highway, Poor visibility of opposite vehicles, Poor horizontal/vertical alignment

Proposed safety improvements

1 Change horizontal/vertical alignment

(See picture)

\section{Conditions 7}

Intersection inconspicuous, Advance warning sign posted, Warning sign poorly visible/recognizable, Improperly warning sign maintained

Proposed safety improvements

1 Replace, repair, or clean the warning signs 


\section{Conditions 8}

Intersection inconspicuous, Advance warning sign posted, Warning sign poorly visible/recognizable, Warning sign obstruction

Proposed safety improvements

1 Relocate the sign to make it visible

2 Remove the object obstructing sight of the warning sign

Comments

Trees can obstruct the signs

Report generated by RSIT, developed by Joint Transportation Research Program, Purdue University, West Lafayette.

Attach:

Condition 3:

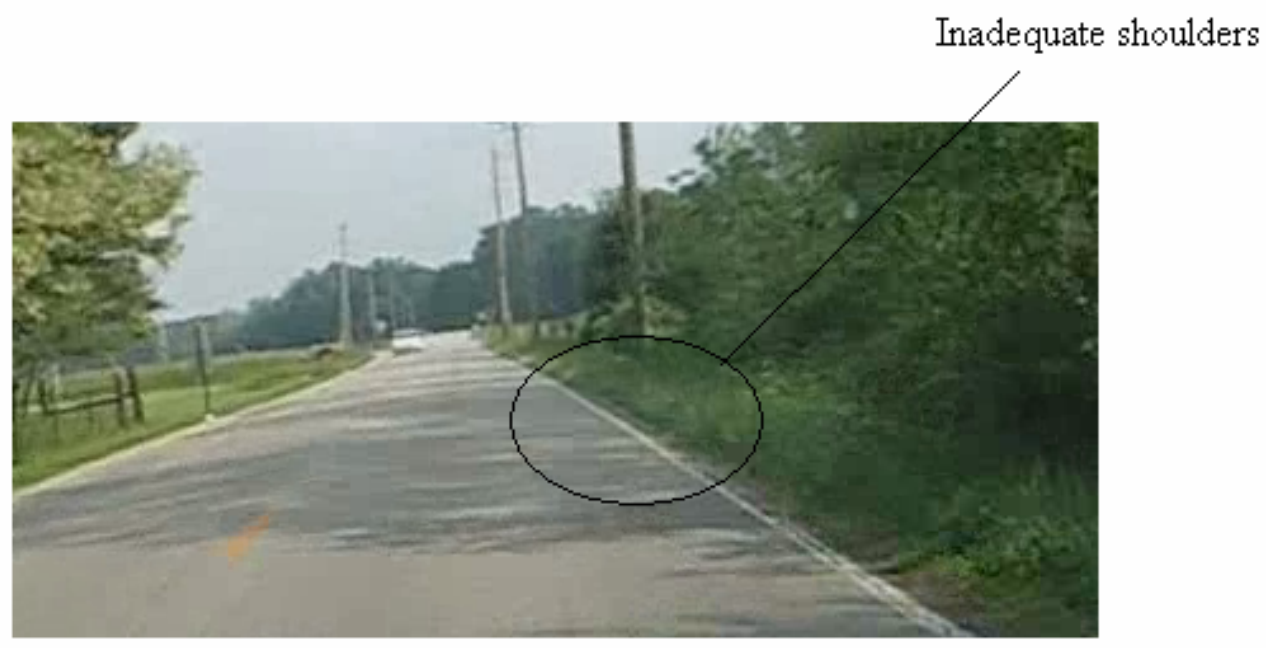

Cartersburg toward North

Condition 6 


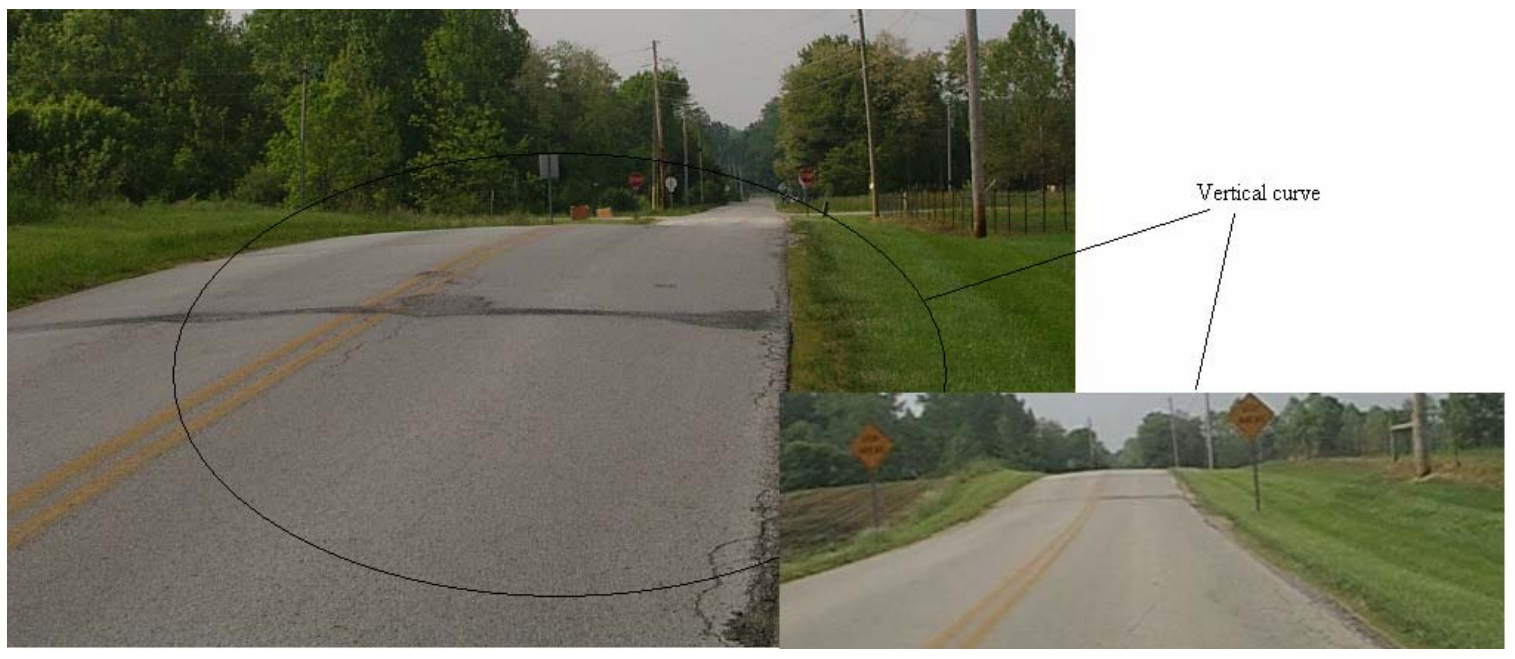

Cartersburg Road toward South 


\section{Appendix $\boldsymbol{H}$}

\section{Site investigation Report: Locust Rd. and Ireland Rd Report 1}

Site Investigation Report 1

Jurisdiction: St. Joseph County Facility Type: two-way stop control

Location: Locust Rd. and Ireland Rd

Project: test

Investigators:

Andrew M. Kwasniak

Date: 5/26/2006

Time: 04:00 PM

Weather: sunny

Light Conditions:

Comments:

Conditions 1

Night time collisions, Lack of street lights

Proposed safety improvements

1 Install street lights

Conditions 2

Night time collisions, Poor signs visibility

Proposed safety improvements

1 Upgrade signing

2 Improve/install reflective signs

Comments

The investigation should take place additional during night time condition. But because of time possibility we assume according to shape of the signs that this will be an issue.

Conditions 3

Off-road collisions, Inadequate pavement marking

Proposed safety improvements

1 Install reflectorized pavement marking

Conditions 4

Off-road collisions, Inadequate shoulders width

Proposed safety improvements 
1 Increase width of the shoulders

Comments

This problem is present especially for the Ireland road toward East. (See picture)

Shoulders are not consistent

\section{Conditions 5}

Right-angle collisions, Stop sign not missing, Stop sign visible, Insufficient sight distance from the minor road

Proposed safety improvements

Comments

Increase visibility toward west Ireland Rd. from the North side of the Locust Rd. (See picture) Problem with vertical alignment

\section{Conditions 6}

Right-angle collisions, Stop sign not missing, Stop sign visible, Insufficient gaps in the priority traffic

Proposed safety improvements

1 Adjust signal offsets at the upstream signalized intersections to create more gaps

\section{Conditions 7}

Right-angle collisions, Stop sign not missing, Stop sign visible, Inadequate pavement marking

Proposed safety improvements

1 Provide adequate delineation for left-turns at the intersection (markers or lines) (See picture)

\section{Conditions 8}

Right-angle collisions, Stop sign not missing, Stop sign not visible, Improperly stop sign maintained

Proposed safety improvements

1 Replace, repair, or clean the sign 


\section{Conditions 9}

Right-angle collisions, Stop sign not missing, Stop sign not visible, Stop sign obstruction

Proposed safety improvements

1 Remove the object obstructing the sight of the stop sign

Comments

See picture

Conditions 10

Rear-end collisions, Crashes on major road, Crashes on the exit, Considerable turning volume entering the major road

Proposed safety improvements

1 Install an acceleration lane

Comments

Propose solution show install an acceleration lane

Conditions 11

Left-turn collisions on major road, Inadequate pavement marking

Proposed safety improvements

1 Provide adequate turning markers or pavement markings

Conditions 12

Intersection inconspicuous, No advance warning sign

Proposed safety improvements

1 Install warning signs in advance of intersections

\section{Conditions 14}

Intersection inconspicuous, Advance warning sign posted, Warning sign poorly visible/recognizable, Improperly warning sign maintained

Proposed safety improvements

1 Replace, repair, or clean the warning signs 
Comments:

See picture

Conditions 15

Intersection inconspicuous, Advance warning sign posted, Warning sign poorly visible/recognizable, Warning sign obstruction

Proposed safety improvements

1 Relocate the sign to make it visible

2 Remove the object obstructing sight of the warning sign

Comments

See picture

Conditions 16

Intersection inconspicuous, Advance warning sign posted, Warning sign poorly visible/recognizable, Visual distraction

Proposed safety improvements

1 Install larger regulatory and warning signs at and in advance of intersections

2 Install regulatory signs on the both side of the road

3 Install overhead flashing beacon lights

4 Provide on-pavement horizontal signing

Report generated by RSIT, developed by Joint Transportation Research Program, Purdue University, West Lafayette.

Condition 4 


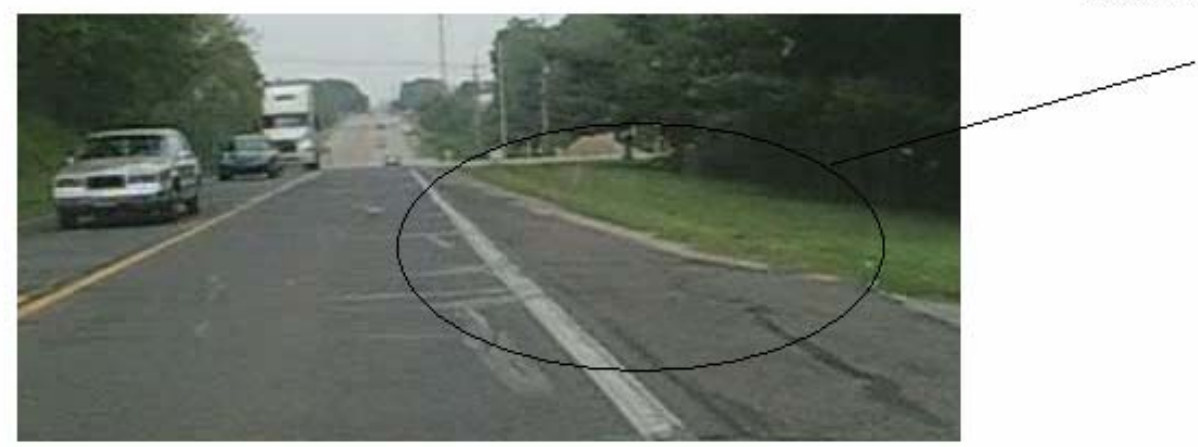

Ireland Road toward East

\section{Condition 5}

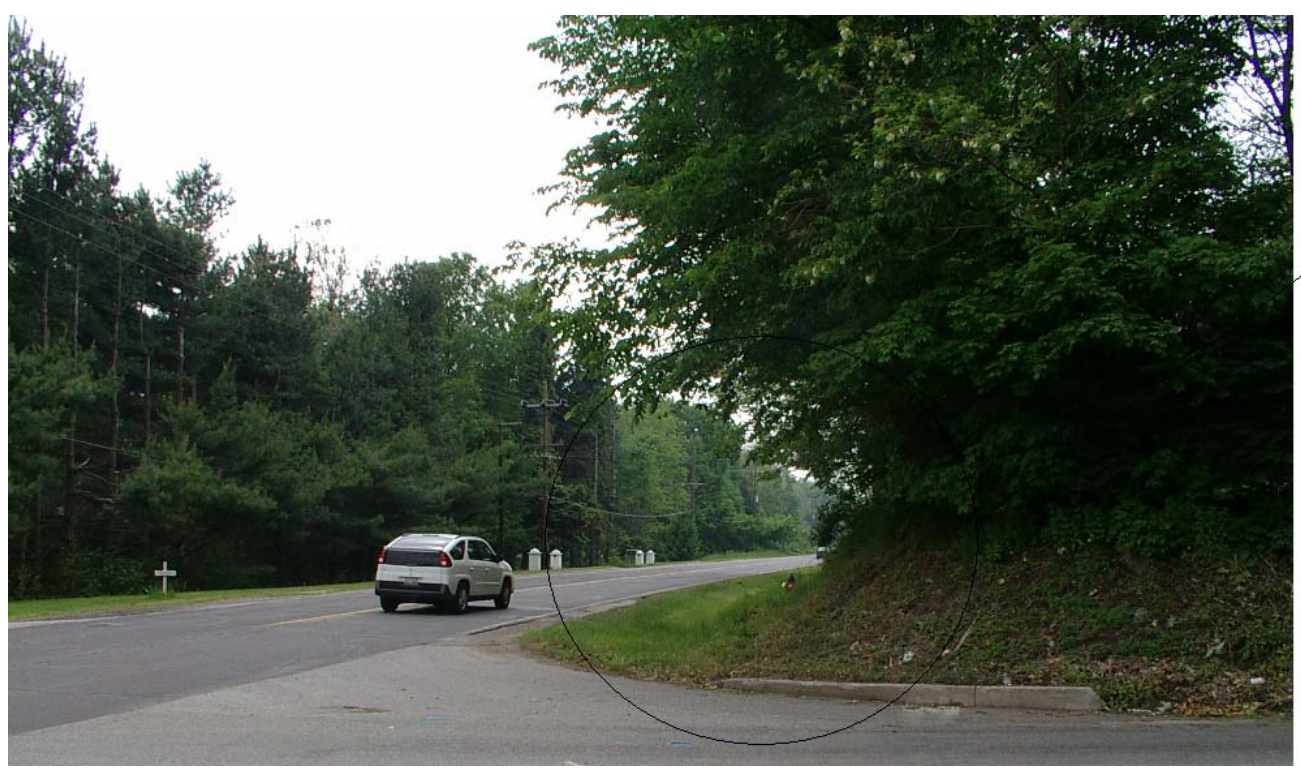

Locust toward South

Insufficient sight distance 
Condition 7

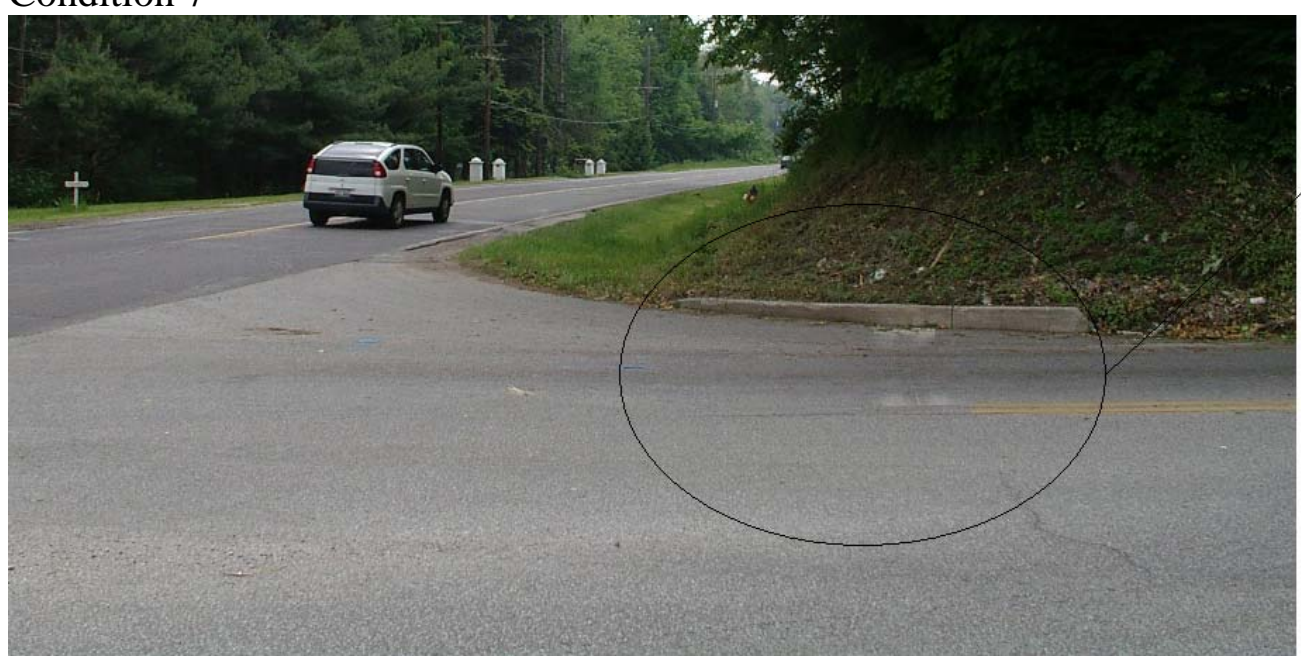

Insufficient marking

\section{Locust toward South}
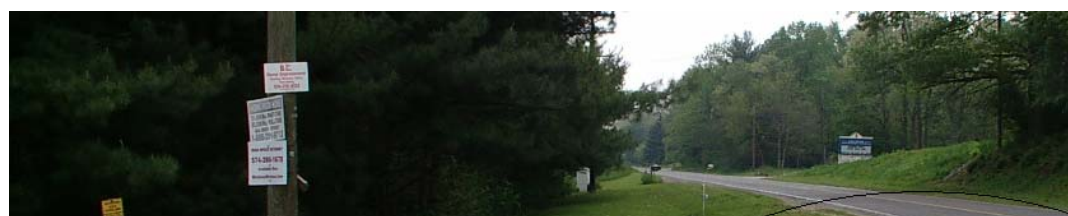

ivis.

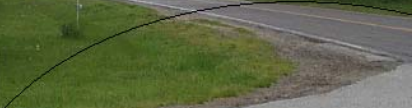

Locust toward North

\section{Condition 9}

Stop sign not viible

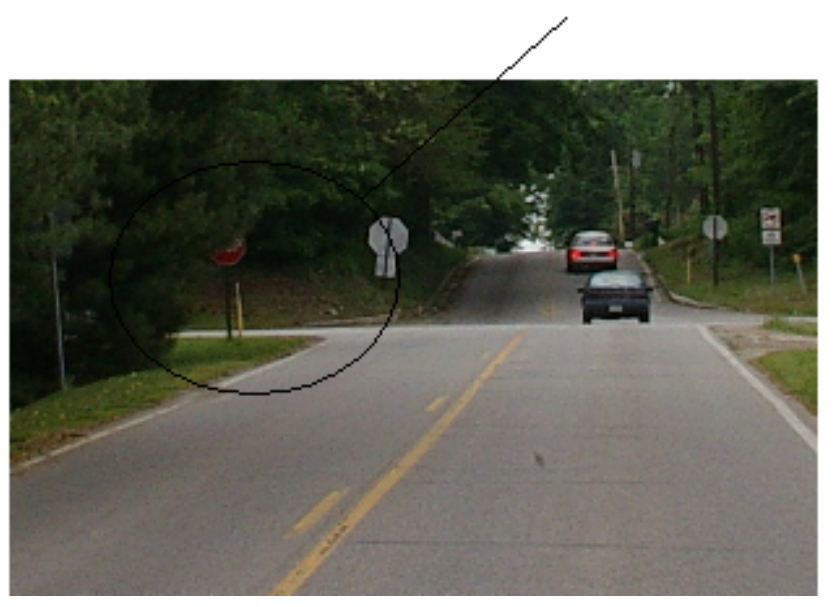




\section{Locust toward North}

\section{Condition 14}

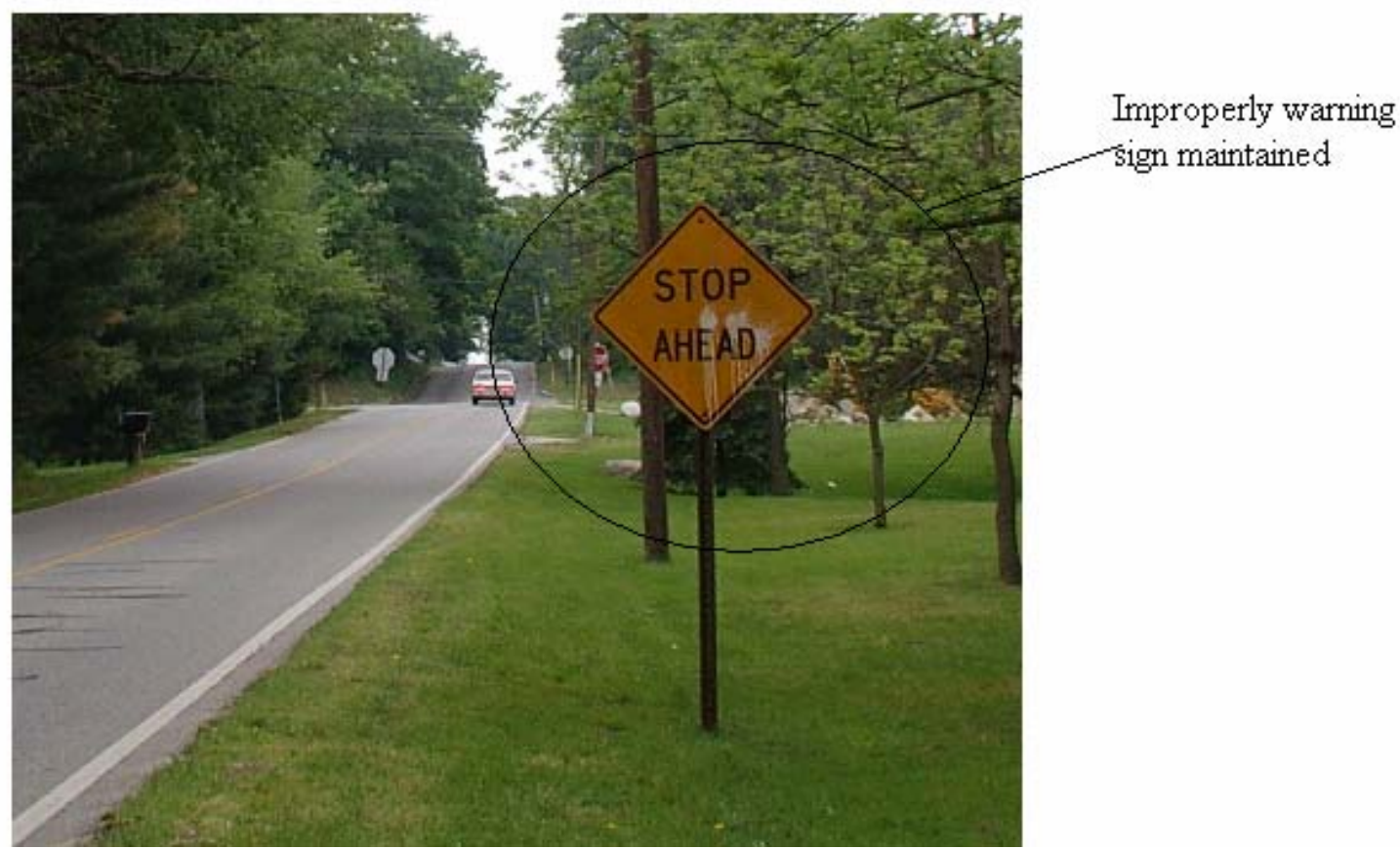

Locust Rd. North approach

\section{Condition 15}

Warning sign poorly visible

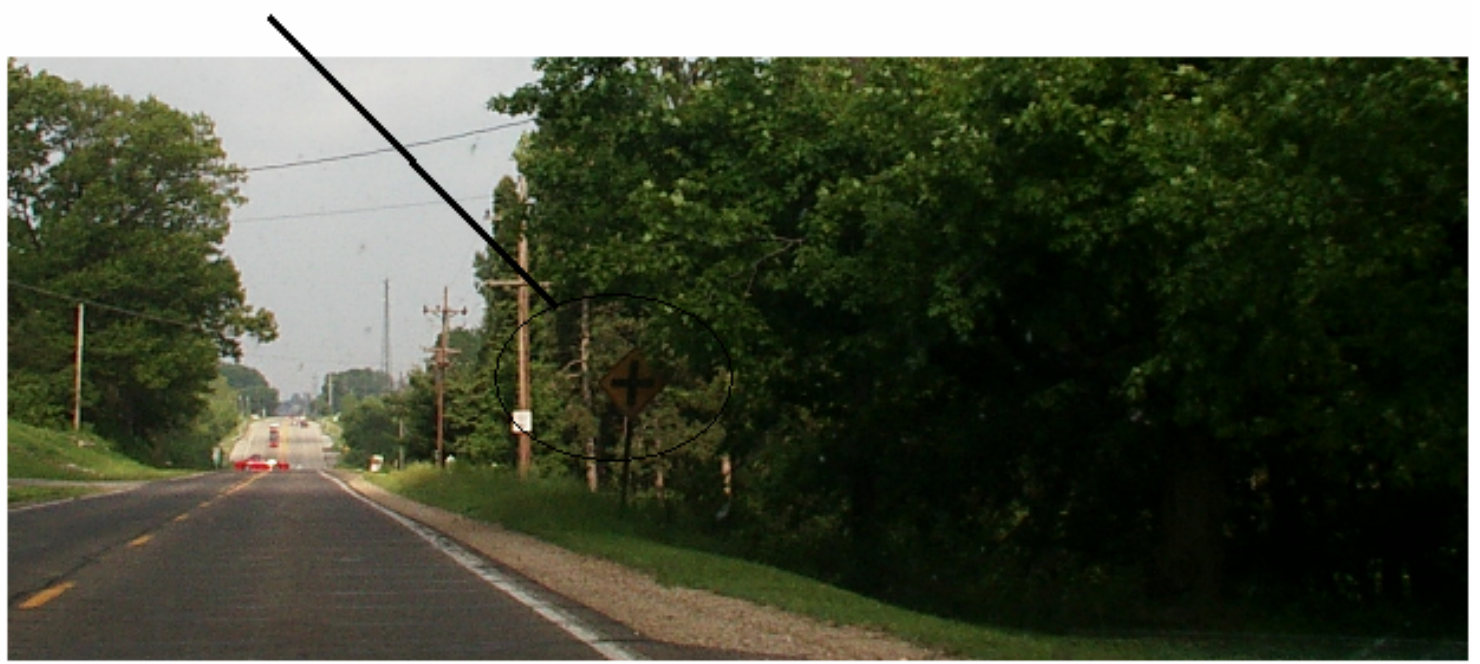

Ireland Road toward East 


\section{Appendix I}

\section{Site investigation Report: Locust Rd. and Ireland Rd Report 2}

Site Investigation Report 2

Jurisdiction: South Bend Facility Type:

Location: Locust \&Ireland

Project:

Investigators:

Anna

Date: 5/26/2006

Time: 4:00pm

Weather: sunny

Light Conditions:

Comments:

Conditions 1

Night time collisions, Lack of street lights

Proposed safety improvements

1 Install street lights

Conditions 2

Night time collisions, Poor signs visibility

Proposed safety improvements

1 Upgrade signing

2 Improve/install reflective signs

Conditions 3

Off-road collisions, Fix object close to traveled way

Proposed safety improvements

1 Remove or relocate the object

Comments

trees

Conditions 4

Off-road collisions, Inadequate pavement marking 
Proposed safety improvements

\section{Conditions 5}

Off-road collisions, Inadequate shoulders width

Proposed safety improvements

1 Increase width of the shoulders

Comments

The pavement on the shoulders is not constant, with different materials on the WB.

Conditions 6

Right-angle collisions, Stop sign not missing, Stop sign visible, Insufficient sight distance from the minor road, Poor horizontal/vertical alignment

Proposed safety improvements

1 Change horizontal/vertical alignment

Comments

On the WB

\section{Conditions 7}

Left-turn collisions on major road, Undivided highway, Poor visibility of opposite vehicles, Opposite left turn vehicles obstruct visibility

Proposed safety improvements

Conditions 8

Left-turn collisions on major road, Inadequate pavement marking

Proposed safety improvements

1 Provide adequate turning markers or pavement markings

Conditions 9

Excessive speed, Posted speed limit 
Proposed safety improvements

Conditions 10

Intersection inconspicuous, Advance warning sign posted, Warning sign poorly visible/recognizable, Improperly warning sign maintained

Proposed safety improvements

1 Replace, repair, or clean the warning signs

Comments

All approach signs.

Conditions 11

Intersection inconspicuous, Advance warning sign posted, Warning sign poorly visible/recognizable, Warning sign obstruction

Proposed safety improvements

1 Relocate the sign to make it visible

2 Remove the object obstructing sight of the warning sign

Comments

This problem is present on the main road toward East.

\section{Conditions 12}

Intersection inconspicuous, Advance warning sign posted, Warning sign poorly visible/recognizable, Visual distraction

Proposed safety improvements

1 Install larger regulatory and warning signs at and in advance of intersections

2 Install regulatory signs on the both side of the road

3 Install overhead flashing beacon lights

4 Provide on-pavement horizontal signing

Report generated by RSIT, developed by Joint Transportation Research Program, Purdue University, West Lafayette. 